\title{
Advanced Demonstration and Test Reactor Options Study
}

January 2017

Prepared by:
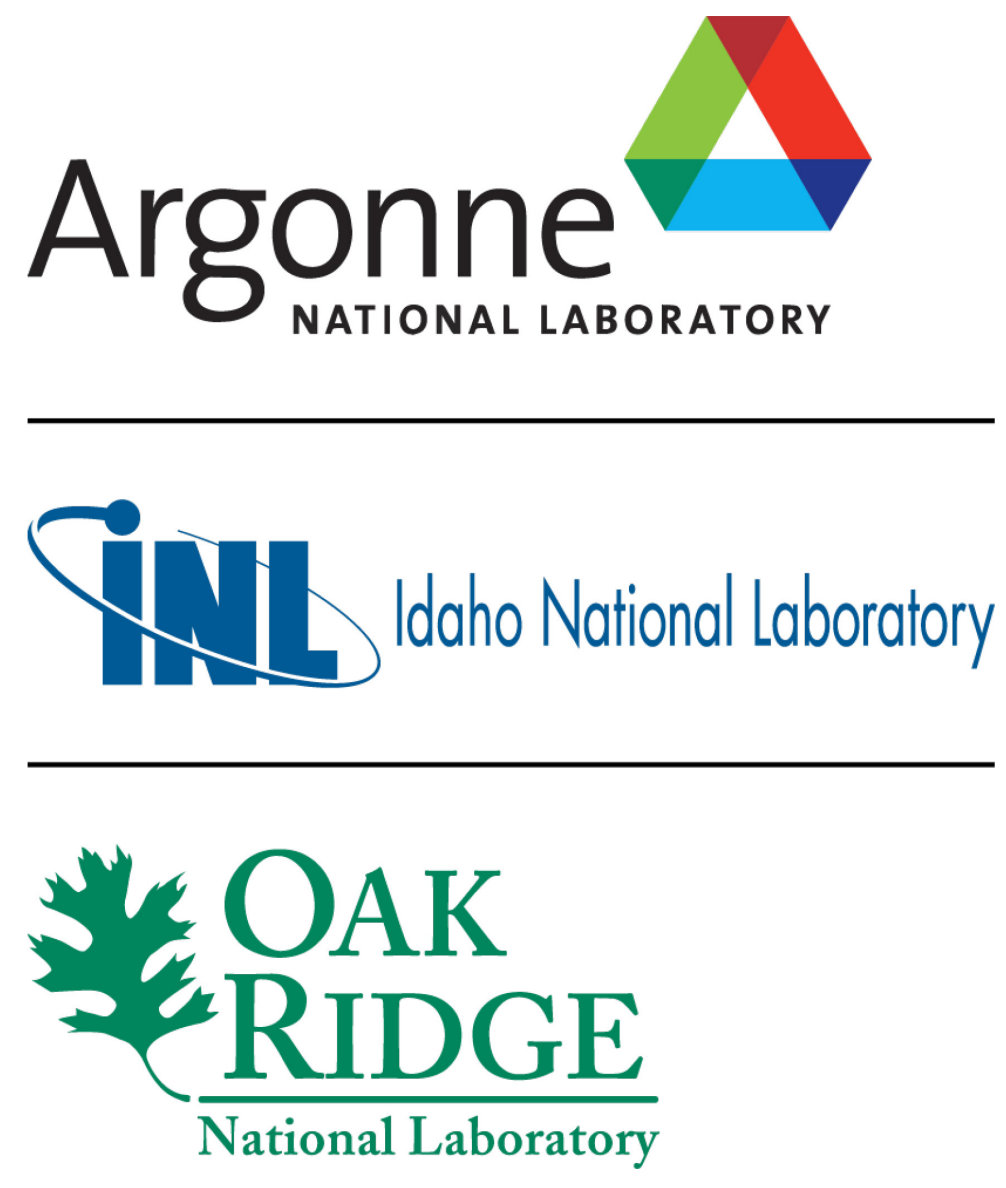


\section{DISCLAIMER}

This information was prepared as an account of work sponsored by an agency of the U.S. Government. Neither the U.S. Government nor any agency thereof, nor any of their employees, makes any warranty, expressed or implied, or assumes any legal liability or responsibility for the accuracy, completeness, or usefulness, of any information, apparatus, product, or process disclosed, or represents that its use would not infringe privately owned rights. References herein to any specific commercial product, process, or service by trade name, trade mark, manufacturer, or otherwise, does not necessarily constitute or imply its endorsement, recommendation, or favoring by the U.S. Government or any agency thereof. The views and opinions of authors expressed herein do not necessarily state or reflect those of the U.S. Government or any agency thereof. 


\title{
Advanced Demonstration and Test Reactor Options Study
}

\author{
D. Petti (INL), R. Hill (ANL), J. Gehin (ORNL) \\ H. Gougar (INL), G. Strydom (INL), F. Heidet (ANL), J. Kinsey (INL), C. Grandy \\ (ANL), A. Qualls (ORNL), N. Brown (ORNL), J. Powers (ORNL), E. Hoffman (ANL),
} D. Croson (INL)

January 2017

\begin{abstract}
Idaho National Laboratory
ART Program

Idaho Falls, Idaho 83415
\end{abstract}

http://www.inl.gov

Prepared for the

U.S. Department of Energy

Office of Nuclear Energy

Under DOE Idaho Operations Office

Contract DE-AC07-05ID14517 



\section{ART Program}

\section{Advanced Demonstration and Test Reactor Options Study}

INL/EXT-16-37867

Revision 3

January 2017

Author:

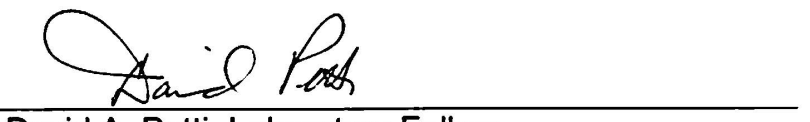

David A. Petti, Laboratory Fellow

NS\&T Nuclear Fuels \& Materials Director

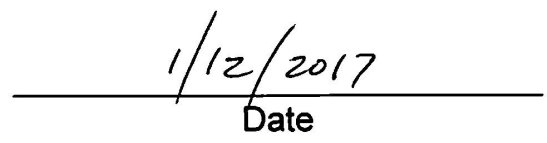

Approved by:
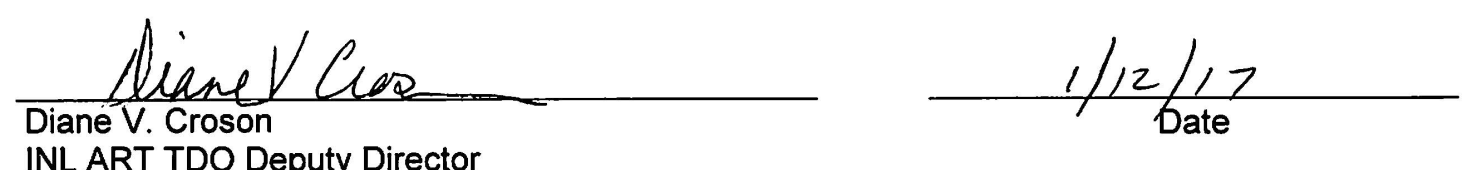

INL ART TDO Deputy Director
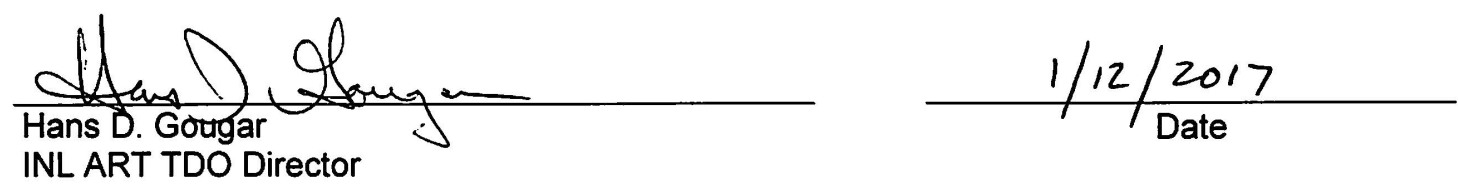

Concurrence:

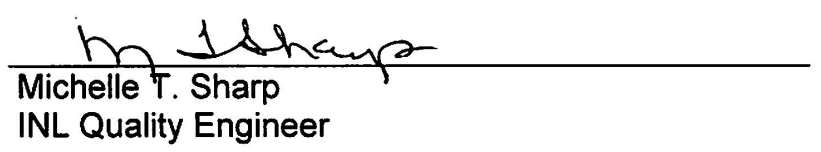

$\frac{1 / 12 / 17}{\text { Date }}$ 


\begin{abstract}
This report presents the results of an assessment of advanced reactor technology options and is intended to provide a sound comparative technical context for future decisions concerning these technologies. A wide variety of important missions and advanced reactor technology needs were identified based on recent Department of Energy and international studies. Strategic objectives were established that span the range of key nuclear energy missions and needs. A broad team of stakeholders from industry, academia and government was assembled as part of the study. The team developed a comprehensive set of goals, criteria and metrics to evaluate advanced test and demonstration reactor concepts. Point designs of a select number of concepts were commissioned to provide a deeper technical basis for evaluation. The technology options were compared on the bases of technical maturity and the ability to meet the different strategic objectives. Pathways to deployment for concepts of varying technical maturity were estimated for the different demonstration systems with regard to cost, schedule and possible licensing approaches. This study also presents the tradeoffs that exist among the different irradiation test reactor options in terms of the ability to conduct irradiations in support of advanced reactor R\&D and to serve potential secondary missions.
\end{abstract}




\section{EXECUTIVE SUMMARY}

Global efforts to address climate change will require large-scale decarbonization of energy production in the United States and elsewhere. Nuclear power already provides $20 \%$ of electricity production in the United States (U.S.) and is increasing in countries undergoing rapid growth around the world. Because reliable, grid-stabilizing, low-emission electricity generation, energy security, and energy resource diversity will be increasingly valued, nuclear power's share of electricity production has a potential to grow. In addition, there are non-electricity applications (e.g., process heat, desalination, hydrogen production) that could be better served by advanced nuclear systems. Thus, the timely development, demonstration, and commercialization of advanced nuclear reactors could diversify the nuclear technologies available and offer attractive technology options to expand the impact of nuclear energy for electricity generation and non-electricity missions.

The purpose of this planning study is to provide transparent and defensible technology options for a test and/or demonstration reactor(s) to be built to support public policy, innovation and long term commercialization within the context of the Department of Energy's (DOE's) broader commitment to pursuing an "all of the above" clean energy strategy and associated time lines. This planning study includes identification of the key features and timing needed for advanced test or demonstration reactors to support research, development, and technology demonstration leading to the commercialization of power plants built upon these advanced reactor platforms. This planning study is consistent with the Congressional language contained within the fiscal year 2015 appropriation that directed the DOE to conduct a planning study to evaluate "advanced reactor technology options, capabilities, and requirements within the context of national needs and public policy to support innovation in nuclear energy".

Advanced reactors are defined in this study as reactors that use coolants other than water. a Advanced reactor technologies have the potential to expand the energy applications, enhance the competitiveness, and improve the sustainability of nuclear energy. These advanced reactor concepts offer a range of technology innovations including:

- Higher outlet temperatures than light water reactors (LWRs), which yield enhanced efficiency of electricity generation as well as for a variety of process heat applications

- Enhanced inherent safety, including passive decay heat removal systems

- Advanced fuels (liquid, particle, metallic, ceramic) and cladding enabling high burnup, extensive actinide destruction, and enhanced accident tolerance

- Advanced power conversion systems (Brayton cycle, supercritical $\mathrm{CO}_{2}$ ) to improve overall energy conversion efficiency and reduce water usage

- Modular design to shorten construction times and to support phased deployment to allow flexibility in meeting demand

- Greater degrees of autonomous control to minimize operating cost.

\footnotetext{
a Advanced LWRs, their R\&D and licensing extension needs, and their potential applications are addressed under specific DOE-
} NE programs (e.g., the LWR sustainability program, the SMR licensing technical support program, the Consortium for Advanced Simulation of LWRs). 


\section{Important High-Level Findings and Observations}

For the fundamental mission of efficient and reliable electricity production, advanced reactor technologies have favorable features (e.g., high thermal efficiency, inherent safety) that promote improved performance. Furthermore, advanced reactors provide the opportunity to extend the impact of nuclear power beyond the traditional electricity market. For this study, a series of four strategic objectives that span the range of key advanced reactor nuclear energy missions and needs has been established: the first three are focused on potential demonstration reactor options and the fourth on irradiation test reactors options. These four strategic objectives are:

1. Deploy a high-temperature process heat application (e.g., synfuels production) for industrial applications and electricity demonstration using an advanced reactor system to illustrate the potential that nuclear energy has in reducing the carbon footprint in the U.S. industrial sector

2. Demonstrate actinide management to extend natural resource utilization and reduce the burden of nuclear waste for future generations

3. Deploy an engineering demonstration reactor for a less-mature reactor technology with the goal of increasing the technology readiness level of the overall system for the longer term

4. Provide an irradiation test reactor to support development and qualification of fuels, materials, and other important components/items (e.g., control rods, instrumentation) of both thermal and fast neutron-based Generation-IV (Gen-IV) advanced reactor systems.

Goals, criteria, and metrics were established to assess these point design options against the strategic objectives. Expert judgment was used to elicit goals, criteria, and metrics from a large group of scientists and engineers from the nuclear community spanning industry, national laboratories, and universities. Different teams comprised of industry and national laboratory partners developed point designs within a standardized framework as part of the study. The following sections document important findings of the study. First, a number of technology neutral findings are documented, followed by an assessment of options against each identified strategic objective.

\section{Advanced Reactor Technology Readiness Assessment}

To determine which reactor technology concepts the study would consider, a technology readiness assessment was conducted. The starting point for the assessment was the six Gen-IV advanced reactor technology concepts. The holistic assessment identified four options for consideration as demonstration reactors and two options for consideration as irradiation test reactors for this study:

- The modular High Temperature Gas-Cooled Reactor (HTGR) and sodium-cooled fast reactor (SFR) have high enough technology readiness levels to support a commercial demonstration in the near future. These technologies are considered mature as a result of several successful demonstrations brought about through billions of dollars of public and private investment in the U.S. over more than fifty years. These systems are also being built internationally, further confirming the high level of maturity of these systems as evaluated in this study. 
- The fluoride-cooled high-temperature reactor (FHR) and lead-cooled fast reactor (LFR) are less mature and require additional research and development (R\&D) and engineering demonstration in the near future. International and U.S. technology development activities are underway to mature these technologies, and technology demonstrations are planned. Other options examined (e.g., gas-cooled fast reactor) were even lower in maturity or did not have significant U.S. commercial interest (e.g., super-critical water-cooled reactor).

- The irradiation test reactor options require a mature base technology if they are to be deployed in a timeframe to support the research needs of Gen-IV reactors. The HTGR and SFR were considered as thermal neutron spectrum and fast neutron spectrum irradiation test reactor options.

\section{Deployment Options, Cost and Schedule}

The study identified a step-wise approach to reactor technology deployment that has been used historically in the U.S. and internationally. This historical pattern is shown in Figure ES-1. Development and deployment of reactor concepts in the U.S. and internationally has followed the following four steps:

- Research and development to prove scientific feasibility of key features associated with fuel, coolant, and geometrical configuration. Irradiation test reactor services are particularly important in this phase, although they can be beneficial at each step (e.g., to explore additional fuel/material options).

- Engineering demonstration at reduced scale for proof of concept for concepts that have never been built. The goal at this demonstration level is the viability of the integrated system. Historically, these have been small reactors $(<50 \mathrm{MWe})$.

- Performance demonstration(s) to establish that scale-up of the system works and to gain operating experience to validate the integral behavior of the system (including the fuel cycle in some cases) resulting in proof of performance.

- Commercial demonstrations that will be replicated for subsequent commercial offerings if the system works as designed.

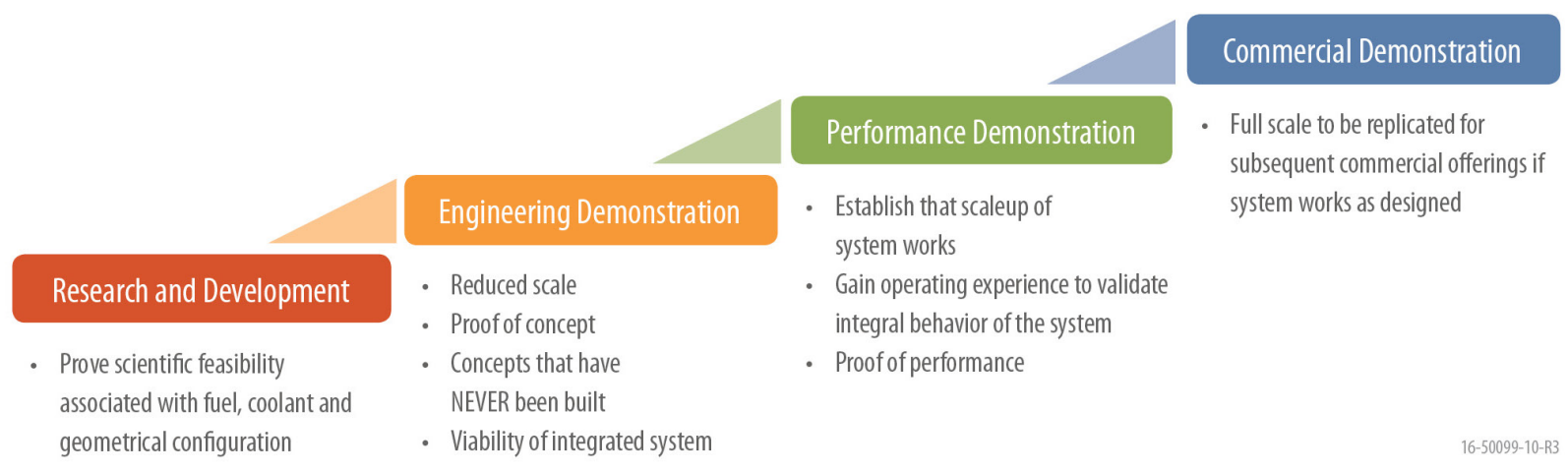

Figure ES-1. Reactor development and deployment steps based on U.S. and international experience. 
The location along the deployment path depends on the maturity of the underlying advanced reactor technologies. As shown in Figure ES-2, the maturity of HTGRs and SFRs are based on technologies that underwent engineering and performance demonstration steps to the extent that they put electricity on the grid over a period of many years. They are mature enough to enable deployment of their first modules at commercial scale (the commercial demonstration step) in the early 2030s with additional commercial offerings soon thereafter. Estimates from reactor vendors suggest it will take 13 to 15 years to achieve operation of the first module at a cost of $\sim \$ 4$ billion, including $\$ 1$ billion in first-time design and licensing. These estimates were found to be largely independent of the technology.

The less-mature technologies, FHR and LFR, are facing a longer technology development path (as shown in Figure ES-2, to commercial offerings because they need a combination of both the engineering demonstration step and the performance demonstration step through 2040, prior to commercial offerings in $\sim 2050$. The details of the development paths are different and represent some flexibility and innovation in the strategies available to reactor vendors.

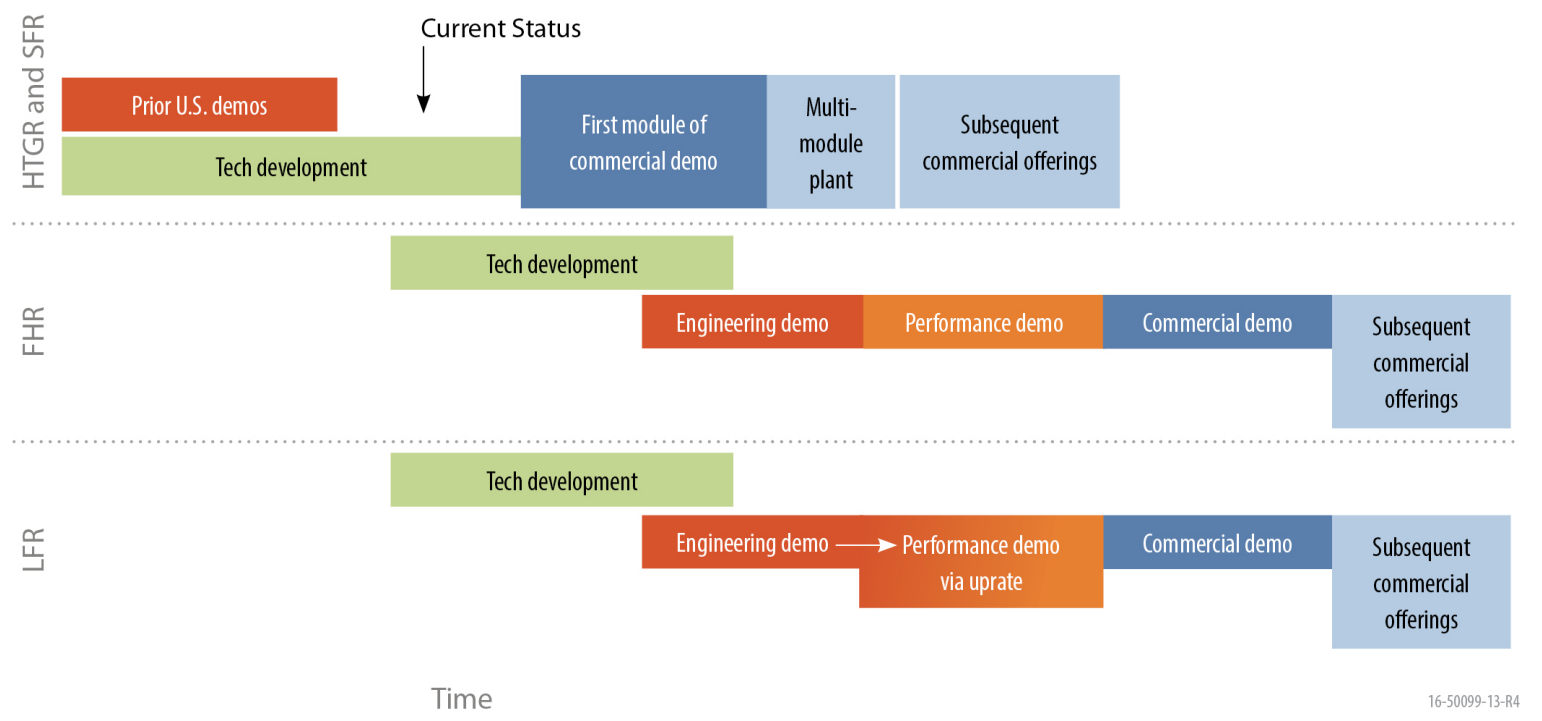

Figure ES-2. Development and deployment pathway of different advanced reactor technologies.

A range of test capabilities will also be needed for these advanced reactors, and will be provided through a combination of both new and existing facilities. From a long-term perspective, many advanced concepts will benefit from an irradiation test reactor that can support fuel and material testing and qualification. Design and construction of an irradiation test reactor are estimated to take about 10 to 13 years. Cost estimates for these irradiation test reactors are both around $\$ 3$ billion and are highly uncertain at this early stage in the design process. 


\section{Licensing Options}

The licensing options also vary by concept maturity. For the mature concepts (HTGR and SFR), both reactor vendors providing demonstration reactor point designs have reported they would pursue a commercial power reactor Class 103 Nuclear Regulatory Commission (NRC) license. Considerable data exist from past demonstration projects and R\&D activities conducted over the past 50 years to support licensing. Both concepts (General Atomics MHTGR and GE PRISM) have received safety evaluation reports from the NRC. The modular HTGR has also been the subject of recent pre-application discussions with NRC as part of the Next Generation Nuclear Plant Project (NGNP). As a part of the point design effort focused on Strategic Objectives \#1 and \#2, both reactor vendors (AREVA and GEH) proposed licensing the first module using the Part 50 process which allows detailed design to be completed after the start of construction, in advance of issuance of the operating license. Operational experience (e.g., construction, testing, operations, maintenance, etc.) from this first module can then be used by the reactor vendor to modify or refine the design, before next applying for NRC design certification. This would then allow the refined and certified design to be replicated for follow-on modules using the Part 52 licensing process, without the need for additional NRC reviews of the certified design.

For the engineering demonstration and irradiation test reactors, a Class 104(c) non-power reactor license is an option that may allow for greater regulatory framework flexibility given the state of the technology. However, it is noted that once any of the reactors get larger than 10-20 MWt, NRC could be expected to apply the same level of technical review to the engineering demonstration or irradiation test reactor as to a similarly sized power reactor, due to the potential public risk from the larger source term.

An additional restriction regarding this class of reactor license is that the facility must be used so that no more than $50 \%$ of the annual cost of owning and operating the facility is from the production of materials, products, or energy for sale or commercial distribution. This license type has been used in the past for small university reactors and the National Institute of Standards and Technology research reactor. It is noted that the last large-scale demonstration reactors were built and operated in the U.S. (e.g., Peach Bottom, Fermi-1) before the NRC existed.

\section{Promising Options for Each Strategic Objective}

\section{Strategic Objective 1: Process Heat}

The assessment for this objective identified two discriminators between point designs: suitability and prototypicality for a variety of high temperature applications and commercially relevant scale of the demonstration. The higher maturity options were favored, with the most promising option being the HTGR because of its high outlet temperature $\left(>700^{\circ} \mathrm{C}\right)$, flexibility for energy applications and its state of development.

Of the point designs in the study, the modular SC-HTGR design by AREVA best supports generating electricity using higher efficiency Rankine cycles in addition to process heat (e.g., synfuels) demonstration. The SC-HTGR is a modular, helium-cooled, graphite-moderated high-temperature energy supply system. With a $750^{\circ} \mathrm{C}$ reactor outlet temperature, it operates at temperatures much higher than LWRs, but within the range of existing technology demonstrated in previous HTGR projects. Modular 
HTGRs offer a very high degree of passive safety. The tristructural isotropic (TRISO)-coated particle fuel, which retains virtually all fission products at very high temperatures, the tall slender core and low-power density, the inert helium coolant, and the ceramic graphite moderator provide a system that is robust at very high temperatures and does not melt even under postulated beyond design basis events. The passively safe modular HTGR does not rely on AC power during postulated design basis events.

\section{Strategic Objective 2: Extend Natural Resource Utilization and Reduce the Burden of Nuclear Waste}

The assessment for the resource utilization and waste reduction objective identified two discriminators between point designs: suitability and the prototypicality for demonstrating high natural resource utilization and commercially relevant scale of the demonstration. The higher maturity options were favored, with the most promising option for resource utilization and waste reduction being the SFR because of its ability to efficiently convert uranium and utilize recycled fuel and its state of development.

Of the point designs in the study, the SFR proposed by GEH best supports the extension of natural resources and reduction of the nuclear waste burden, as well as fulfilling the fundamental mission of efficient and reliable electricity production. The Power Reactor Inherently Safe Module (PRISM) module Mod $A$ is a $471 \mathrm{MW}$ th fast reactor cooled by sodium coupled to a superheated Rankine power cycle with a single helical coil steam generator producing 165 MWe (35\% efficiency). PRISM's extensive design development, state of knowledge, operational experience, and conservative design approach are based on the use of technologies proven by decades of operation and testing of EBR-II and Fast Flux Test Facility (FFTF). To support fuel cycle closure, U-Zr fuel can be quickly followed by U-Pu-Zr fuel and in the future fuel bearing minor actinides. The PRISM modularity, inherent passive safety and commercial scale allow for a relatively low complexity system that will not be hindered by scaling issues. These features reduce regulatory and financial risks. The inherent safety of metal fueled sodium-cooled fast reactors in beyond design basis events was demonstrated at EBR-II.

\section{Strategic Objective 3: An Engineering Demonstration Reactor for a Less-Mature Reactor Technology}

The ability of engineering demonstration reactors to advance the TRL of a less mature reactor technology was assessed. Both the FHR and LFR are both low maturity technologies that require significant research, development and demonstration in order to significantly advance the TRL towards eventual commercialization. Significant discriminators between the FHR and LFR point designs related to readiness for an engineering demonstration were not identified in the assessment. However, the distinct approaches that the two design teams took to advancing the TRL were used to illuminate potential pathways to reactor technology development. The FHR and LFR point designs, as engineering demonstration reactors, scored essentially the same in their ability to increase the technology readiness of these less mature technologies.

The FHR is a class of molten salt reactors (MSRs) that uses solid fuel in low-pressure fluoride salt coolants to produce high-temperature heat with a high degree of inherent safety and significant margins to coolant boiling and fuel damage. The FHR point design proposed by ORNL is a $100 \mathrm{MWth}$, engineering demonstration designed to test key technologies prior to their next step - a performance 
demonstration. The current goal of the FHR engineering demonstration is to advance the FHR technologies towards commercial deployment supporting Strategic Objective 1. It is designed using the most mature component technologies available today, but not optimized or configured as a commercial plant. Initially, it uses TRISO fuel compacts in graphite blocks cooled by the molten fluoride-lithiumberyllium ( $\mathrm{FLiBe}$ ) salt with an outlet temperature slightly greater than $700^{\circ} \mathrm{C}$. Key features of the $\mathrm{FHR}$ demonstration reactor concept are directly relevant and scalable to commercial applications.

By contrast, the LFR point design proposed by Westinghouse is a much larger power system (500 MWth). The LFR engineering demonstration could advance the LFR concept towards commercial deployment supporting Strategic Objective 1 and/or 2. Initially, the uranium oxide fuel would use D9 cladding and will operate with a lower coolant temperature $\left(510^{\circ} \mathrm{C}\right)$ than intended for future commercial application. Eventually, the fuel will use D9 cladding with an alumina coating to enable higher temperatures, higher flow rates, and higher power conversion efficiency. The inherent safety derives from pool-type integral system design, a bayonet-based passive decay heat removal system, and the favorable thermal properties of lead coolant. This engineering demonstration reactor would then allow for integral testing in a prototypic environment. As confidence is built in its operation and other R\&D occurs in parallel, the flow rate, outlet temperature, and power would be increased to values more typical of a commercial LFR (outlet temperature of $\sim 700-750^{\circ} \mathrm{C}$ and power of $700 \mathrm{MWth}$ ). This engineering demonstration would then be modified to support performance demonstration scale related experiments. If successful, the technology maturation could be accelerated, but risks are higher because not all design features/components can be exchanged if the design were to evolve outside of the anticipated envelope.

As seen in Figure 11, the assessment determined that the FHR and the LFR point design development strategies will take longer to reach commercialization than those associated with the SFR or HTGR.

\section{Strategic Objective 4: Irradiation Test Reactor}

Water-cooled irradiation test reactors platforms have been the workhorse of nuclear fuels and materials irradiation testing for thermal reactor systems over the past 50 years. These water-cooled materials test reactors (MTRs) produce damage rates (up to $10 \mathrm{dpa} / \mathrm{yr}$ ) sufficient to support most thermal reactor development, but are already operating near full capacity. However, to attain peak doses typical of advanced fast reactors ( 200 to $500 \mathrm{dpa}$ ) using a water- cooled MTRs would take 20 to 50 years. Advanced fast neutron reactor systems experience neutron damage rates that are significantly higher because the neutrons are typically not thermalized and the magnitude of the fast neutron flux is much higher than for thermal systems. Fast neutron irradiation capability is largely lacking worldwide.

A water-cooled reactor cannot meet the needs to support research and development of advanced fast reactor designs because it is not possible to achieve the high fast to thermal neutron flux ratio that is needed for the development of any fast spectrum system and to accelerate materials irradiations needed for both thermal and fast reactors. Furthermore, Generation IV concepts using coolants other than water may require fast neutrons for the study of materials, fuels and corrosion control. Closed test loops with such coolants must be carefully designed so as not to significantly perturb the spectrum of the driver core, and thus are generally unavailable and expensive to install in existing water-cooled MTRs. 
Mature technologies are required for reliable operations of an irradiation test reactor. Thus, only SFR and a HTGR were examined to determine their ability to provide neutron irradiation services to support nuclear fuels and materials testing for advanced reactor systems. The assessment for the irradiation test reactor objective identified two discriminators between point designs: fast flux levels and irradiation volumes. Overall, the SFR irradiation test reactor design is the preferred option, because it can provide very high fast neutron flux as well as high-thermal neutron flux in moderated zones to meet many of the needs of both the fast and thermal reactor developers. Being a thermal system, the HTGR does not provide a high fast flux, but the large size and inert coolant accommodates testing of a wide array of fuels and materials at a very large scale, including half-scale LWR fuel assemblies. Both systems can incorporate multiple test loops to test fuels and materials under different coolant conditions. The impact of the closed loops on the safety and operation of the reactors cannot be fully ascertained until more details about the specific loops are developed. Both point designs produce enough power at relevant temperatures to produce electricity to offset some of the operating costs. Both systems could be licensed under an NRC Class 104(c) license for irradiation test reactors.

A follow-on study is currently in the planning stage to take the next step and evaluate in more detail the need, capabilities and testing requirements, as well as the time frame, for a new irradiation test reactor to support the broad user community (National Laboratories, academia, industry, reactor vendors, supply chain manufactures, material suppliers, the United States Government, and the international community). 


\section{ACKNOWLEDGEMENTS}

We thank the following individuals for their contributions:

\section{Sponsor}

Department of Energy Nuclear Energy

T. O'Connor

\begin{tabular}{|c|c|}
\hline Point Design Teams & \\
\hline AREVA & $\begin{array}{l}\text { L. Lommers } \\
\text { J. Mayer } \\
\text { F. Shahrokhi }\end{array}$ \\
\hline Argonne National Laboratory & $\begin{array}{l}\text { H. Belch } \\
\text { A. Brunett } \\
\text { C. Grandy } \\
\text { S. Hayes (INL) } \\
\text { F. Heidet } \\
\text { R. Hill } \\
\text { E. Hoffman } \\
\text { E. Jin } \\
\text { W. Mohamed } \\
\text { A. Moisseytsev } \\
\text { S. Passerini } \\
\text { J. Sienicki } \\
\text { T. Sumner } \\
\text { R. Vilim }\end{array}$ \\
\hline GE Hitachi Nuclear Energy & Team \\
\hline Idaho National Laboratory & $\begin{array}{l}\text { P. Bayless } \\
\text { H. Gougar } \\
\text { J. Kinsey } \\
\text { L. Nelson } \\
\text { J. W. Sterbentz } \\
\text { G. Strydom }\end{array}$ \\
\hline Oak Ridge National Laboratory & $\begin{array}{l}\text { B. Betzler } \\
\text { N Brown } \\
\text { J. Carbajo } \\
\text { M. Greenwood } \\
\text { R. Hale } \\
\text { T. Harrison } \\
\text { D. Holcomb } \\
\text { J. Powers } \\
\text { L. Quals } \\
\text { K. Robb } \\
\text { J. Terrell } \\
\text { A. Wysocki }\end{array}$ \\
\hline Westinghouse & $\begin{array}{l}\text { P. Ferroni } \\
\text { F. Franceschini } \\
\text { A. Harkness } \\
\text { C. Stansbury } \\
\text { K. Hosack } \\
\text { K. Josephic } \\
\text { G. Grasso (ENEA, Italy) }\end{array}$ \\
\hline
\end{tabular}




\begin{tabular}{|ll|}
\hline Assessment Team & \\
\hline Argonne National Laboratory & C. Grandy \\
& B. Hill \\
AREVA & F. Heidet \\
Bechtel & E. Hoffman \\
BWX Technologies & L. Lommers \\
Department of Energy Nuclear Energy & D. Chan \\
General Electric & G. Neeley \\
& T. O'Connor \\
Idaho National Laboratory & D. Bass \\
& E. Loewen \\
& D. Croson \\
& H. Gougar \\
National Institute of Standards and Technology & J. Kinsey \\
Oak Ridge National Laboratory & D. Petti \\
& G. Strydom \\
& T. Newton \\
& N. Brown \\
Oregon State University/ANS & J. Gehin \\
Southern Company & J. Powers \\
Westinghouse & L. Qualls \\
\end{tabular}

\begin{tabular}{|ll|}
\hline Technical Criteria Workshop & \\
\hline AREVA & L. Lommers \\
Argonne National Laboratory & F. Heidet \\
Brookhaven National Laboratory & R. Bari \\
Electric Power Research Institute & A. Sowder \\
General Atomics & H. Choi \\
General Electric Hitachi & D. Crawford \\
Georgia Institute of Technology & A. Erickson \\
Idaho National Laboratory & G. Strydom \\
Massachusetts Institute of Technology & L. Hu \\
Nuclear Energy Institute & E. Redmond \\
Oak Ridge National Laboratory & J. Powers \\
Pacific Northwest National Laboratory & R. Omberg \\
Sandia National Laboratory & M. Denman \\
TerraPower & P. Hejzlar \\
University of California - Berkeley & M. Fratoni \\
University of Missouri & M. Flagg \\
University of Wisconsin & M. Anderson \\
Westinghouse & F. Franceschini \\
\hline
\end{tabular}


Technology Assessment Team

Argonne National Laboratory

${ }^{*}$ T. Kim

Bechtel

D. Chan

Brookhaven National Laboratory

${ }^{*}$ R. Bari

BWX Technologies

Department of Energy-Nuclear Energy

G. Neeley

${ }^{*}$ T. Sowinski

T. O'Connor

Electric Power Research Institute

A. Sowder

Georgia Institute of Technology

A. Erickson

General Atomics

H. Choi

General Electric

D. Bass

E. Loewen

Idaho National Laboratory

D. Croson

${ }^{*}$ H. Gougar

J. Kinsey

D. Petti

Los Alamos National Laboratory

S. Maloy

Massachusetts Institute of Technology

L. $\mathrm{Hu}$

National Institute of Standards and Technology

T. Newton

Nuclear Energy Institute

E. Redmond

Oak Ridge National Laboratory

${ }^{*} \mathrm{~A}$. Worrall

J. Gehin

J. Powers

L. Qualls

N. Brown

Oregon State University/ANS

A. Klein

Pacific Northwest National Laboratory

R. Omberg

Sandia National Laboratory

M. Denman

Southern Company

B. Meadors

TerraPower

P.Hejzlar

University of Berkeley

M. Fratoni

University of Michigan

G. Was

University of Missouri

M. Flagg

University of Wisconsin

M. Anderson

Westinghouse

F. Franceschini

*Also members of the Technology Readiness Level Working Group 


\section{CONTENTS}

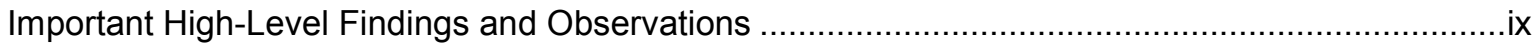

Advanced Reactor Technology Readiness Assessment ................................................. ix

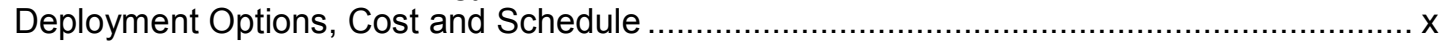

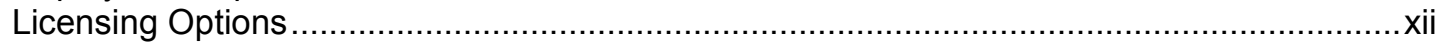

Promising Options for Each Strategic Objective ........................................................................

Strategic Objective 1: Process Heat .........................................................................

Strategic Objective 2: Extend Natural Resource Utilization and Reduce the Burden

of Nuclear Waste............................................................................................. xiii

Strategic Objective 3: An Engineering Demonstration Reactor for a Less-Mature

Reactor Technology .................................................................................... xii

Strategic Objective 4: Irradiation Test Reactor ................................................................xiv

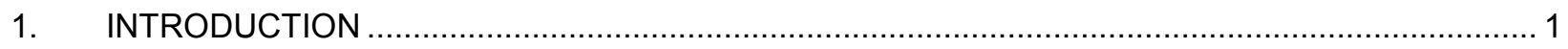

1.1 U.S. Interest in Advanced Reactor Technologies ......................................................... 2

1.2 International Interest in Advanced Reactor Technologies .................................................... 3

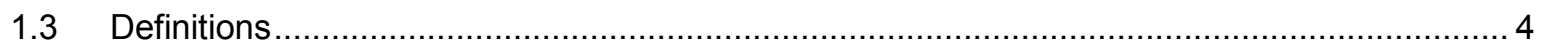

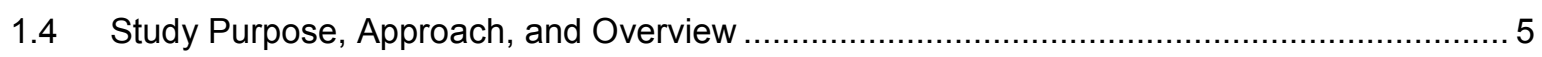

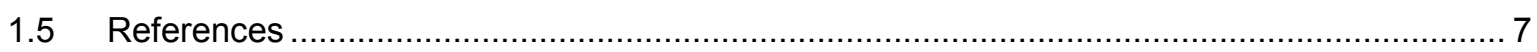

2. ESTABLISHING STRATEGIC OBJECTIVES, GOALS EVALUATION CRITERIA, AND

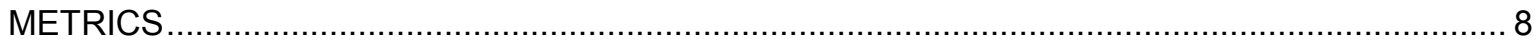

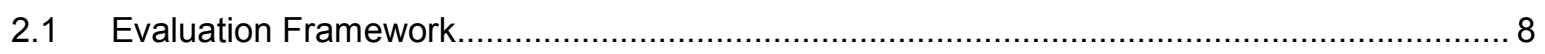

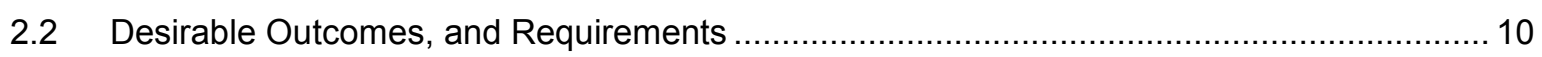

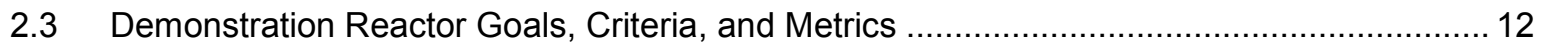

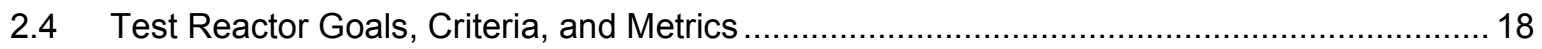

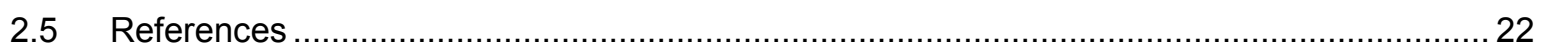

3. ASSESSMENT OF TECHNOLOGY READINESS OF TECHNOLOGY OPTIONS ....................... 23

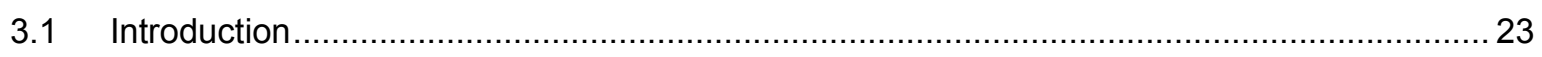

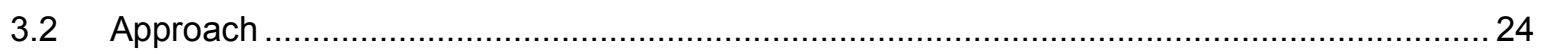

3.3 Summary of the Technology Assessment .............................................................. 26

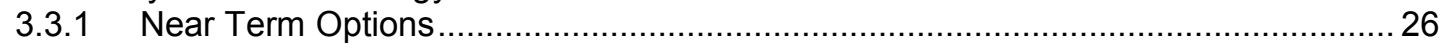

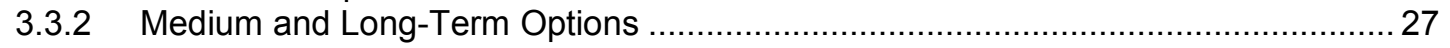

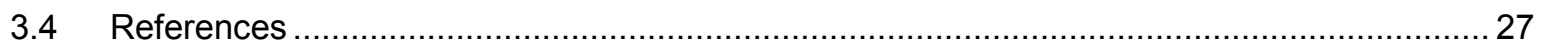

4. DEMONSTRATION POINT DESIGN CONCEPTS AND ASSESSMENT OF CONCEPTS

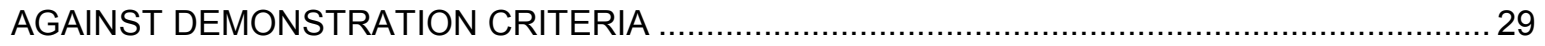

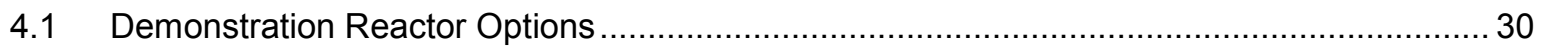

4.1.1 AREVA Steam Cycle-High Temperature Gas Reactor .......................................... 30

4.1.2 General Electric Hitachi (GEH) Sodium-Cooled Fast Reactor .................................. 32

4.1.3 Oak Ridge National Laboratory Fluoride-Salt-Cooled High-Temperature

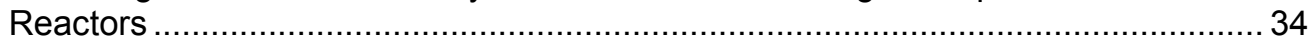

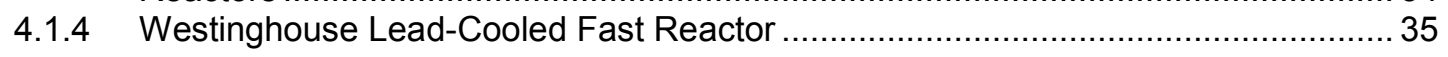

4.2 Assessment against Demonstration Criteria ............................................................. 37

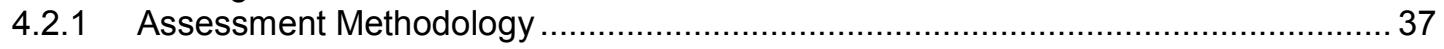

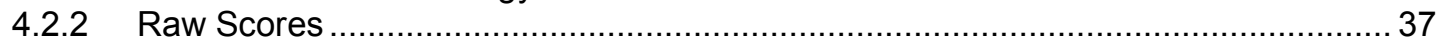

4.2.3 Weighted Scores against Strategic Objectives 1-3 .......................................... 38

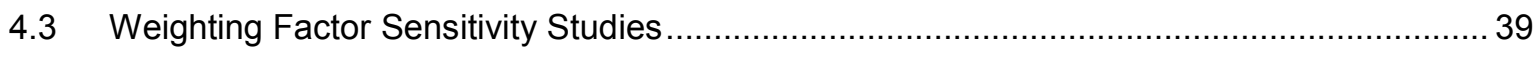


5. TEST REACTOR POINT DESIGN CONCEPTS AND ASSESSMENT OF CONCEPTS

AGAINST TEST REACTOR CRITERIA ......................................................................... 41

5.1 Gap Analysis of Test Reactor Capabilities for Advanced Reactor Testing ........................... 41

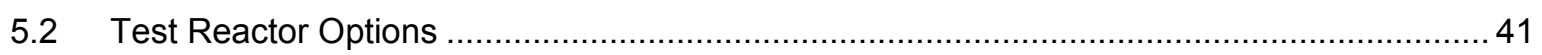

5.2.1 Argonne National Laboratory Sodium-Cooled Fast Reactor ................................. 42

5.2.2 Idaho National Laboratory High Temperature Gas-Cooled Reactor.......................... 44

5.3 Assessment against Test Reactor Criteria ............................................................... 46

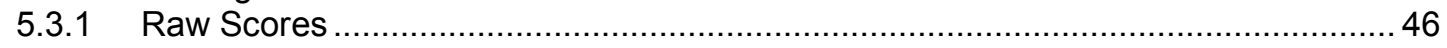

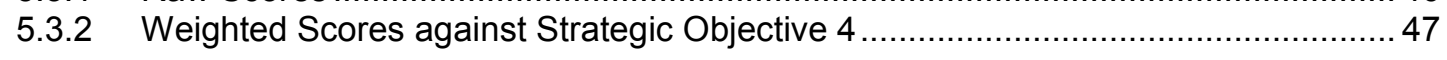

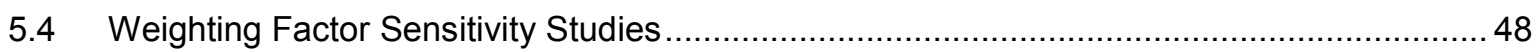

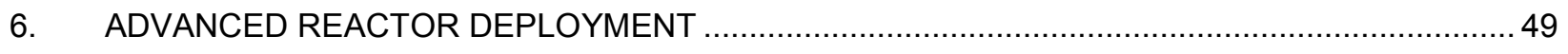

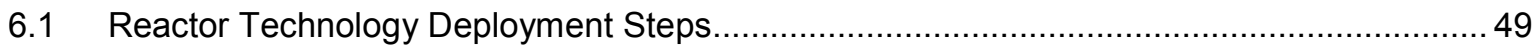

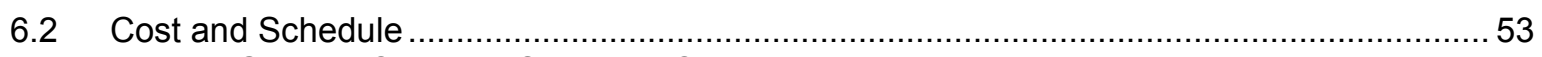

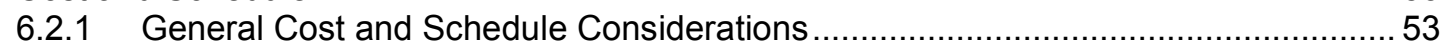

6.2.2 Commercial Demonstration Results (SFR, HTGR) ........................................... 55

6.2.3 Engineering Demonstration Concept Results (FHR, LFR) ….............................. 57

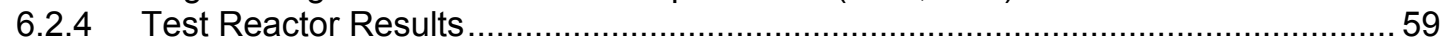

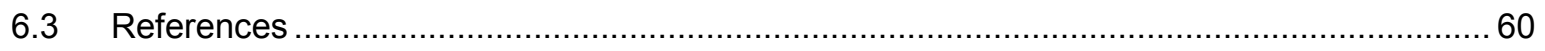

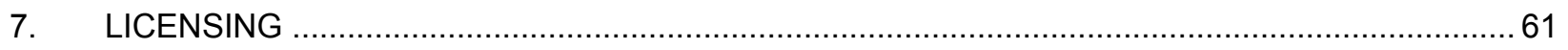

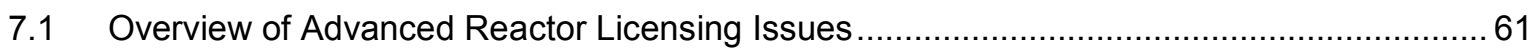

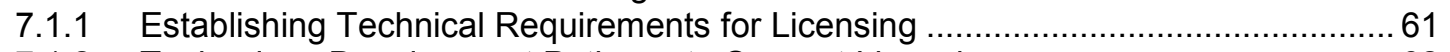

7.1.2 Technology Development Pathway to Support Licensing .......................................6 62

7.1.3 Relationship between Commission Policy and Technical Requirements ..................6 65

7.2 Licensing Pathways for the Six Demonstration and Test Reactor Point Designs..................66

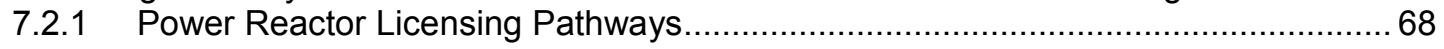

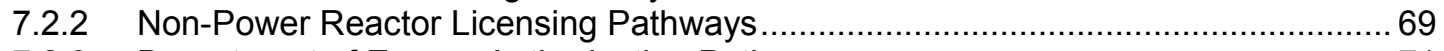

7.2.3 Department of Energy Authorization Pathway .................................................... 71

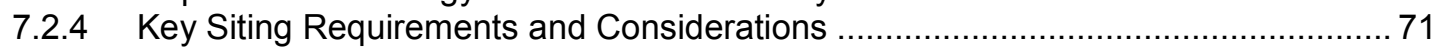

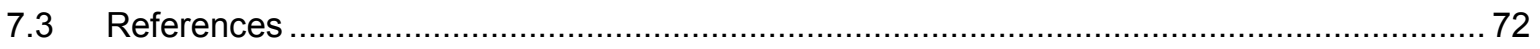

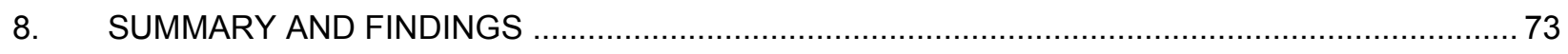

8.1 Important High-Level Findings and Observations ....................................................... 73

8.1.1 Advanced Reactor Technology Readiness Assessment ..................................... 74

8.1.2 Deployment Options, Cost and Schedule ..................................................... 74

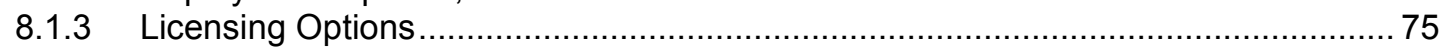

8.2 Promising Options for Each Strategic Objective ......................................................... 76

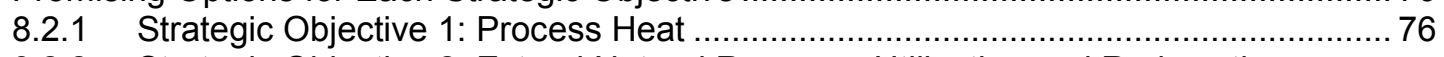

8.2.2 Strategic Objective 2: Extend Natural Resource Utilization and Reduce the Burden of Nuclear Waste ............................................................................ 77

8.2.3 Strategic Objective 3: An Engineering Demonstration Reactor for a Less-Mature Reactor Technology ................................................................ 77

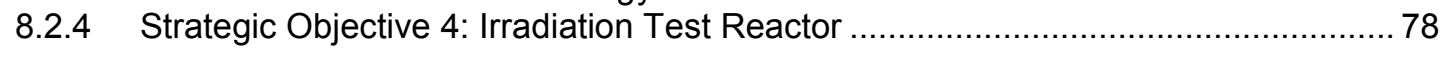

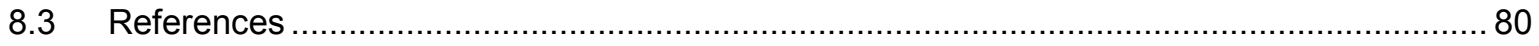

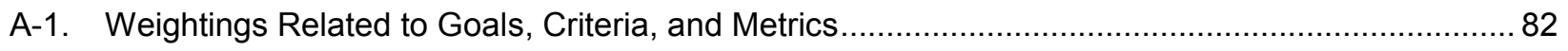

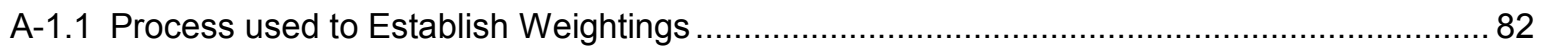

A-1.2 Goal Weightings for Demonstration Reactor Strategic Objectives ..................................... 83

A-1.3 Criteria and Metrics Weightings Related to Demonstration Reactor Goals ......................... 84

A-1.4 Goals Weightings for Test Reactor Strategic Objective ............................................... 86 
A-1.5 Criteria and Metrics Weightings Related to Test Reactor Goals ..................................... 87

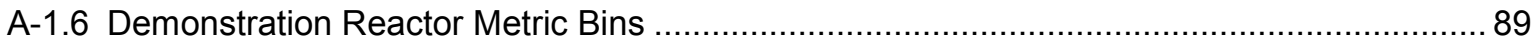

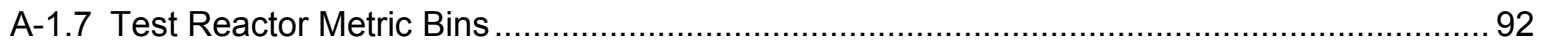

B-1. Demonstration Reactor Goals, Criteria, and Metrics ............................................................ 95

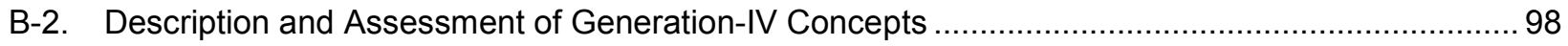

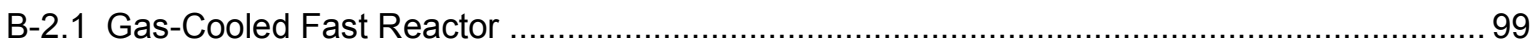

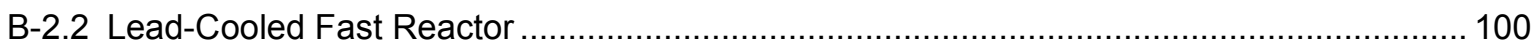

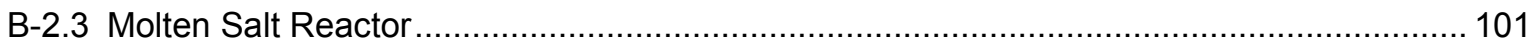

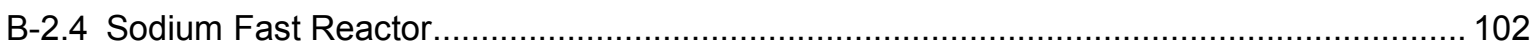

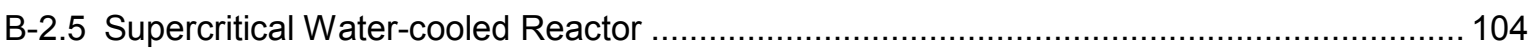

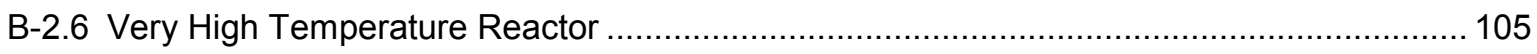

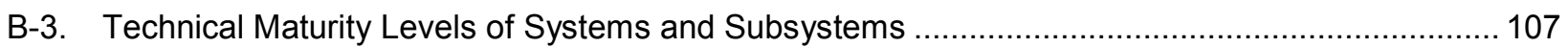

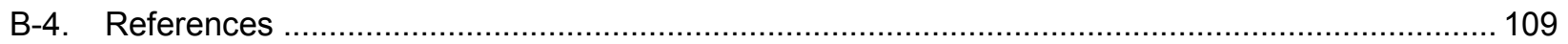

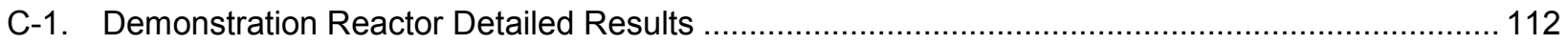

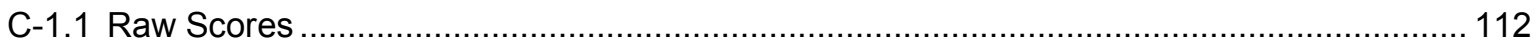

C-1.1.1 Weighted Scores against Strategic Objectives 1-3 ….................................... 116

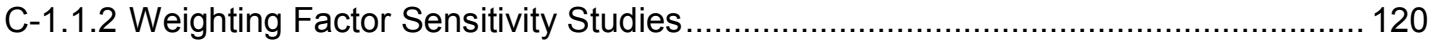

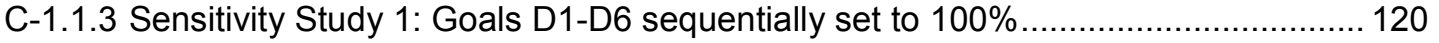

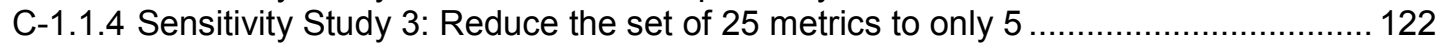

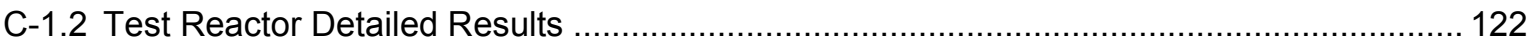

C-1.2.1 Weighted Scores against Strategic Objective 4 ............................................... 124

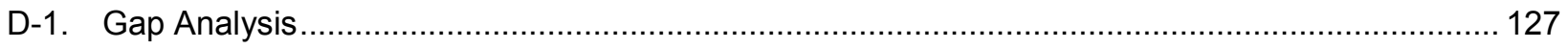

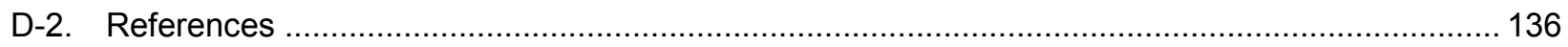

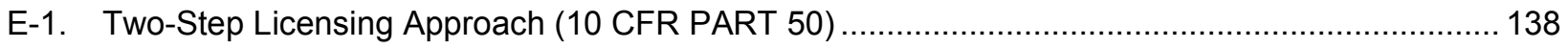

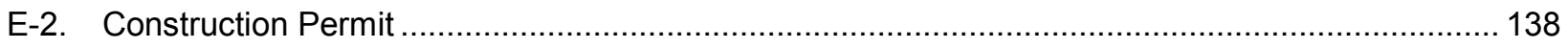

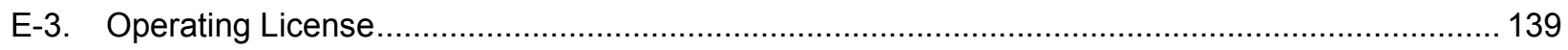

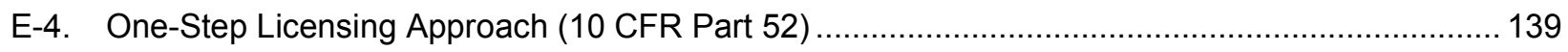

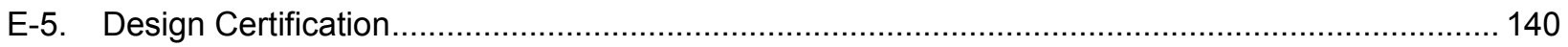

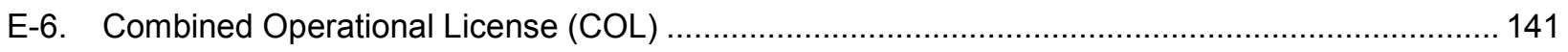

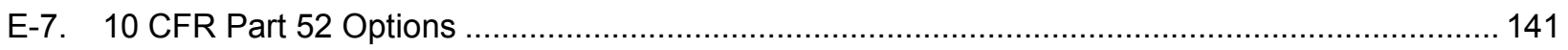

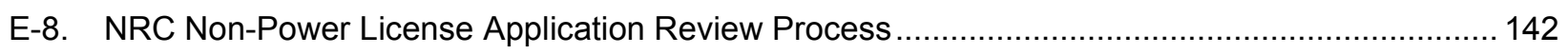

F-1. Site Geology, Seismology, and Soil Geotechnical Properties ............................................... 145

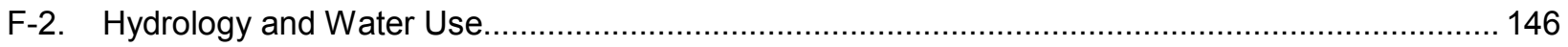

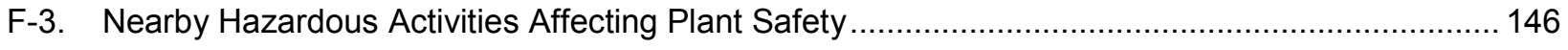


F-4. Dispersion of Radiological Releases During Accident Conditions

F-5. Dose Limits

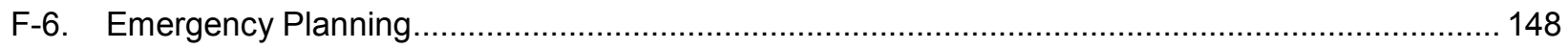

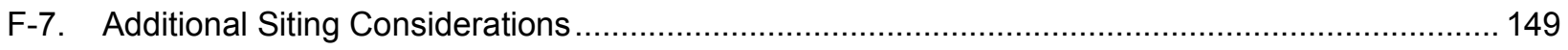

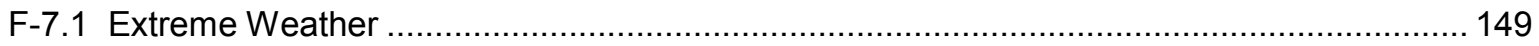

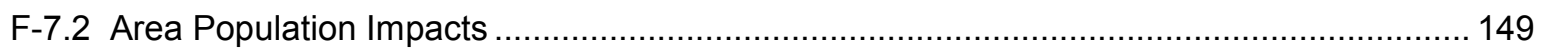

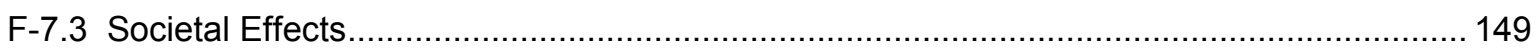

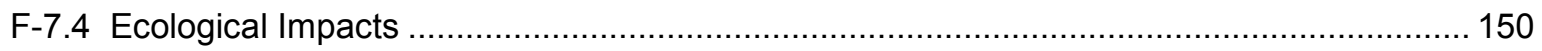

F-7.5 Land Use for Transmission Corridors and Transportation Routes ................................. 150

F-7.6 Historic/Archeological/Cultural Resources ............................................................ 150

F-7.7 Land Availability to Support Safe Operations ............................................................. 150

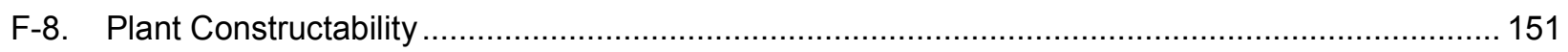

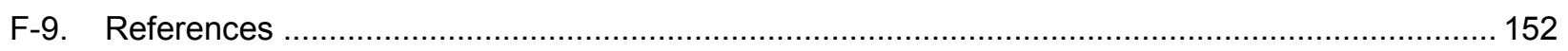

\section{FIGURES}

Figure ES-1. Reactor development and deployment steps based on U.S. and international

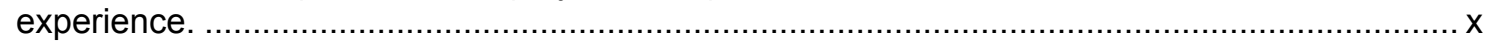

Figure ES-2. Development and deployment pathway of different advanced reactor technologies............ xi

Figure 1. Overview of approach used in technical evaluation of options.............................................. 10

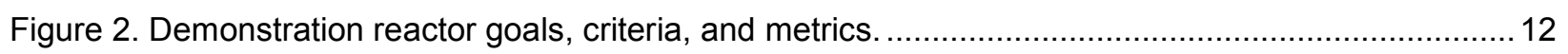

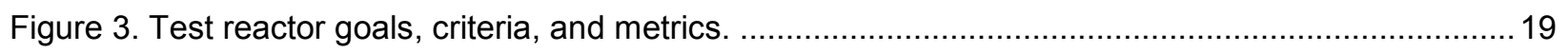

Figure 4. SC-HTGR core cross section and primary circuit layout. .................................................... 31

Figure 5. PRISM core cross section and reactor module isometric view. ............................................ 33

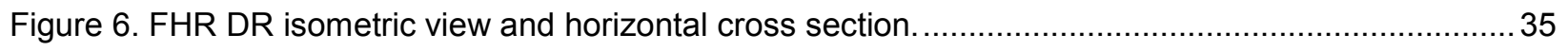

Figure 7. DLFR primary system layout, vertical and horizontal cross sections. ...................................... 36

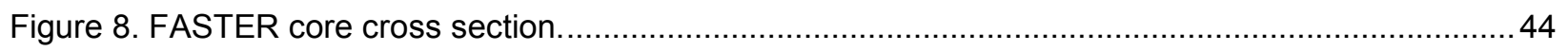

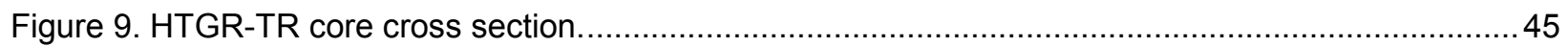

Figure 10. Reactor development and deployment steps based on U.S. and international

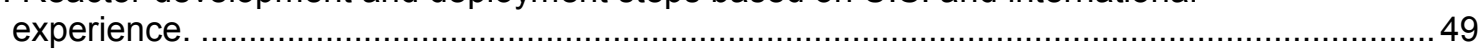

Figure 11. Development and deployment pathway of different advanced reactor technologies. ..............52

Figure 12. Graphical representation of activities necessary to advance the technical, licensing,

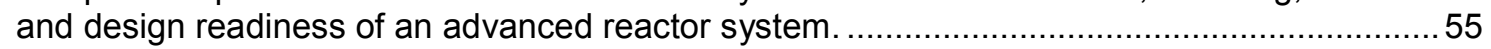

Figure 13. Notional schedule for a high TRL advanced reactor technology ........................................5 56

Figure 14. Example schedule for the HTGR test reactor point design. ................................................ 59

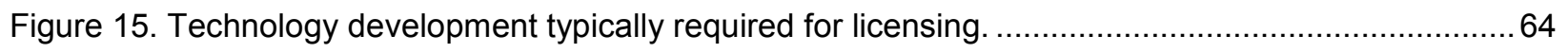

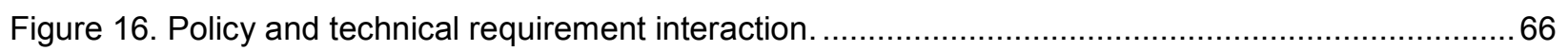

Figure 17. Available Nuclear Regulatory Commission licensing paths. ................................................67 


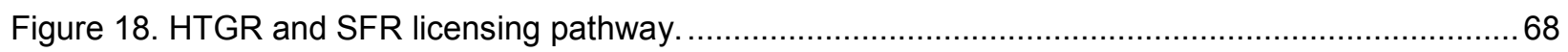

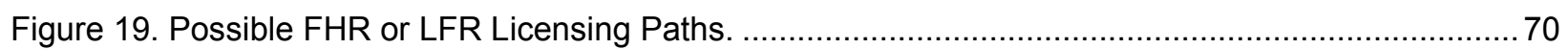

Figure D-1. Temperature/displacement damage (dose) windows for fission and fusion concepts. .........127

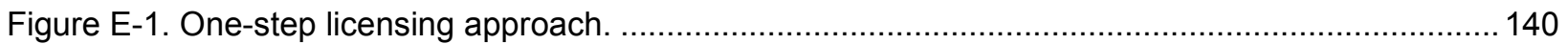

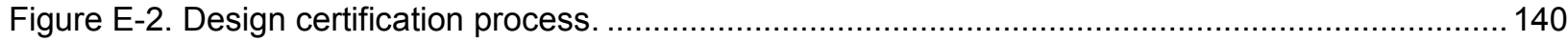

Figure E-3. Combined license application process................................................................... 141

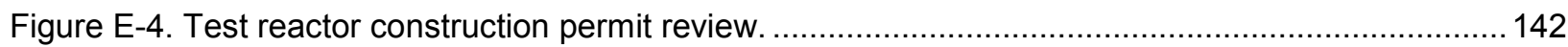

Figure E-5. Test reactor operating license review. .................................................................... 143

TABLES

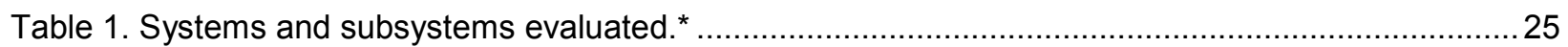

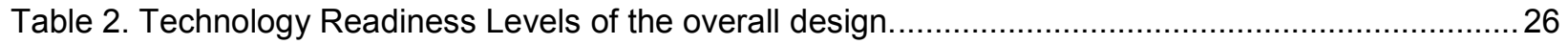

Table 3. Key design parameters of the demonstration reactors........................................................ 30

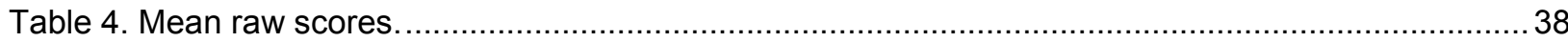

Table 5. Summary of demonstration reactor weighted scores (\%) by goal. .............................................. 39

Table 6. Difference between the nominal total weighted score and the six sensitivity variances

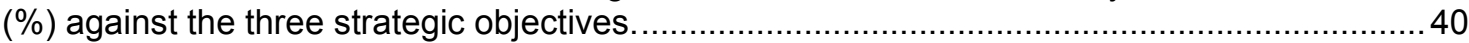

Table 7. Key design parameters of the test reactors. ...................................................................... 42

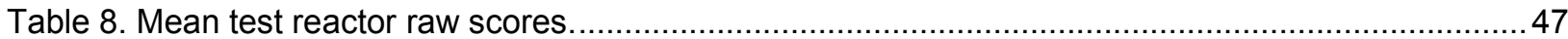

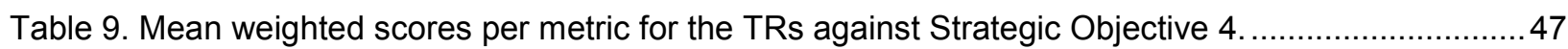

Table 10. U.S. and international reactors for each deployment step.....................................................51

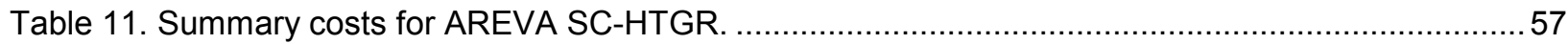

Table A-1. Goal weightings against demonstration reactor strategic objectives. ................................. 83

Table A-2. Criteria weightings related to demonstration reactor goals. .............................................. 85

Table A-3. Goal weightings for test reactor strategic objective.......................................................... 87

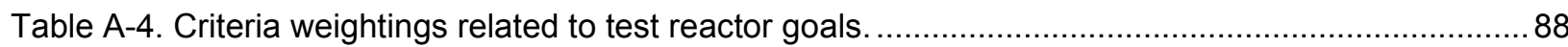

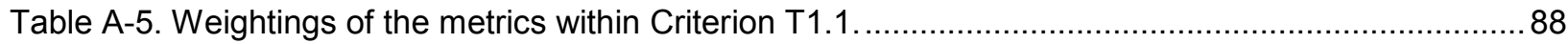

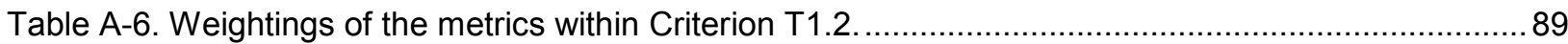

Table B-1. Technology readiness levels for each system and subsystem for reactor deployment. ${ }^{*}$....... 108

Table C-1. Mean raw scores and variances per metric for all four DRs............................................ 112

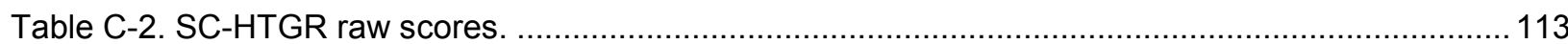

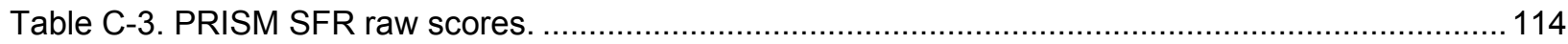

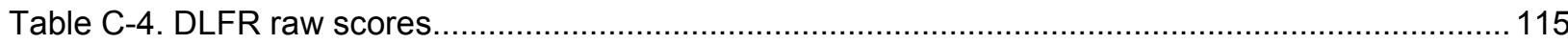

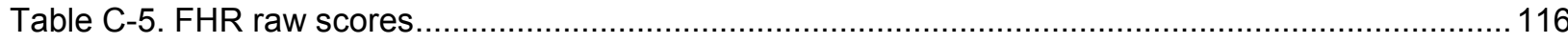

Table C-6. Demonstration reactor effective metric contributions...................................................... 117

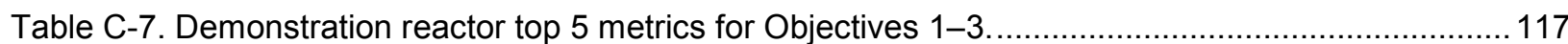

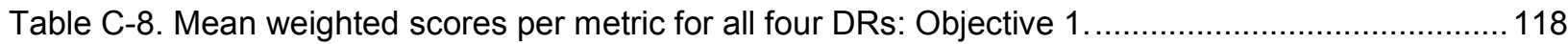


Table C-9. Mean weighted scores per metric for all four DRs: Objective 2.

Table C-10. Mean weighted scores per metric for all four DRs: Objective 3 120

Table C-11. Weights for Goal D1 set to $100 \%$. 121

Table C-12. Weights for Goal D2 set to $100 \%$.

Table C-13. Weights for Goal D3 set to $100 \%$

Table C-14. Weights for Goal D4 set to $100 \%$

Table C-15. Weights for Goal D5 set to $100 \%$. 122

Table C-16. Weights for Goal D6 set to $100 \%$. 122

Table C-17. Updated weighting factors for the top five metrics. 122

Table C-18. Mean and standard deviation raw scores per metric for the two test reactors. 123

Table C-19. HTGR-TR raw scores. 123

Table C-20. SFR-TR raw scores. 124

Table C-21. Test reactor effective metric contributions. 124

Table C-22. Detailed weighted scores per metric for the HTGR-TR. 125

Table C-23. Detailed weighted scores per metric for SFR-TR. 125

Table D-1. Listing of reactor irradiation facilities around the world. ${ }^{a}$...... 129

Table F-1. Test reactors: occupational, public, and accident dose requirements. 147

Table F-2. Power reactors: top-level regulatory requirements associated with dose. 147

\section{ATTACHMENTS}

Attachment 1 AREVA Inc.: Summary Report - SC-HTGR Demonstration Reactor

Attachment 2 GE Hitachi Nuclear Energy: Demonstration Sodium-Cooled Fast Reactor GE PRISM

Attachment 3 Oak Ridge National Laboratory: Fluoride Salt-Cooled High-Temperature Demonstration Reactor Point Design

Attachment 4 Westinghouse Electric Company LLC: Demonstration Lead-cooled Fast Reactor

Attachment 5 Argonne National Laboratory: FASTER Test Reactor Preconceptual Design Report Summary

Attachment 6 Idaho National Laboratory: High-Temperature Gas-cooled Test Reactor Point Design: Summary Report 


\section{ACRONYMS}

$\begin{array}{ll}\text { AFR } & \text { advanced fast reactor } \\ \text { AHTR } & \text { advanced high-temperature reactor } \\ \text { ANL } & \text { Argonne National Laboratory } \\ \text { ASLB } & \text { Atomic Safety and Licensing Board } \\ \text { ASME } & \text { American Society of Mechanical Engineers } \\ \text { ATR } & \text { Advanced Test Reactor } \\ \text { AVR } & \text { Arbeitsgemeinschaft Versuchsreaktor } \\ \text { BR2 } & \text { Belgian Reactor 2 } \\ \text { BWR } & \text { boiling water reactor } \\ \text { CEA } & \text { Commissariat à l'Energie Atomique } \\ \text { CEFR } & \text { China's first Experimental Fast Reactor } \\ \text { CFR } & \text { Code of Federal Regulations } \\ \text { CLS } & \text { closed loop system } \\ \text { COL } & \text { combined license } \\ \text { CP } & \text { construction permit } \\ \text { DHRS } & \text { decay heat removal system } \\ \text { DLFR } & \text { Demonstration Lead Fast Reactor } \\ \text { DOE } & \text { Department of Energy } \\ \text { DOE-NE } & \text { Department of Energy Office of Nuclear Energy } \\ \text { dpa } & \text { displacements-per-atom } \\ \text { DR } & \text { demonstration reactor } \\ \text { DRACS } & \text { direct auxiliary cooling system } \\ \text { EA } & \text { exclusion area } \\ \text { EAB } & \text { exclusion area boundary } \\ \text { EBR-II } & \text { Experimental Breeder Reactor II } \\ \text { EIS } & \text { Environmental Impact Statement } \\ \text { EM } 2 & \text { Energy Multiplier Module } \\ \text { EPA } & \text { Environmental Protection Agency } \\ \text { EPZ } & \text { emergency planning zone } \\ \text { ER } & \text { environmental report } \\ \text { ESP } & \text { early site permit } \\ \text { ETR } & \text { Engineering Test Reactor } \\ \text { FBTR } & \text { Fast Breeder Test Reactor } \\ \text { FERC } & \text { Federal Energy Regulatory Commission } \\ \text { FFTF } & \text { Fast Flux Test Facility } \\ \text { FHR } & \text { Fluoride-cooled High-temperature Reactor } \\ \text { FLiBe } & \text { fluoride lithium beryllium } \\ \text { GA } & \text { General Atomics } \\ \text { GAIN } & \text { Gateway to Accelerated Innovation in Nuclear } \\ \text { GEH } & \text { GE Hitachi } \\ \text { Gen-IV } & \text { Generation IV } \\ \text { GFR } & \text { gas-cooled fast reactor } \\ \text { GIF } & \text { Generation IV International Forum } \\ & \end{array}$




\begin{tabular}{|c|c|}
\hline HANARO & High Flux Advanced Neutron Application Reactor \\
\hline HBWR & Halden Boiling Water Reactor \\
\hline HFIR & High-Flux Isotope Reactor \\
\hline HFR & High Flux Reactor \\
\hline HTGR & High Temperature Gas-Cooled Reactor \\
\hline I\&C & instrumentation and Controls \\
\hline INL & Idaho National Laboratory \\
\hline IRPs & Integrated Research Programs \\
\hline ITAAC & inspections, tests, analyses, and acceptance criteria \\
\hline JHR & Jules Horowitz Reactor \\
\hline JMTR & Japanese Materials Test Reactor \\
\hline JOYO & Japan Experimental Fast Reactor \\
\hline LFR & lead-cooled fast reactor \\
\hline LOOP & loss-of-offsite-power \\
\hline LWA & limited work authorizations \\
\hline LWR & light water reactor \\
\hline MHTGR & Modular High Temperature Gas-Cooled Reactor \\
\hline MSR & molten salt reactor \\
\hline MSRE & Molten Salt Reactor Experiment \\
\hline MTR & materials test reactor \\
\hline MITR & Massachusetts Institute of Technology Reactor \\
\hline MURR & Missouri University Research Reactor \\
\hline MYRRHA & Multi-purpose hYbrid Research Reactor for High-tech Applications \\
\hline NAA & neutron activation analysis \\
\hline NDE & nondestructive examination \\
\hline NEPA & National Environmental Policy Act \\
\hline NGNP & Next Generation Nuclear Plant \\
\hline NIST & National Institute of Standards and Technology \\
\hline NPP & nuclear power plants \\
\hline NRC & Nuclear Regulatory Commission \\
\hline NRO & Office of New Reactors \\
\hline NSBR & National Bureau of Standards Reactor \\
\hline NUREG & Nuclear Regulatory Commission technical report designation \\
\hline O\&M & operations and maintenance \\
\hline OECD & Organization for Economic Cooperation and Development \\
\hline OPAL & Open Pool Australian Lightwater Reactor \\
\hline ORNL & Oak Ridge National Laboratory \\
\hline PAG & Protective Action Guidelines \\
\hline PCS & power conversion system \\
\hline PHTS & primary heat transport system \\
\hline PRISM & Power Reactor Inherently Safe Module \\
\hline PWR & pressurized water reactor \\
\hline R\&D & research and development \\
\hline RD\&D & research, development, and demonstration \\
\hline
\end{tabular}




$\begin{array}{ll}\text { RG } & \text { regulatory guideline } \\ \text { RTDP } & \text { Regulatory Technology Development Plan } \\ \text { RVACS } & \text { Reactor Vessel Ausiliary Cooling System } \\ \text { SAFARI } & \text { South Africa Fundamental Atomic Research Installation } \\ \text { SANS } & \text { small angle neutron scattering } \\ \text { SC-HTGR } & \text { Steam Cycle - High Temperature Gas-Cooled Reactor } \\ \text { SCWR } & \text { Super-Critical Water-Cooled Reactor } \\ \text { SECY } & \text { Secretary of the Commission } \\ \text { SFR } & \text { sodium-cooled fast reactor } \\ \text { SmAHTR } & \text { small modular advanced high-temperature reactor } \\ \text { SNM } & \text { special nuclear material } \\ \text { SSCs } & \text { structures, systems, and components } \\ \text { TEDE } & \text { total effective dose equivalent } \\ \text { TRISO } & \text { tristructural isotropic } \\ \text { TRL } & \text { Technology Readiness Levels } \\ \text { UC } & \text { uranium carbide } \\ \text { UN } & \text { uranium mononitride } \\ \text { V\&V } & \text { verification and validation } \\ \text { VHTR } & \text { very high temperature reactor } \\ \text { WG } & \text { working group }\end{array}$




\section{Advanced Demonstration and Test Reactor Options Study}

\section{INTRODUCTION}

Global efforts to address climate change will require large-scale decarbonization of energy production in the United States and elsewhere. Nuclear power already provides $20 \%$ of electricity production in the United States (U.S.) and is increasing in countries undergoing rapid growth around the world. Because reliable, grid-stabilizing, low-emission electricity generation, energy security, and energy resource diversity will be increasingly valued, nuclear power's share of electricity production has a potential to grow. In addition, there are non-electricity applications (e.g., process heat, desalination, hydrogen production) that could be served by nuclear power.

Between 2030 and 2040, more than 50\% of the existing U.S. light water reactor (LWR) capacity may be retired. Almost all of the existing reactors will be retired by 2050 , unless their operating licenses are renewed. Some of this capacity will almost certainly be retained by extension of the licenses of existing LWRs (perhaps to 80 years) or with the addition of new LWRs (whether advanced large or new small modular options under development). However, the timely development, demonstration, and commercialization of advanced nuclear reactors in the 2030 to 2040 timeframe are needed to diversify the nuclear technologies available and offer attractive technology options to expand the impact of nuclear energy for electricity generation and non-electricity missions.

As defined here, advanced reactors use coolants other than water. ${ }^{b}$ Following the discovery of nuclear fission, investigation of a variety of different reactor types was important to better understand the full commercial potential of nuclear energy. As a result, it was understood that different reactor technologies are better suited for different missions. With the encouragement of the U.S. government, a variety of systems were built and tested, both in the U.S. and around the world, from the 1950s through the 1980s. In 2000, under the Generation IV (Gen-IV) initiative, six systems were prioritized for continued study by the international community [1] because they generally offer improved safety, sustainability, proliferation and economic benefits compared to current LWR systems. The Gen-IV study began with a comprehensive evaluation of over 100 reactor systems, and the six concepts selected for further study were considered the most likely to be developed and deployed.

Today, there are numerous advanced reactor concepts under development, both nationally and internationally. Responses to recent Department of Energy (DOE) requests for information from the community $[2,3]$ demonstrate the diversity of the concepts. Many concepts can be classified as small and/or modular while others generate baseload electricity at magnitudes comparable to modern LWRs. The missions of some of these concepts go beyond fundamental electricity production to address important issues in the U.S. as noted in the recent DOE Roadmap including:

- Process heat applications, including cogeneration, to reduce the carbon footprint of the U.S. industry

b Advanced LWRs, their R\&D and licensing extension needs, and their potential applications are addressed under specific DOE-NE programs (e.g., the LWR sustainability program, the SMR licensing technical support program, the Consortium for Advanced Simulation of LWRs). 
- Actinide management to extend fuel resource utilization and reduce the nuclear waste burden for future generations

- Integration of nuclear systems with non-baseload (intermittent) energy sources to form reliable alternative energy systems.

Advanced concepts offer a range of technology innovations that can potentially improve economic performance and safety such as:

- Higher thermodynamic efficiency for electricity production

- Elimination of active safety systems in favor of inherent safety and/or passive systems

- Greater plant autonomy to minimize labor costs

- Advanced fuels (e.g., dissolved, particle, metallic, ceramic) and cladding-enabling high burnup, extensive actinide destruction, and enhanced accident tolerance

- Attractive and versatile fuel cycle options

- Advanced power conversion systems (e.g., Brayton, supercritical $\mathrm{CO}_{2}$ ) to improve overall energy conversion efficiency and reduce water usage

- Modular design to shorten construction times and allow phased deployment to better match anticipated increases in demand

- Temperatures suitable for process heat applications currently served by fossil fuels.

\subsection{U.S. Interest in Advanced Reactor Technologies}

A commitment to build, license, and operate the most promising advanced reactor systems would demonstrate continued U.S. leadership in advanced nuclear technology and re-establish a critical domestic U.S. supply chain with its concomitant impact on energy security and employment.

Novel reactor concepts are attracting the attention of the media, policy makers, and private investors. Many advanced reactor startups have received funding from venture capitalists that recognize both the importance of nuclear energy as a virtually inexhaustible supply of clean energy and the opportunity to innovate and re-capture U.S. leadership in this area.

The following recent activities demonstrate the emerging importance of advanced reactor technologies:

- The idea of promoting innovation in nuclear energy was re-affirmed at both the DOE Big Ideas Summit in March 2014 [4] and the accompanying series of follow-on innovation workshops [5]. A conclusion from the summit was that the government needs to support a research, development, and demonstration (RD\&D) paradigm that can advance the technology readiness level from concept to commercially ready in less than 10 years.

- Two meetings (in June and November 2015) were held at the White House to discuss how government can support more-rapid deployment of advanced nuclear energy systems that attract private sector investment. The recently announced Gateway to Accelerated Innovation in Nuclear (GAIN); see www.gain.inl.gov) initiative is the framework for these activities. 
- For any of these systems, licensing represents a significant element of risk to deployment in terms of time and cost. Companies can raise private capital more easily if there is a well-defined and time-limited regulatory approval process. A recent meeting between stakeholders, DOE, and the Nuclear Regulatory Commission (NRC) was held [6] to discuss licensing of advanced reactors. Over 300 people participated in the meeting. Many agree that the regulatory approach and rule set used to license LWRs needs to be adapted and modified to better address the different technologies of advanced systems.

- In July 2015, in response to Congressional budget language, Department of Energy Office of Nuclear Energy (DOE-NE) issued a financial opportunity announcement in support of advancement of industry advanced reactor concepts [6]. Two of the 14 teams proposing innovative concepts were each presented a 5-year, $\$ 50$ million award.

- In January 2016, an Advanced Nuclear Summit and Showcase was organized by Third Way, Argonne National Laboratory, Idaho National Laboratory, and Oak Ridge National Laboratory. This summit was convened to inform national policymakers of the robust advanced nuclear reactor sector being developed by private companies and research institutions and establish that government-including national laboratories - has a vital role to play in deployment of advanced reactor technologies.

- In February 2016, an Advanced Reactors Technical Summit III focusing on key movers, technology and process innovation was held under the auspices of the U.S. Nuclear Infrastructure Council and the Energy Innovation Reform Project at Oak Ridge National Laboratory. The Summit III followed a 2015 Summit at University of Massachusetts Lowell and an inaugural Summit at Argonne National Laboratory in 2014. The Summit III continued the discussion on approaches for improving the cost and deployment time frame of advanced reactors as well as common ground practical ideas and concepts that have the potential of significantly accelerating advanced reactor design deployment and operations.

The Nuclear Energy Institute and the Electric Power Research Institute are supporting commercialization of advanced reactors through working groups and other activities (including this study) to learn about the underlying nuclear technologies, understand their RD\&D needs, establish owner-operator requirements for Gen-IV systems, and estimate their potential deployment timelines. These synergistic efforts further the understanding of each other's interests and assets, which can then be leveraged to achieve common objectives.

\subsection{International Interest in Advanced Reactor Technologies}

There are ongoing international efforts to design and construct irradiation facilities. The Jules Horowitz reactor is under construction at the Commissariat à l'Energie Atomique (CEA) Cadarache site (France). This facility has a broad range of testing environments and experiment testing capabilities. Once commissioned, it is expected to be the state of the art irradiation testing facility. SCK-CEN (Belgium) is designing an 85-MWth subcritical accelerator-driven test reactor called the Multi-purpose hYbrid Research Reactor for High-tech Applications (MYRRHA) with a lead bismuth eutectic spallation target and coolant to function as a fast test reactor. Also on the horizon is a replacement for the High Flux Reactor (HFR) in Petten, Netherlands. Known as the "Pallas" reactor, it is currently in the design phase. These reactors are replacing aging facilities built in the same era as those currently operating within the DOE complex. The 
investment by the French and the European Union recognizes the importance of modern irradiation-testing infrastructure for both nuclear fuels and materials development and isotope production for future generations.

Additionally, development plans exist around the world to commercialize a number of advanced power reactor technologies including:

- Sodium-cooled fast reactor (SFR) demonstration projects have recently been completed in Russia (880 MWe BN-800) and India (500 MWe PFBR). Design projects are ongoing for demonstration reactors in Korea (150 MWe PGSFR) and France (300 MWe ASTRID). China's first Experimental Fast Reactor (CEFR) has been in operation since 2010. Japan continues to work on restart of the Japan Experimental Fast Reactor (JOYO) test reactor and Monju demonstration reactor.

- The Chinese are building a two-unit $250 \mathrm{MWth}$ (200 MWe total) pebble bed high temperature gas-cooled reactor (HTGR) based on the German technology developed in the 1970s and 1980s. The Chinese have plans for a follow-on $600 \mathrm{MWe}$ plant in China and have recently signed a memorandum of understanding with Saudi Arabia to deploy similar systems there.

- The Russians are working on the design of an experimental lead-cooled fast reactor (LFR) called BREST-300 and SVBR-100, a small lead-bismuth eutectic reactor. These are expected to be in operation after 2020.

- Molten salt reactor (MSR) systems are in study phases in Europe and Russia. The Chinese Academy of Sciences is planning to build a small $(2-10 \mathrm{MW})$ demonstration molten salt pebble bed reactor with plans for larger versions in the longer term.

- The ALLEGRO project in Eastern Europe is centered on designing the first ever fast-spectrum gas-cooled reactor. It is recognized as a longer term project given the low technology readiness.

The collection of these activities are broad in the range of technologies under investigation and deep in terms of the number of systems that have been recently built or are under construction. For the lower maturity technologies, the focus is on fundamental research and development (R\&D) to identify and qualify fuel, cladding, coolant, and structural materials. For more mature concepts, the focus is on integral testing and deployment of demonstration, state-owned, or state-commissioned commercial power plants.

\subsection{Definitions}

Throughout this document, reactors mainly serving one of two functions are discussed: a demonstration reactor and a test reactor. In addition, the terms prototypic and scalable are used. For this study, definitions for each of these terms are as follows.

Prototypic. A system, structure, component, or process that is similar to or representative of its application or use in a commercial plant in terms of features, function, and performance.

Scalable. A system, structure, component, or process that is potentially of different physical size, feature, or function, but the performance of which is captures the relevant physics of, and can be confidently scaled to, the commercial plant. 
Demonstration reactor. Broadly defined for this study ${ }^{c}$ as one which exhibits, in terms of safety and performance, the essential features and behavior of the plant to be deployed commercially. It can range both in physical size (power level) and degree of prototypicality.

Test reactor. A nuclear reactor system designed to irradiate materials with a range of neutron energies (fast and thermal) for testing nuclear fuels and materials under prototypical nuclear reactor conditions.

Many demonstration reactors based upon some of the technologies considered in this study as well as LWRs have been built and operated. They can be broadly categorized as one of the following.

- Engineering demonstrations are reduced scale system to establish proof of concept for concepts that have never been built. The goal of the demonstration at this level is the viability of the integrated system. Historically these have been small reactors ( $<50 \mathrm{MWe})$.

- Performance demonstrations are generally larger scale systems designed to establish that scale-up of the system works and to gain operating experience to validate the integral behavior of the system (including fuel cycle in some cases) resulting in proof of performance.

- Commercial demonstrations are full-scale systems that will be replicated for subsequent commercial offerings if the system works as designed.

Examples of such systems are described in more detail in Section 7.

\subsection{Study Purpose, Approach, and Overview}

In light of the promise of advanced reactor systems, specific congressional language contained within the fiscal year 2015 appropriation directed DOE to conduct an advanced test/demonstration reactor planning study to

"evaluate advanced reactor technology options, capabilities, and requirements within the context of national needs and public policy to support innovation in nuclear energy."

This study, commissioned by Congress to be executed by DOE, was an extensive effort that spanned approximately 1 year and sought to incorporate the perspective of industry, academia, and government technical experts. An evaluation was performed of reactor technology options for both a test reactor and for demonstration reactors for the advancement of reactors for commercial deployment. The study included a formulation stage to define what would be assessed and how it would be assessed.

To guide the scope and establish the evaluation framework of this study, strategic objectives for the development of advanced reactor technology were defined by considering the anticipated missions and development needs. The strategic objectives recognize the potential of advanced reactor demonstration/test reactors to demonstrate missions beyond nuclear electricity production (e.g., other energy products or improved fuel cycles), to mature innovative new technology options, and to provide high-performance irradiation testing capabilities.

c. This definition of 'demonstration reactor' is different than that used by the Nuclear Regulatory Commission. 
The ability of a concept to meet a strategic objective is assessed through a set of goals, criteria, and metrics. The general list of traditional reactor requirements such as safety and security are implicit in the assessment. Strategic objectives, goals, criteria, and metrics for this study are defined in Section 2.

The Generation-IV advanced reactor technologies were assessed to identify which options should be evaluated in this study. Many Gen-IV options have sufficient maturity to be considered for engineering demonstration of an integrated reactor systems; whereas, only a few Gen-IV options have sufficient maturity to be considered as the base technology for a test reactor. The process and results utilized for assessment of the Gen-IV reactor technology options is presented in Section 3.

For the reactor technologies identified in the Gen-IV assessment, point designs were solicited from domestic reactor vendor or national laboratory experts; the point designs in this study are representative examples of a technology and should not be considered as the only option for that technology. The resulting six point designs were assessed against the identified goals, criteria, and metrics. The demonstration reactor point design and assessment results are given in Section 4, with the test reactor point design results in Section 5.

The evaluations conducted in this study revealed important considerations regarding the licensing and deployment strategies (including cost and schedule) for advanced reactor technology. Key results and considerations are discussed in Section 6 (Deployment) and Section 7 (Licensing). In summary, over the course of a year and as part of this study, the assessment team:

- Assembled a broad team of stakeholders from industry, academia, and government

- Chose a set of strategic objectives that support both innovation and the long-term commercialization of advanced reactor systems

- Considered a broad set of potential reactor technologies and selected a set for evaluation

- Commissioned point designs to develop the technical basis for evaluation

- Developed a comprehensive set of goals, criteria, and metrics to evaluate advanced test and demonstration reactor concepts ability to meet the strategic objectives

- Solicited extensive stakeholder input to evaluate candidate designs with respect to the goals, criteria, and metrics

- Identified pathways to deployment for concepts of varying technical maturity.

This report reflects the team's effort to provide a sound comparative technical context for decisions concerning advanced reactor technology. It compares different technology options and identifies the tradeoffs that exist when trying to meet the strategic objectives. Timelines and costs are estimated for the different demonstration systems, including perspectives on possible licensing approaches. It also presents the tradeoffs that exist among the different test reactor options in terms of the ability to conduct irradiations in support of advanced reactor R\&D and to serve potential secondary missions. 


\subsection{References}

1. Generation IV International Forum, Technology Roadmap Update for Generation IV Nuclear Energy Systems, January 2014.

2. DOE Office of Nuclear Energy, Advanced Reactor Concepts Technical Review Panel Report Evaluation and Identification of Future R\&D on Eight Advanced Reactor Concepts, conducted April-September 2012, December 2012.

3. DOE Office of Nuclear Energy, Advanced Reactor Concepts Technical Review Panel Public Report Evaluation and Recommendations on Seven Advanced Reactor Concepts conducted March through June 2014, October 2014.

4. DOE, National Laboratory Big Ideas Summit, Washington, D.C., March 12-13, 2014.

5. Idaho National Laboratory, Nuclear Innovation Workshops, INL/EXT-15-36509, September 2015.

6. NRC-DOE Advanced Reactor Workshop, (https://nuclearinnovationworkshop.inl.gov) Bethesda, Maryland, September 1-2, 2015, (http://www.nrc.gov/public-involve/conference-symposia/adv-rxnon-lwr-ws.html).

7. DOE Idaho Operations Office, Advanced Reactor Research and Development Funding Opportunity, DE-FOA-0001163, August 28, 2015. 


\section{ESTABLISHING STRATEGIC OBJECTIVES, GOALS EVALUATION CRITERIA, AND METRICS}

\subsection{Evaluation Framework}

The purpose of the set of objectives, goals, criteria, and metrics developed for this study is to provide a consistent basis for evaluating advanced test and demonstration concepts utilizing a variety of technology options. Expert judgment was used to elicit goals, criteria, and metrics from a diverse group of scientists and engineers from the nuclear community spanning industry, national laboratories, and universities. The initial sets were based on previous studies performed by Gen-IV participants and the recent NE-5 Fuel Cycle Options Study [1] appropriately modified for the goals established here. A later workshop was held in April 2015 to obtain additional input from a larger group of stakeholders that resulted in further refinements.

A wide variety of important missions and advanced reactor technology needs have been identified as a result of the nuclear energy strategies identified in the DOE-NE Roadmap, NE-7 Advanced Reactor Technical Review Panel [2], NE-5 Fuel Cycle Options Study [3], recent industry proposals, and international (e.g., Gen-IV) efforts. A fundamental mission for all reactor technologies is to provide efficient, reliable electricity production without carbon emissions. Beyond the high-efficiency electricity production mission, advanced reactor technologies target features that can improve the performance and/or extend the impact of nuclear power deployment. For this study, four strategic objectives that span the range of key nuclear energy missions and needs were considered; the first three of which relate to demonstration reactor options and the fourth relates to test reactors options. The strategic objectives are as follows:

1. Deploy a high-temperature process heat application for industrial applications and electricity demonstration using an advanced reactor system to illustrate the potential that nuclear energy has in reducing the carbon footprint in the U.S. industrial sector

2. Demonstrate actinide management to extend natural resource utilization and reduce the burden of nuclear waste for future generations

3. Deploy an engineering demonstration reactor for a less-mature reactor technology with the goal of increasing the technology readiness level of the overall system for the longer term

4. Provide an irradiation test bed to support development and qualification of fuels, materials, and other important components/items (e.g., control rods, instrumentation) of both thermal and fast neutron-based Gen-IV advanced reactor systems.

This report evaluates the performance of different advanced reactor technology options for each objective. It is recognized that economics is a key consideration for any objective; and the demonstration reactor and test reactor project costs are assessed in this study. However, more detailed design, technology development, and operational experience will be necessary before accurate and consistent costs can be compared for these systems. Furthermore, recent studies have examined the cost of advanced systems under the Gen-IV initiative and at this early stage were found to be comparable to, but slightly greater than, existing LWRs [4,5]. Given the ranges of maturity and uncertainties in costs estimates, there appears to be no defensible cost differentiation among advanced reactor concepts at this time, thus technology selection based on cost is premature. 
For this study, the goals are a subset of the desired attributes of either a test or demonstration reactor. Some attributes are presumed of all designs (e.g., safety and security) and are not used to differentiate the concepts. Other key performance attributes will differ between concepts and between the overall test and demonstration missions. Thus, the goals are the set of desirable attributes that are used to differentiate among designs. A separate set of goals was established for test reactors and demonstration reactors.

For each goal, specific criteria are identified. Criteria comprise the key features and/or performance parameters needed to meet each goal (e.g., capital cost for an economic goal, or flux level for an irradiation testing goal). For evaluation studies, it is not the intent that the identified criteria be an exhaustive list for each goal; rather, criteria were selected to discriminate among the concepts considered in this study.

For each criterion, specific metrics are identified. The metrics are a quantifiable measure of key performance characteristics that are important to a given criterion. As the point designs considered in this study are at varying levels of technical maturity, the values of some metrics reflect relative performance or qualitative assessment.

The evaluation process involves the assignment of "weightings" to the different goals, criteria, and metrics. The intent is that the weightings reflect importance of features within specific strategic objectives. The evaluation informs the decision process by providing information on the relative benefits and challenges for different options toward a variety of strategic objectives. In practice, one would expect subsequent clarification of strategic targets and refinement of a particular design to be an iterative process. This study represents an initial evaluation to identify reactor concepts that have the potential to meet the test and demonstration reactor goals. The approach used is illustrated in Figure 1 and includes five steps:

- Establish strategic objectives that reflect the range of DOE's nuclear energy objectives. As discussed in Section 2.1, three distinct strategic objectives have been developed focused on different reactor demonstrations and one strategic objective focused on a test reactor.

- Establish a set of goals and criteria (and associated metrics) for demonstration reactors and a set for test reactors with which to evaluate the options

- For each of the strategic objectives, establish unique weightings for each of the goals and criteria (because some goals and criteria will be more important for a given objective than others). In the case of more than one metric for a given criterion, a subweighting is established.

- Develop different reactor technology options (a number of different point design options are evaluated in this report)

- Use the goals, criteria, metrics, and the objective-specific weightings to evaluate each proposed design against the associated strategic objective.

The goals, criteria, and associated metrics are identified in Sections 2.3 and 2.4. The metric performance ranges selected for this study are detailed in Appendix A, and the relevant weightings for each strategic objective are described in Appendix A. 


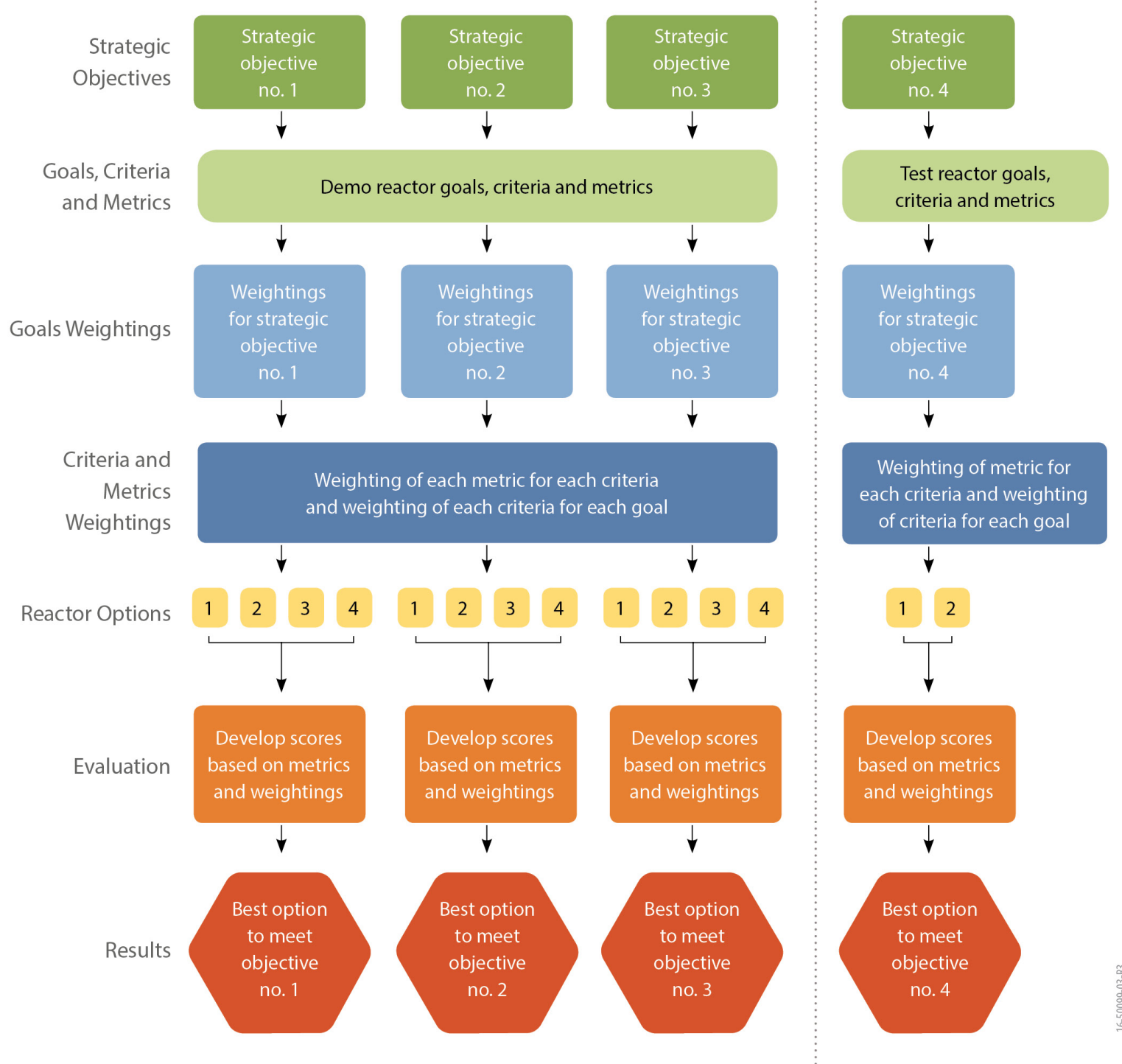

Figure 1. Overview of approach used in technical evaluation of options.

\subsection{Desirable Outcomes, and Requirements}

As part of the process of establishing goals, criteria, and metrics for a test and/or demonstration reactor, a number of participants in the workshop felt strongly about certain attributes necessary for each reactor. However, when examining these items as part of the development of detailed metrics and weighting (see Appendix A), several goals and their associated criteria and metrics, while important in terms of reactor safety or performance, are generically applicable and would not distinguish reactor concepts. Some goals associated with key features of a successful test or demonstration reactor are not dependent on reactor type (i.e., technology choices), but rather the goals rely on project structures and/or operational paradigms. In other cases, because of the limited time associated with this study, the required level of detail necessary to compare against a quantitative metric would not be available. Thus, some of these goals were classified as desirable outcomes realized by any test and/or demonstration reactor 
project, while others were identified as requirements that would be imposed independent of the details of the reactor designs that were evaluated. These desirable attributes and requirements are captured in this section.

Desirable Outcome. Test or demonstration reactor project and operations provide a focal point for U.S. nuclear energy R\&D activities to support diverse stakeholders.

The ability of a new reactor to be a focal point for U.S. nuclear energy R\&D is a highly desirable attribute. However, independent of the technology option selected, any reactor development activity will be a focal point. In particular, such a facility would enable (1) training of next generation engineers and scientists, (2) strategic utilization of national laboratories facilities and expertise, (3) engagement and access for U.S. industry, (4) engagement with regulator (U.S. NRC), (5) access and coordination with university programs, and serve as a model for international users and collaborations.

Requirement 1 . Test or demonstration reactor has a robust safety design basis.

The ability to license a reactor by the NRC was considered an important prerequisite as it is an indicator of a high degree of safety. Two important criteria identified were (1) the ability to tolerate a broad range of upset conditions, and (2) having a safety envelope that would accommodate a wide variety of test conditions.

These items represent important requirements for each system going forward. However, because the concepts considered started from the Gen-IV concepts, all have the fundamental characteristics that provide a robust safety basis. Furthermore, the level of technical detail required (e.g., safety analyses and risk assessment) would not be available in this study and is insufficient to quantitatively differentiate among the options. Thus, this criterion was not used at this point in the assessment.

Requirement 2. Safeguards and security are adequate.

The ability to meet safeguards and security requirements is another important pre-requisite for any reactor to be built. The initial criteria identified were (1) to have prototypic material accounting by incorporating proliferation resistance features in the physical design and adhering to other relevant IAEA safeguards requirements and (2) to meet current standard for reactor security by including robust security features in the physical design and meeting associated NRC security requirements. Because the concepts considered started from the Gen-IV concepts, all have the fundamental characteristics that can provide for safeguards and security. They were not used in the assessment because they did not differentiate among the options at the point design stage.

Requirement 3. Ability to accommodate in-pile instrumentation for experiments.

The ability of a test reactor to have a suite of tools to measure the local test environment (e.g., temperature, neutron flux/fluence, flow) is considered an enabling technology that differentiates the facility from others. It is also important to most customers interested in fuels and materials qualification and modeling/simulation validation testing that will eventually receive regulatory scrutiny. This criterion was not used in the assessment because the test reactor point designs would not be mature enough to incorporate such detail. However, it is listed explicitly here as a requirement because of its seminal importance for experimentation in a test reactor. 


\section{Other Requirements}

A few metrics were omitted because they did not differentiate among the technology options, or the level of detail available did not allow a credible qualitative or quantitative measurement in the assessment. In the area of test reactor metrics, the following items were omitted as metrics but were viewed as more valuable requirements once the designs matured: (1) maintainability of the system, and (2) margin available for future upgradability of the reactor system. For the demonstration reactor similar metrics related to maintainability and upgradability were identified.

\subsection{Demonstration Reactor Goals, Criteria, and Metrics}

The following section identifies the goals, criteria and associated metrics used for the demonstration reactor evaluation. The goals, criteria, and associated metric are shown graphically in Figure 2. For each metric, the assessment ranges and scoring are detailed in Appendix A. For the six goals established for the demonstration reactor, a listing of each goal, the associated criteria, its rationale, and associated metric(s) are provided.

\begin{tabular}{|c|c|c|}
\hline \multicolumn{3}{|c|}{ Demonstration Reactor Goals, Criteria and Metrics } \\
\hline Goal & Criteria & Metrics \\
\hline \multirow{5}{*}{$\begin{array}{l}\text { 1. Demonstration Reactor } \\
\text { significantly advances the } \\
\text { technology toward a potential } \\
\text { commercial plant }\end{array}$} & $\begin{array}{l}1.1 \text { Capability to demonstrate safety } \\
\text { behavior of commercial system }\end{array}$ & $\begin{array}{l}\text { 1.1.1 Does the demonstration system have safety characteristics and } \\
\text { systems/components expected in the commercial plant? }\end{array}$ \\
\hline & $\begin{array}{l}\text { 1.2 Detailed instrumentation and data } \\
\text { for code validation tests }\end{array}$ & $\begin{array}{l}\text { 1.2.1 Does the design have adequate instrumentation and will it gather appropriate } \\
\text { data for code validation tests? }\end{array}$ \\
\hline & 1.3 Scalable technology choices & $\begin{array}{l}\text { 1.3.1 Does the design implement technology selections that are prototypic or scalable } \\
\text { to commercial unit? }\end{array}$ \\
\hline & $\begin{array}{l}1.4 \text { Scalable maintenance techniques } \\
\text { and schedules }\end{array}$ & $\begin{array}{l}\text { 1.4.1 Does the design have maintenance approaches that are prototypic or scalable to } \\
\text { commercial unit? }\end{array}$ \\
\hline & 1.5 Scalable fabrication options & $\begin{array}{l}\text { 1.5.1 Does the design use prototypic of scalable technologies in the fabrication of } \\
\text { important systems and components? }\end{array}$ \\
\hline \multirow{4}{*}{$\begin{array}{l}\text { 2. Demonstration Reactor } \\
\text { operations help resolve technical } \\
\text { barriers (e.g. predictability) to } \\
\text { advanced reactor economics and } \\
\text { reliability }\end{array}$} & \multirow{2}{*}{ 2.1 Project costs and Schedule } & 2.1.1 Project cost \\
\hline & & 2.1.2 Project schedule - the time from today to first operation \\
\hline & 2.2 Operational costs & 2.2.1 Annual operating costs \\
\hline & 2.3 Reliability of operations & 2.3.1 Availability factor \\
\hline \multirow{2}{*}{$\begin{array}{l}\text { 3. Demonstration Reactor has a } \\
\text { robust safety design basis for } \\
\text { licensing }\end{array}$} & \multirow{2}{*}{$\begin{array}{l}\text { 3.1 Licensed by Nuclear Regulatory } \\
\text { Commission }\end{array}$} & 3.1.1 Ability to address key licensing issues for follow-on commercial units \\
\hline & & 3.1.2 EPZ size \\
\hline \multirow{8}{*}{$\begin{array}{l}\text { 4. Demonstration reactor } \\
\text { supports demonstration of } \\
\text { technology and system } \\
\text { integration (enhancing } \\
\text { immediate, intermediate and } \\
\text { long term value of the project) }\end{array}$} & $\begin{array}{l}\text { 4.1 Facilitate component } \\
\text { demonstration }\end{array}$ & $\begin{array}{l}\text { 4.1.1 Does the system facilitate demonstration of components in an integral sense of } \\
\text { that expected in follow-on commercial units? }\end{array}$ \\
\hline & \multirow{2}{*}{$\begin{array}{l}\text { 4.2 Ability to demonstrate alternate } \\
\text { core configurations and fuel types }\end{array}$} & 4.2.1 Number of alternative core configurations \\
\hline & & 4.2.2 Number of alternative fuel types \\
\hline & \multirow{2}{*}{$\begin{array}{l}\text { 4.3 R\&D required before } \\
\text { demonstration reactor } \\
\text { construction/operation }\end{array}$} & 4.3.1 R\&D time \\
\hline & & 4.3.2 R\&D cost \\
\hline & \multirow{3}{*}{$\begin{array}{l}\text { 4.4 Provide ability to conduct } \\
\text { irradiations of materials and fuels }\end{array}$} & 4.4.1 Fast flux conditions at test location \\
\hline & & 4.4.2 Thermal flux conditions at test location \\
\hline & & 4.4.3 Irradiation volumes and length \\
\hline \multirow{4}{*}{$\begin{array}{l}\text { 5. Demonstrate reactor stage of } \\
\text { advanced fuel cycle }\end{array}$} & $\begin{array}{l}\text { 5.1 Ability to demonstrate utilization } \\
\text { of natural resources }\end{array}$ & 5.1.1 Use of natural fuel resources \\
\hline & 5.2 Prototypic fuel fabrication & 5.2.1 Is the fuel fabrication approach prototypic or scalable to commercial unit? \\
\hline & 5.3 Prototypic fuel performance & 5.3.1 Is anticipated fuel performance prototypic or scalable to commercial unit? \\
\hline & 5.4 Used fuel handling & 5.4.1 Is the spent fuel handling prototypic or scalable to commercial unit? \\
\hline \multirow{2}{*}{$\begin{array}{l}\text { 6. Demonstrate high temperature } \\
\text { reactor process heat applications }\end{array}$} & $\begin{array}{l}\text { 6.1 Demonstrate integration with } \\
\text { various energy conversion systems or } \\
\text { process heat for industrial applications }\end{array}$ & 6.1.1 Number of energy conversion systems or industrial applications \\
\hline & $\begin{array}{l}\text { 6.2 Ability to demonstrate industrial } \\
\text { heat applications }\end{array}$ & 6.2.1 Coolant outlet temperature \\
\hline
\end{tabular}

Figure 2. Demonstration reactor goals, criteria, and metrics. 


\section{Goal D1 Demonstration reactor significantly advances the technology toward a potential commercial plant}

Criteria D1.1 Capability to demonstrate safety behavior of commercial system

Rationale: Advanced reactors have both inherent and passive design features that should enable a demonstrable benefit for public acceptance. However, the size of the demonstration reactor or other constraints may limit the ability of the system to demonstrate the safety behavior of the ultimate commercial system because of lack of prototypicality and/or scalability. The metrics give the highest score to systems that incorporate the inherent and passive design features anticipated in the commercial system.

Metric D1.1.1 Does the demonstration system have safety characteristics and systems/components expected in the commercial plant?

Criteria D1.2 Detailed instrumentation and data for code validation tests

Rationale: To enable proper scaling and to validate reactor performance and system level safety proper detailed instrumentation is necessary. (Instrumentation is explicitly incorporated here for the demonstration reactor since it is not required and could be an important differentiator.) In addition, data on reactor performance, fuel performance, and component reliability are critical for licensing of follow-on units.

Metric D1.2.1 Does the design have adequate instrumentation and will it gather appropriate data for code validation tests?

Criteria D1.3 Scalable technology choices

Rationale: Evaluate scalability/prototypicality of technology choices (materials, fuel, components, and systems) in the design to determine relevancy to the commercial unit.

Metric D1.3.1 Does the design implement technology selections that are prototypic or scalable to commercial unit?

Criteria D1.4 Scalable maintenance techniques and schedules

Rationale: Evaluate the scalability/prototypicality of maintenance approaches relative to that anticipated in the commercial unit.

Metric D1.4.1 Does the design have maintenance approaches that are prototypic or scalable to commercial unit?

Criteria D1.5 Scalable fabrication options

Rationale: Evaluate the scalability/prototypicality of fabrication choices of important systems and components relative to that anticipated in the commercial unit.

Metric D1.5.1 Does the design use prototypic or scalable technologies in the fabrication of important systems and components? 


\section{Goal D2. Demonstration reactor operations help resolve technical barriers (e.g., predictability) to advanced reactor economics and reliability}

Criterion D2.1 Project costs and schedule

Rationale: Project cost and construction schedule are key inputs to help improve predictability of economics of advanced reactor systems. The demonstration reactor is not expected to meet any specific overnight cost or levelized cost of electricity metric as might be considered for subsequent commercial offerings. An objective of the demonstration reactor would be to provide data to improve the predictability of the cost of the commercial offering. Project cost includes R\&D, design, licensing, construction, and contingency.

Metric D2.1.1 Project cost

Metric D2.1.2 Project schedule - the time from today to first operation

Criterion D2.2 Operational costs

Rationale: Operating costs are also important in economic models for advanced reactors. These costs include operations, maintenance, and fuel. The metric will deal with the net annual costs so any offsets by product revenue streams (e.g., selling electricity) will be accounted for in the metric.

Metric D2.2.1 Annual operating costs

Criterion D2.3 Reliability of operations

Rationale: Predictable and sustained reactor operations are vital for eventual commercial application of advanced reactor technology. Operating campaigns in the demonstration reactor can confirm this performance. The overall availability is a key measure in terms of the number of full-power days available per year to provide routine operations.

Metric D2.3.1 Availability factor 


\section{Goal D3 Demonstration reactor has a robust safety design basis for licensing}

\section{Criterion D3.1 Licensed by the Nuclear Regulatory Commission}

Rationale Obtaining a license from the NRC for an advanced reactor system is viewed as a key hurdle that should be overcome with a demonstration or commercial system. There are multiple facets to licensing including the establishment of the licensing technical requirements that must later be met when obtaining an NRC license for the commercial version of the advanced reactor system, and the resolution of non-technology specific Commission policy issues. The primary metric is qualitative and is related to the ability of the demonstration reactor to address the key unresolved technical issues that will provide the foundation for demonstrating a robust safety design basis to exercise the advanced-reactor licensing framework. The second metric is the size of the emergency planning zone, which is related to the safety of the system and the impact on the public. The smaller the emergency planning zone (EPZ) the lesser potential impact on the public.

Metric D3.1.1 Ability to address key licensing issues for follow-on commercial units.

Metric D3.1.2 EPZ size 


\section{Goal D4 Demonstration reactor supports demonstration of technology and system integration (enhancing immediate, intermediate, and long-term value of the project)}

Criterion D4.1 Facilitate component demonstration

Rationale: Demonstrating (prototypic or scalable) integral component performance (i.e., performance within an operating reactor system) is a key objective for deployment of follow-on commercial units. The more the integral demonstration is prototypic the greater the predictability of cost and operational performance for the follow-on units.

Metric D4.1.1 Does the system facilitate demonstration of components in an integral sense of that expected in follow-on commercial units?

Criterion D4.2 Ability to demonstrate alternate core configurations and fuel types

Rationale: The ability of the reactor system to support alternative core configurations (e.g., seed blanket and core; burning versus breeding) and alternative fuel types (e.g., metal versus oxide fuel; oxide versus oxycarbide fuel; SiC tristructural isotropic [TRISO] versus ZrC TRISO) are important measures of the flexibility of the system.

Metric D4.2.1 Number of alternative core configurations

Metric D4.2.2 Number of alternative fuel types

Criterion D4.3 R\&D required before demonstration reactor construction/operation

Rationale: This criterion measures directly the impact of technology development on the actual deployment of the demonstration unit. Metrics are related to the time and cost for the technology development.

Metric D4.3.1 R\&D time

Metric D4.3.2 R\&D cost

Criterion D4.4 Provide ability to conduct irradiations of materials and fuels

Rationale: This criterion measures another flexibility attribute that increases the value of the demonstration unit. Metrics in terms of flux and irradiation volume and length similar to that for the test reactor are used here.

Metric D4.4.1 Fast flux conditions at test location

Metric D4.4.2 Thermal flux conditions at test location

Metric D4.4.3 Irradiation volumes and length 


\section{Goal D5 Demonstrate reactor stage of advanced fuel cycle}

Criterion D5.1 Ability to demonstrate utilization of natural resources

Rationale: The goal is to extend the amount of energy produced by a given amount of natural resources. Advanced reactors can perform this function by utilizing recycle materials in advanced fuel cycles and/or extending fuel burnup. Relevant fuel performance can be validated in a demonstration reactor. The quantitative metric is taken directly from the Gen-IV evaluation criteria with the lower range that is typical of advanced LWRs.

Metric D5.1.1 Use of fuel natural resources

Criterion D5.2 Prototypic fuel fabrication

Rationale: This criterion measures the prototypicality of fuel fabrication (and indirectly the maturity of the fuel production supply chain) for the advanced demonstration reactor, which is an important part of demonstrating the reactor's fuel cycle. Metrics are developed based on whether it is prototypic, scalable (meaning a pilot or engineering scale with representative; not laboratory scale or surrogate materials), or neither.

Metric D5.2.1 Is the fuel fabrication approach prototypic or scalable to commercial unit?

Criterion D5.3 Prototypic fuel performance

Rationale: This criterion measures the prototypicality of anticipated fuel performance for the advanced reactor. Metrics are developed based on whether it is prototypic, scalable, or neither.

Metric D5.3.1 Is the anticipated fuel performance prototypic or scalable to commercial unit?

Criterion D5.4 Used fuel handing

Rationale: This criterion measures the prototypicality of used fuel handling techniques for the advanced reactor. Metrics are developed based on whether it is prototypic, scalable, or neither.

Metric D5.4.1 Is the spent fuel handling prototypic or scalable to commercial unit? 


\section{Goal D6 Demonstrate high temperature reactor process heat applications}

Criterion D6.1 Demonstrate integration with various energy conversion systems or process heat for industrial applications

Rationale: A measure of how well the proposed system can integrate with other energy conversion systems or industrial applications with minimal change to the demonstration concept. This is based on the actual design and not the potential of the technology.

Metric D6.1.1 Number of energy conversion systems or industrial applications

Criterion D6.2 Ability to demonstrate industrial heat applications

Rationale: To expand the utilization of nuclear energy beyond the electricity sector, a variety of industrial heat applications have been identified. These processes span a range of high-temperature conditions. This criterion measures the potential to capture a large and diverse portfolio of industry heat applications.

Metric D6.2.1. Coolant outlet temperature

\subsection{Test Reactor Goals, Criteria, and Metrics}

The following section identifies the goals, criteria, and associated metrics used for the test reactor evaluation. The goals, criteria and associated metrics are shown graphically in Figure 3. For each metric, the assessment ranges and scoring are detailed in Appendix A. For the three goals established for the test reactor, a listing of each goal, the associated criteria, its rationale and associated metric(s) is provided. 


\begin{tabular}{|c|c|c|}
\hline \multicolumn{3}{|c|}{ Test Reactor Goals, Criteria and Metrics } \\
\hline Goal & Criteria & Metrics \\
\hline \multirow{8}{*}{$\begin{array}{l}\text { 1. Test Reactor provides } \\
\text { irradiation services for a variety } \\
\text { of reactor and fuel technology } \\
\text { options }\end{array}$} & \multirow{5}{*}{1.1 Irradiation conditions } & 1.1.1 Fast flux conditions \\
\hline & & 1.1.2 Thermal flux conditions \\
\hline & & 1.1.3 Irradiation volumes and length for largest test location \\
\hline & & $\begin{array}{l}\text { 1.1.4 Maximum sustainable time at power, to provide a time-at-power for a single } \\
\text { irradiation (i.e. cycle length) }\end{array}$ \\
\hline & & $\begin{array}{l}\text { 1.1.5 Provisions for testing prototypic and bounding conditions (temperature, coolant } \\
\text { chemistry) }\end{array}$ \\
\hline & \multirow{3}{*}{$\begin{array}{l}\text { 1.2 Support diverse irradiation testing } \\
\text { configurations concurrently } \\
\text { (accommodate various sizes and tailor } \\
\text { irradiation parameters to wide group } \\
\text { of simultaneous users) }\end{array}$} & 1.2.1 Number of test zones \\
\hline & & $\begin{array}{l}\text { 1.2.2 Number and type of distinct irradiation test loops each with a different cooling } \\
\text { system independent of the primary reactor coolant }\end{array}$ \\
\hline & & 1.2.3 Ability to insert/retrieve of irradiation specimen while staying at power \\
\hline \multirow{4}{*}{$\begin{array}{l}\text { 2. Test Reactor will be built and } \\
\text { operated reliably and in a } \\
\text { sustainable cost-effective } \\
\text { manner. (Need to be able to } \\
\text { justify initial and long-term } \\
\text { expense) }\end{array}$} & \multirow{2}{*}{$\begin{array}{l}\text { 2.1 Project costs and schedule } \\
\text { (including design, licensing, R\&D, } \\
\text { construction, and contingency that }\end{array}$} & 2.1.1 Project cost \\
\hline & & 2.1.2 Project schedule - The time from today to first operation \\
\hline & $\begin{array}{l}\text { 2.2 Operational costs and schedule } \\
\text { (including contingency that reflects } \\
\text { technical maturity of the concept) }\end{array}$ & 2.2.1 Annual operating costs \\
\hline & 2.3 Reliability of operations & 2.3.1 Availability factor \\
\hline $\begin{array}{l}\text { 3. Capability to accommodate } \\
\text { secondary missions (electricity, } \\
\text { isotope production, etc.) of } \\
\text { modest value (million dollar) } \\
\text { without compromising primary } \\
\text { mission of testing fuels and } \\
\text { materials for advanced reactor } \\
\text { technologies }\end{array}$ & $\begin{array}{l}3.1 \text { Identification of secondary } \\
\text { missions }\end{array}$ & 3.1.1 Number of secondary missions \\
\hline
\end{tabular}

Figure 3. Test reactor goals, criteria, and metrics. 


\section{Goal T1 Test reactor provides irradiation services for a variety of reactor and fuel technology options. (Needs to provide necessary gross parameters, both current and potential.)}

Criterion T1.1 Irradiation conditions

Rationale: The nature of the irradiation test conditions established by the test reactor is critical to evaluate its ability to meet the reactor and fuel testing needs. Thus, five metrics were established to characterize the irradiation conditions: $(1,2)$ the magnitude of the fast and thermal fluxes that influence the level of radiation damage that can be accumulated on a test specimen and the rate at which burnup can be accumulated on a fuel specimen, (3) the available irradiation volumes and lengths that dictate the size of test that could be accommodated ranging from small material specimen to a scaled fuel subassembly, (4) the sustainable time at power that influences the number of (undesirable) shutdown/startup transients the experiment will have to experience until it can meet its dose and burnup requirements, and (5) the ability of the reactor to enable the creation of a prototypic and/or bounding test environment that is different from the test reactor environment (e.g., temperature, coolant, and coolant chemistry) for fuels and materials testing.

Metric T1.1.1 Fast flux conditions

Metric T1.1.2 Thermal flux conditions

Metric T1.1.3 Irradiation volumes and length for largest test location

Metric T1.1.4 Maximum sustainable time at power, to provide a time-at-power for a single irradiation (i.e., cycle length)

Metric T1.1.5 Provisions for testing prototypic and bounding conditions (temperature, coolant, chemistry)

Criterion T1.2 Support diverse irradiation testing configurations concurrently (accommodate various sizes and tailor irradiation parameters to wide group of simultaneous users)

Rationale: Test reactors have historically provided for extensive flexibility in terms of the number of testing configurations that can be accommodated within the facility. Three metrics were established to characterize the level of flexibility: (1) the number of test locations available for irradiation, (2) the number and type of test loops with cooling systems that are independent of the primary test reactor coolant to enable tailoring of the test environment, and (3) the ability to insert/retrieve an irradiation specimen while at power.

Metric T1.2.1 Number of test zones

Metric T1.2.2 Number and type of distinct irradiation test loops each with a different cooling system independent of the primary reactor coolant

Metric T1.2.3 Ability to insert/retrieve irradiation specimen while staying at power 


\section{Goal T2 Test reactor will be built and operated reliably and in a sustainable cost-effective manner. (Need to be able to justify initial and long-term expense)}

Criterion T2.1 Project costs and schedule (including design, licensing, R\&D, construction, and contingency that reflects technical maturity of the concept)

Rationale: Total project cost (in January 2016) and construction schedule are important metrics to compare different options to balance against the other metrics that attempt to measure the value the reactor provides

Metric T2.1.1 Project cost

Metric T2.1.2 Project schedule - The time from today to first operation

Criterion T2.2 Operational costs and schedule (including contingency that reflects technical maturity of the concept)

Rationale: Test reactor operating cost is important to understand relative to the experiment flexibility that it enables and the value that it delivers. Thus, the annual operating cost is a good metric. It should include operations, maintenance, fuel replacement, and experiment infrastructure. This operating cost does NOT include any cost recovery revenue. Potential products are separately identified in the secondary mission Metric 3.1.1.

Metric T2.2.1 Annual operating costs

Criterion T2.3 Reliability of operations

Rationale: The overall availability is a key measure in terms of the number of full-power days available per year to provide neutron irradiation services.

Metric T2.3.1 Availability factor

\begin{tabular}{|rl|}
\hline Goal T3 & $\begin{array}{l}\text { Capability to accommodate secondary missions (electricity, isotope } \\
\text { production, etc.) of modest value (million dollar) without } \\
\text { compromising primary mission of testing fuels and materials for } \\
\text { advanced reactor technologies }\end{array}$ \\
\hline Criterion T3.1 & Identification of secondary missions \\
Rationale: & $\begin{array}{l}\text { Secondary missions can be useful to offset operations costs and provide a different } \\
\text { measure of value of the test reactor }\end{array}$ \\
Metric T3.1.1 & Number of secondary missions \\
\hline
\end{tabular}




\subsection{References}

1. Department of Energy. "Nuclear Energy Research and Development Roadmap, "Report to Congress, April 2010.

2. Department of Energy, "Nuclear Fuel Cycle Evaluation and Screening - Final Report," FCRD-FCO-2014-000106, October 2014.

3. Advanced Reactor Concepts Technical Review Panel Report, "Evaluation and Identification of future R\&D on eight Advanced Reactor Concepts, conducted April - September 2012", TRP Report Final December 2012.

4. van Heek, A., "Cost estimation with G4ECONS for Generation IV reactor concepts," GIF Symposium, San Diego, November 15-16, 2012.

5. Locatelli, G., M. Mancini, and N. Todeschini, "Generation IV nuclear reactors: Current status and future prospects," Energy Policy, Vol. 61. 2013, pp. 1503-1520. 


\section{ASSESSMENT OF TECHNOLOGY READINESS OF TECHNOLOGY OPTIONS}

\subsection{Introduction}

An assessment of the technical maturity of different advanced reactor concepts was completed to estimate how soon each could be deployed as a demonstration or test reactor given a concerted development effort. A working group (WG) comprised of a technical experts from the national laboratories performed the maturity assessment using the technology readiness levels (TRLs) as defined in DOE's Technology Readiness Guide [1].

One representative design was selected for assessment from of each of the six Gen-IV reactor types: gas-cooled fast reactor (GFR), LFR, MSR, supercritical water-cooled reactor (SCWR), SFR, and very high temperature reactor (VHTR). Background information was obtained from previous detailed evaluations such as the Gen-IV Roadmap [2], Advanced Reactor Technologies Technical Review Panel [3] reports, the Next Generation Nuclear Plant Project (NGNP) technical reports [4], and other technical references as well as private consultations with concept proponents and subject matter experts. Except for Gen-IV collaborative research activities to which the U.S. is a party, non-U.S. experience or data sources were generally not factored into the evaluations because of the uncertainty with regard to the accessibility or quality of that data for the purposes of development, demonstration, and ultimately licensing and deployment of a U.S. facility. The WG established the scope of the assessment (which systems and subsystems needed to be considered), adapted a specific technology readiness scale, and scored each system through discussions designed to achieve internal consistency across concepts.

In general, the WG sought to determine which of the reactor options have sufficient maturity to serve either the test or demonstration reactor missions. The purpose of a test reactor is to irradiate test specimens, often within a specific range of thermochemical conditions, while that of a demonstration reactor is to demonstrate certain performance and safety attributes in the integrated system. Compared to a demonstration reactor, an increased level of maturity in certain systems and subsystems is expected of a test reactor to meet its mission objectives. The maturity is quantified in terms of TRLs, which can be assigned to the overall concept as well as to major systems and subsystems of the concept. More specifically, for each advanced reactor concept, the following were specified as key questions and assumptions for the assessment:

- What is the current technology readiness? What are the key technology hurdles that must be overcome for deployment? Can these hurdles be addressed in a test or demonstration reactor?

- How soon will the technology be mature enough to be used as the base technology for a test reactor (with a primary mission of irradiation services)?

- How soon will the technology be mature enough to be considered for a demonstration reactor? If so, what technology features would be demonstrated? If not, what feasibility issues need to be resolved before demonstration? 


\subsection{Approach}

The evaluation process consisted of the following steps:

1. Choose the reference advanced reactor design (or design family) for each concept to be evaluated (concepts described in Appendix A)

2. Adopt a TRL scale appropriate to nuclear reactor systems

3. Identify the major systems and subsystems to which TRLs are to be assigned

4. Review the technical background for each reference design and assign TRLs to each subsystem based upon this information

5. "Roll up" the subsystem scores into an overall TRL for each major plant system and into an overall TRL for the design.

An existing technology readiness scale developed by DOE [1] was adopted and is described in Appendix B-1. It was deemed most appropriate by the WG for the nuclear systems under evaluation in this study. This same DOE scale was used by the Advanced Reactor Concepts Technical Review Panel [4].

The TRL levels can be tied to the demonstration steps defined in Section 2. Concepts that have never been built have very low TRL (1-3). Once their basic scientific feasibility has been established these concepts would need an engineering demonstration (e.g., salt systems, lead systems, gas-cooled fast reactor systems). For systems with a moderate TRL (4-5) for which concept feasibility has been demonstrated but for which significant new features have been added, a performance demonstration would be the next step. Examples include an advanced SFR with a supercritical $\mathrm{CO}_{2}$ power conversion system or a VHTR (outlet temperature $>950^{\circ} \mathrm{C}$ ) with an intermediate heat exchanger. For the high-maturity systems for which basic engineering and performance has been demonstrated, commercial demonstration can commence using proven technologies (e.g., Power Reactor Inherently Safe Module [PRISM] and the modular HTGR).

In some cases, especially the less-mature technologies, detailed design information did not exist or was not available for the assessment. Thus, engineering judgment was required to assess technology readiness. There was also sufficient ambiguity in the definitions of terms such as laboratory scale, pilot scale, engineering scale, and prototypical to defy easy mapping into one of the TRL definitions. Experiments and facilities associated with one concept may not easily map onto those of another concept, thus confounding direct comparison. Overall, the reference information was only used as a basis for the assessment and comparison. The TRLs were assessed independently of previous maturity assessments.

It should be noted that the effort and time needed to raise the technical maturity of different subsystems may vary significantly. Thus, different designs with the same overall TRL may require very different development pathways and timelines. Additionally, the teams that developed the test and demonstration reactor concepts assess the technical maturity of their respective concepts. They used their own scales and definitions, which generally differed from the DOE TRL scale used in this assessment. No attempt was made to reconcile this independent assessment with those of the individual team assessments. 
The major systems and subsystems assessed by the WG are shown in Table 1. A TRL was assigned to each subsystem (if applicable). The overall system TRL was derived from the subsystem values. Emphasis was placed upon achieving consistency of scores for comparative purposes for a given subsystem across the reactor concepts such that the relative maturity could be ascertained with confidence.

Certain systems were identified as "key" because of the essential nature and complexity of the technology. Therefore, while the TRL of a specific system is derived from all of the subsystems supporting it, the overall technology readiness of a reference design was derived from the key systems and subsystems.

The evaluated systems and subsystems are listed in Table 1 with key subsystems shown in bold.

Table 1. Systems and subsystems evaluated.*

\begin{tabular}{|c|c|}
\hline System & Subsystem \\
\hline Nuclear Heat Supply & $\begin{array}{l}\text { Fuel element } \\
\text { Reactor internals } \\
\text { Reactivity control } \\
\text { Reactor enclosure (pressure vessel, core barrel, and supports) } \\
\text { Operations/inspection/maintenance } \\
\text { Core instrumentation }\end{array}$ \\
\hline Heat Transport & $\begin{array}{l}\text { Coolant chemistry control/purification } \\
\text { Primary heat transport } \\
\text { Intermediate heat exchanger } \\
\text { Pumps/valves/piping } \\
\text { Auxiliary cooling } \\
\text { Residual heat removal }\end{array}$ \\
\hline Power Conversion & $\begin{array}{l}\text { Turbine } \\
\text { Compressor/recuperator (Brayton) } \\
\text { Steam generator (Rankine) } \\
\text { Pumps/valves/piping } \\
\text { Process heat plant }\end{array}$ \\
\hline Balance of Plant & $\begin{array}{l}\text { Fuel handling and interim storage } \\
\text { Waste heat rejection } \\
\text { Instrumentation and control } \\
\text { Radioactive waste management }\end{array}$ \\
\hline Safety & $\begin{array}{l}\text { Inherent safety features } \\
\text { Active safety system }\end{array}$ \\
\hline Licensing & $\begin{array}{l}\text { Safety design criteria and regulations } \\
\text { Licensing experience } \\
\text { Safety and analysis tools }\end{array}$ \\
\hline Fuel Cycle & $\begin{array}{l}\text { Recycled fuel fabrication technology } \\
\text { Used fuel separation technology }\end{array}$ \\
\hline Safeguards & $\begin{array}{l}\text { Proliferation resistance-intrinsic design features and special nuclear } \\
\text { material (SNM) accountability } \\
\text { Physical protection - intrinsic design features and plant security }\end{array}$ \\
\hline
\end{tabular}




\subsection{Summary of the Technology Assessment}

Descriptions of the concepts and specific designs used for this readiness assessment are found in Appendix B-2. For the more mature concepts, details of a specific design (e.g., the GE-Hitachi PRISM) were available to get a better grasp of the maturity of the systems and subsystems. For less mature concepts (e.g., LFR), only general features of the systems could be assessed and were assumed to represent all designs built upon that platform. For some concepts, near-term (mature) and long-term (less mature) designs have been proposed and were assessed.

The overall concept TRLs are listed in Table 2. The complete list of a TRL values assigned to the systems and subsystems of a concept is provided in Appendix B-3.

Table 2. Technology Readiness Levels of the overall design.

\begin{tabular}{|l|c|c|c|c|c|c|c|c|}
\hline & GFR & LFR & \multicolumn{2}{|c|}{ SFR } & \multicolumn{2}{c|}{ VHTR } & SCWR & \multicolumn{2}{c|}{ MSR } \\
\cline { 2 - 9 } & EM $^{2}$ & Gen4 & AFR-100 & PRISM & SC-HTGR & & FHR & LF-MSR \\
\hline $\begin{array}{l}\text { Overall Technology } \\
\text { Readiness Levels }\end{array}$ & 2 & 3 & 3 & 5 & 5 & 3 & 3 & 3 \\
\hline
\end{tabular}

\subsubsection{Near Term Options}

The sodium-cooled fast reactor built upon the EBR-II platform is considered mature enough to support commencement of preliminary design and licensing activities for either test or demonstration reactors in the near term (5-10 years). The GEH PRISM design uses, for the most part, technologies demonstrated in EBR-II, specifically the U-Zr fuel, pool-type core, and passive heat removal system. PRISM/Mod-A is a much larger core than EBR-II (471 MWt versus $62 \mathrm{MWt}$ ) but SFRs have operated successfully in this power range. The advanced SFR under development at Argonne National Laboratory (ANL) (advanced fast reactor [AFR]-100) requires significantly more R\&D before a demonstration facility could be licensed.

The HTGR with an outlet temperature under $800^{\circ} \mathrm{C}$ is also ready for preliminary design and licensing activities. The DOE-sponsored TRISO fuel and graphite qualification efforts will be completed within the next 5 years, along with the completion of integral experiments demonstrating benign response to various upset conditions. The AREVA SC-HTGR exploits these technologies as well as those demonstrated in Fort St. Vrain and other demonstration HTGRs. HTGRs with higher $\left(>800^{\circ} \mathrm{C}\right)$ outlet temperatures will require the qualification of new materials; thus, the VHTR is a longer-term option.

Therefore, two Generation-IV technology options (SFR and HTGR) with conventional features are ready for a commercial demonstration. Alternately, a performance demonstration could be envisioned for advanced features (e.g., very high temperature, new energy conversion technology, etc.). Furthermore, only these two advanced reactor technologies will be considered as test reactor base technology options in this study. 


\subsubsection{Medium and Long-Term Options}

R\&D on the SCWR could lead to preliminary design and licensing activity in the ten-to-twenty year timeframe if certain control and water-based corrosion issues could be resolved. An engineering demonstration would be needed to raise the technical readiness to the level needed to support a performance demonstration. Currently, however, there is no DOE or U.S. commercial interest in the SCWR.

Based on U.S. experience with the Molten Salt Reactor Experiments and more recent commercial and academic activity, design and licensing of a solid fueled FHR could begin in this timeframe following a concerted effort to resolve material corrosion and tritium issues. The proposed design would also drive a novel power conversion system that has yet to be demonstrated as part of a nuclear plant.

Likewise, the lead-cooled fast reactor faces corrosion challenges that will require additional R\&D to overcome, perhaps in conjunction with an engineering demonstration (no LFR has been built or operated outside of Russia). Advanced cladding and steam generator tube material will need to be developed for this concept to realize its full potential.

The liquid-fueled FHR (MSR) faces similar corrosion and tritium transport challenges as the solid-fueled version. In some ways controlling corrosion is easier with the uranium dissolved in the salt. On the other hand, a fluid fuel with online separation must overcome significant licensing and safeguards hurdles.

The gas-cooled fast reactor was deemed the least mature because of its high power density and its associated need to quickly remove decay heat and the very low maturity of the systems proposed to do this. The thermal inertia of the core is lower than that of a typical HTGR and the proposed (but not qualified) fuel forms would need to withstand more severe temperature spikes in the event of a blower trip. Potential engineering solutions to decay heat removal are being proposed but numerous separate and integral effects testing must be completed before an engineering demonstration can be planned.

For any of these medium to long term Generation-IV technology options, research and development is required prior to an engineering demonstration to prove the concept. The timing of such an engineering demonstration depends on the specific technology choices and operational performance range (e.g., temperature). For this study, near-term engineering demonstration concepts of FHR and LFR technology (i.e., using fuel forms previously developed for HTGR and SFR) are considered, as described in Section 4.

\subsection{References}

1. Technology Readiness Assessment Guide, DOE G 413.3-4A, U.S. Department of Energy, September 2011.OECD Nuclear Energy Agency, Generation IV International Forum Annual Report 2014, 2015.

2. DOE, A Technology Roadmap for Generation IV Nuclear Energy Systems, Issued by the U.S. DOE Nuclear Energy Research Advisory Committee and the Generation IV International Forum, 2002. 
3. OECD Nuclear Energy Agency, Technology Roadmap Update for Generation IV Nuclear Energy Systems, January 2014.

4. DOE, Advanced Reactor Concepts Technical Review Panel Report-Evaluation and Recommendations for Future R\&D on Eight Advanced Reactor Concepts, Department of Energy, November 2012. 


\section{DEMONSTRATION POINT DESIGN CONCEPTS AND ASSESSMENT OF CONCEPTS AGAINST DEMONSTRATION CRITERIA}

The reactor technologies selected for evaluation were used to develop reactor point designs that were assessed against their ability to meet the strategic objectives. The different maturity levels result in point designs that are in different places along the path to deployment; thus, there is some variability it the amount and credibility of the information available by the study team to assess a technology. As noted in Section 2.1, a common mission for all reactor technologies is to provide efficient, reliable electricity production without carbon emissions. It should also be noted that concepts derived from the evaluated technologies represent examples of that technology for evaluation purposes and should not be considered as a preferred design option within a technology category.

High-level overviews of the major attributes for each design were compiled from the point design reports by the authors of this report, and are provided in Section 4.1. Key design parameters of the demonstration reactors are summarized in Table 3. More detailed information on these point designs are available in Attachment 1, "AREVA Inc.: Summary Report - SC-HTGR Demonstration Reactor," Attachment 2, "GE Hitachi Nuclear Energy: Demonstration Sodium-Cooled Fast Reactor GE-PRISM," Attachment 3 "Oak Ridge National Laboratory: Fluoride Salt-Cooled High-Temperature Demonstration Reactor Point Design," Attachment 4, "Westinghouse Electric Company LLC: Demonstration Lead-cooled Fast Reactor," Attachment 5, "Argonne National Laboratory: FASTER Test Reactor Preconceptual Design Report - Summary," and Attachment 6 "Idaho National Laboratory: High-Temperature Gas-cooled Test Reactor Point Design: Summary Report.”

The assessment of the four demonstration reactor options included in this study is presented in this section. The evaluation approach, raw and weighted scores, and the results of a sensitivity study on various weighting factors are discussed in Sections 4.2 and 4.3, respectively. Further details can be found in Appendix C. 
Table 3. Key design parameters of the demonstration reactors.

\begin{tabular}{|c|c|c|c|c|}
\hline Parameters & SC-HTGR & PRISM SFR & FHR DR & DLFR \\
\hline Rated power & $\begin{array}{l}625 \mathrm{MWth} \\
272 \mathrm{MWe}\end{array}$ & $\begin{array}{l}471 \text { MWth } \\
165 \mathrm{MWe}\end{array}$ & $\begin{array}{l}100 \mathrm{MWth} \\
42 \mathrm{MWe}\end{array}$ & $\begin{array}{l}500 \mathrm{MWth} \\
210 \mathrm{MWe}\end{array}$ \\
\hline $\begin{array}{l}\text { Thermal } \\
\text { efficiency }\end{array}$ & $43.5 \%$ & $35 \%$ & $42 \%$ & $42 \%$ \\
\hline $\begin{array}{l}\text { Power } \\
\text { conversion } \\
\text { system }\end{array}$ & $\begin{array}{l}\text { Conventional } \\
\text { Rankine steam } \\
\text { cycle }\end{array}$ & $\begin{array}{l}\text { Superheated } \\
\text { Rankine steam } \\
\text { cycle }\end{array}$ & $\begin{array}{l}\text { Open-air Brayton } \\
\text { cycle }\end{array}$ & $\begin{array}{l}\text { Superheated } \\
\text { Rankine steam } \\
\text { cycle }\end{array}$ \\
\hline $\begin{array}{l}\text { Core inlet/outlet } \\
\text { temperature }\end{array}$ & $325^{\circ} \mathrm{C} / 750^{\circ} \mathrm{C}$ & $352^{\circ} \mathrm{C} / 500^{\circ} \mathrm{C}$ & $660^{\circ} \mathrm{C} / 700^{\circ} \mathrm{C}$ & $390^{\circ} \mathrm{C} / 510^{\circ} \mathrm{C}$ \\
\hline $\begin{array}{l}\text { Primary } \\
\text { pressure }\end{array}$ & $6 \mathrm{MPa}$ & $\sim 0.1 \mathrm{MPa}$ & $\sim 0.1 \mathrm{MPa}$ & $\sim 0.1 \mathrm{MPa}$ \\
\hline Cycle length & 18 months & 18 months & 18 months & 18 months \\
\hline Reactor vessel & SA-508/533 & SS-316 & $\begin{array}{l}\text { Alloy } 800 \mathrm{H} \text { lined } \\
\text { with alloy } \mathrm{N}\end{array}$ & SS-316 \\
\hline Primary coolant & Helium & Sodium & $\begin{array}{l}\text { FLiBe } \\
\left(99.995 \%{ }^{7} \mathrm{Li}\right)\end{array}$ & Lead \\
\hline Moderator & Graphite & $\mathrm{N} / \mathrm{A}$ & Graphite & $\mathrm{N} / \mathrm{A}$ \\
\hline Fuel type & $\begin{array}{l}\text { TRISO-coated } \\
\text { UCO particles }\end{array}$ & $\begin{array}{l}\text { U-Zr in HT-9 } \\
\text { cladding }\end{array}$ & $\begin{array}{l}\text { TRISO- coated } \\
\text { UCO particles }\end{array}$ & $\begin{array}{l}\mathrm{UO}_{2} \text { in alumina } \\
\text { coated D-9 } \\
\text { cladding }\end{array}$ \\
\hline Fuel enrichment & $15.5 \%$ & $<20 \%$ & $15.5 \%$ & $\begin{array}{l}17.5 \% \text { (inner) } \\
19.9 \% \text { (outer) } \\
\end{array}$ \\
\hline Fuel form & $\begin{array}{l}\text { Hexagonal } \\
\text { graphite blocks } \\
\text { with cylindrical } \\
\text { fuel compacts }\end{array}$ & $\begin{array}{l}\text { Fuel rods in a } \\
\text { hexagonal } \\
\text { assembly }\end{array}$ & $\begin{array}{l}\text { Hexagonal } \\
\text { graphite blocks } \\
\text { with cylindrical } \\
\text { fuel compacts }\end{array}$ & $\begin{array}{l}\text { Fuel rods in a } \\
\text { hexagonal } \\
\text { assembly }\end{array}$ \\
\hline $\begin{array}{l}\text { Fueled core } \\
\text { configuration }\end{array}$ & $\begin{array}{l}102 \text { columns, } \\
10 \text { blocks/column }\end{array}$ & 99 assemblies & $\begin{array}{l}18 \text { assemblies, } \\
3 \text { blocks/column }\end{array}$ & 82 assemblies \\
\hline
\end{tabular}

\subsection{Demonstration Reactor Options}

\subsubsection{AREVA Steam Cycle-High Temperature Gas Reactor}

The Steam Cycle - High Temperature Gas-cooled Reactor (SC-HTGR) is a full-scale near-term advanced reactor concept that is being developed to provide high-temperature steam for process heat applications. It also provides high-efficiency electricity generation for small markets and markets requiring incremental capacity addition. This will extend the benefits of nuclear power to the broader energy economy. The ability to deploy the full-scale plant without an intermediate smaller scale reactor eliminates substantial cost and shortens the overall commercialization schedule significantly. 
The SC-HTGR is a modular, helium-cooled, graphite-moderated, high-temperature nuclear heat source. The reactor module has an annular prismatic block core with a power level of $625 \mathrm{MWth}$ (272 MWe net module output) and a core outlet temperature of $750^{\circ} \mathrm{C}$. The reactor uses low enriched uranium (LEU) oxycarbide (UCO) fuel, which is encapsulated in TRISO coated fuel particles contained in graphite fuel elements. This provides high-burnup capability $(\sim 15 \%)$ and excellent fission product retention.

The reactor produces superheated steam at $566^{\circ} \mathrm{C}$ and $16.7 \mathrm{MPa}$. The reactor module is coupled to two helical coil steam generators in parallel. A shutdown cooling system is also available for heat removal during maintenance. A natural circulation reactor cavity cooling system provides cooling of the reactor cavity under all operating and accident conditions. Table 3 summarizes key parameters associated with this baseline design for the module shown in Figure 4.
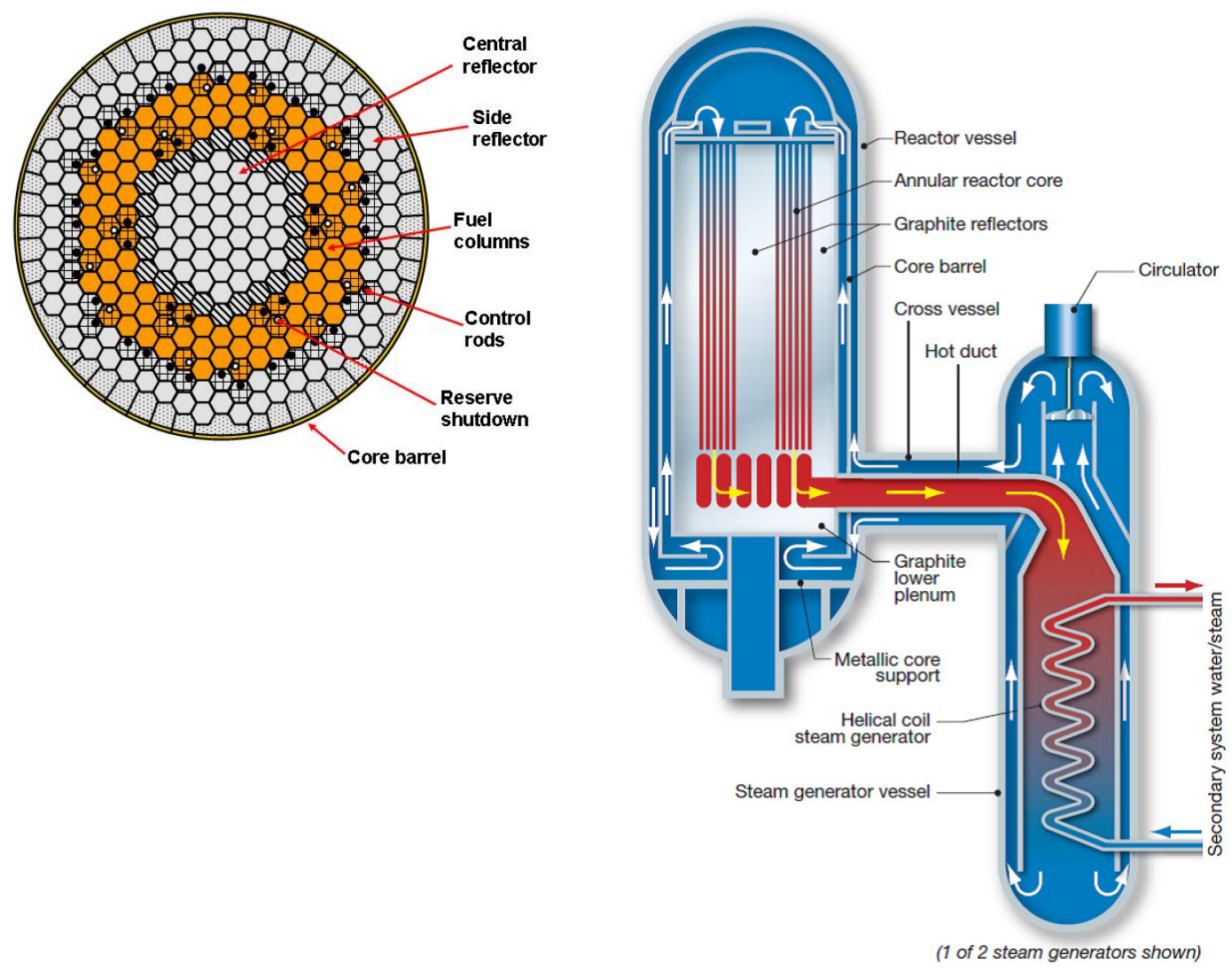

Figure 4. SC-HTGR core cross section and primary circuit layout.

The commercial SC-HTGR plant contains one or more standard reactor modules. The use of standardized reactor modules best leverages the substantial investments in design, licensing, and fabrication capability to minimize deployment cost. In the all-electric mode, the plant uses a conventional Rankine cycle with a net efficiency of $43.5 \%$. 
High-temperature steam from the SC-HTGR meets the needs of a broad segment of the process heat market. The use of a modular reactor concept allows the plant capacity to be adjusted for individual applications. In addition, the safety characteristics of the SC-HTGR results in low co-location investment risk for the chemical plant owners.

The SC-HTGR has a high degree of passive safety. The high-purity helium reactor coolant is inert and does not change phase or react with other reactor materials under any circumstances. The ceramic core structural elements are graphite, which is robust at very high temperature and does not melt. The reactor has redundant shutdown systems and a negative temperature coefficient of reactivity, so the reactor will shut itself down even if the active shutdown systems fail to respond to an accident.

The SC-HTGR configuration ensures acceptable fuel and component temperatures for all design basis events. This favorable accident behavior is achieved without the need for active cooling systems, AC electrical power, operator actions, or even reactor coolant. The TRISO coated particles retain virtually all fission products, even at very high temperatures beyond those experienced during normal operation and accidents. These safety characteristics result in enhanced public safety and increased siting flexibility. As a result of the extremely low accident doses, no evacuation is required beyond $400 \mathrm{~m}$ from the reactor.

The SC-HTGR design relies on mature technology to minimize project risk and to serve near-term markets as soon as possible. All major components are based on technology already demonstrated in previous steam cycle HTGRs or in other industrial applications. Their maturity allows design, procurement, and fabrication of the full-size equipment. Key remaining development activities are limited to the ongoing TRISO coated particle fuel and nuclear grade graphite qualification work being performed by Idaho National Laboratory (INL), Oak Ridge National Laboratory (ORNL), and BWX Technologies (BWXT). Interim results from these programs are excellent, and the remaining work will be completed in time to support the full-size demonstration plant.

The objective of the proposed demonstration reactor project is to design, license, build, and operate a full-size SC-HTGR commercial demonstration unit. This will provide data needed to support NRC Design Certification necessary for commercial deployment, and it will provide the confidence expected in the commercial marketplace. The SC-HTGR demonstration unit is a necessary precursor to full commercial deployment of the technology beginning around 2035.

\subsubsection{General Electric Hitachi (GEH) Sodium-Cooled Fast Reactor}

The PRISM Mod-A is a single $471 \mathrm{MWt}$ reactor coupled to a superheated Rankine power cycle with a single helical coil steam generator producing $165 \mathrm{MWe}$ (35\% efficiency). The reactor and steam generator are located on a single seismically isolated nuclear island. PRISM uses a superheated steam energy conversion cycle, with a coolant outlet temperature of $500^{\circ} \mathrm{C}$, producing $35 \%$ net cycle efficiency. PRISM will start up on U-Zr fuel and later converted to U-Pu-Zr fuel. Minor actinide bearing fuel could be used in the future to support fuel cycle closure. PRISM could also support irradiation testing of fuels such as mixed oxide, nitride, thorium and other fuel types with a peak fast flux level in excess of $\sim 3 \times 10^{15}$ $\mathrm{n} / \mathrm{cm}^{2}-\mathrm{s}$. The demonstration reactor core is capable of achieving 12 to $24-$ month fuel cycles. 
Specific design features include a pool configuration for the primary radioactive sodium, and the use of primary and secondary electromagnetic pumps for moving sodium. The pumps have already been tested at full scale. The reactor has two intermediate heat transfer loops coupled to a single helical coil steam generator. Transportability of reactor components to the plant construction site is expected to be enhanced by the use of modular construction which is pre-sized for trucks and rail cars. All components, including the reactor vessel and the guard vessel, would be rail shippable thereby reducing construction costs and increasing the quality of fabrication of these components.

The fast reactor technology in the PRISM design supports the most promising fuel cycles identified in the recent multi-year DOE fuel cycle evaluation and screening study. The demonstration module could be paired with additional facilities to explore a wide range of fuel cycle options. The reactor could be utilized to demonstrate used fuel recycling from a variety of potential sources. The used PRISM fuel could be utilized to demonstrate storage and disposal options ranging from direct disposal to multi-recycle.

The PRISM design includes power grid flexibility features. The demonstration module can instantaneously respond to $10 \%$ step changes in power, and is designed to be automatically controlled for daily load following at a maximum rate of $2 \%$ per minute. No direct operator control actions are required for the reactor to respond to demand changes.

Previous experience gained through the design and operations of EBR-II and FFTF provide a strong technical basis for the PRISM design. The PRISM modularity, inherent passive safety and commercial scale allow for a relatively low complexity system which will not be hindered by scaling issues. These features reduce regulatory and financial risks. PRISM could be demonstrated in the 2035 time frame.

The reactor design uses simple, passive safety systems for improved safety at lower cost, such as the Auxiliary Cooling System, and the Reactor Vessel Auxiliary Cooling System. Both safety systems reduce capital and O\&M costs compared to their active system predecessors. Table 3 summarizes key parameters associated with the PRISM design shown in Figure 5.
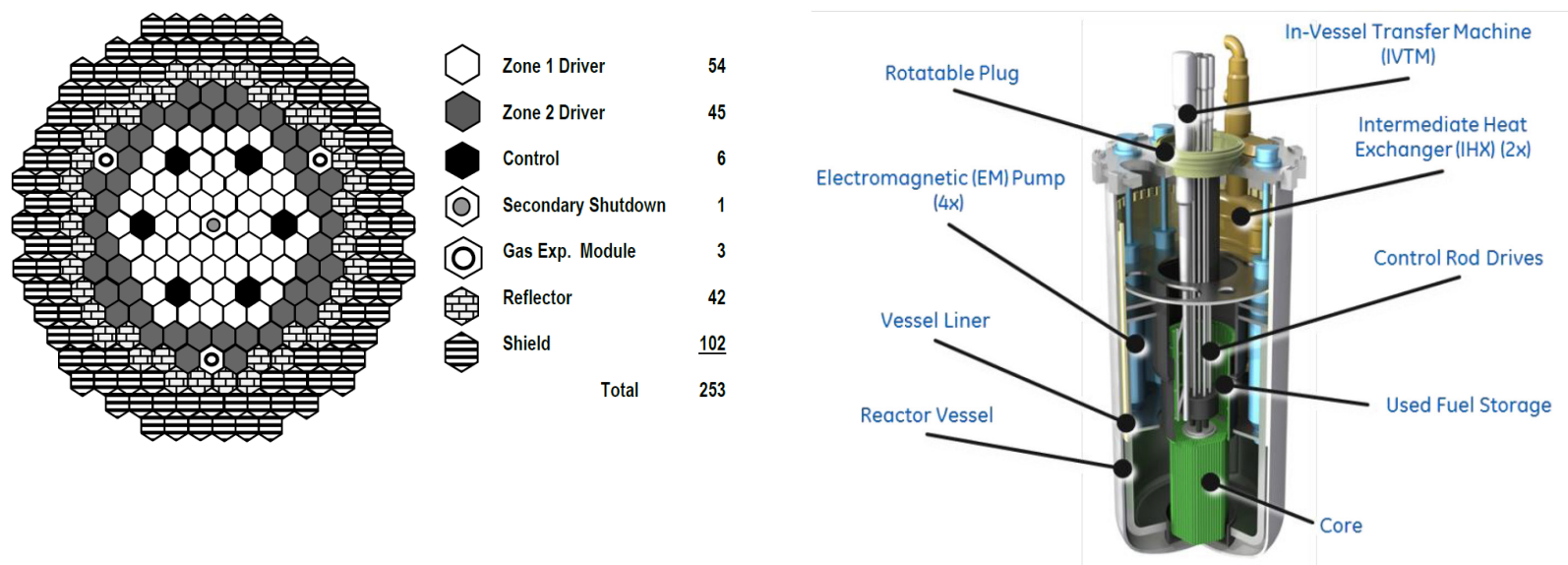

Figure 5. PRISM core cross section and reactor module isometric view. 


\subsubsection{Oak Ridge National Laboratory Fluoride-Salt-Cooled High-Temperature Reactors}

The FHR demonstration reactor (DR) is a 100-MWth engineering demonstration salt-cooled reactor that uses $15.5 \%$ enriched TRISO particle fuel within prismatic graphite blocks. FLiBe $\left(2{ }^{7} \mathrm{LiF}-\mathrm{BeF}_{2}\right)$ is the reference primary coolant, with a core outlet temperature of $700^{\circ} \mathrm{C}$.

The FHR DR core resides in a pool of primary coolant salt within a cylindrical vessel of Alloy $800 \mathrm{H}$ lined with alloy $\mathrm{N}$. The FHR DR vessel and piping material are capable of testing a number of candidate salt coolants. The primary heat transport system (PHTS) is a two-loop system with heat transfer to independent intermediate loops each carrying $\sim 50 \mathrm{MWt}$ to a common salt containment vessel with a net cycle efficiency of $42 \%$. The baseline design of the FHR DR is coupled to an open-air Brayton power conversion system as also proposed for the Mk 1 pebble bed FHR concept from University of California Berkeley. It can also demonstrate the ability of an FHR to supply low-pressure, high-temperature process heat.

Key features of the FHR DR are directly relevant to and are either at scale or scalable to commercial demonstration. Examples include (1) the use of hexagonal fuel arrangements with TRISO fuel in a graphite matrix, (2) the ability to move and replace the fuel and core internal structure within the vessel, and (3) active and passive Direct Reactor Auxiliary Cooling Systems (DRACS). Three isolated sections within the downcomer region on the inner vessel wall house independent heat exchangers to remove heat directly from the primary salt within the vessel in the event of a loss of flow accident and during routine maintenance outages.

Several preconceptual and conceptual design efforts have been conducted on FHR concepts that have heavily influenced the FHR DR. Specific designs include the ORNL advanced high-temperature reactor (AHTR) with $3400 \mathrm{MW}$ th output, as well as a $125 \mathrm{MW}$ th small modular AHTR (SmAHTR). The features of the FHR DR are most representative of that of the AHTR, and it will demonstrate key operational conditions of that design. However, it is closely scaled in power and flows to the SmAHTR concept, and any technologies demonstrated will be directly applicable to a reactor concept of that size. The FHR DR directly benefits from the design and operating experience of the Molten Salt Reactor Experiment (MSRE) and related programs.

The FHR DR is intentionally designed to be small and simple to minimize costs. The FHR DR is seen as an intermediate step to enable technology maturation of near-term commercial FHRs. Lower risk technologies are purposely included in the initial FHR DR design to ensure that the reactor can be built, licensed, and operated within an acceptable budget and schedule. The FHR DR as a platform for testing technologies that will be included in later commercial demonstration of FHRs thereby reducing commercial demonstration project risk and cost. As such, it would be licensed under a Class 104(c) non-power reactor license as defined by the NRC and it is expected to have a limited operational lifetime compared to a commercial plant. A primary reason to build the FHR DR is to learn about salt reactor technologies and demonstrate solutions to remaining technical gaps for a broad range of FHR concepts. It is expected that some systems will be less mature than what is needed for commercial applications and it is acknowledged that estimating the costs of some of these systems inherently have large uncertainties. 
Simplicity in design, size, and the use of the most mature technology available enables flexibility in testing a number of concept technologies for FHRs. Because the FHR DR targets a relatively immature advanced reactor technology, there is currently no one specific design. Therefore, the FHR DR point design proposed is not targeting a specific commercial design concept. The FHR DR is reconfigurable, versatile and its operation will mature a number of component technologies for a range of FHR designs.

Table 3 summarizes key parameters associated with the FHR DR design shown in Figure 6.

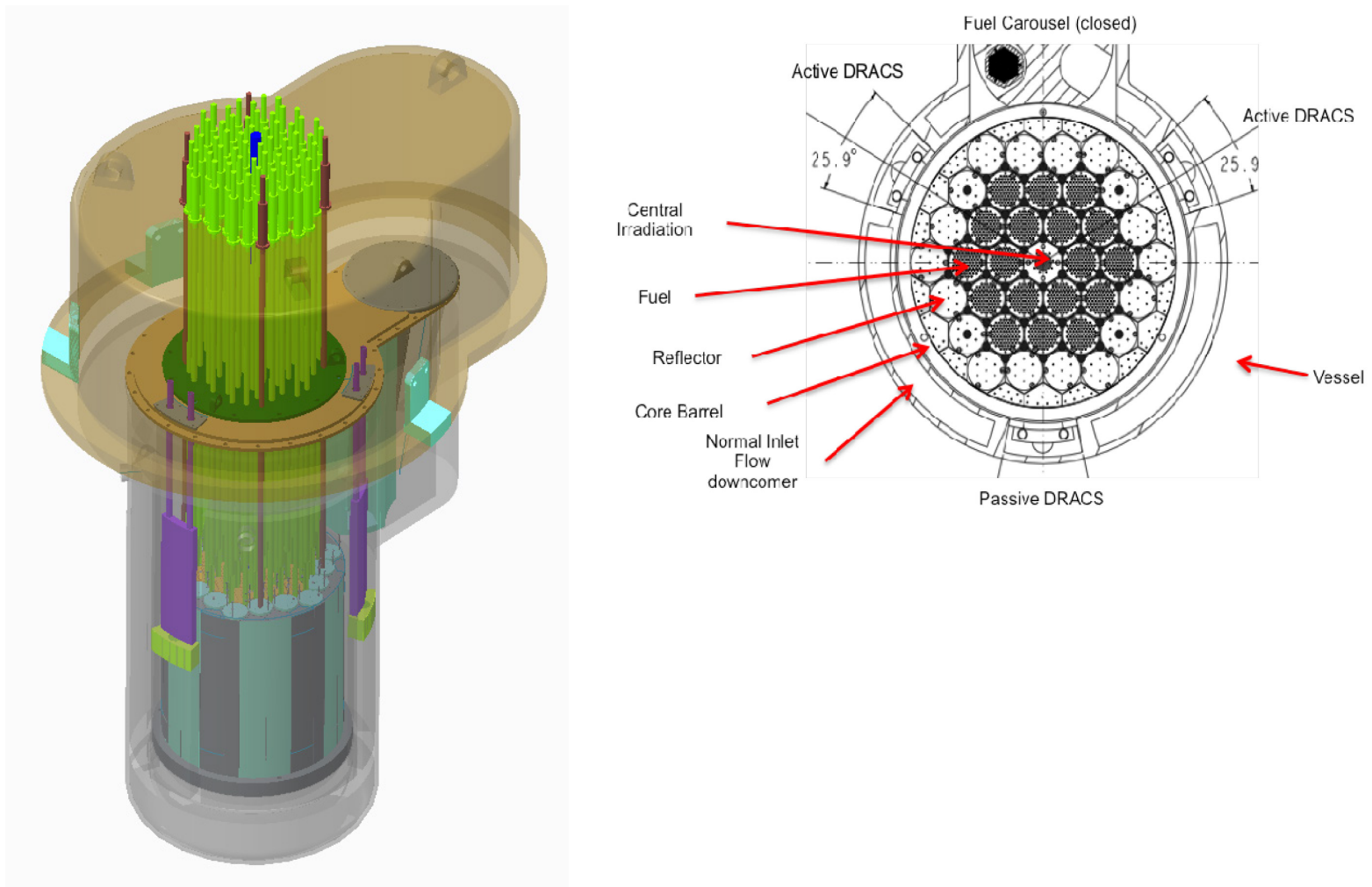

Figure 6. FHR DR isometric view and horizontal cross section.

\subsubsection{Westinghouse Lead-Cooled Fast Reactor}

The Westinghouse Demonstration Lead Fast Reactor (DLFR) is a lead-cooled, pool-type fast reactor. It starts as an engineering demonstration establishing feasibility and basic performance of DLFR-based technology. Economics and safety are the key elements driving its design. The DLFR features a compact, pool-type, primary system, with the main vessel containing all primary components immersed in liquid lead.

The power rating is 500 MWth (210 MWe) with a peak fast neutron flux of about $2 \times 10^{15} \mathrm{n} / \mathrm{cm}^{2} \mathrm{~s}$ but the plant is designed to facilitate power uprates (up to $\sim 700 \mathrm{MWth}$ ) to become a performance demonstration once the initial engineering demonstration mission is fulfilled. An average core outlet temperature of $510^{\circ} \mathrm{C}$ using a superheated steam power conversion system, results in a net plant efficiency of approximately $42 \%$, which may be further increased to near $50 \%$ in the follow-on commercial plants through increased operating temperature, enhanced materials, and modifications to the power conversion cycle. $\mathrm{UO}_{2}$ fuel within D9 steel cladding is chosen for the DLFR. In addition, the DLFR has the 
capability to host fueled lead test rods/assemblies enabling qualification of higher-performance uranium mononitride (UN) fuel and advanced cladding materials for future reloads.

The DLFR intends to leverage pre-existing technologies where possible to facilitate licensing and reactor operation. The lead-containing operating environment is exposed to temperatures and lead velocities for which corrosion is managed with currently available materials, as demonstrated from over a decade of lead loop design and operation experience.

The proposed refueling operations use an innovative fuel assembly design approach that extends above the free surface of the lead pool, thereby potentially eliminating the need for a refueling machine operating under lead, resulting in increased system reliability. All of DLFR elements are designed to be prototypic of the commercial reactor technology or scalable such that the performance of the commercial product can be estimated.

The DLFR point design technology embodies inherent safety that derives from innovative system design features combined with favorable lead properties. The integral reactor configuration eliminates the need for primary coolant loop piping and, due to the use of a main and a safety vessel operating at nearly atmospheric pressure, virtually eliminates loss-of-coolant accidents. The lack of exothermic chemical reaction between lead and air/water is favorable to the overall safety of the plant. The high boiling point of lead and high density prevent the formation of core voids due to lead boiling and the intrusion of secondary system fluid into the core making for safe, void-free reactor operation. The strong, favorable reactivity feedback provides inherent safety protection from a range of postulated accidental conditions such as unprotected events. The high-thermal inertia of the primary system results in very slow transients and less coupling with the balance of plant. The robustness of the safety case is intended to simplify the licensing process.

The inherent safety benefits mentioned above allow reduction in the complexity and number of safetyrelated systems. The resulting compact nuclear island, combined with the high core power density and the high thermodynamic efficiency, are expected to result in lower construction costs.

Finally, design simplicity, with minimization and replaceability, of primary system components was chosen to enhance reliability and minimize operational costs. While initially operating on a once-through $\mathrm{UO}_{2}$ core, the DLFR technology has the typical capability of fast spectrum reactors to support advanced fuel cycles with high uranium utilization and a range of actinide recycle schemes.

Table 3 summarizes key parameters associated with the FHR DR design shown in Figure 7.
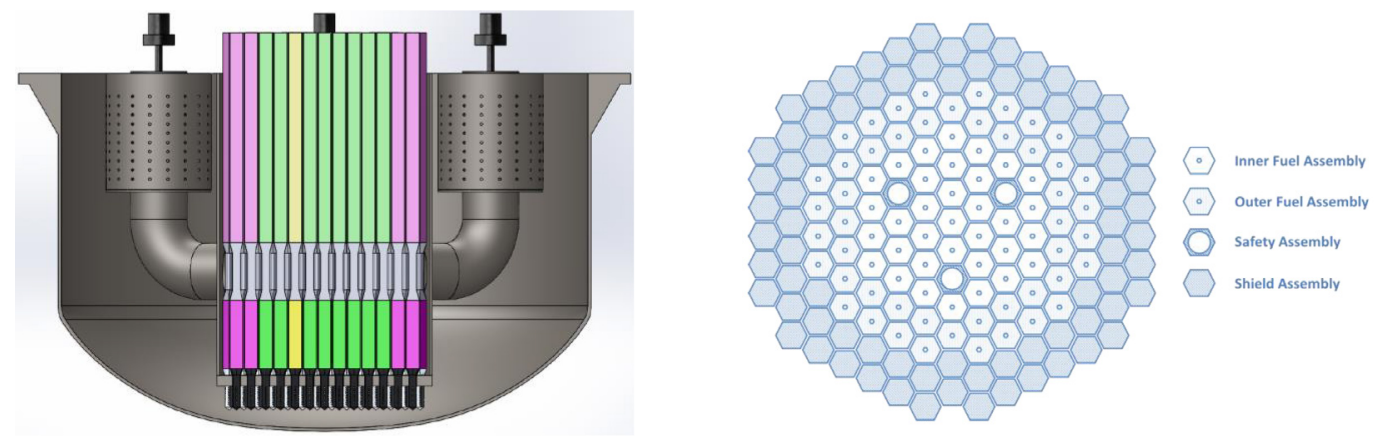

Figure 7. DLFR primary system layout, vertical and horizontal cross sections. 


\subsection{Assessment against Demonstration Criteria}

In this section, a summary is provided of the evaluations performed on the four demonstration reactors by a team with a range of experience in both LWRs and advanced reactors. The evaluation team consisted of representatives from the national laboratories, academia, reactor designers/vendors, and utilities. An overview is provided on the assessment process applied to the demonstration and test reactors, the raw scores provided by the evaluation team, and the subsequent conversion of these raw scores into weighted scores for each of the three strategic objectives defined in Section 2. The detailed scores are included in Appendix $\mathrm{C}$. The results of a weighting factor sensitivity study are also included here to verify the conclusions reached, and to address concerns on the subjective nature of the weights assigned to the metrics (described in Appendix A).

\subsubsection{Assessment Methodology}

Participants from DOE and the national laboratories developed the goals, metrics, and criteria, as detailed in Section 2. This material, as well as the point design reports for the two test and four demonstration reactor designs, were distributed to the evaluation team before a 3-day workshop was held. The 11 "voting" participants at the assessment workshop were requested to evaluate the designs using a three-tiered scoring system, ranging from a top score of 9 , a mid-score of 5 , and a low score of 1 (the performance ranges and scoring bins for all the metrics are listed in Appendix A). The evaluation team members each had to assign one score per metric. The 11 votes all had equal weights.

During the workshop, representatives of the reactor design teams presented summaries of their designs and clarified remaining issues. It should be noted that the weights assigned to the metric bins were not provided to the evaluation team to ensure a round of blind scoring and allow equal discussion of all aspects. The scores obtained in this way are referred to in this report as "raw" scores. The weighted scores for each of the three strategic objectives were then processed for the 25 metrics defined in Section 2, using the following simple multiplicative formula (shown here for Metric D1.1.1, for example):

Weighted_score D1.1.1 = weights (goal D1 * criterion D1.1 * metric D1.1.1) * raw_score (metric D1.1.1)

The total mean score for a particular design was determined by the sum of these 25 fractional scores. Statistical analyses of the 11 scores sets were then performed to calculate the mean and one standard deviation values for each of the metrics. Summarized results are presented here, and additional detail is found in Appendix C.

\subsubsection{Raw Scores}

The mean raw scores for each metric obtained for all four demonstration reactor designs are presented in Table 4. The detailed raw score breakdown for each design is provided in Appendix C. The two more-mature designs (SC-HTGR and PRISM SFR) were scored better on most of the metrics than the two less-mature designs (DLFR and FHR), reflecting the higher confidence levels in their claimed capabilities, costs and schedule data, potential licensing status, and prototypical nature. These raw scores are intermediate values in the assessment process. Only by applying the weights is the 
performance of a given point design against the strategic objectives obtained, as shown in the next section.

Table 4. Mean raw scores.

\begin{tabular}{|l|l|c|c|c|c|}
\hline \multirow{2}{*}{ Metric } & \multicolumn{1}{|c|}{ Description } & \multicolumn{3}{|c|}{ Mean Values } \\
\cline { 3 - 6 } & & HTGR & SFR & FHR & LFR \\
\hline D1.1.1 & Safety characteristics and systems/components & 9.0 & 9.0 & 4.3 & 5.4 \\
\hline D1.2.1 & Adequate instrumentation for code validation tests & 9.0 & 9.0 & 9.0 & 9.0 \\
\hline D1.3.1 & Prototypic technology selections & 9.0 & 9.0 & 5.4 & 5.0 \\
\hline D1.4.1 & Prototypic maintenance approaches & 9.0 & 9.0 & 5.0 & 7.2 \\
\hline D1.5.1 & Prototypic fabrication technologies & 9.0 & 9.0 & 4.6 & 7.2 \\
\hline D2.1.1 & Project cost & 7.9 & 7.9 & 9.0 & 6.1 \\
\hline D2.1.2 & Project schedule & 5.0 & 4.6 & 5.7 & 3.5 \\
\hline D2.2.1 & Annual operating costs & 7.9 & 7.2 & 1.0 & 6.1 \\
\hline D2.3.1 & Availability factor & 8.6 & 8.6 & 6.1 & 6.8 \\
\hline D3.1.1 & Ability to address key licensing issues & 8.6 & 9.0 & 6.8 & 7.2 \\
\hline D3.1.2 & EPZ size & 8.3 & 7.5 & 7.9 & 7.2 \\
\hline D4.1.1 & Prototypic or scalable integral component performance & 9.0 & 9.0 & 5.4 & 6.1 \\
\hline D4.2.1 & Number of alternative core configurations & 9.0 & 9.0 & 9.0 & 9.0 \\
\hline D4.2.2 & Number of alternative fuel types & 9.0 & 9.0 & 9.0 & 9.0 \\
\hline D4.3.1 & R\&D time & 5.0 & 7.2 & 4.3 & 4.3 \\
\hline D4.3.2 & R\&D cost & 5.4 & 6.8 & 5.4 & 4.3 \\
\hline D4.4.1 & Fast flux conditions at test location & 1.0 & 5.0 & 1.0 & 5.0 \\
\hline D4.4.2 & Thermal flux conditions at test location & 5.0 & 2.1 & 5.0 & 1.0 \\
\hline D4.4.3 & Irradiation volumes and length & 9.0 & 6.8 & 9.0 & 6.1 \\
\hline D5.1.1 & Use of natural fuel resources & 1.4 & 9.0 & 1.4 & 9.0 \\
\hline D5.2.1 & Prototypic fuel fabrication & 8.6 & 8.6 & 5.0 & 6.1 \\
\hline D5.3.1 & Prototypic fuel performance & 8.6 & 9.0 & 6.8 & 5.4 \\
\hline D5.4.1 & Prototypic spent fuel handling & 9.0 & 5.0 & 9.0 & 5.0 \\
\hline D6.1.1 & Number of energy conversion systems & 9.0 & 5.0 & 9.0 & 5.0 \\
\hline D6.2.1 & Coolant outlet temperature & & 5.4 & 8.3 \\
\hline
\end{tabular}

\subsubsection{Weighted Scores against Strategic Objectives 1-3}

Using the weights discussed in Appendix A, the raw scores provided in Table 4 were weighted to establish scores by goal and then summed to obtain an overall score for each strategic objective. Goal level scores are summarized in Table 5. Detailed scores per metric and standard deviations are provided in Appendix C.

For Strategic Objective 1 the SC-HTGR scores highest because of high maturity (Goals 1-4) and process heat capabilities (Goal 6). Detailed examination also indicates that the FHR DR scores equally well on Goal 6 related to process heat, but its lower maturity reduced its overall score. 
For Strategic Objective 2 the PRISM SFR scores highest because of high maturity and resource utilization (Goal 5). Detailed examination indicates that the DLFR scores similar on Goal 5, but its lower maturity reduced its overall score.

For Strategic Objective 3 the FHR DR and DLFR score similarly, especially in light of the high standard deviations. This is indicative of a lack of consensus among the assessment team for many of the metrics because of the relatively low maturity and the inherent uncertainties in the technologies at this early stage of development. The SC-HTGR and PRISM SFR designs were not assessed against Strategic Objective 3.

Table 5. Summary of demonstration reactor weighted scores (\%) by goal.

\begin{tabular}{|c|c|c|c|c|c|c|c|c|c|c|c|c|}
\hline \multirow[b]{2}{*}{ Goals } & \multicolumn{4}{|c|}{ Strategic Objective 1} & \multicolumn{4}{|c|}{ Strategic Objective 2} & \multicolumn{4}{|c|}{ Strategic Objective 3} \\
\hline & $\begin{array}{c}\text { HTG } \\
\mathbf{R}\end{array}$ & SFR & FHR & LFR & HTGR & SFR & $\begin{array}{c}\mathbf{F H} \\
\mathbf{R}\end{array}$ & LFR & TGR & SFR & FHR & LFR \\
\hline 1 & 25.0 & 25.0 & 14.9 & 17.7 & 20.0 & 20.0 & 11.9 & 14.2 & \multirow{8}{*}{\multicolumn{2}{|c|}{$\begin{array}{l}\text { Not scored } \\
\text { against this } \\
\text { strategic } \\
\text { objective }\end{array}$}} & 20.9 & 24.8 \\
\hline 2 & 16.2 & 15.7 & 12.8 & 12.4 & 16.2 & 15.7 & 12.8 & 12.4 & & & 12.8 & 12.4 \\
\hline 3 & 14.2 & 14.2 & 12.0 & 12.0 & 14.2 & 14.2 & 12.0 & 12.0 & & & 12.0 & 12.0 \\
\hline 4 & 16.9 & 17.7 & 13.9 & 14.1 & 16.9 & 17.7 & 13.9 & 14.1 & & & 13.9 & 14.1 \\
\hline 5 & 0.0 & 0.0 & 0.0 & 0.0 & 14.9 & 24.8 & 10.5 & 21.1 & & & 2.1 & 4.2 \\
\hline 6 & 20.0 & 11.1 & 20.0 & 11.1 & 0.0 & 0.0 & 0.0 & 0.0 & & & 5.0 & 2.8 \\
\hline Total & 92.3 & 83.7 & 73.6 & 67.3 & 82.2 & 92.4 & 61.2 & 73.7 & & & 66.7 & 70.3 \\
\hline $1 \sigma$ & 4.1 & 3.6 & 7.4 & 11.4 & 6.3 & 3.7 & 8.0 & 13.7 & & & 8.5 & 13.3 \\
\hline
\end{tabular}

\subsection{Weighting Factor Sensitivity Studies}

Sensitivity studies were performed to determine if changes in weighting functions would alter the outcomes. Three sets of sensitivity studies were performed. The results are shown in Table 6. Additional details are included in Appendix C.

Set 1 contains six cases (1a-1f). In each case, the weight of one of the goals was set to $100 \%$, while all other goal weights were set to $0 \%$. The relative weights of the criteria and metrics within the goals were unchanged. In these cases, Strategic Objectives 1-3 are not relevant.

Set 2 contains two cases. In Case 2a, the raw scores of the two participants that on average scored the lowest and highest were removed. In Case $2 b$, the lowest and highest scores for each metric were removed from the raw score sets.

Set 3 contains a single case in which only the five highest-weighted metrics for each strategic objective were preserved and re-normalized to $100 \%$. The weights for all other metrics were set to zero. The metrics retained are listed in Appendix $C$. 
Table 6. Difference between the nominal total weighted score and the six sensitivity variances (\%) against the three strategic objectives.

\begin{tabular}{|c|c|c|c|c|c|c|c|c|c|c|}
\hline \multirow{2}{*}{$\begin{array}{l}\text { Sensitivit } \\
\text { y study }\end{array}$} & \multicolumn{4}{|c|}{ Strategic Objective 1} & \multicolumn{4}{|c|}{ Strategic Objective 2} & \multicolumn{2}{|c|}{$\begin{array}{c}\text { Strategic Objective } \\
3\end{array}$} \\
\hline & $\begin{array}{l}\text { HTG } \\
\text { R }\end{array}$ & SFR & FHR & LFR & HTGR & SFR & FHR & LFR & FHR & LFR \\
\hline Reference & 92 & 84 & 74 & 67 & 82 & 92 & 61 & 74 & 67 & 70 \\
\hline $1 a$ & 100 & 100 & 60 & 71 & \multirow{6}{*}{\multicolumn{6}{|c|}{$\begin{array}{c}\text { For sensitivity Set } 1 \text {, strategic objectives are not } \\
\text { relevant }\end{array}$}} \\
\hline $1 b$ & 81 & 78 & 64 & 62 & & & & & & \\
\hline $1 \mathrm{c}$ & 95 & 94 & 80 & 80 & & & & & & \\
\hline $1 d$ & 85 & 89 & 70 & 70 & & & & & & \\
\hline $1 e$ & 60 & 99 & 42 & 84 & & & & & & \\
\hline $1 f$ & 100 & 56 & 100 & 56 & & & & & & \\
\hline $2 a$ & 93 & 84 & 74 & 68 & 83 & 92 & 60 & 74 & 67 & 71 \\
\hline $2 b$ & 89 & 80 & 67 & 61 & 77 & 88 & 53 & 66 & 59 & 63 \\
\hline 3 & 99 & 81 & 79 & 64 & 73 & 97 & 54 & 77 & 64 & 65 \\
\hline
\end{tabular}

Examining sensitivity Set 1, when all the weight is given to Goals D1 through D4 (Cases 1a-1d) the overall scores of the SC-HTGR and PRISM SFR are observed to be very similar. This result is expected as both point designs have similar levels of underlying technological maturity, which is captured in these goals. For Case 1e, where all the weight is put on D5 (demonstrating the reactor stage of an advanced fuel cycle), the PRISM SFR and DLFR logically outscore the other two point designs. Similarly, for Case 1f, where all the weight is put on D6 (demonstrate high-temperature reactor process heat applications), the SC-HTGR and FHR DR outscores the other two point designs. The overall outcome of the assessment is unchanged.

Examining sensitivity Set 2, the results for Case 2a are within the statistical uncertainty margins of the reference score. The removal of the lowest and highest averaged participant scores did not result in any discernable difference for any of the strategic objectives. For Case $2 b$, the total scores of all four-point designs are slightly decreased by about the same amount across all strategic objectives as a result of removing the highest and lowest score for each metric. This decrease reflects the distribution of the scores and does not affect the overall outcomes of the assessment.

Examining sensitivity Set 3, using only the five metrics with the highest weight for each strategic objective resulted in increasing the score of the highest ranked point design. The scores of the lower ranked point designs were only slightly increased and that of the lowest ranked point designs were slightly reduced. 


\section{TEST REACTOR POINT DESIGN CONCEPTS AND ASSESSMENT OF CONCEPTS AGAINST TEST REACTOR CRITERIA}

\subsection{Gap Analysis of Test Reactor Capabilities for Advanced Reactor Testing}

Water-cooled test reactors have been the workhorse of nuclear fuels and materials testing for thermal reactor systems over the past 50 years. These materials test reactors (MTRs) produce high-damage rates (relative to LWRs) on the order of 1 to $10 \mathrm{dpa} /$ year; thus, the testing to qualify new materials or identify material changes can be accomplished fairly quickly and in a schedule-efficient manner. Existing, albeit aging, facilities provide the capability to irradiate LWR components in water-cooled test reactors for a wide range of customers and test conditions.

For advanced fast neutron reactor systems, neutron damage rates are significantly higher because the neutrons are not thermalized and the magnitude of the fast neutron flux is much higher than for thermal systems. Thus, to attain peak doses of 200 to 500 dpa using a water-cooled test reactor would take 20 to 50 years. Fast neutron irradiation capability is largely lacking.

Therefore, a water-cooled reactor cannot meet the needs to support research and development of advanced reactor designs because it is not possible to achieve the high fast to thermal neutron flux ratio that is needed for the development of any fast spectrum system and to accelerate materials irradiations for both thermal and fast reactors. Furthermore, Gen-IV concepts using coolants other than water may also require fast neutrons for the study of fuels and corrosion control. Test loops with such coolants must be carefully designed so as not to significantly perturb the spectrum of the driver core; thus, the test loops are generally unavailable and expensive to install. A more detailed assessment about the available testing capabilities around the world and the needs for advanced reactor systems are found in Appendix D.

\subsection{Test Reactor Options}

High-level overviews of the major attributes for the two test reactors were compiled from the point design reports and are provided in Sections 5.2.1 and 5.2.2. Key design parameters of the demonstration reactors are summarized in Table 7. More detailed information on these point designs are available in Attachment 5:"Argonne National Laboratory: FASTER Test Reactor Preconceptual Design Report Summary," and Attachment 6: "Idaho National Laboratory: High-Temperature Gas-cooled Test Reactor Point Design: Summary Report."

The assessment of the two tests reactor options included in this study is presented in this section. The evaluation approach, raw and weighted scores, and the results of a sensitivity study on various weighting factors are discussed in Section 5.3. Further details can be found in Appendix C. 
Table 7. Key design parameters of the test reactors.

\begin{tabular}{|c|c|c|}
\hline Parameters & SFR-TR & HTGR-TR \\
\hline \multirow{2}{*}{ Rated power } & 300 MWth & 200 MWth \\
\hline & $120 \mathrm{MWe}$ & $80 \mathrm{MWe}$ \\
\hline Cycle length & 100 days & 110 days \\
\hline Primary pressure & $\sim 0.1 \mathrm{MPa}$ & $7 \mathrm{MPa}$ \\
\hline Primary coolant & Sodium & Helium \\
\hline Moderator & $\mathrm{N} / \mathrm{A}$ & Graphite \\
\hline Fuel type & U-Pu-Zr in HT-9 cladding & TRISO-coated UCO particles \\
\hline Fuel fissile content & $19.40 \%$ & $15.50 \%$ \\
\hline Fuel form & $\begin{array}{l}\text { Fuel rods in a hexagonal } \\
\text { assembly }\end{array}$ & $\begin{array}{l}\text { Hexagonal graphite blocks with } \\
\text { cylindrical fuel compacts }\end{array}$ \\
\hline Fueled core configuration & 55 assemblies & 12 columns, 8 blocks/column \\
\hline Power conversion system & $\begin{array}{l}\text { Superheated Rankine steam } \\
\text { cycle }\end{array}$ & $\begin{array}{l}\text { Conventional Rankine steam } \\
\text { cycle }\end{array}$ \\
\hline Core inlet/outlet temperature & $355^{\circ} \mathrm{C} / 510^{\circ} \mathrm{C}$ & $325^{\circ} \mathrm{C} / 650^{\circ} \mathrm{C}$ \\
\hline \multicolumn{3}{|c|}{ Irradiation conditions } \\
\hline Number of irradiation locations & 39 & 36 \\
\hline Peak fast flux level & $5.0 \times 10^{15} \mathrm{n} / \mathrm{cm}^{2}-\mathrm{s}$ & $1.6 \times 10^{14} \mathrm{n} / \mathrm{cm}^{2}-\mathrm{s}$ \\
\hline Peak thermal flux level & $>5.8 \times 10^{14} \mathrm{n} / \mathrm{cm}^{2}-\mathrm{s}$ & $3.9 \times 10^{14} \mathrm{n} / \mathrm{cm}^{2}-\mathrm{s}$ \\
\hline Irradiation length & $100-200 \mathrm{~cm}$ & $634 \mathrm{~cm}$ \\
\hline Irradiation volume & 21 L/location & 30 L/location \\
\hline Total irradiation volume & $820 \mathrm{~L}$ & $1100 \mathrm{~L}$ \\
\hline
\end{tabular}

\subsubsection{Argonne National Laboratory Sodium-Cooled Fast Reactor}

A point design for a $300 \mathrm{MWth}$ sodium-cooled (SFR) test reactor, referred to as FASTER, has been developed. The FASTER design leverages information and experience from both previously constructed and operated SFRs.

The FASTER reactor plant is a sodium-cooled fast spectrum test reactor that provides very high levels of fast and thermal neutron flux for scientific research and development. High-thermal fluxes are achieved through thermalizing neutrons escaping the fuel region with beryllium. The $300 \mathrm{MWth} / 120 \mathrm{MWe}$ FASTER reactor plant is equipped with a superheated steam power conversion system that provides electrical power to a local grid allowing for recovery of operating costs for the reactor plant. In addition, the FASTER reactor plant could be used for isotope production or as a heat source, if desired.

The FASTER core layout shown in Figure 8 contains 55 fuel assemblies using U-Pu-Zr ternary metallic fuel with $6 \mathrm{wt} \%$ zirconium. The required plutonium content is $19.4 \%$ for the proposed configuration with a 100-day cycle length. About one-third of the 55 fuel assemblies are replaced every cycle. The plant will have an availability of at least $80 \%$. 
Out of the 39 test locations, 33 are in a fast flux region, three are in a thermalized region, two are closed loops located in a fast flux region, and the remaining one is a closed loop located in a thermalized region. In test assemblies, the peak fast flux is about $5.0 \times 10^{15} \mathrm{n} / \mathrm{cm}^{2}-\mathrm{s}$ and the peak thermal flux $(<0.1 \mathrm{eV})$ is about $1.8 \times 10^{14} \mathrm{n} / \mathrm{cm}^{2}-\mathrm{s}$. These peak flux values do not occur in the same location. Although the fuel height is $80 \mathrm{~cm}$, the large mean free paths of fast neutrons enable irradiation lengths up to $200 \mathrm{~cm}$, corresponding to an irradiation volume of $21 \mathrm{~L}$ per test assembly. The total test volume in the current configuration is $820 \mathrm{~L}$, but any of the reflector assemblies could be replaced with a test assembly.

The three closed loop systems (CLS) are an important capability of FASTER. They enable the reactor to be utilized to irradiate and test fuels and materials in a prototypical flowing coolant environment with different coolants for different reactor types. Each CLS with a different coolant is a demonstration of that coolant and its technology inside of an operating nuclear reactor. Sizing and basic design characteristics of the CLS have been determined as part of FASTER point design study for a number of different coolants. Although the flux levels will vary based on the coolant used, the CLS located in the fast flux region are experiencing a peak fast flux of about $2.3 \times 10^{15} \mathrm{n} / \mathrm{cm}^{2}-\mathrm{s}$, and the closed loop located in the thermalized region is experiencing a peak thermal flux of about $5.8 \times 10^{14} \mathrm{n} / \mathrm{cm}^{2}-\mathrm{s}$.

As a result of its very compact design, FASTER core achieves a negative sodium void worth reactivity coefficient. Other feedback coefficients are also negative as typically observed in SFRs. During normal operation the inlet and average outlet coolant temperatures are $355^{\circ} \mathrm{C}$ and $510^{\circ} \mathrm{C}$, respectively. During beyond-design-basis accident scenarios, these temperatures are increased, but remain within comfortable margin from maximum acceptable temperatures.

The proposed FASTER design is capable of accommodating various beyond-design-basis accident initiators without producing high temperatures and conditions that might lead to a severe accident, such as coolant boiling, cladding failures, or fuel melting. The inherent neutronic, hydraulic, and thermal performance characteristics of the FASTER design provide self-protection in beyond-design-basis sequences to limit accident consequences without activation of engineered systems or operator action (inherent passive safety). The FASTER plant contains three decay heat removal systems (DHRS) each capable of removing $0.25 \%$ of the nominal power, which is sufficient even when one of the three DHRS is unavailable.

FASTER would be licensed under a Class 104(c) non-power reactor license as defined by the NRC. Licensing issues are discussed in further detail in Section 6. 


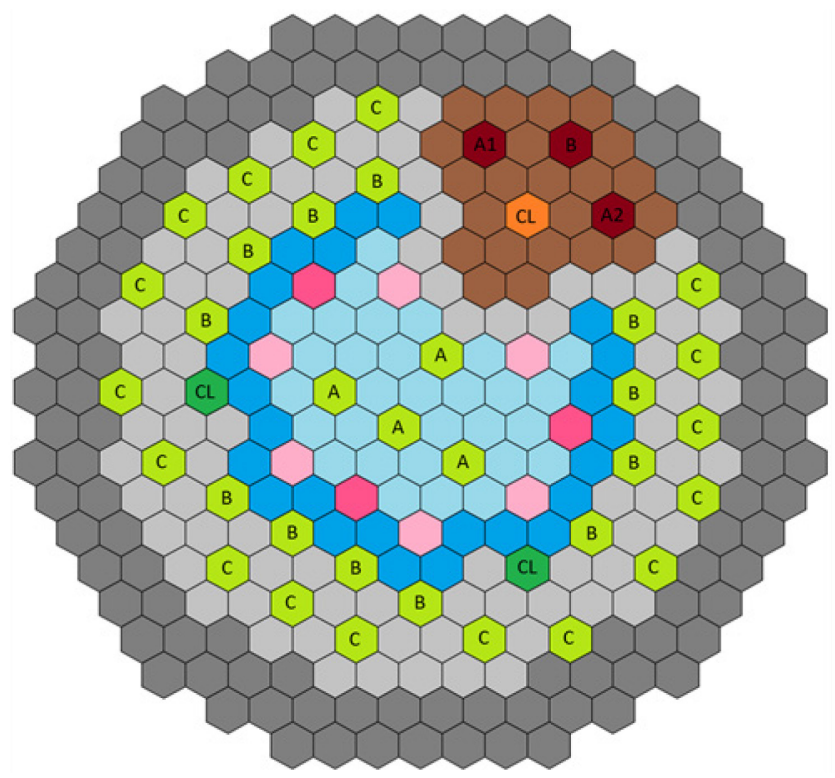

Inner core (30)

Outer core (25)

Prim. control (6)

Sec. control (3)

Reflector (77)

Shield (111)

Fast test location (33)

Fast closed loop (2)

Moderator (22)

Thermal test location (3)

Thermal closed loop (1)

Figure 8. FASTER core cross section.

\subsubsection{Idaho National Laboratory High Temperature Gas-Cooled Reactor}

A point design for a 200-MWth graphite-moderated, HTGR-TR has been developed. Although there are no HTGRs operating today in the U.S., the design of the HTGR-TR leverages information and experience from both previously constructed and operated commercial U.S. HTGRs and more modern HTGR designs with annular cores. In addition, the HTGR-TR is drawing heavily on recent advancements in TRISO particle fuel, graphite, and in-core HTGR materials from the DOE Advanced Gas Reactor Program and associated U.S. NRC interactions.

The 200-MWth HTGR-TR uses a conventional Rankine steam cycle to produce 80 MWe of electricity. The HTGR-TR core, shown in Figure 9, contains 12 fuel columns of eight hexagonal prismatic fuel blocks (96 fuel blocks total) arranged to form a relatively compact, high-power density (for an HTGR). The TRISO particle fuel form has been adopted with a 425- $\mu$ m diameter UCO kernel with a fixed uranium enrichment of $15.5 \mathrm{wt} \%$. The HTGR-TR achieves a cycle length of 110 days. A 4-week shutdown time between cycles is assumed, resulting in a maximum availability factor of $78 \%$.

The HTGR-TR is predominantly a thermal-neutron spectrum reactor with a sizable graphite pile cooled by helium gas. Due to its primary mission being material irradiation, the core has been designed and optimized to achieve the highest possible thermal and fast neutron fluxes. The proposed core can support independent closed loops containing a variety of coolant fluids. Power levels and coolant conditions are such that it can serve as a test bed supporting developments in high-efficiency electricity conversion systems (Rankine or Brayton cycle), as well as process heat-driven energy products such as hydrogen. Other secondary missions could also be supported. 


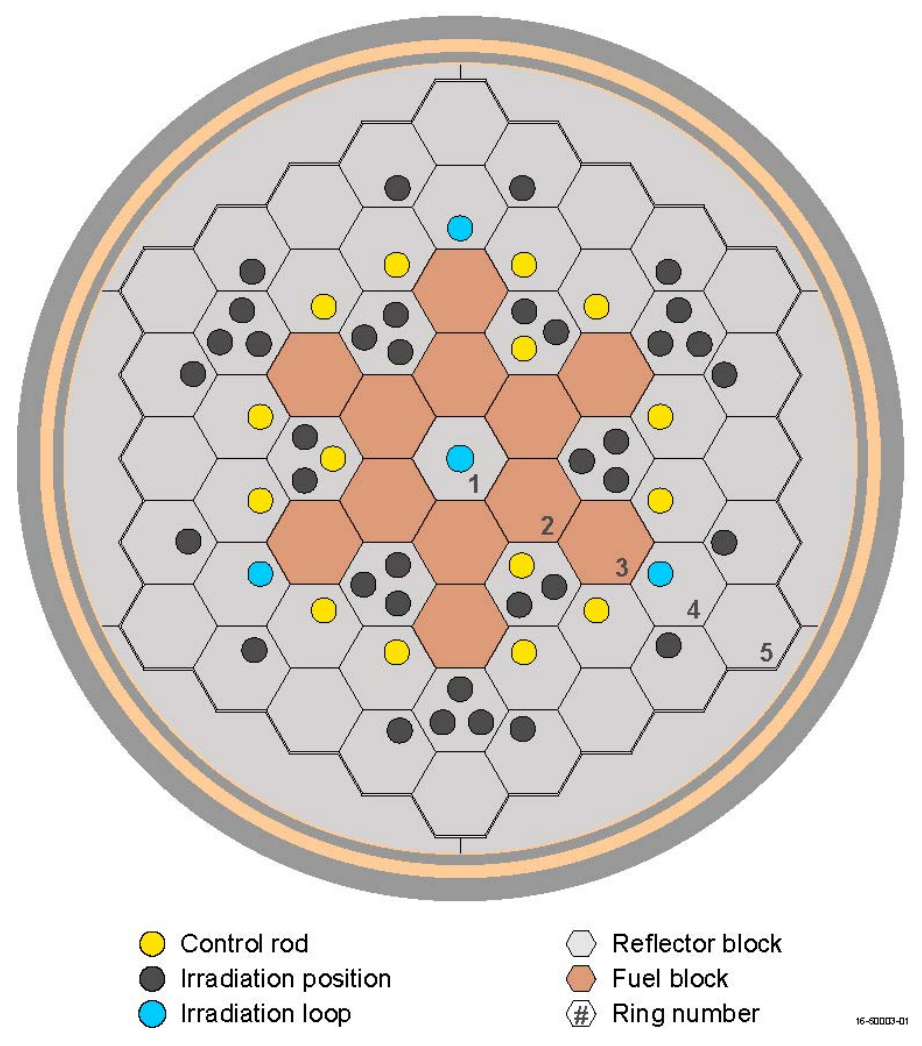

Figure 9. HTGR-TR core cross section.

In its proposed configuration, the core contains 36 irradiation positions for drop-in test capsules in the outer graphite reflector. For these test locations, the peak thermal flux of $3.9 \times 10^{14} \mathrm{n} / \mathrm{cm}^{2}-\mathrm{s}$ occurs in the outer reflector and the corresponding fast flux is $5.2 \times 10^{13} \mathrm{n} / \mathrm{cm}^{2}-\mathrm{s}$. All test locations can be the full length of the active core $(6.34 \mathrm{~m})$, allowing for irradiation of large test articles. Each test location has an irradiation volume of $30 \mathrm{~L}$, resulting in a total test volume of about $1100 \mathrm{~L}$. Using additional reflector blocks as test locations could increase the number of test locations. In addition, the irradiation volume of each existing test location could be increased up to $120 \mathrm{~L}$ by using larger diameter holes.

Provisions are made in the plant layout for four test closed-loop facilities with pressure tube boundaries to isolate test articles and test fluids from the primary helium coolant system. One of these test loop facilities is located in the center of the core while the three other loop facilities are located in the outer reflector. For the closed loops, a peak thermal flux of $2.8 \times 10^{14} \mathrm{n} / \mathrm{cm}^{2}-\mathrm{s}$ occurs in loops in the outer reflector while a peak fast flux of $1.6 \times 10^{14} \mathrm{n} / \mathrm{cm}^{2}-\mathrm{s}$ occurs in the loop in the center of the core. A pneumatically driven rabbit system is expected to be contained in one of the closed-loops.

The HTGR-TR is designed to operate at $7 \mathrm{MPa}$ with an outlet gas temperature of $650^{\circ} \mathrm{C}$. The outlet temperature was selected to ensure sufficient thermal margin under normal operating conditions to prevent melting of metallic in-pile tubes during accident conditions. Penetration of the top-head reactor pressure vessel boundary by both control rod guide tubes and loop pressure tubes could potentially result in top-head crowding. Future engineering analyses are needed to assess possible crowding issues resulting from the penetration of the top-head reactor pressure vessel boundary, and due to frequent loading and unloading of fuel and experiments. 
The HTGR-TR has strong negative fuel and moderator temperature coefficients. Under normal operation and over the entire cycle length, the reactor will operate safely because of these negative feedbacks and high-thermal inertia of the graphite. Burnable poison will play an important role in reducing the initial core excess reactivity and in flattening the power distribution.

The reactor design is passively safe and peak fuel temperatures during design-basis conduction cooldown (loss of forced cooling) accidents are below the steady-state operating temperatures and below safety limits. Long-term decay heat removal is provided by a natural-circulation driven, water-cooled system such that no powered systems are required. Heat is transferred from the reactor vessel to the cooling system by passive radiation and natural convection mechanisms.

The HTGR-TR would be licensed under a Class 104(c) non-power reactor license as defined by the NRC. Licensing issues are discussed in further detail in Section 6.

\subsection{Assessment against Test Reactor Criteria}

\subsubsection{Raw Scores}

The mean raw scores for each metric obtained for the two test reactor designs are presented in Table 8. The detailed raw score breakdown for each design and evaluator is provided in Appendix $C$. The SFR-TR scored higher or the same than the HTGR-TR on all the metrics with the exception of metric T1.1.3 (irradiation volume and length). The standard deviations provided in Appendix $C$ highlight the good agreement between the evaluators for these two designs. This is mostly a result of the maturity of these two concepts and the fact that most of the metrics used for the test reactors are quantifiable and less subject to personal interpretation.

These raw scores are intermediate values in the assessment process. Only by applying the weights the performance of a given point design against the strategic objectives is obtained, as shown in the next section. 
Table 8. Mean test reactor raw scores.

\begin{tabular}{|l|l|c|c|}
\hline Metric & \multicolumn{1}{|c|}{ Description } & HTGR & SFR \\
\hline T1.1.1 & Fast flux conditions & 1.0 & 9.0 \\
\hline T1.1.2 & Thermal flux conditions & 5.0 & 9.0 \\
\hline T1.1.3 & Irradiation volumes and length & 9.0 & 6.8 \\
\hline T1.1.4 & Cycle length & 9.0 & 9.0 \\
\hline T1.1.5 & Prototypic and bounding conditions & 6.5 & 9.0 \\
\hline T1.2.1 & Number of test zones & 9.0 & 9.0 \\
\hline T1.2.2 & Number of test loops & 6.1 & 9.0 \\
\hline T1.2.3 & Specimen retrievability at power & 9.0 & 9.0 \\
\hline T2.1.1 & Project cost & 4.6 & 5.0 \\
\hline T2.1.2 & Project schedule & 4.6 & 4.6 \\
\hline T2.2.1 & Annual operating costs & 5.0 & 5.0 \\
\hline T2.3.1 & Availability factor & 5.0 & 7.9 \\
\hline T3.1.1 & Number of secondary missions & 9.0 & 9.0 \\
\hline
\end{tabular}

\subsubsection{Weighted Scores against Strategic Objective 4}

Using the weights discussed in Appendix A, the raw scores provided in Table 8 were weighted to establish scores by goal and then summed to obtain an overall score for the strategic objective. Goal level scores are summarized in Table 9. Detailed scores per metric are provided in Appendix C.

For strategic objective 4 the SFR-TR scores highest mainly because of the irradiation conditions (Goal 1). Therefore, the SFR-TR is found to be a much better fit than the HTGR-TR against Strategic Objective 4.

Table 9. Mean weighted scores per metric for the TRs against Strategic Objective 4.

\begin{tabular}{|c|c|c|}
\hline \multirow{2}{*}{ Goals } & \multicolumn{2}{|c|}{ Strategic Objective 4 } \\
\cline { 2 - 3 } & HTGR-TR & SFR-TR \\
\hline 1 & 47.3 & 67.2 \\
\hline 2 & 13.5 & 16.6 \\
\hline 3 & 5.0 & 5.0 \\
\hline Total & $\mathbf{6 5 . 9}$ & $\mathbf{8 8 . 9}$ \\
\hline $\mathbf{1 0}$ & $\mathbf{5 . 5}$ & $\mathbf{3 . 9}$ \\
\hline
\end{tabular}




\subsection{Weighting Factor Sensitivity Studies}

Examination of Table 8 indicates that the SFR-TR outscores the HTGR-TR in all but one metric (T1.1.3 irradiation volume and length). As a result, any other weighting scheme would result in the same outcome. Only if virtually all of the weight is assigned to T1.1.3 would the result change, thus the selection of the SFR-TR is robust. Therefore, no formal sensitivity studies were performed for the test reactors. 


\section{ADVANCED REACTOR DEPLOYMENT}

The objective of this section is to outline how the demonstration and test reactors can contribute to commercialization of advanced reactor technologies. In addition, the cost and schedule for the point design options is compared.

\subsection{Reactor Technology Deployment Steps}

Development and deployment of reactors in the U.S. and internationally has followed the four steps shown schematically in Figure 10:

1. R\&D to prove scientific feasibility of key features associated with fuel, coolant, and geometrical configuration. Test reactor irradiation services are particularly important in this phase, although they can be beneficial at each step (e.g., to explore fuel/material options).

2. Engineering demonstration at reduced scale for proof of concept for concepts that have never been built. The goal of the demonstration at this level is the viability of the integrated system. Historically, these have been small reactors ( $<50 \mathrm{MWe}$ ).

3. Performance demonstration(s) to establish that scale up of the system works and to gain operating experience to validate the integral behavior of the system (including fuel cycle in some cases) resulting in proof of performance.

4. Commercial demonstrations that will be replicated for subsequent commercial offerings if the system performs as designed.

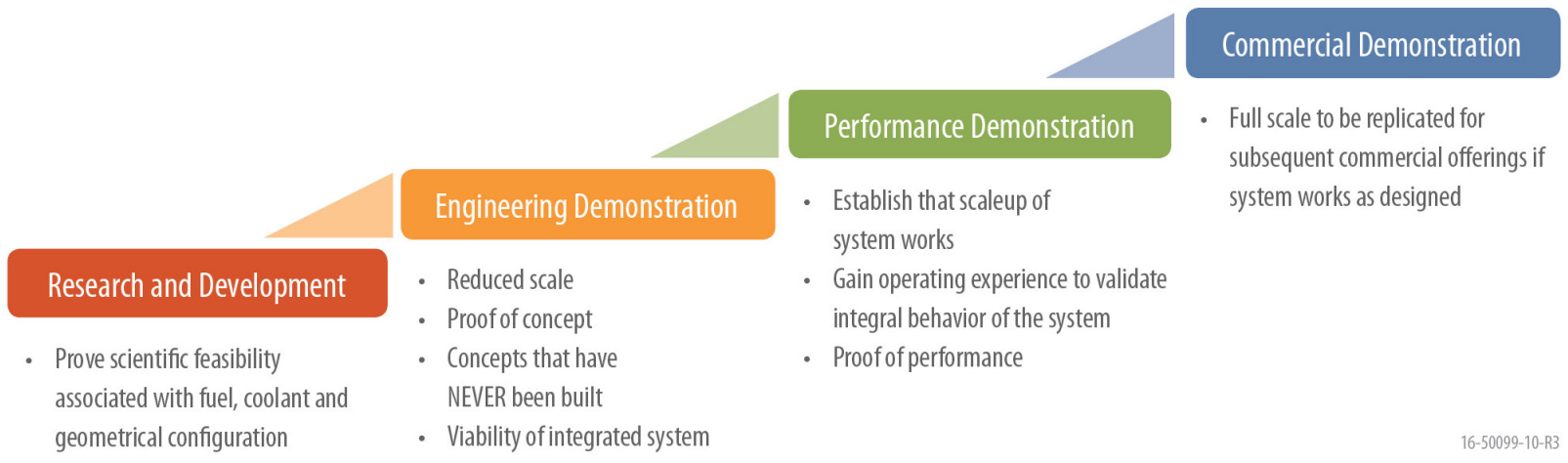

Figure 10. Reactor development and deployment steps based on U.S. and international experience.

This approach to reactor technology development requires maturation of the individual nuclear technologies (e.g., fuels, materials, instrumentation and controls [I\&C], component testing, and safety demonstration) along with complementary design activities to assure that the technology development activities are aligned with the design and licensing needs. Each individual component or system is qualified through testing and/or analysis with the ultimate goal of demonstrating that each component or system will work as intended. In this paradigm, new or innovative technology aspects require focused development efforts because of the lack of prior experience with such systems or components, especially as they relate to the safety of the overall system. Future reactor concepts may follow these same paths or develop innovative approaches to addressing the information needed by the designers and the regulators 
needed to demonstrate safety and achieve licensability. While innovative approaches may shorten development schedules and reduce costs, this conventional methodology takes several decades and billions of dollars to bring the technology to the level of maturity for ultimate deployment, as evidenced by the existing LWR fleet. This technical approach supports the advanced reactor licensing pathways identified in Section 7, although it's recognized that those pathways to deployment would be more certain and efficient if the associated Commission policy issues summarized in Section 7.1.3 are resolved in the near term.

Table 10 lists the different U.S. and international demonstration reactors that have been built as part of each technology's development path. As shown in Table 10, both the SFR and HTGRs have already had engineering and performance demonstrations, and currently have design concepts for either the commercial demonstration stage (base technology) or performance stage (advanced options [e.g., very high temperature]). Assuming feasible technology development solutions are developed in the R\&D step, a specific reactor technology would then be ready for an engineering demonstration. Future reactor concepts may follow these same paths (a performance demonstration and subsequent commercial demonstration) or would have to develop innovative approaches to addressing the information needed by the designers and the regulators needed to demonstrate safety and achieve licensability. 
Table 10. U.S. and international reactors for each deployment step.

\begin{tabular}{|c|c|c|c|c|c|c|c|c|c|}
\hline \multirow{2}{*}{$\begin{array}{l}\text { Step in } \\
\text { Deployment } \\
\text { Path }\end{array}$} & \multirow{2}{*}{$\begin{array}{c}\begin{array}{c}\text { Light Water } \\
\text { Reactor } \\
\text { (example) }\end{array} \\
\text { U.S. }\end{array}$} & \multicolumn{2}{|c|}{ Sodium Fast Reactor } & \multicolumn{2}{|c|}{$\begin{array}{l}\text { High Temperature } \\
\text { Gas-cooled Reactor }\end{array}$} & \multicolumn{2}{|c|}{ Lead Fast Reactor } & \multicolumn{2}{|c|}{ Molten Salt Reactor } \\
\hline & & U.S. & International & U.S. & International & U.S & International & U.S. & $\begin{array}{c}\text { Internation } \\
\text { al }\end{array}$ \\
\hline $\begin{array}{l}\text { R\&D for } \\
\text { scientific } \\
\text { feasibility }\end{array}$ & $\begin{array}{l}\text { SPERT, } \\
\text { BORAX, PBF }\end{array}$ & $\begin{array}{l}\text { SEFOR } \\
\text { (20 MWth), } \\
\text { TREAT }\end{array}$ & CABRI & & & & & & \\
\hline $\begin{array}{l}\text { Engineering } \\
\text { Demonstration }\end{array}$ & $\begin{array}{l}\text { S1W } \\
\text { EBWR }\end{array}$ & $\begin{array}{l}\text { EBR-I (1.4 MWth) } \\
\text { EBR-II (20 MWe) }\end{array}$ & $\begin{array}{l}\text { Dounreay } \\
\text { (14 MWe), } \\
\text { Rhapsodie } \\
\text { (40 MWth), }\end{array}$ & $\begin{array}{l}\text { Peach } \\
\text { Bottom } \\
(40 \mathrm{MWe})\end{array}$ & $\begin{array}{l}\text { DRAGON } \\
\text { (20 MWth), } \\
\text { HTR-10 } \\
\text { (10 MWth), } \\
\text { HTTR } \\
\text { (30 MWth), } \\
\text { AVR } \\
\text { (15 MWe) }\end{array}$ & & $\begin{array}{l}\text { Soviet } \\
\text { submarines }^{a}\end{array}$ & $\begin{array}{l}\text { Aircraft } \\
\text { Reactor } \\
\text { Experiment } \\
\text { (2.5 MWth); } \\
\text { MSRE } \\
(7.4 \mathrm{MWth})^{\mathrm{b}}\end{array}$ & \\
\hline $\begin{array}{l}\text { Performance } \\
\text { Demonstration }\end{array}$ & $\begin{array}{l}\text { USS Nautilus, } \\
\text { Shippingport }\end{array}$ & $\begin{array}{l}\text { Fermi-1 } \\
(69 \text { MWe); FFTF } \\
(400 \text { MWth) }\end{array}$ & $\begin{array}{l}\text { Phenix } \\
(233 \mathrm{MWe}), \\
\text { Monju } \\
(300 \mathrm{MWe}) \text {, } \\
\mathrm{BN}-300 \text { and } \\
\text { BN-600 (300 } \\
\text { and } \\
600 \mathrm{MWe}) \text {, } \\
\text { PFR } \\
(250 \mathrm{MWe})\end{array}$ & $\begin{array}{l}\text { FSV } \\
(842 \text { MWth })^{\mathrm{c}}\end{array}$ & $\begin{array}{l}\text { THTR } \\
\left(^{(750 ~ M W t h)^{c}}\right.\end{array}$ & & & & \\
\hline $\begin{array}{l}\text { Commercial } \\
\text { Demonstration }\end{array}$ & $\begin{array}{l}\text { Yankee Rowe } \\
\text { (485-600 } \\
\text { MWth) }\end{array}$ & & $\begin{array}{l}\text { Superphenix } \\
\text { (3000 MWth), } \\
\text { BN-800 } \\
(800 \mathrm{MWe})\end{array}$ & & $\begin{array}{l}\text { HTR-PM } \\
(200 \mathrm{MWe})\end{array}$ & & & & \\
\hline $\begin{array}{l}\text { a. The Soviet e. } \\
\text { engineering } \\
\text { b. The Aircraft } \\
\text { c. FSV and TH }\end{array}$ & $\begin{array}{l}\text { nce with lead-bi } \\
\text { nstration reactor } \\
\text { or Experiment ar } \\
\text { re commercial d }\end{array}$ & $\begin{array}{l}\text { th eutectic cooled } \\
\text { the LFR. } \\
\text { ISRE were liquid } f\end{array}$ & $\begin{array}{l}\text { narine reactor } \\
\text { d reactors, wit }\end{array}$ & thut & ctly aoplic & & & e they & $\begin{array}{l}\text { lered } \\
\text { monstration. }\end{array}$ \\
\hline
\end{tabular}


Consideration of technology risk mitigation at each step in this process is important because of:

- The radiological source term involved with nuclear power development and demonstration

- The long timescales associated with large-scale energy technology development

- The costs involved in energy technology to go from basic R\&D through demonstration/prototyping and full-scale commercialization

- The complexity of nuclear reactor systems in general.

Given these considerations, unexpected performance outcomes can set a technology back years and may not be amenable to quick fixes. Therefore, it is anticipated that any new advanced reactor technology would go through the stepwise process shown in Figure 10.

Figure 11 provides representative deployment paths based on the point designs in this study. The differing levels of maturities of the technologies underlying the point designs result in these technologies being at different points along the way to ultimate commercial deployment. A discussion of the deployment strategies is necessary to better understand and put in context the cost and schedule estimates provided in this study.

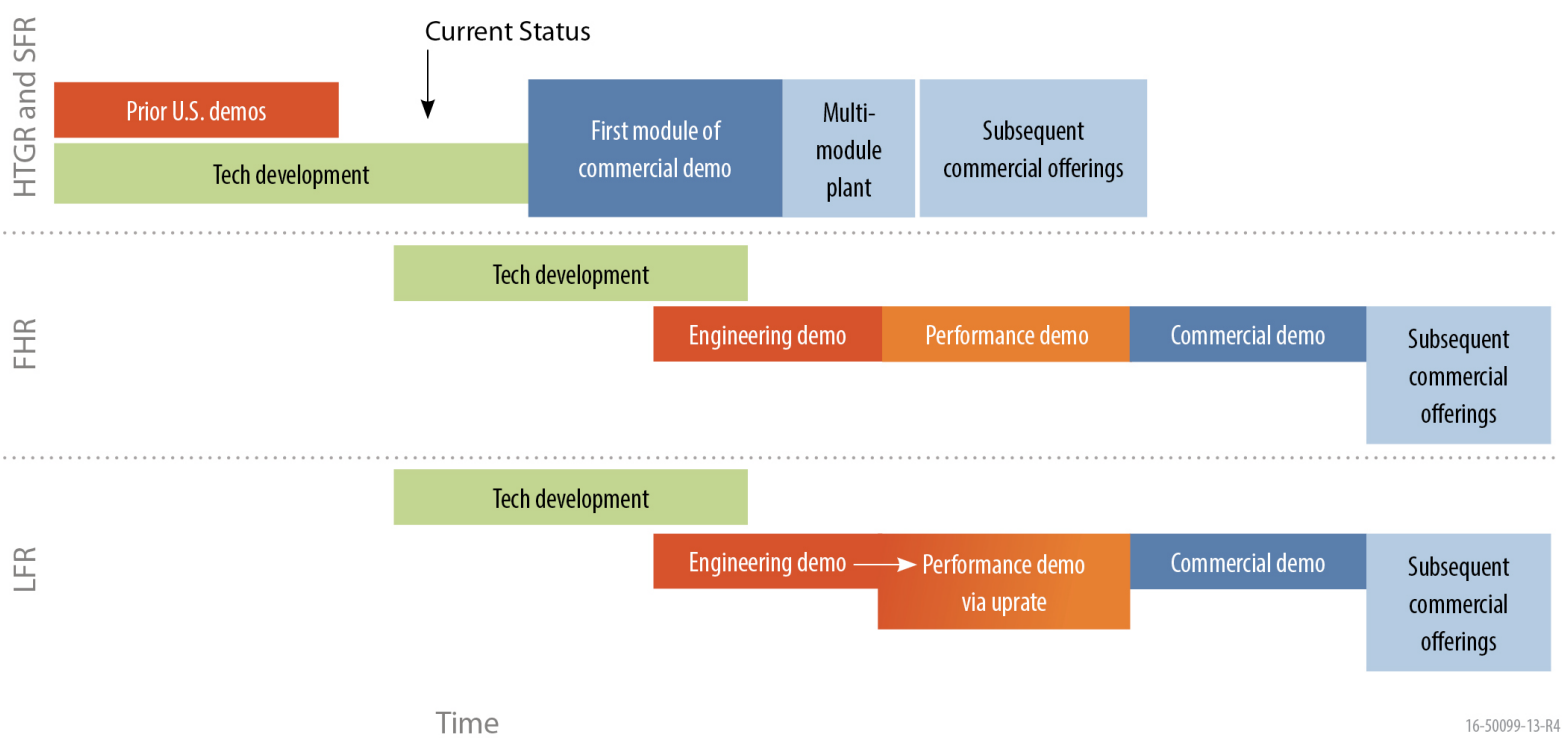

Figure 11. Development and deployment pathway of different advanced reactor technologies.

The most mature technologies, HTGR and SFR, are ready to deploy a first module (a commercial demonstration), then multiple modules, and soon thereafter additional commercial deployments. Each technology had engineering and performance demonstration systems over three decades ago. Their licensing strategies align with that for commercial systems. The more mature technology point designs are focused on mission demonstration (e.g., power production, high temperature heat, fuel cycle). They strive to be prototypic for commercial application (larger/full lifetime), and to operate as a power reactor after initial testing operations. 
The relatively less-mature technologies, the FHR and LFR, need to demonstrate their technology. The two-point designs are intended to be flexible, test different options, and typically be designed to be smaller and/or have a shorter lifetime than intended for a commercial power reactor. The FHR proposed point design utilizes separate engineering and performance demonstrations, while the LFR proposed point design utilizes a combined engineering and performance demonstration. Thus, as shown in Figure 11, the timeline to ultimate commercial deployment is longer than for the mature concepts because of the need for both engineering and performance demonstrations prior to commercialization. While the mature concepts are deployable in the 2030 timeframe, the less-mature concepts are anticipated to take 10 to 20 years longer to commercial deployment because of the additional technology development and demonstration steps required.

\subsection{Cost and Schedule}

Project cost and schedule were estimated for both the demonstration and test reactor options. For any new reactor technology, the cost estimates and associated schedule are highly uncertain. For the two most mature concepts (the HTGR and SFR demonstration reactors), the designs are more established and the costs and schedules are more detailed. The cost metric used in this study is the total project cost to deliver the commercial demonstration reactor (first module) and make it operational to produce electricity, a prerequisite to meeting any of the broader strategic objectives. It does not include subsequent costs for follow-on units or all of the non-reactor costs that would be required to demonstrate the strategic objectives. Thus, neither the costs of the industrial process heat plant associated with the first strategic objective nor the costs of the front and back end fuel cycle facilities for the second strategic objective is included here. This study focuses solely on the reactor technology.

For less-mature concepts, the point designs are engineering demonstration reactors using near-term technology options (e.g., existing materials) to demonstrate behavior of key systems and plant behavior. The power levels and operating lifetimes of these engineering demonstration reactors may be considerably lower than the commercial demonstration built upon the same platform. Successful deployment of such an engineering demonstration would likely not eliminate the need for a performance demonstration prior to the commercial demonstration, although integrated engineering and performance demonstrations might afford opportunities for cost reductions.

\subsubsection{General Cost and Schedule Considerations}

The overall schedule to deployment contains a number of activities that fall into five major areas: (1) R\&D, (2) design, (3) licensing, (4) procurement and supply chain, and (5) construction and operation. The overall schedule includes interplay, linkages, and constraints between the R\&D activities, design, licensing, and procurement.

- Research and Development. The R\&D activities can be long-duration tasks because of the time to demonstrate material behavior needed for American Society of Mechanical Engineers (ASME) code approval (e.g., environmental effects, lifetime behavior), or qualification of new fuels and/or materials. Also R\&D needs will arise during the final design that were not foreseen during preliminary or conceptual design stages. These needs must be considered. For the less-mature technologies, the R\&D needs are anticipated to be greater than for the more mature technologies. 
- Design. Design usually proceeds through three traditional phases: conceptual, preliminary, and final. The durations are somewhat variable depending on the level of engineering staff involved. (A larger engineering staff can complete the design activities faster than a small staff.) For the less-mature technologies, additional design effort is anticipated to reflect evolving technology options and establish the most optimal configuration.

- Licensing. As discussed in Section 7 the most mature concepts are proposing to obtain a commercial power (Class 103) license from NRC by using the 10 CFR Part 50 two-step process for the first module and then using 10 CFR Part 52 for follow-on modules (and in some cases design certification) using experience gained in operation of the first module [1,2]. For technologies with lower relative maturity, a Class 104(c) reactor license is an option allowing for greater flexibility given the state of the technology, with subsequent demonstrations at the commercial scale most likely using a Part 50 license.

- Procurement and Supply Chain Development. Reactor technology procurements need a significant amount of design detail (typical of final design) to write an adequate specification; thus, lead times may be long. In addition, there is a need to develop unique supply chains associated with these advanced reactor systems (e.g., fuel, unique alloys, graphite, electromagnetic pumps, gas circulator, and salt centrifugal pumps).

- Construction and Operation. Activities include site preparation, construction, and initial operation.

Figure 12 shows activities in the areas of technology development, system design, and licensing that must be completed for deployment of a demonstration reactor. Some aspects of Figure 12, such as establishing a mature supply chain, are only relevant for the commercial demonstration step. A number of key interfaces across these five areas can influence the overall duration of the schedule. In many cases, activities are conducted in parallel. For example:

- To support a preliminary safety analysis report, the design of safety important SSC should be mature.

- R\&D results are needed to confirm design assumptions or provide data for safety analysis/licensing (e.g., source term, behavior of passive safety systems, and data for verification and validation [V\&V] of codes).

- For the final safety analysis report, the design detail of overall plant must support final licensing, allow for design certification (if applicable), allow for necessary engineering component testing, and allow procurements (e.g., reactor vessel, steam generator) to proceed. 


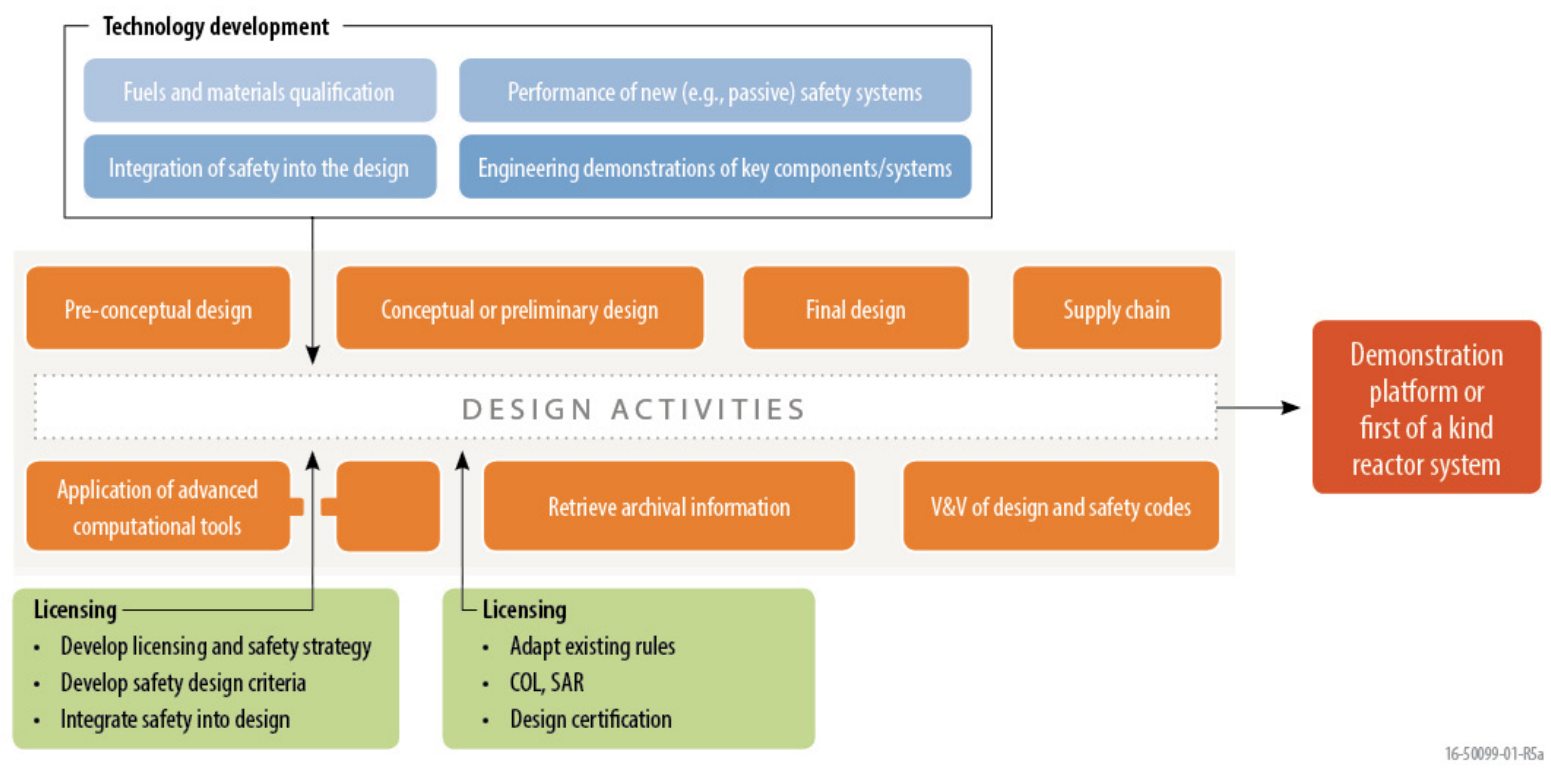

Figure 12. Graphical representation of activities necessary to advance the technical, licensing, and design readiness of an advanced reactor system.

Additionally, there are interactions among these areas where information from one area is needed to advance in another area (for simplicity this is not shown in Figure 12). For example, designers typically make assumptions about the performance of the design at the earliest design stages. These assumptions are turned into design data needs that the technology developers must resolve so the design can be validated or changed as the design matures. This data supports licensing technology development needs, as summarized in Section 6.1 .

\subsubsection{Commercial Demonstration Results (SFR, HTGR)}

The relatively more mature technologies estimate similar timelines for deployment of the first module, independent of the technology with a total duration of about 13 to 15 years to operation of the first module. A notional schedule based on a number of the demonstration vendor schedules is shown in Figure 13. This schedule reflects many parallel efforts such as 7 years for design, and 8-9 years for obtaining an operating licensing for the first unit. 


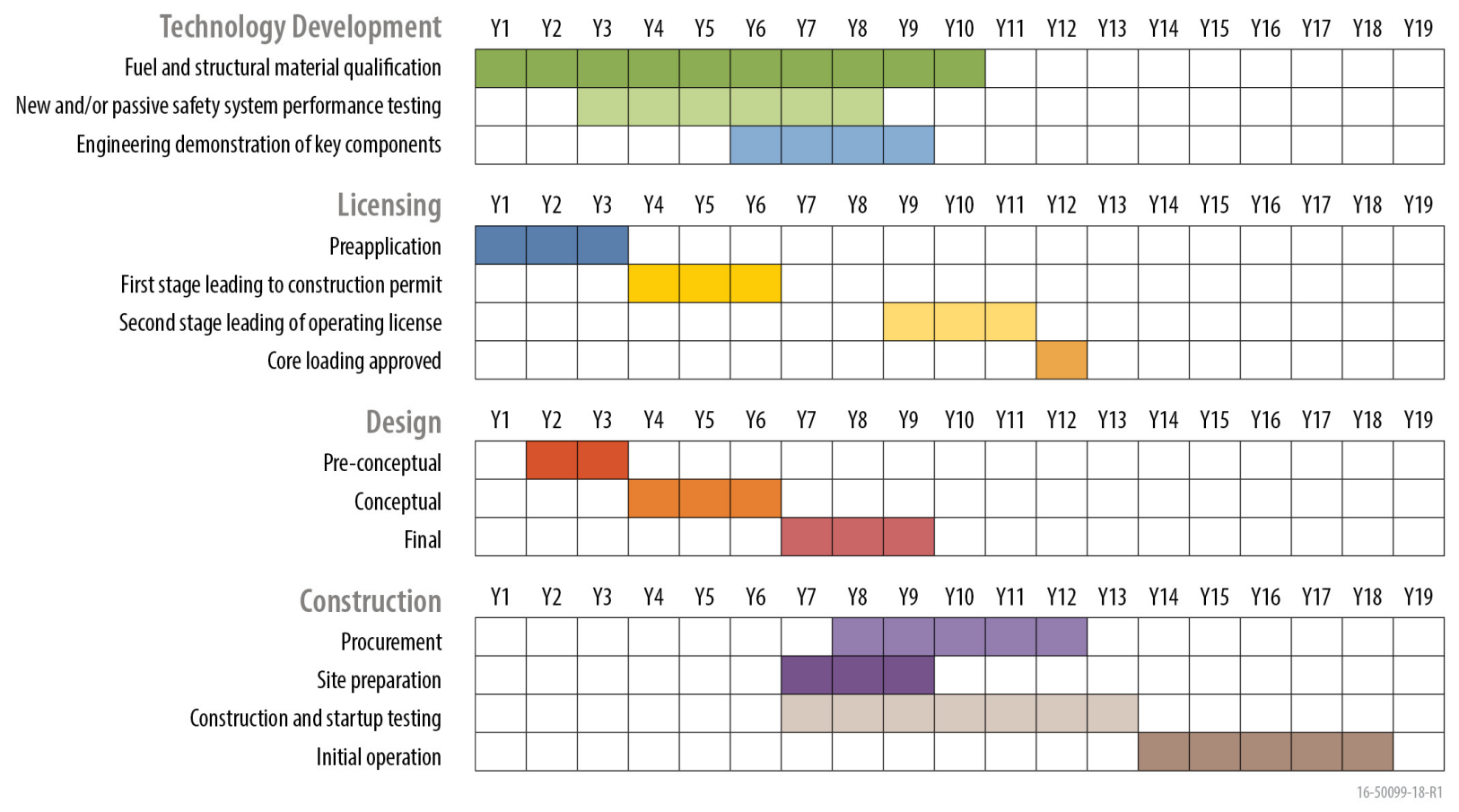

Figure 13. Notional schedule for a high TRL advanced reactor technology.

As shown in Figure 13 fuel and structural material qualification is important for scheduling. Both the SFR and HTGR concepts have spent significant resources qualifying their unique fuel forms, metallic fuel rods for the SFR, and TRISO coated particle fuel in compacts for the HTGR. The TRISO fuel program is scheduled to complete in the next 6 years and will have established a domestic vendor for their fuel to fabricate first core for an HTGR (e.g., AREVA's SC-HTGR design). For SFR metallic fuel, the fuel was qualified at pilot scale when EBR-II was in operation. Early cores can be fabricated at INL using the same equipment. In parallel, a domestic vendor would be established for future fuel loadings. For either technology this work can be completed in the 13-15 years prior to operation of the first module and is incorporated in their costs and schedule.

The estimated costs follow the five key areas identified in Section 7.2.1. The R\&D costs depend extensively on the maturity of the technology and the design. Hundreds of millions of dollars is not unreasonable for these advanced reactor concepts because of the use of new coolants, fuels, materials, and configurations compared to LWRs. Based on the most detailed vendor input from AREVA for the SC-HTGR (Table 11), design costs can run up to $\$ 800$ million for these facilities, and licensing is about $\$ 200$ million. The design and licensing activities are not size dependent. Only a fraction of the construction costs scale with the reactor power, although this may vary with reactor technology and design. Estimated construction costs for the SC-HTGR point design are $\sim \$ 1.5$ billion. Another important and non-trivial cost is indirect cost, which includes field engineering and other costs [3]. For the SC-HTGR, AREVA estimates this to be $\$ 638$ million. Thus, the overall cost of their first module is $\sim \$ 4$ billion, similar to the SFR commercial demonstration estimate. 
Table 11. Summary costs for AREVA SC-HTGR.

\begin{tabular}{|l|c|}
\hline \multicolumn{1}{|c|}{ Item } & Cost \\
\hline R\&D & $\$ 321 \mathrm{M}$ \\
\hline Design & $\$ 800 \mathrm{M}$ \\
\hline Licensing & $\$ 200 \mathrm{M}$ \\
\hline Infrastructure Supply Chain Development & $\$ 175 \mathrm{M}$ \\
\hline Fuel & $\$ 168 \mathrm{M}$ \\
\hline Construction & $\$ 1500 \mathrm{M}$ \\
\hline Owner's Indirect Cost & $\$ 638 \mathrm{M}$ \\
\hline Total & $\sim \$ 4000 \mathrm{M}$ \\
\hline
\end{tabular}

Many of these commercial demonstration costs (e.g., design, R\&D) are onetime costs; thus, costs for multiple unit and commercial nth-of-a-kind reactors are expected to be much lower. For example, based on detailed NGNP estimates [3], the first-of-a-kind cost for four $600 \mathrm{MW}$ HTGRs is $\sim \$ 6.5$ billion and the overnight cost is $\sim \$ 6200 / \mathrm{kWeh}$. For the nth-of-a-kind, the corresponding values are $\sim \$ 4.6$ billion and $\sim \$ 4365 / \mathrm{kWeh}$.

Thus, the two most mature demonstration reactor concepts, the HTGR and SFR, have benefited from billions of dollars and decades of research, development, and design trade studies to establish an optimized configuration culminating in the designs described in this report. They have high degrees of passive safety and provide opportunities for nuclear power to expand into missions beyond just electricity. Both concepts have received safety evaluation reports from the NRC [4,5]. And more recently, the modular HTGR has been the subject of pre-application discussion with NRC as part of the NGNP program. Deployment of either of these concepts is a $\sim \$ 4$ billion endeavor, taking about $13-15$ years to operation of the first module in the 2030 timeframe. Commercial demonstration reactors using similar technology options are being built around the world today reaffirming the readiness of these systems.

These costs and the associated financial and deployment schedule uncertainties at this stage are high enough that private industry in the U.S. will most likely not deploy these systems without government assistance. A public-private partnership will most likely be necessary to reduce both the risk and cost to the private industry. The cost and risk-sharing model that is developed should consider the strengths of both government and industry in the deployment strategy and seek to maximize benefits for both partners given the value that advanced nuclear reactor technologies can have to the U.S.

\subsubsection{Engineering Demonstration Concept Results (FHR, LFR)}

The FHR and LFR, while having significant potential, have been much less studied both in the U.S. and internationally. The proposed demonstration reactors for these two less-mature concepts would run with lower thermal output and serve different roles in their respective technology development paths. The FHR demonstration reactor is a small-scale machine (100 MWth) designed to test key technologies, essentially an engineering demonstration. It is built using the most mature component technologies available today and might not be optimized nor configured as a commercial plant. The small demonstrator is a predecessor to a next step, a larger scale performance demonstration followed by a commercial demonstration - using the traditional technology development pathway shown in Figure 11. 
By contrast, the LFR demonstration reactor is a much larger power system (500 MWth). The machine is designed conservatively with an outlet temperature of only $510^{\circ} \mathrm{C}$, well below that envisioned for a mature LFR, because of the significant corrosion of currently qualified structural materials in lead above this temperature. The engineering demonstration reactor would then allow for integral testing in a prototypic environment. As confidence is built in its operation and other R\&D occurs in parallel, particularly qualification of a new cladding alloy, the flowrate, outlet temperature and power would be increased to values more typical of a commercial LFR. It is anticipated that the outlet temperature would be $\sim 700-750^{\circ} \mathrm{C}$ and the reactor power would be increased to $700 \mathrm{MW}$ th. Therefore, the demonstration reactor would be evolved into a performance demonstration, as illustrated in Figure 7. If successful, the development schedule could be accelerated, but the technical risks are higher because not all features/components can be exchanged if the technology evolves outside of the anticipated envelope. Either of these development strategies will take longer to reach commercialization than those associated with the SFR or HTGR, given their current level of maturity.

For the FHR and LFR concepts, important R\&D must be conducted before the engineering demonstration system can be deployed. Detailed technology development road-mapping needs to be completed for either point design. For example, corrosion issues have been identified for both technologies. Out-of-pile and in-pile loops will be needed to demonstrate relevant corrosion performance under prototypic flow rates, temperature gradients, and neutron flux levels for the requisite time necessary to obtain ASME code qualification.

Another important issue is the utilization of relevant international technology development, experience, and R\&D. For example, LFR-related technology was deployed in the Soviet Union (submarines), but the details of that technology necessary to support a license may not be available in the U.S. Significant out-of-pile work has been done in Italy on corrosion relevant to this point design, but in-pile testing of the fuel (with the alumina coating) will most likely be necessary prior to construction of a demonstration unit. In FHRs, the ability to demonstrate corrosion control (redox) and limit tritium permeation will also require a practical solution that can be demonstrated in-pile at a relevant scale prior to the operation of the engineering demonstration unit. Relevant testing data may be generated by the ongoing Chinese molten salt program. These R\&D activities are anticipated to be on the critical path to any reactor system deployment, with the timelines in the point design reports presuming a success-based development program.

It is difficult to develop engineering demonstration cost and schedule estimates with high levels of confidence because of their low level of technical maturity. Current cost estimates are highly uncertain. Thus, costs are judged to be in the range of $\$ 2$ to $\$ 4$ billion, and taking about 10 to 15 years to start operation and longer to complete the R\&D and initial technology demonstration. Given that some combination of an engineering and performance demonstration is necessary in their development path, commercial offerings are not anticipated before 2045-2050, based on recent experience with qualification of materials, ongoing licensing of Gen III+ reactors, and past experience with other engineering demonstration reactors. Furthermore, there would be an additional cost associated with the development and deployment of performance and commercial demonstrations for the FHR and LFR technologies. 


\subsubsection{Test Reactor Results}

The schedule estimates for the HTGR and SFR test reactors were generally consistent. Both schedule estimates project that the test reactors would be operational in approximately 13 years. The test reactor schedules include similar periods for conceptual design (1-2 years), preliminary design (2 years), and detailed design ( 3 years) along with similar licensing timelines (5-6 years). An example schedule for the HTGR-TR is shown in Figure 14. This example schedule is also largely representative, within uncertainties, of the proposed schedule for the SFR-TR point design.

\begin{tabular}{|c|c|c|c|c|c|c|c|c|c|c|c|c|c|c|c|c|}
\hline HTGR Test Reactor Schedule & 1 & 2 & 3 & 4 & 5 & 6 & 7 & 8 & 9 & 10 & 11 & 12 & 13 & 14 & 15 & 16 \\
\hline \multicolumn{17}{|l|}{ Research and Development } \\
\hline & & & & & & & & & & & & & & & & \\
\hline \multicolumn{17}{|l|}{ Test Reactor Licensing } \\
\hline \multicolumn{17}{|l|}{ Pre-application Review } \\
\hline \multicolumn{17}{|l|}{ CP Application and Review } \\
\hline \multicolumn{17}{|l|}{ CP Issued } \\
\hline \multicolumn{17}{|l|}{ OL Application and Review } \\
\hline \multicolumn{17}{|l|}{ OL ssued and fuel load authorized } \\
\hline \multicolumn{17}{|l|}{ Test and verification of safety features } \\
\hline \multicolumn{17}{|l|}{ OL restrictions satisfied and removed } \\
\hline \multirow{2}{*}{\multicolumn{17}{|c|}{\begin{tabular}{|l|} 
Test Reactor Design and Deployment \\
Conceptual Design
\end{tabular}}} \\
\hline & & & & & & & & & & & & & & & & \\
\hline \multicolumn{17}{|l|}{ Prelimnary Design } \\
\hline \multicolumn{17}{|l|}{\begin{tabular}{|l|} 
Final Design \\
\end{tabular}} \\
\hline \multirow{2}{*}{\multicolumn{17}{|c|}{\begin{tabular}{|l|} 
Procurement \\
Construction and Startup Testing \\
\end{tabular}}} \\
\hline & & & & & & & & & & & & & & & & \\
\hline Test Reactor Operational - with restrictions & \multicolumn{7}{|c|}{ Construction and Startup Testing } & & & & & & & $\diamond$ & & \\
\hline Test Reactor Fulfy Operational & & & & & & & & & & & & & & & & 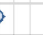 \\
\hline
\end{tabular}

Figure 14. Example schedule for the HTGR test reactor point design.

The test reactor costs have limited detail and high uncertainty at the point design stage. The SFR-TR is estimated at $\$ 2.8$ billion. The HTGR-TR is estimated at $\$ 3.1$ billion with a range of $\$ 2.2$ to $\$ 4.7$ billion given the early stage of the design. Both test reactor point designs contain a number of closed test loops each estimated at $\$ 80-\$ 100$ million per loop. These are expensive, but are important aspects of the test reactor that give it a high degree of flexibility to accommodate a wide range of future advanced reactor technology needs. The total project cost of either system could drop significantly if the heat were dumped instead of being put through a power conversion system; however, no operating revenue would then be generated to offset annual operating costs. The schedule leading to operation is similar for both options, independent of the technology, and about 13 years driven by design and licensing. Operating costs for the two systems including fuel is $\$ 140-\$ 170$ million/year, with potential offsetting revenues from electricity production ranging from $\$ 40-\$ 80$ million/year, depending on the deployment market.

These costs are larger than the \$1-\$2 billion reported for the CEA Jules Horowitz test reactor. Reasons for the higher costs are the larger power of these test reactors, the test loops that are incorporated in the design, and the cost of the power conversion system. However, the performance achieved by the test reactor point designs in this study is superior (higher flux intensity and/or irradiation volumes). The versatile and flexible testing capabilities could entice the international research community to invest in the reactor or pay for irradiation services. Both the Organization for Economic Cooperation and Development (OECD) Halden Reactor Project and the Jules Horowitz Project offer a few effective models for international cooperation for irradiation test services. The effort to pre-sell irradiation services 
for the Russian MBIR project is indicative of the extensive international interest in fast neutron irradiation services at high neutron flux.

In summary, the test reactor options costs are estimated to be $\$ 3$ billion with a 13-year project schedule. Annual operating costs around $\$ 150$ million/year are estimated. However, both point designs include provisions for revenue through power production, and opportunities for sale of irradiation services exist. Thus, a more detailed business case for test reactor services is required to assess the demand for irradiation services and net operating costs.

\subsection{References}

1. 10 CFR 50, "Domestic Licensing of Production and Utilization Facilities," United States Nuclear Regulatory Commission, December 2, 2015.

2. 10 CFR 52, "Licenses, Certifications, and Approvals for Nuclear Power Plants," United States Nuclear Regulatory Commission, December 2, 2015.

3. TEV-1196, "Assessment of High Temperature Gas-Cooled Reactor (HTGR) Capital and Operating Costs," January 9, 2012.

4. U.S. NRC, "Preapplication Safety Evaluation Report for the Power Reactor Innovative Small Module (PRISM) Liquid-Metal Reactor," NUREG-1368 (1994)

5. NUREG 1338 "Pre-Application Safety Evaluation Report for the Modular High-Temperature Gas-Cooled Reactor (MHTGR)" U.S. Nuclear Regulatory Commission, March, 1989 


\section{LICENSING}

The objective of this section is to provide an overview of possible licensing pathways within these available options for the six-point designs considered in this study. This section also presents a generic review of advanced reactor licensing issues.

\subsection{Overview of Advanced Reactor Licensing Issues}

Advanced reactor developers must determine how the safety case and underlying technical bases that are established for the respective advanced technology can be confirmed to satisfy the applicable NRC rules, regulations, and their associated technical requirements. It is recognized that the majority of the currently applicable NRC technical requirements are based on the large LWR design types that constitute the operating fleet. Therefore, the establishment of appropriate policy and licensing technical requirements that satisfy the underlying safety bases of this existing LWR-based licensing framework for innovative (non-LWR) designs is critical to bringing stability and efficiency to the innovative reactor development process. This "regulation" topic of identifying both the NRC licensing technical requirements and policies that will apply to advanced reactors is typically an area of significant challenge and uncertainty for the stakeholder community.

It is noted that the NRC staff has provided recent summaries to the Commission regarding its readiness to address these challenges as they relate to advanced non-LWR designs (SECY-14-0095), and has indicated that the NRC staff would be challenged to efficiently review a new non-LWR application if one is submitted in the near term (within 5 years) [1]. NRC has summarized that its plan for addressing those challenges has three major components: (1) regulatory structure, (2) research efforts, and (3) human resource development. Going forward, it will be critical for advanced reactor developers, research organizations, technology end-users, DOE, and NRC to work closely in establishing and implementing the efforts necessary to address the above three "regulation" components. These areas are covered in more detail below.

\subsubsection{Establishing Technical Requirements for Licensing}

The NRC (Commission) established a series of overarching expectations regarding the establishment of the safety case for future reactors when it issued its "Policy Statement on the Regulation of Reactors," after an extensive development and public comment process [2]. In this policy, the NRC provided its expectation that advanced reactors will provide enhanced margins of safety and/or use simplified, inherent, passive, or other means to accomplish their safety and security functions. The NRC also summarized a series of attributes that could assist in establishing the "licensability" of a proposed advanced reactor design, including the following:

- Highly reliable and less-complex shutdown and decay heat removal systems

- Longer time constants before challenging safety systems

- Simplified safety with reduced reliance on required operator actions

- Minimize the potential for severe accidents and their consequences. 
As discussed below, a key to establishing technical licensing requirements for advanced reactors is to first identify the underlying safety basis for the existing LWR-based regulation or technical requirements. This understanding then allows the adaptation of the existing requirements for use in advanced reactor development and licensing, while addressing the above attributes and maintaining (and potentially increasing) the current levels of protection of public health and safety.

It is noted that many in the advanced reactor development community point to a need for the development of a new set of NRC regulations that are non-LWR based before various advanced reactor technologies can be effectively and efficiently licensed. This view is different from the conclusion reached by a joint DOE-NRC team that studied this topic in detail (2006-2008) while evaluating the available options and most timely approaches for licensing the NGNP, which was to be a commercial non-LWR demonstration facility. The results of that review, which are summarized in the Next Generation Nuclear Plant Licensing Strategy - A Report to Congress (August 2008) and would generally be expected to apply to other advanced technology types, indicated that adapting the existing set of regulatory requirements “... will provide for the most effective and efficient use of NRC and applicant resources while reducing licensing and financial risk and optimizing the review and construction schedule" [3].

This concept of adapting regulatory requirements to accommodate innovative reactor technologies, while retaining and addressing the underlying safety bases of the existing regulatory requirements, is also the approach that was selected by NRC and DOE in 2013, and is being implemented in the joint initiative on design criteria development for advanced reactors. The initiative and its licensing technical requirements adaptation approach have been reviewed by the advanced reactor stakeholder community, with general concurrence and support. It is noted that this initiative should be considered a "first step" in establishing a series of licensing technical requirements for advanced reactors. It could be expanded and implemented by technology developers and the NRC through a combination of the existing NRC processes and feedback mechanisms (topical reports, standard review plans, interim staff guidance, regulatory exemptions, etc.) for performing focused reviews of technology-specific topics.

\subsubsection{Technology Development Pathway to Support Licensing}

A key component of all reactor technology development activities, and the primary focus of the NRC and its associated licensing processes, is to confirm that proposed reactor facilities do not pose an undue risk to public health and safety. The establishment of this "safety case," and the development of the underlying technical bases and associated justifications that support it, are foundational elements of successful advanced reactor development, licensing, and commercial deployment.

The key to the safety case, for both the previously deployed large LWR fleet and for the advanced reactor technologies under development, is to establish a very clear understanding of the following high-level attributes of the proposed reactor technology and the associated facility design being developed for the use of that technology:

- Identify the various plant events that could lead to radionuclide release

- Establish the form and quantity of the radionuclide source in the proposed fuel type and reactor design that could potentially be released when challenged by those plant events 
- Establish the capability to analyze and assess the timing, form, and magnitude of the transport and release of that radionuclide source to the environment and members of the public.

The NRC provided additional information and insights regarding its expectations about the safety case for innovative reactor designs in its Report to Congress: Advanced Reactor Licensing (August 2012), as noted below [4].

The applicant's demonstration of the "safety case" supporting its application requires comprehensive documentation of the research conducted, testing accomplished, and analyses performed necessary to support both the design and the technical basis for the safety analysis. For example, applicants are responsible for conducting R\&D to:

- Demonstrate safe performance of the proposed design and applied technology

- Provide the technical basis for the application

- Demonstrate sufficient margins to safety-significant structures, systems, and components (SSC) design and safety limits

- Search for and identify, as well as assess and resolve, safety issues involving large uncertainties

- Develop, verify, and validate the proposed safety analysis evaluation methods

- Provide the technical basis for requirements, criteria, codes, or standards that are proposed for the licensing design basis

- Quantify the failure thresholds for safety-significant SSC

- Support NRC regulatory and licensing decisions.

Advanced reactor development must therefore involve close coordination and integration of the technical aspects of the design being established to meet commercial end-user needs with the technical aspects required to support the safety case and associated regulatory requirements. Although a more detailed assessment of technical knowledge gaps is needed for each advanced reactor technology being considered, technical areas typically requiring consideration and technical justification as a part of the development and licensing processes associated with commercial reactors are reflected in Figure 15. 


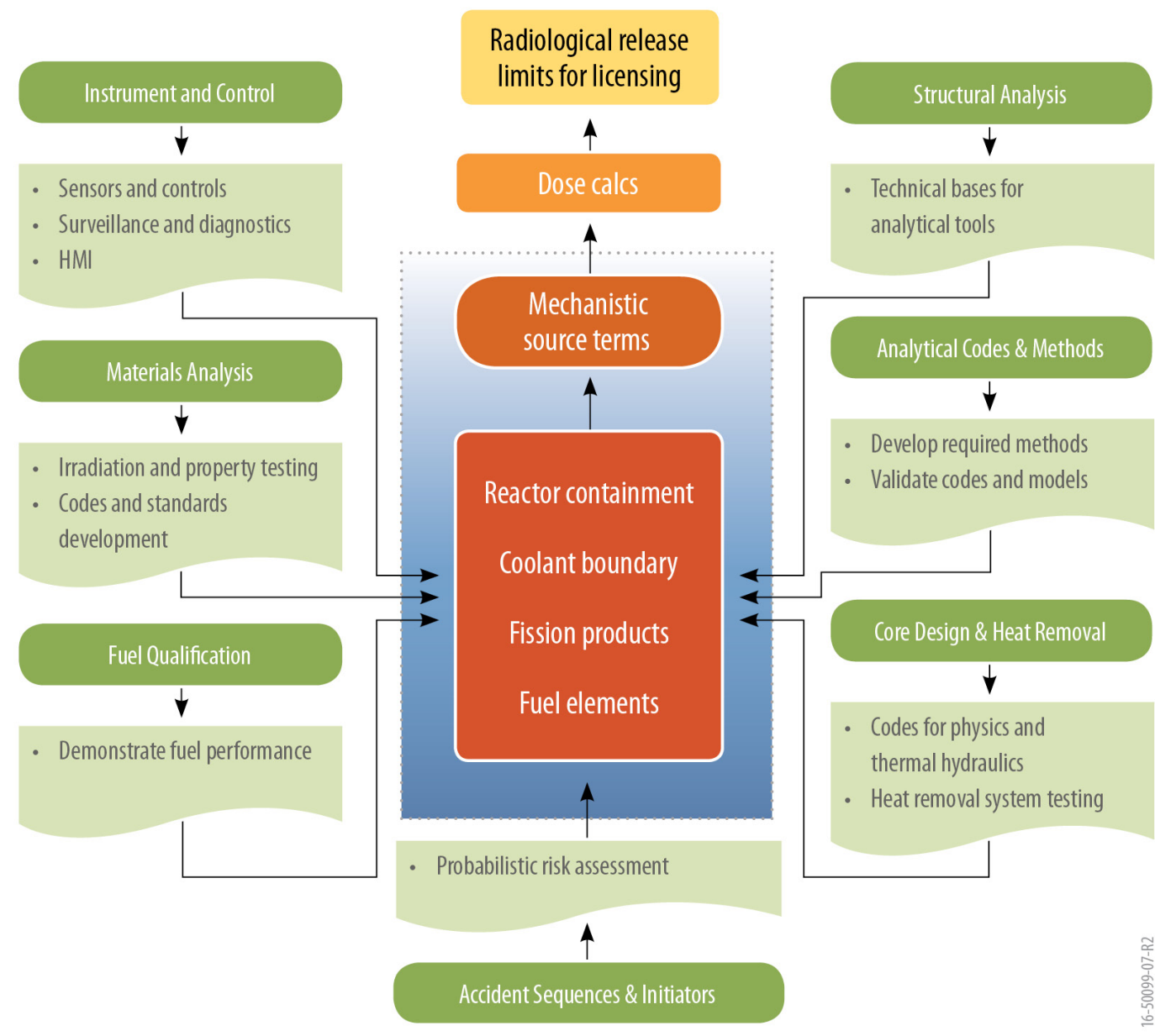

Figure 15. Technology development typically required for licensing.

It is critical that those technical issue analyses and resolution efforts, with identification of necessary $R \& D$, are closely integrated with the confirmation and defense of the respective advanced technology's safety case. This integration is a key to assuring that critical path and long lead time items are not overlooked on the technology development timeline, giving investors and other stakeholders confidence that technical progress and readiness can indeed support a successful NRC licensing and advanced reactor technology deployment effort.

A focused and systematic assessment of technology development areas necessary to support the future NRC licensing of selected advanced reactors (modular HTGRs and SFRs) was recently completed by the DOE's ART Program team. The "Advanced Reactor Technology - Regulatory Technology Development Plan (RTDP)" provides a detailed and prioritized listing of critical research activities necessary to support advanced reactor licensing, and should be used as a primary input when establishing the overall purpose and planned facility capabilities through the advanced test and demonstration reactor effort [5]. 
The technical information represented by the branches in the technology development "tree" in Figure 15 is collected during all the stages of demonstration: engineering, performance, and commercial. Specifically:

- Fuels and materials qualification is usually done as early as possible given the long timeframe for these activities.

- Codes and methods are developed during the design of the engineering demonstration and are continually improved based upon operation of the engineering and performance demonstrations. Developmental assessment and ultimate validation of codes is a continual process of gathering data from both the demonstration and scaled experiments to establish the foundation of qualification.

- Development of instrumentation and controls may occur during any of the demonstration phases with upgrades as required as operational experience is gained and improvements in sensor and control technology occur.

- Demonstrating passive heat removal (and any other passive safety feature in the design) can be done at both the engineering and performance demonstration stages, depending on the scale of the systems and the ability to extrapolate those results to the commercial system. Alternately, out-of-pile scaled thermal hydraulic experiments can be used to confirm the viability of the heat removal technology and the ability of computer codes to calculate the response of the system.

\subsubsection{Relationship between Commission Policy and Technical Requirements}

A series of overarching Commission policies have been established over the years, and are occasionally revised, that form the overarching framework within which NRC regulations, regulatory guidance, and inspection practices are established for implementation by the NRC staff. Although the underlying safety bases for these policies are generally applicable to advanced reactor technologies, the policies themselves frequently cannot be readily implemented as written due to innovative reactor design differences, and because many of the existing policies were developed prior to the development of modern technical assessment tools and capabilities. This creates a lack of policy direction that results in significant regulatory uncertainty for both innovative reactor developers and for the NRC's technical staff.

These challenges are recognized by NRC and DOE as summarized in their 2008 Next Generation Nuclear Plant Licensing Strategy - A Report to Congress regarding the NGNP Licensing Strategy, and in NRC's 2010 SECY-10-0034, "Potential Policy, Licensing, and Key Technical Issues for Small Modular Nuclear Reactor Designs," citing specific challenges for small modular reactors and NGNP $[3,6]$. The NRC's more recent SECY-15-0077 document addresses the Commission policy topic of emergency preparedness, and also makes note of the need to address and resolve a number of other closely related policy topics, including the same topics identified in the 2008 and 2010 documents above [7].

Reactor developers, end-users, and other stakeholders must address the establishment of key licensing technical requirements in conjunction with resolution of the Commission policy issues that apply or may arise. An example of how those two areas interact for a notional multi-reactor facility is depicted in Figure 16, which is based on the most significant technical and policy issue that were identified by the NGNP Project and by previous pre-licensing efforts from the 1980s as the keys to modular HTGR licensing and deployment. In this example, it is noted that the performance of the modular HTGR's 
particle fuel form provides a critical technical foundation for this reactor type's safety case, and the establishment of related technical licensing requirements. The fuel's performance requirements must also be closely integrated with the following four key Commission policy topics:

- Selection of events

- Source term

- Containment requirements

- Emergency planning requirements.

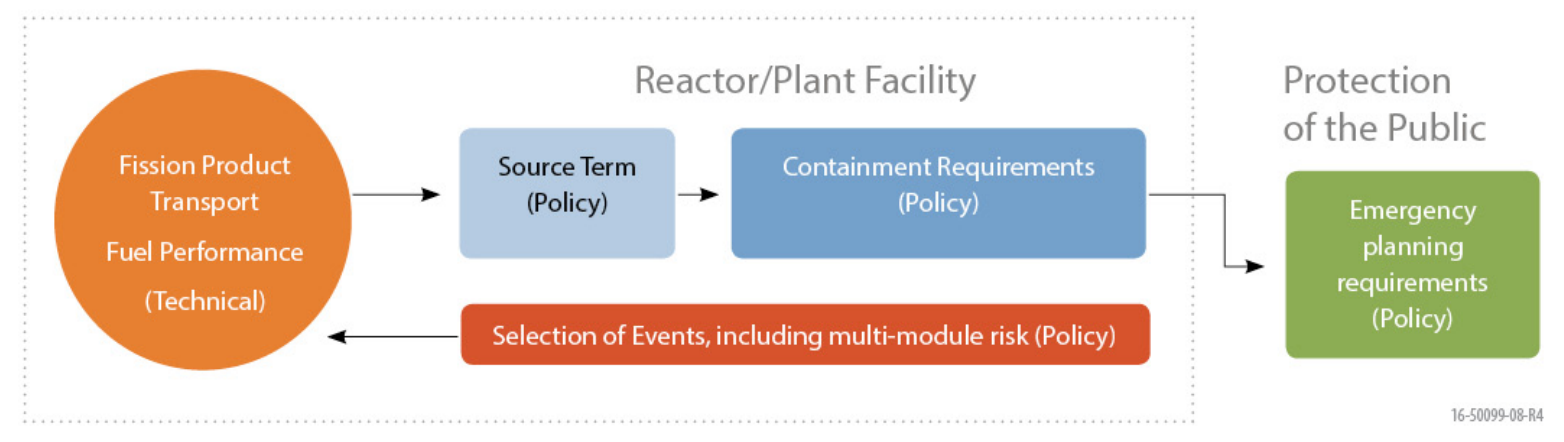

Figure 16. Policy and technical requirement interaction.

The four key Commission policy topics reflected above also form the core or "trunk" of the technology development efforts needed for licensing that are reflected in Figure 5. Therefore, it is clear from the related depictions in Figure 15 and Figure 16 that establishing increased regulatory certainty and a viable licensing framework for advanced reactor technologies requires the retirement of risk in multiple, closely coupled technical and Commission policy areas. The key technical areas identified in Figure 15 can be addressed through the activities described within other sections of this report.

\subsection{Licensing Pathways for the Six Demonstration and Test Reactor Point Designs}

Two distinct paths exist for NRC licensing and deployment of nuclear reactors in the U.S. depicted in Figure 17:

1. Research or test (non-power) reactors

2. Commercial (power) reactors, including prototype plants. 


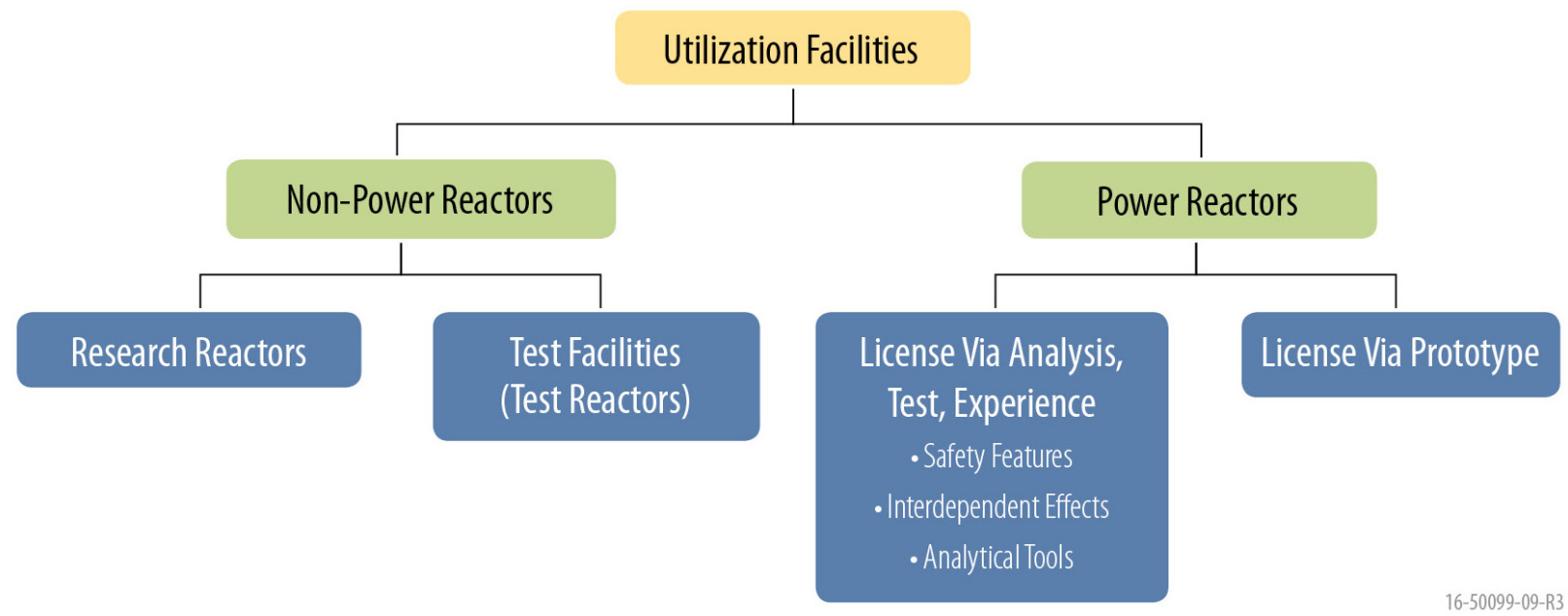

Figure 17. Available Nuclear Regulatory Commission licensing paths.

Non-power reactors are defined within NRC regulations as: a research or test reactor licensed under 10 Code of Federal Regulations (CFR) 50.21(c) for research and development. The NRC defines "research and development" as (1) theoretical analysis, exploration, or experimentation; or (2) the extension of investigative findings and theories of a scientific or technical nature into practical application for experimental and demonstration purposes, including the experimental production and testing of models, devices, equipment, materials, and processes. This series of regulations describes the two types of non-power reactors: a research reactor or a test facility (test reactor).

A research reactor is a nuclear reactor licensed by the NRC under the authority of subsection 104(c) of the Atomic Energy Act and pursuant to the provisions of $\S 50.21$ (c) for operation at a thermal power level of 10 megawatts or less, and which is not a testing facility as defined in this Section [8]. Examples of research reactors are the pool-type designs found at universities. None of the point designs considered in this study would be licensable as research reactors.

A test facility (test reactor) is also licensed under Subsection 104(c), and is defined as a nuclear reactor which is of a type described in $\S 50.21$ (c) ....for operation at:

1. A thermal power level in excess of 10 megawatts; or

2. A thermal power level in excess of 1 megawatt, if the reactor is to contain:

a. A circulating loop through the core in which the applicant proposes to conduct fuel experiments; or

b. A liquid fuel loading.

NOTE: There is currently one NRC-licensed test reactor - National Institute of Standards and Technology (NIST). Although authorized by DOE and not licensed by NRC, the Advanced Test Reactor providing irradiation services at INL would be considered a test reactor per the above NRC regulations. The ATR was grandfathered in by Section 202 of the Energy Reorganization Act of 1974 because it was in existence on the effective date of the Act.

A prototype plant is one that is developed, constructed, and operated to implement the prototype plant licensing option for power reactors. This option is established within 10 CFR 50.43(e) as described 
further below, and can be used when the combination of an advanced technology's available analyses, test programs, and operating experience are not adequate by themselves to support NRC license application approval [9]. The NRC staff has indicated that prototype plants are typically similar to standard plant designs in features and size, but may have additional safety features.

The key attributes of these available "non-power" and "power" reactor licensing paths are summarized in the following sections. Additional detail is found in Appendix E.

\subsubsection{Power Reactor Licensing Pathways}

Of the four demonstration point designs described in this report, the modular HTGR and the SFR are the most technically mature and have been determined to be ready for commercial demonstration.

Therefore, these two technologies would be licensed through this NRC power reactor licensing pathway and a Class 103 license, as depicted in Figure 18. The LFR point design would also utilize this pathway.

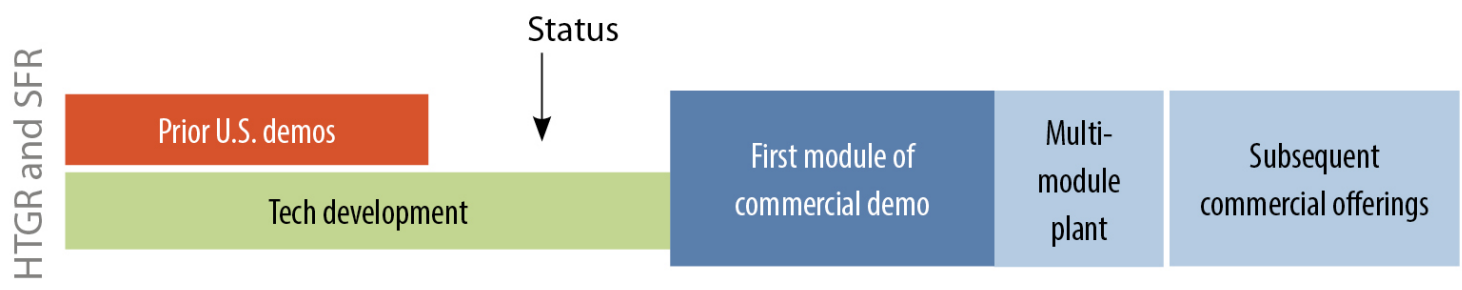

Licensing Path \# 1

Part 50 "two step"
Prototype Licensing Class 103 $\rightarrow \begin{gathered}\text { Part 52 } \\ \text { design cart }\end{gathered} \rightarrow \begin{gathered}\text { Replicate } \\ \text { certified design }\end{gathered}$

Time

16-50099-18a-RO

Figure 18. HTGR and SFR licensing pathway.

Commercial Power reactors must meet the requirements contained in the NRC regulations provided predominantly in 10 CFR 50, "Domestic Licensing of Production and Utilization Facilities," and 10 CFR 52, "Licenses, Certifications, and Approvals for Nuclear Power Plants" [10,11]. These regulations contain a series of technical and administrative requirements that implement associated Commission policy, and are focused on the protection of public health and safety. 
Reactor technologies within the power reactor classification are reviewed by the NRC's Office of New Reactors (NRO). The NRC staff's reviewers rely on NUREG-0800, "Standard Review Plan for the Review of Safety Analysis Reports for Nuclear Power Plant: LWR Edition," for guidance on how to apply the associated regulations and regulatory guidance when performing their reviews [12]. In addition to this guidance, for innovative or advanced designs that differ significantly from light-water reactor designs that were licensed before 1997, or use simplified, inherent, passive, or other innovative means to accomplish their safety functions, the NRC reviewers must confirm that one of the following two paths has been adequately addressed [10 CFR 50.43(e)] [9]:

1. (i) The performance of each safety feature of the design has been demonstrated through analysis, appropriate test programs, experience, or a combination thereof;

(ii) Interdependent effects among the safety features of the design are acceptable, as demonstrated by analysis, appropriate test programs, experience, or a combination thereof; and

(iii) Sufficient data exist on the safety features of the design to assess the analytical tools used for safety analyses over a sufficient range of normal operating conditions, transient conditions, and specified accident sequences, including equilibrium core conditions;

or

2. There has been acceptable testing of a prototype plant over a sufficient range of normal operating conditions, transient conditions, and specified accident sequences, including equilibrium core conditions. If a prototype plant is used to comply with the testing requirements, then the NRC may impose additional requirements on siting, safety features, or operational conditions for the prototype plant to protect the public and the plant staff from the possible consequences of accidents during the testing period.

NOTE: It is noted that both light water small modular reactors (NUSCALE, HOLTEC, mPower, Westinghouse) and the advanced non-LWR power reactors (PRISM, XE-100, etc.) in development fall under the above requirements of 10CFR 50.43(e). They are all nuclear reactor designs that differ significantly from LWR designs that were licensed before 1997, or use simplified, inherent, passive, or other innovative means to accomplish their safety functions.

\subsubsection{Non-Power Reactor Licensing Pathways}

This non-power reactor licensing pathway depicted in Figure 19 could be utilized for non-power engineering demonstration reactors such as the FHR or LFR point designs, and is characterized by flexible and tailored technical requirements specific to the advanced technologies being developed. 


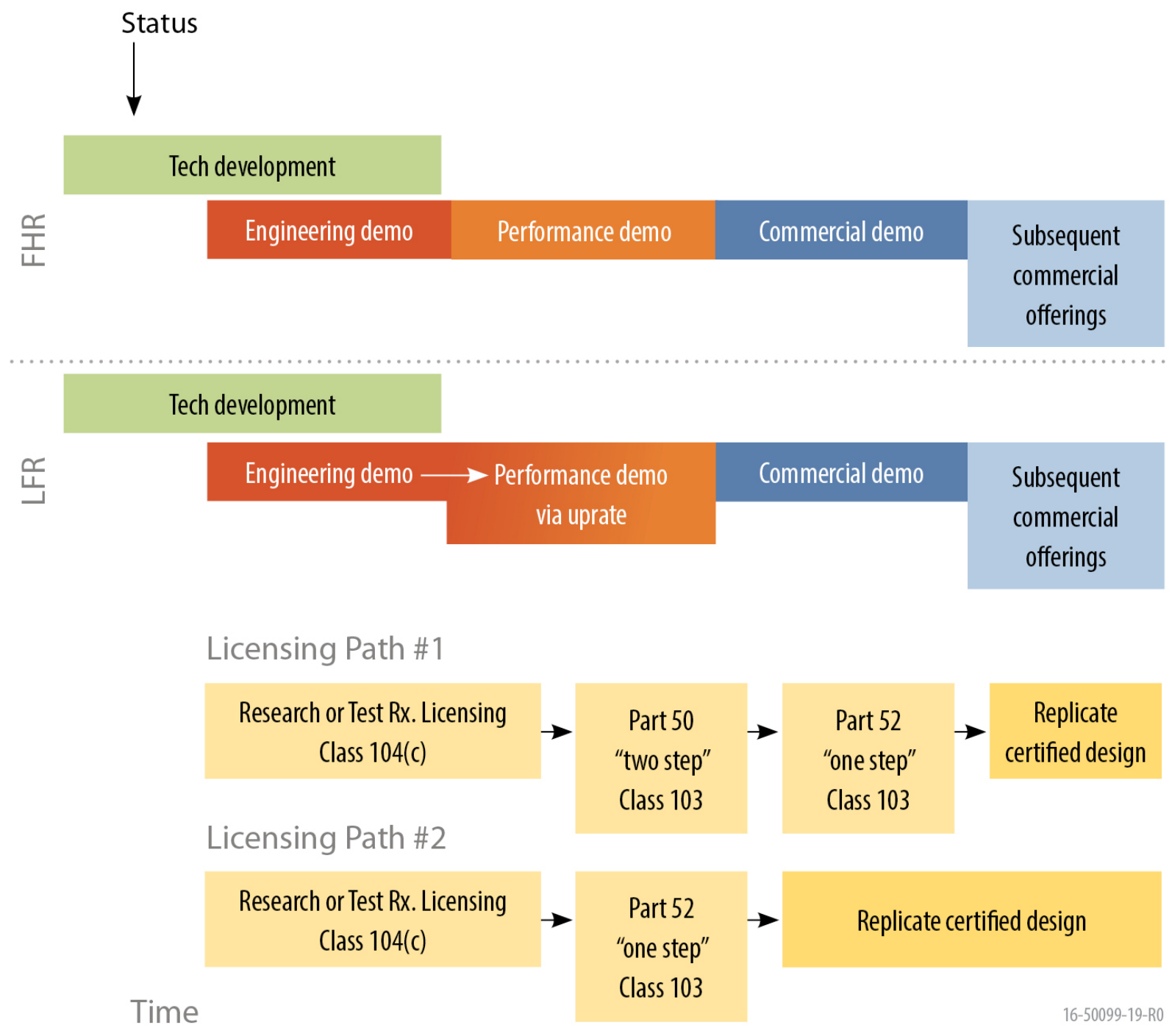

Figure 19. Possible FHR or LFR Licensing Paths.

The NRC was directed by Congress (starting with the Atomic Energy Act in 1954) to impose the minimum amount of regulation on 104(c) research and test reactor licensees. In keeping with this direction, the NRC staff utilizes NUREG-1537, "Guidelines for Preparing and Reviewing Applications for the Licensing of Non-Power Reactors," as the primary guidance for review of research and test reactor technologies and license applications [13]. This NUREG is based on the key constituents from Part 50, and utilizes "performance based" approach, rather than the more prescriptive review approach utilized when licensing commercial power reactors under the NRC's Standard Review Plan for LWRs (NUREG-0800) [12].

An additional restriction regarding this class of reactor license is that the facility must be used so that no more than $50 \%$ of the annual cost of owning and operating the facility is devoted to the production of materials, products, or energy for sale or commercial distribution, or to the sale of services, other than $R \& D$, education, or training. For clarity, it is noted that this allows for the entire output of the facility to be used for commercial purposes, so long as the generated revenue does not exceed $50 \%$ of the annual 
ownership/operating costs. If the reactor's use exceeds this $50 \%$ cost threshold, then it is considered to be a commercial facility and must be licensed through the commercial power reactor licensing process.

\subsubsection{Department of Energy Authorization Pathway}

The Energy Reorganization Action of 1974 summarizes respective regulatory authorities and responsibilities for NRC and DOE of the type that are expected to be applicable to the various kinds of test or demonstration facilities being contemplated [14]. It indicates that the NRC shall have licensing authority for demonstration nuclear reactors, other than those already in existence in 1974, that "... are operated as part of the power generating facilities of an electric utility system, or when operated in any other manner for the purpose of demonstrating the suitability for commercial application of such a reactor."

Advanced reactor attributes that are critical to the technology's safety basis will ultimately need to be reviewed by the NRC technical staff prior to the demonstration and commercial deployment of that technology. Deferring formal NRC review of those attributes under DOE authority causes the NRC's review to be deferred, perpetuating the underlying regulatory uncertainty related to the technology, thus doing nothing to mitigate the subsequent commercial license applicant's business risk due to regulation. Therefore, this authorization pathway is likely not the most efficient option to support deployment of the demonstration technologies summarized in this report. However, the two test reactor options are candidates for DOE authorization, although examination of their design characteristics against existing and or new NRC requirements would significantly reduce the subsequent NRC commercial license applicant's business risk.

\subsubsection{Key Siting Requirements and Considerations}

Determining a suitable location for a nuclear facility built and operated under NRC regulatory authority requires early and careful consideration of site features relative to licensing requirements. To help applicants address these requirements, guidance relative to a typical large LWR design can be found in NUREG-0800 [12]. More detail on the key siting requirements and consideration can be found in Appendix F.

Application for a construction permit (CP), early site permit (ESP), or combined license (COL) will require site investigation and consequence analysis for elements ranging from physical and biological attributes of the site to factors dealing with regional demographics and socioeconomics. The licensing process also mandates consideration of alternative sites with adequate detail to support submission of an environmental report (ER) by the applicant; this report will be the basis for an environmental impact statement (EIS) that satisfies requirements of the National Environmental Policy Act (NEPA). NRC review of an ER is followed by public hearing(s) and an EIS decision where NRC acts as the lead federal agency. How DOE NEPA requirements (including issues regarding DOE "programmatic" EIS needs) might interface with and be satisfied by the NRC NEPA process would need to be clarified through interagency consultations and agreement.

Key aspects of the siting evaluation and selection process include the consideration of:

- The facility's potential impact on public health and safety (offsite dose, emergency planning aspects) 
- Site hazards and risks

- Ability of the site to support the facility's technical requirements (infrastructure, cooling, etc.).

Top level NRC requirements on radiological dose limits to personnel and to the public for both power and non-power reactors are summarized in Appendix F-8. Offsite dose is a key consideration in evaluating the appropriate sizing of a facility's emergency planning zone.

\subsection{References}

1. SECY-14-0095, "Status of the Office of New Reactors Readiness to Review Small Modular Reactor Applications," United States Nuclear Regulatory Commission, August, 24, 2014.

2. U.S. NRC, "Policy Statement on the Regulation of Advanced Reactor," FR/Vol. 73, No. 199/October 14, 2008 /Rules and Regulations, pg. 60612.

3. U.S. NRC, Next Generation Nuclear Plant Licensing Strategy - A Report to Congress, United States Nuclear Regulatory Commission, August 2008.

4. U.S. NRC, Report to Congress: Advanced Reactor Licensing, United States Nuclear Regulatory Commission, August 2012.

5. PLN-4910, "Advanced Reactor Technology - Regulatory Technology Development Plan (RTDP)," Rev. 0, May 18, 2015.

6. SECY-10-0034, "Potential Policy, Licensing, and Key Technical Issues for Small Modular Nuclear Reactor Designs," United States Nuclear Regulatory Commission, March 28, 2010.

7. SECY-15-0077, "Options for Emergency Preparedness for Small Modular Reactors and Other New Technologies," United States Nuclear Regulatory Commission, May 29, 2015.

8. 10 CFR 171.5, "Definitions," United States Nuclear Regulatory Commission.

9. 10 CFR 50.43(e), "Additional Standards and Provisions Affecting Class 103 Licenses and Certifications for Commercial Power," United States Nuclear Regulatory Commission.

10. 10 CFR 50, "Domestic Licensing of Production and Utilization Facilities," United States Nuclear Regulatory Commission.

11. 10 CFR 52, "Licenses, Certifications, and Approvals for Nuclear Power Plants," United States Nuclear Regulatory Commission.

12. NUREG-0800, "Standard Review Plan for the Review of Safety Analysis Reports for Nuclear Power Plant: LWR Edition,” United States Nuclear Regulatory Commission, July 17, 2014.

13. NUREG-1537, "Guidelines for Preparing and Reviewing Applications for the Licensing of Non-Power Reactors" United States Nuclear Regulatory Commission, March 29, 2012.

14. NRC, "The Energy Reorganization Action of 1974," United States Nuclear Regulatory Commission, 1974. 


\section{SUMMARY AND FINDINGS}

Congressional language contained within the fiscal year 2015 appropriation directed DOE to conduct a planning study to evaluate "advanced reactor technology options, capabilities, and requirements within the context of national needs and public policy to support innovation in nuclear energy." This study includes identification of the key features and timing needed for advanced test or demonstration reactors to support research, development, and technology demonstration leading to the commercialization of power plants built upon these advanced reactor platforms. The purpose of this planning study is to identify the steps and challenges to deployment for the identified advanced reactor technologies and to develop pathways for addressing those challenges.

Advanced reactors are defined in this study as reactors that use coolants other than water . Advanced reactor technologies have the potential to expand the energy applications, enhance the competitiveness, and improve the sustainability of nuclear energy. These advanced reactor concepts offer a range of technology innovations including:

- Higher outlet temperatures than LWRs, which yields enhanced efficiency of electricity generation as well as a variety of process heat applications

- Enhanced inherent safety, including passive decay heat removal systems

- Advanced fuels (liquid, particle, metallic, ceramic) and cladding enabling high burnup, extensive actinide destruction, and enhanced accident tolerance

- Advanced power conversion systems (Brayton cycle, supercritical $\mathrm{CO}_{2}$ ) to improve overall energy conversion efficiency and reduce water usage

- Modular design to shorten construction times and to support phased deployment to allow flexibility in meeting demand

- Greater degrees of autonomous control to minimize operating cost.

\subsection{Important High-Level Findings and Observations}

In addition to a base mission of efficient and reliable electricity production, a series of four strategic objectives that span the range of key advanced reactor nuclear energy missions and needs has been established: The first three are focused on potential demonstration reactor options and the fourth on test reactors options. These four strategic objectives are:

1. Deploy a high-temperature process heat application (e.g., synfuels production) for industrial applications and electricity demonstration using an advanced reactor system to illustrate the potential that nuclear energy has in reducing the carbon footprint in the U.S. industrial sector

2. Demonstrate actinide management to extend natural resource utilization and reduce the burden of nuclear waste for future generations

\footnotetext{
d Advanced LWRs, their R\&D and licensing extension needs, and their potential applications are addressed under specific DOE-NE programs (e.g., the LWR sustainability program, the SMR licensing technical support program, the Consortium for Advanced Simulation of LWRs).
} 
3. Deploy an engineering demonstration reactor for a less-mature reactor technology with the goal of increasing the technology readiness level of the overall system for the longer term

4. Provide an irradiation test reactor to support development and qualification of fuels, materials, and other important components/items (e.g., control rods, instrumentation) of both thermal and fast neutron-based Gen-IV advanced reactor systems

Goals, criteria, and metrics were established to assess these point design options against the strategic objectives. Expert judgment was used to elicit goals, criteria, and metrics from a large group of scientists and engineers from the nuclear community spanning industry, national laboratories, and universities. Different teams comprised of industry and national laboratory partners developed point designs within a standardized framework as part of the study. We report important findings of this study in this section. A number of technology neutral findings are reported first followed by an assessment of options against each identified strategic objective.

\subsubsection{Advanced Reactor Technology Readiness Assessment}

To determine which options were considered, a technology readiness assessment was conducted. The starting point for the assessment was the six Gen-IV advanced reactor technology concepts. The holistic assessment identified four options for consideration as demonstration reactors and two options for consideration as test reactors as part of this study:

- The modular HTGR and SFR can have high enough technology readiness levels to support a commercial demonstration in the near future. These technologies are mature because of the billions of dollars of public and private investment in the U.S. over more than 40 years. These systems are also being built internationally, further confirming the high level of maturity of these systems as evaluated in this study.

- The FHR and LFR are less mature and require additional R\&D and engineering demonstration in the near future. International technology development activities are underway to mature these technologies and technology demonstrations are planned. Other options examined (e.g., GFR) were even lower in maturity or did not have significant commercial interest (e.g., SCWR).

- The test reactor options require a mature base technology. The HTGR and SFR were considered as the thermal neutron spectrum and fast neutron spectrum test reactor options, respectively.

\subsubsection{Deployment Options, Cost and Schedule}

The study identified a step-wise approach to reactor technology deployment that has been used historically in the U.S. and internationally. This historical pattern is shown in Figure 10. Development and deployment of reactor concepts in the U.S. and internationally has followed the following four steps:

- Research and development to prove scientific feasibility of key features associated with fuel, coolant and geometrical configuration. Test reactor irradiation services are particularly important in this phase, although they can be beneficial at each step (e.g., to explore fuel/material options). 
- Engineering demonstration at reduced scale for proof of concept for concepts that have never been built. The goal at this level is to prove the viability of the integrated system. Historically these have been small reactors ( $<50 \mathrm{MWe}$ ). Example past systems include Peach Bottom 1 for HTGRs and EBR-II for SFRs.

- Performance demonstration(s) to establish that scale-up of the system works and to gain operating experience to validate the integral behavior of the system (including fuel cycle in some cases) resulting in proof of performance. Examples past systems include Shippingport for LWRs and Fermi I for SFRs.

- Commercial demonstrations that will be replicated for subsequent commercial offerings if the system works as designed. Example past systems include Yankee-Rowe for LWRs.

Based on the point designs assessed, the recommended deployment strategies depend on the maturity of the underlying advanced reactor technologies. As shown in Figure 11, the HTGR and SFR are based on technologies that underwent engineering and performance demonstration steps to the extent that they put electricity on the grid over a period of many years. They are mature enough to enable deployment of their first modules at commercial scale (the commercial demonstration step) in the early 2030s with additional commercial offerings soon thereafter. Estimates from the vendors suggest it will take 13 to 15 years to achieve operation of the first module at a cost of $\sim \$ 4$ billion, including $\$ 1$ billion in first-time design and licensing. These estimates were found to be largely independent of the technology.

The less-mature technologies, FHR and LFR, are facing a longer technology development path (as shown in Figure 11) to commercial offerings because they need a combination of both the engineering demonstration step and the performance demonstration step through 2040 prior to commercial offerings in $\sim 2050$. As discussed in Section 6.2.3, the details of the development paths are different and represent some flexibility in the strategies available to reactor vendors.

A range of test capabilities will also be needed for these advanced reactors, and will be provided through a combination of both new and existing facilities. For many advanced concepts, one key new facility will be a test reactor that can support fuel and material testing and qualification.

\subsubsection{Licensing Options}

The licensing options also vary by concept maturity. For the mature concepts (HTGR and SFR), both reactor vendors providing demonstration reactor point designs have reported they would pursue a commercial power reactor Class 103 NRC license. Considerable data exist from past demonstration projects and R\&D activities conducted over the past 50 years to support licensing. Both concepts have received draft safety evaluation reports from the NRC, which is evidence of their licensing maturity. The HTGR has been the subject of recent pre-application discussions with NRC as part of the NGNP. A preapplication safety evaluation was completed for the GE PRISM design. Both vendors (AREVA and GEH) plan on licensing the first module using the two-step 10 CFR Part 50 process [1]. They will gain operational experience (e.g., construction, testing, operations, maintenance, etc.) from that module to apply for a design certification and licensing of the follow-on modules using the one-step 10 CFR Part 52 licensing process [2]. 
For the engineering demonstration and test reactors, a Class 104(c) non-power reactor license is an option that may allow for greater regulatory framework flexibility given the state of the technology. However, it's noted that once any of the reactors get larger than 10-20 MWt, NRC could be expected to apply the same level of technical review to the engineering demonstration or test reactor as to a similar size power reactor, due to the potential public risk from the larger source term.

An additional restriction regarding this class of reactor license is that the facility must be used so that no more than $50 \%$ of the annual cost of owning and operating the facility is devoted to the production of materials, products, or energy for sale or commercial distribution. This license type has been used in the past for small university reactors and the NIST research reactor. It is noted that the last large-scale demonstration reactors were built and operated in the U.S. (e.g., Peach Bottom, Fermi-1) before the NRC existed.

\subsection{Promising Options for Each Strategic Objective}

\subsubsection{Strategic Objective 1: Process Heat}

The assessment for the process heat objective identified two discriminators between point designs: suitability and prototypicality for a variety of high-temperature applications and commercially relevant scale of the demonstration. The higher maturity options were favored, with the most promising option being the HTGR because of its high outlet temperature $\left(>700^{\circ} \mathrm{C}\right)$, flexibility for energy applications and its state of development.

Of the point designs in the study, the modular SC-HTGR design by AREVA best supports a process heat (e.g., synfuels) demonstration. The SC-HTGR is a modular, helium-cooled, graphite moderated hightemperature energy supply system. With a $750^{\circ} \mathrm{C}$ reactor outlet temperature, it operates at temperatures much higher than LWRs, but within the range of existing technology demonstrated in previous HTGR projects. Modular HTGRs offer a very high degree of passive safety. The TRISO-coated particle fuel, which retains virtually all fission products at very high temperatures, the tall slender core and low-power density, the inert helium coolant, and the ceramic graphite moderator provide a system that is robust at very high temperature and does not melt even under postulated beyond design basis events. The modular HTGR being passively safe does not rely on AC power during postulated design basis events. The reactor uses an annular prismatic block core to produce $625 \mathrm{MWth}$, which is the largest and most economical system achievable with fully passive heat removal. The SC-HTGR core transfers heat to a steam generator to provide high-temperature, superheated steam at $566^{\circ} \mathrm{C}$ for a variety of process heat applications and electricity generation. The SC-HTGR can be operated in a dedicated process steam supply mode, a dedicated electricity generation mode, or in a cogeneration mode where both high-temperature process steam and electricity are supplied (either for in-plant use or for sale of surplus energy to the grid). In the dedicated electricity generation mode, each module has a nominal output of 272-MWe with a net efficiency of $43.5 \%$. 


\subsubsection{Strategic Objective 2: Extend Natural Resource Utilization and Reduce the Burden of Nuclear Waste}

The assessment for the resource utilization and waste reduction objective identified two discriminators between point designs: suitability and prototypicality for demonstrating high natural resource utilization and commercially relevant scale of the demonstration. The higher maturity options were favored, with the most promising option for resource utilization and waste reduction being the SFR because of its ability to efficiently convert uranium and utilize recycled fuel and its state of development.

Of the point designs in the study, the SFR proposed by GEH best supports the extension of natural resources and reduction of the nuclear waste burden, as well as fulfilling the fundamental mission of efficient and reliable electricity production. The PRISM module is a 471-MWth fast reactor cooled by sodium coupled to a superheated Rankine power cycle with a single helical coil steam generator producing $165 \mathrm{MWe}$ (35\% efficiency). PRISM's extensive design development, state of knowledge, operational experience, and conservative design approach are based on the use of technologies proven by decades of operation and testing of EBR-II and FFTF. The PRISM point design assessed in this study is the same design evaluated by the NRC and issued a draft preliminary safety evaluation report. PRISM supports all of the most promising fuel cycles identified in the recent multi-year DOE fuel cycle Evaluation and Screening study [3]. The PRISM commercial demonstration reactor will start up on U-Zr fuel, which has a high level of technology readiness. To support fuel cycle closure, U-Zr fuel can be quickly followed by U-Pu-Zr fuel and in the future fuel bearing minor actinides. Previous experience gained through the design and operations of EBR-II and FFTF provide a strong technical basis for the PRISM design. The PRISM modularity, inherent passive safety, and commercial scale allow for a relatively low complexity system, which will not be hindered by scaling issues. These features reduce regulatory and financial risks. The inherent safety of metal fueled fast reactors in beyond design basis events was demonstrated at EBR-II.

\subsubsection{Strategic Objective 3: An Engineering Demonstration Reactor for a Less-Mature Reactor Technology}

The ability of engineering demonstration reactors to advance the TRL of a less-mature reactor technology was assessed. Both the FHR and LFR engineering demonstration reactors would significantly advance the TRL towards eventual commercialization for the respective technologies. Significant discriminators between the FHR and LFR point designs related to readiness for an engineering demonstration were not identified in the assessment. However, the distinct approaches that the two design teams took to advancing the TRL were used to inform on the potential pathways to reactor technology development. The FHR and LFR point designs, as engineering demonstration reactors, scored essentially the same in their ability to increase the technology readiness of these less-mature technologies.

The FHR is a class of MSRs that uses solid fuel in low-pressure fluoride salt coolants to produce high-temperature heat with a high degree of inherent safety and significant margins to coolant boiling and fuel damage. The FHR point design proposed by ORNL is a $100 \mathrm{MWth}$, engineering demonstration designed to test key technologies prior to their next step-a performance demonstration. The current goal of the FHR engineering demonstration is to advance the FHR technologies towards commercial 
deployment supporting Strategic Objective 1. It is built using the most-mature component technologies available today and might not be optimized nor configured as a commercial plant. It uses TRISO fuel compacts in graphite blocks cooled by the molten salt FLiBe with an outlet temperature slightly greater than $700^{\circ} \mathrm{C}$. Key features of the FHR demonstration reactor concept are directly relevant and scalable to commercial applications. Active safety systems have been selected for the FHR engineering demonstration because adequate data do not exist to prove performance of passive salt-based heat removal safety systems for licensing purposes. The FHR demonstration reactor will demonstrate passive safety system operation and generate data needed for licensing and deployment of passively safe commercial FHRs. This engineering demonstration is a predecessor to a larger performance demonstration prior to a commercial demonstration and subsequent commercial offerings.

By contrast, the LFR point design proposed by Westinghouse is a much larger power system (500 MWth). The LFR engineering demonstration could advance the LFR concept towards commercial deployment supporting Strategic Objective 1 and/or 2. Initially, the uranium oxide fuel will use D9 cladding and will operate with a lower coolant temperature $\left(510^{\circ} \mathrm{C}\right)$ than intended for future commercial application. Eventually, the fuel will use D9 cladding with an alumina coating to enable higher temperatures, higher flow rates, and higher power conversion efficiency. The inherent safety derives from pool-type integral system design, a bayonet-based passive decay heat removal system, and the favorable thermal properties of lead coolant. The lack of exothermic chemical reaction between lead and air/water eliminates a class of abnormal events. The reactivity feedback behavior provides inherent safety. The high-thermal inertia of the primary system results in very slow transients. This engineering demonstration reactor would then allow for integral testing in a prototypic environment. As confidence is built in its operation and other R\&D occurs in parallel, the flow rate, outlet temperature and power would be increased to values more typical of a commercial LFR. It is anticipated that the outlet temperature would be $\sim 700-750^{\circ} \mathrm{C}$ and the reactor power would be increased to $700 \mathrm{MWth}$. By upgrading technology, the engineering demonstration reactor could be turned into a performance demonstration. If successful, the technology maturation could be accelerated, but risks are higher because not all design features/components can be exchanged if the design were to evolve outside of the anticipated envelope.

As seen in Figure 11, the assessment determined that the FHR and the LFR point design development strategies will take longer to reach commercialization than those associated with the SFR or HTGR.

\subsubsection{Strategic Objective 4: Irradiation Test Reactor}

Water-cooled test reactors have been the workhorse of nuclear fuels and materials testing for thermal reactor systems over the past 50 years. These MTRs produce damage rates (up to $10 \mathrm{dpa} / \mathrm{yr}$ ) sufficient to support most thermal reactor development, but are already operating near full capacity. However, to attain peak doses typical of advanced fast reactors (200 to $500 \mathrm{dpa}$ ), using a water-cooled test reactor would take 20 to 50 years. For advanced fast neutron reactor systems, neutron damage rates are significantly higher because the neutrons are typically not thermalized and the magnitude of the fast neutron flux is much higher than for thermal systems. Fast neutron irradiation capability is largely lacking. 
A water-cooled reactor cannot meet the needs to support research and development of advanced fast reactor designs because it is not possible to achieve the high fast to thermal neutron flux ratio that is needed for the development of any fast spectrum system and to accelerate materials irradiations for both thermal and fast reactors. Furthermore, Gen-IV concepts using coolants other than water may also require fast neutrons for the study of fuels and corrosion control. Closed test loops with such coolants must be carefully designed so as not to significantly perturb the spectrum of the driver core; thus, the closed test loops are generally unavailable and expensive to install in existing reactors.

The assessment for the test reactor objective identified two discriminators between point designs: fast flux levels and irradiation volumes. Both a SFR and a HTGR were examined to determine their ability to provide neutron irradiation services to support nuclear fuels and materials testing for advanced reactor systems. Overall, the SFR test reactor design is the preferred option, because it can provide very high fast neutron flux as well as high-thermal neutron flux in moderated zones to meet many of the needs of both the fast and thermal reactor developers. The SFR test reactor can provide very high fast neutron flux as well as high-thermal neutron flux in moderated zones to meet many of the needs of both the fast and thermal reactor developers. Being a thermal system, the HTGR does not provide a high fast flux but the large size and inert coolant accommodates testing of a wide array of fuels and materials at a very large scale, including half-scale LWR fuel assemblies. Both systems can incorporate multiple test loops to test fuels and materials under different coolant conditions. The impact of the closed loops on the safety and operation of the reactors cannot be fully ascertained until more details about the specific loops are developed. Both point designs produce enough power at relevant temperatures to produce electricity to offset some of the operating costs. Both systems could be licensed under an NRC 104(c) license for test reactors. Design and construction are estimated to take about 10 to 13 years. Cost estimates for these test reactors are both around $\$ 3$ billion and are highly uncertain at this early stage in the design process.

Operating costs for the two systems, including fuel, is estimated to be in the range of $\$ 140$ to 170 million/year, which includes significant costs to execute experiments but does not account for offsetting revenue streams. Beyond construction costs, successful test reactors require an operating budget that allows for cost efficient testing to meet its users' needs and a maintenance budget to ensure the MTR's availability. This entails having both resources and trained personnel who can execute the testing mission. MTRs in Europe (e.g., Halden and in some cases HFR Petten) use standardized test rigs with an array of advanced instrumentation for their irradiations that offer economic solutions for users. (Development of specialized test rigs can take time and money that make development difficult from both a schedule and cost perspective.) They also have sufficient base funding to maintain a trained staff that know how to execute the experiments (which is different than the skill set used to operate the reactor). The new Jules Horowitz Reactor is planning a similar operations funding strategy. The lack of such an approach in current U.S. test reactors, such as Advanced Test Reactor (ATR), has driven the U.S. nuclear industry, and in some cases DOE, to fulfill their nuclear testing needs overseas, largely in Halden. The U.S. DOE could benefit from adopting this operations funding approach for any new U.S. MTR to remain globally competitive and attract domestic and international users to the U.S. for their testing needs. 
A follow-on study is currently in the planning stage to take the next step and evaluate in more detail the need, capabilities and testing requirements, as well as the time frame, for a new irradiation test reactor to support the broad user community (National Laboratories, academia, industry, reactor vendors, supply chain manufactures, material suppliers, the United States Government and the international community.)

\subsection{References}

1. 10 CFR 50, "Domestic Licensing of Production and Utilization Facilities," United States Nuclear Regulatory Commission, December 2, 2015.

2. 10 CFR 52, "Licenses, Certifications, and Approvals for Nuclear Power Plants," United States Nuclear Regulatory Commission, December 2, 2015.

3. Wigeland, R., T. Taiwo, H. Ludewig, M. Todosow, W. Halsey, J. Gehin, R. Jubin, J. Buelt, S. Stockinger, K. Jenni, B. Oakley, Nuclear Fuel Cycle Evaluation and Screening - Final Report, Idaho National Laboratory, INL/EXT-14-31465, 2014. 


\section{Appendix A}

\section{Weightings Related to Goals, Criteria, and Metrics}




\section{Appendix A Weightings Related to Goals, Criteria, and Metrics}

\section{A-1. Weightings Related to Goals, Criteria, and Metrics}

The goals, criteria, and associated metrics used for the demonstration and test reactor evaluations were discussed in Section 2.3 and 2.4 respectively. Weightings related to goals, criteria, and metrics are presented in this appendix.

\section{A-1.1 Process used to Establish Weightings}

Weightings are needed at different stages in the evaluation: a different set of weightings of the goals for each of the four strategic objectives, a set of weightings of all criteria that support a goal, and a set of weightings of all metrics used to measure a specific criterion.

Three groups, one at each laboratory (Idaho National Laboratory, Oak Ridge National Laboratory, and Argonne National Laboratory), established independent weighting sets based on their expertise, understanding of the objectives/goals/criteria, and the discussion about the importance of specific criteria that occurred at the Criteria and Metrics Workshop. The teams also established goal weightings for each strategic objective. Participants were asked to weight each goal relative to a given strategic objective by answering "How important is goal $\mathrm{X}$ to meeting the strategic objective?"

For each of Strategic Objectives 1, 2, and 3 (those related to the demonstration reactor), this approach was used for the five goals initially established for the demonstration reactor. Then, the process was repeated for Strategic Objective 4 and the three goals developed for the test reactor. The weightings for the goals summed to $100 \%$.

Following the weighting of the goals, to establish criteria weightings, participants were asked to weight each criteria relative to the goals by answering "How important is criterion $\mathrm{X}$ to the goal it is supporting?" This was done for each criterion. Within a goal, the criterion weightings summed to $100 \%$. After completing this step, participants were asked to answer "How important is metric A for criterion X?" This was repeated for all metrics associated with a given criterion. When a single metric was used to measure a given criterion, it was automatically given a weight of $100 \%$. The weightings of the metrics for any given criterion summed to $100 \%$, and are independent of the other criteria.

The product of the goal weighting, the criteria weighting and the metric weighting gives the overall weighting of each metric. The weightings established by the three teams were then harmonized and a consistent set was put together for a final review at the next workshop. After thoroughly reviewing the weighting sets and overall weighting of each metric, the group collectively decided to adjust some of the weightings at all three levels (goals, criteria, and metrics). In particular, it was identified that for goals supported only by one or two criteria the initial weighting of the metrics was sometimes higher than intended. Additionally, a new goal was established for the demonstration reactor to better capture reactor capabilities relative to process heat applications (which is highly relevant for Strategic Objective 1). The final version of the weightings is discussed here. 
In addition to the common agreement reached among the group regarding the goals/criteria/metrics and their weightings, sensitivity analyses were performed as part of the evaluation process. The purpose of these analyses was to evaluate if different weightings of the goals and criteria against each strategic objective would lead to selection of a different reactor technology. The results are presented as part of the evaluations in Sections 4 and 5.

\section{A-1.2 Goal Weightings for Demonstration Reactor Strategic Objectives}

Table A-1 lists the weightings of each goal against each of the strategic objectives. As can be seen from the table, the weightings differed depending on the strategic objective. It is important to recognize that if a given goal contains a large number of criteria and metrics, even with a large weighting, the overall weighting of its metrics can be somewhat low. In particular, the overall weighting of the metrics of a given goal may be lower than that of a different goal carrying a lower weighting. Thus, although the weightings were initially established independently at the goal, criteria, and metric levels, it was necessary to consider the entire decision analysis framework when judging the reasonableness of weightings discussed here.

Table A-1. Goal weightings against demonstration reactor strategic objectives.

\begin{tabular}{l|c|c|c}
\multicolumn{1}{c|}{ Goal } & \multicolumn{2}{c}{ Weighting against Stategic Objectives (\%) } \\
\cline { 2 - 4 } & Stategic Objective 1 & Stategic Objective 2 & Stategic Objective 3 \\
\hline $\begin{array}{l}\text { D1. Demonstration Reactor significantly advances the } \\
\text { technology toward a potential commercial plant }\end{array}$ & 25 & 20 & 35 \\
\hline $\begin{array}{l}\text { D2. Demonstration Reactor operations help resolve technical } \\
\text { barriers (e.g. predictability) to advanced reactor economics and } \\
\text { reliability }\end{array}$ & 20 & 20 & 20 \\
\hline $\begin{array}{l}\text { D3. Demonstration Reactor has a robust safety design basis for } \\
\text { licensing }\end{array}$ & 15 & 15 & 15 \\
\hline $\begin{array}{l}\text { D4. Demonstration reactor supports demonstration of } \\
\text { technology and system integration (enhancing immediate, } \\
\text { intermediate and long term value of the project) }\end{array}$ & 20 & 20 & 20 \\
\hline $\begin{array}{l}\text { D5. Demonstrate reactor stage of advanced fuel cycle } \\
\begin{array}{l}\text { D6. Demonstrate high temperature reactor process heat } \\
\text { applications }\end{array}\end{array}$ & 0 & 25 & 5 \\
\hline
\end{tabular}

For Strategic Objective 1, which is related to deploying a process heat demonstration, the first goal related to advancing technology has the highest weighting at $25 \%$. Goal 6 , related to demonstrating process heat applications, Goal 2, related to resolving technical barriers to advance reactor economics and reliability and Goal 4, related to technology demonstration and system integration, each carry the same weighting of $20 \%$. However Goal 6 , having fewer metrics than Goals 2 and 4, has a higher overall weighting of its criteria. Goal 3, related to a robust safety design basis, was given a weighting of $15 \%$, but given it has only two metrics, the overall weighting makes its metrics as important as those of Goal 1. Goal 5 , related to the fuel cycle, was given a weight of $0 \%$ since it was deemed non-relevant for the process heat strategic objective. Logically, demonstrating process heat applications was seen as a particularly important goal for Strategic Objective 1 followed equally by technology advancement, safety, and licensing. 
For Strategic Objective 2, related to actinide management and fuel resource utilization, Goal 5, related to the fuel cycle, was given the highest weight, $25 \%$, as expected. Equal weightings of $20 \%$ each were assigned to Goal 1, related to technology advancement, to Goal 2, related to resolving technical barriers to advance reactor economics and reliability, and to Goal 4, related to technology demonstration and system integration. Among these three goals, the metrics for Goal 4 have a lower overall weighting than those for Goals 1 and 2. Although Goal 3 received a 15\% weighting, the overall weightings of its metrics are larger than those of the metrics of Goals 1 and 2. Goal 6 related to demonstrating process heat applications was given a weight of $0 \%$ since it was deemed non-relevant for Strategic Objective 2. Thus, the focus here is on successful fuel recycle demonstration followed by safety and licensing, and operational information to inform reactor economics, reliability, and safety.

For Strategic Objective 3, related to deploying an engineering demonstration to mature a reactor technology for the longer term, the highest weighting (35\%) was logically given to Goal 1 related to advancing the technology. Goals 2 and 4, related to resolving technical barriers and technology demonstration and system integration, were each given weightings of $20 \%$. Overall weightings of the metrics of Goal 2 are larger than those of the metrics of Goal 4, because of the different number of metrics. Goal 3 related to a robust safety design basis was assigned a weighting of $15 \%$; however, having only two metrics, their overall weightings are larger than for the metrics of Goals 2 and 4 . Goal 5 related to fuel recycling and Goal 6 related to demonstrating process heat applications were both given a weighting of $5 \%$ to reflect their relative low importance for Strategic Objective 3. Advancing the technology was seen as most important for this objective given the less-mature status of the reactor technology, followed by having a robust safety design basis and resolving technology demonstration and system integration issues. These are all critical goals for a maturing reactor technology to be worthy of advancement in the long term.

\section{A-1.3 Criteria and Metrics Weightings Related to Demonstration Reactor Goals}

Criteria were developed to expand in more detail the demonstration reactor goals. The weightings of each criterion relative to the goal it supports are shown in Table A-2. For Goal 1, related to advancing technology, five criteria were established. The criterion related to demonstrating the safety behavior of the commercial system was given the greatest weight at $35 \%$. A $20 \%$ weighting was assigned to the criterion related to using scalable technology options. The final three criteria related to scalable maintenance approaches, scalable fabrication approaches, and having sufficient instrumentation and data for code validation, were each given $15 \%$ weighting. With only one metric for each criterion, each of them received $100 \%$ weighting.

For Goal 2, related to resolving technical barriers related to economics through operation, three criteria were established: project costs and schedule, operational costs, and reliability of operations. The project costs and schedule, consisting of two metrics, was found to be the most important and received a weighting of $55 \%$. The reliability of operations was considered the second-most important criterion and was given $25 \%$ weighting. The operational cost criteria received the remaining $20 \%$ weighting. The first criterion (Criterion 2.1), related to project costs and schedule, has two metrics: one related to cost and another related to schedule. Each metric is given a $50 \%$ weighting. Other criteria having a single metric, their metric is given a $100 \%$ weighting. 
For Goal 3, there was only one criterion related to a robust safety design basis; thus it was given a $100 \%$ weighting. Its first metric, related to the ability of the reactor to address key licensing issues, for follow-up commercial units is considered the most important and is given a $65 \%$ weighting. The second metric related to the emergency planning zone (EPZ) size is given the remaining $35 \%$ weighting.

Table A-2. Criteria weightings related to demonstration reactor goals.

\begin{tabular}{|c|c|c|}
\hline Goal & Criteria & $\begin{array}{l}\text { Weighting within } \\
\text { Goal (\%) }\end{array}$ \\
\hline \multirow{5}{*}{$\begin{array}{l}\text { D1. Demonstration Reactor significantly advances } \\
\text { the technology toward a potential commercial plant }\end{array}$} & $\begin{array}{l}\text { D1.1 Capability to demonstrate safety behavior of commercial } \\
\text { system }\end{array}$ & 35 \\
\hline & D1.2 Detailed instrumentation and data for code validation tests & 15 \\
\hline & D1.3 Scalable technology choices & 20 \\
\hline & D1.4 Scalable maintenance techniques and schedules & 15 \\
\hline & D1.5 Scalable fabrication options & 15 \\
\hline \multirow{3}{*}{$\begin{array}{l}\text { D2. Demonstration Reactor operations help resolve } \\
\text { technical barriers (e.g. predictability) to advanced } \\
\text { reactor economics and reliability }\end{array}$} & D2.1 Project costs and Schedule & 55 \\
\hline & D2.2 Operational costs & 20 \\
\hline & D2.3 Reliability of operations & 25 \\
\hline $\begin{array}{l}\text { D3. Demonstration Reactor has a robust safety } \\
\text { design basis for licensing }\end{array}$ & D3.1 Licensed by Nuclear Regulatory Commission & 100 \\
\hline \multirow{4}{*}{$\begin{array}{l}\text { D4. Demonstration reactor supports demonstration } \\
\text { of technology and system integration (enhancing } \\
\text { immediate, intermediate and long term value of the } \\
\text { project) }\end{array}$} & D4.1 Facilitate component demonstration & 35 \\
\hline & $\begin{array}{l}\text { D4.2 Ability to demonstrate alternate core configurations and } \\
\text { fuel types }\end{array}$ & 30 \\
\hline & $\begin{array}{l}\text { D4.3 R\&D required before demonstration reactor } \\
\text { construction/operation }\end{array}$ & 20 \\
\hline & $\begin{array}{l}\text { D4.4 Provide ability to conduct irradiations of materials and } \\
\text { fuels }\end{array}$ & 15 \\
\hline \multirow{4}{*}{$\begin{array}{l}\text { D5. Demonstrate reactor stage of advanced fuel } \\
\text { cycle }\end{array}$} & D5.1 Ability to demonstrate utilization of natural resources & 45 \\
\hline & D5.2 Prototypic fuel fabrication & 20 \\
\hline & D5.3 Prototypic fuel performance & 20 \\
\hline & D5.4 Used fuel handling & 15 \\
\hline \multirow{2}{*}{$\begin{array}{l}\text { D6. Demonstrate high temperature reactor process } \\
\text { heat applications }\end{array}$} & $\begin{array}{l}\text { D6.1 Demonstrate integration with various energy conversion } \\
\text { systems or process heat for industrial applications }\end{array}$ & 50 \\
\hline & D6.2 Ability to demonstrate industrial heat applications & 50 \\
\hline
\end{tabular}

For Goal 4, related to technology demonstration and system integration, four criteria were established. A 35\% weighting was given to the criterion associated with facilitating component demonstration, a key objective of the overall demonstration of an advanced reactor system. The ability to demonstrate alternative core configuration and fuel types was given a $30 \%$ weighting. This criterion deals with the flexibility of the demonstration system. The criterion related to research and development (R\&D) 
required prior to construction, representing the maturity of the technology, was given a $20 \%$ weighting. Finally, the ability of the demonstration reactor to conduct irradiations of fuel and materials under prototypic conditions was given a weighting of $15 \%$. This last criterion was seen as not critical to the demonstration reactor mission, but it would enhance the long-term value of the demonstration system.

The second criterion (Criterion D4.2), related to alternative core configurations and fuel types, has two metrics, one for core configuration and one for fuel types. They are each given a $50 \%$ weighting. The third criterion (Criterion D4.3), related to R\&D required prior to construction, has two metrics: one related to R\&D time and the other one related to R\&D cost. Each criterion is given a weighting of $50 \%$. The fourth criterion (Criterion D4.4), related to the ability to conduct irradiations, has three metrics related to fast flux conditions, thermal flux conditions, and irradiation volume and length. The most important metric is considered to be the fast flux and is given a weighting of $40 \%$. The irradiation volume and length metric is considered slightly less important and received a weighting of $35 \%$. The thermal flux metric is given the remaining weighting of $25 \%$.

For Goal 5, related to demonstrating advanced reactor fuel cycles, four criteria were established. The most important one is the ability to demonstrate utilization of natural resources, which carries a weighting of $45 \%$. The demonstration reactor using prototypic fuel fabrication techniques and demonstrating prototypic fuel performance were each weighted $20 \%$. Spent fuel handling was weighted $15 \%$. There is a single metric for each criterion, so they each received a $100 \%$ weighting.

For Goal 6, related to demonstrating high temperature process heat applications, two criteria were established. The ability to demonstrate integration with various energy conversion systems or industrial applications and the ability to demonstrate industrial heat applications both received an equal weighting of $50 \%$. There is a single metric for each criterion so they each received a $100 \%$ weighting.

\section{A-1.4 Goals Weightings for Test Reactor Strategic Objective}

Table A-3 lists the weightings of each goal against Strategic Objective 4, which is related to providing an irradiation test bed to support development and qualification of fuels, materials, and other important components/items. Goal 1, relating to how well the test reactor provides irradiation test services for a variety of reactor and fuel technology options, is logically the most important of the goals and is given a weighting of $70 \%$. Goal 2 , related to reliable operations and cost effective construction, and operation is considered somewhat important and is given a weighting of $25 \%$. The capability of the test reactor to provide secondary missions, Goal 3 , is assigned a weighting of $5 \%$. Although this value might appear small compared to the other two goals, it is composed of a single metric resulting in an overall weighting comparable to that of some of the metrics of the other goals. These goal weightings reflect the importance of the reactor facility to meet its mission as a test reactor, followed by its ability to do so in a reliable and economic manner. The ability to have secondary missions is useful since it provides additional value and potential revenue for the facility. 
Table A-3. Goal weightings for test reactor strategic objective.

\begin{tabular}{|l|c|}
\hline \multicolumn{1}{|c|}{ Goal } & $\begin{array}{c}\text { Weighting } \\
\text { against Stategic } \\
\text { Objective 4 (\%) }\end{array}$ \\
\hline $\begin{array}{l}\text { T1. Test Reactor provides irradiation services for a } \\
\text { variety of reactor and fuel technology options }\end{array}$ & 70 \\
\hline $\begin{array}{l}\text { T2. Test Reactor will be built and operated reliably } \\
\text { and in a sustainable cost-effective manner. (Need to } \\
\text { be able to justify initial and long-term expense) }\end{array}$ \\
\hline $\begin{array}{l}\text { T3. Capability to accommodate secondary missions } \\
\text { (electricity, isotope production, etc.) of modest value } \\
\text { (million dollar) without compromising primary mission } \\
\text { of testing fuels and materials for advanced reactor } \\
\text { technologies }\end{array}$ \\
\hline
\end{tabular}

\section{A-1.5 Criteria and Metrics Weightings Related to Test Reactor Goals}

Criteria were developed to expand in more detail the test reactor goals. The weightings of each criterion relative to its goal are shown in Table A-4. For Goal T1, related to providing irradiation services, two criteria were established: irradiation conditions and supporting diverse testing configurations.

Criterion T1.1 was given a weighting of $65 \%$ and Criterion T1.2 was assigned a weighting of $35 \%$ weight. Given that Criterion T1.1 is made of five metrics and that Criteria T1.2 is made of the metrics, the overall weightings of the metrics of the two criteria are comparable. 
Table A-4. Criteria weightings related to test reactor goals.

\begin{tabular}{|c|c|c|}
\hline Goal & Criteria & $\begin{array}{c}\text { Weighting within Goal } \\
4(\%)\end{array}$ \\
\hline \multirow{2}{*}{$\begin{array}{l}\text { T1. Test Reactor provides irradiation services for } \\
\text { a variety of reactor and fuel technology options }\end{array}$} & T1.1 Irradiation conditions & 65 \\
\hline & $\begin{array}{l}\text { T1.2 Support diverse irradiation testing configurations } \\
\text { concurrently (accommodate various sizes and tailor } \\
\text { irradiation parameters to wide group of simultaneous } \\
\text { users) }\end{array}$ & 35 \\
\hline \multirow{3}{*}{$\begin{array}{l}\text { T2. Test Reactor will be built and operated } \\
\text { reliably and in a sustainable cost-effective } \\
\text { manner. (Need to be able to justify initial and } \\
\text { long-term expense) }\end{array}$} & $\begin{array}{l}\text { T2.1 Project costs and schedule (including design, } \\
\text { licensing, R\&D, construction, and contingency that } \\
\text { reflects technical maturity of the concept) }\end{array}$ & 35 \\
\hline & $\begin{array}{l}\text { T2.2 Operational costs and schedule (including } \\
\text { contingency that reflects technical maturity of the } \\
\text { concept) }\end{array}$ & 30 \\
\hline & T2.3 Reliability of operations & 35 \\
\hline $\begin{array}{l}\text { T3. Capability to accommodate secondary } \\
\text { missions (electricity, isotope production, etc.) of } \\
\text { modest value (million dollar) without } \\
\text { compromising primary mission of testing fuels and } \\
\text { materials for advanced reactor technologies }\end{array}$ & T3.1 Identification of secondary missions & 100 \\
\hline
\end{tabular}

The weightings of the five metrics within Criterion T1.1 are shown in Table A-5. The fast flux irradiation conditions metric is the most important and is given a weighting of $35 \%$, followed by the irradiation volume and length, which received a weighting of $25 \%$. The thermal flux irradiation conditions metric is slightly less important, partly due to the fact that thermal irradiation capabilities are already available in other reactors in the United States and abroad, and is given a weighting of $20 \%$. Cycle length and the ability to test prototypic and bounding conditions are deemed to have a lower importance and are each given a weighting of $10 \%$.

Table A-5. Weightings of the metrics within Criterion T1.1.

\begin{tabular}{|l|l|c|}
\hline \multicolumn{2}{|c|}{ Metric } & $\begin{array}{c}\text { Weighting within } \\
\text { Criteria (\%) }\end{array}$ \\
\hline T1.1.1 & Fast flux conditions & 35 \\
\hline T1.1.2 & Thermal flux conditions (<0.625 eV) & 20 \\
\hline T1.1.3 & Irradiation volume and length & 25 \\
\hline T1.1.4 & Maximum sustainable time at power (cycle length) & 10 \\
\hline T1.1.5 & Provisions for testing prototypic/bounding conditions & 10 \\
\hline
\end{tabular}


The weightings of the three metrics within Criterion T1.2 are shown in Table A-6. The number of test zones and the number of distinct irradiation test loops are both very important characteristics of a test reactor since they are related to the number of simultaneous irradiation experiments that can be run at the same time. Both those metrics are given a weighting of $40 \%$. The ability to insert/retrieve a specimen at power, while a desirable feature, was viewed as less important and is given a weighting of $20 \%$.

Table A-6. Weightings of the metrics within Criterion T1.2.

\begin{tabular}{|l|l|c|}
\hline \multicolumn{2}{|c|}{ Metric } & $\begin{array}{c}\text { Weighting within } \\
\text { Criteria (\%) }\end{array}$ \\
\hline T1.2.1 & Number of test zones & 40 \\
\hline T1.2.2 & Number and type of irradiation test loops & 40 \\
\hline T1.2.3 & Ability to insert/retrieve irradiation specimen at power & 20 \\
\hline
\end{tabular}

For Goal T2, related to reliable and cost effective operation, three criteria were established: project cost and schedule, operational costs, and reliability of operations. Criterion T2.1 related to project costs and schedule has two metrics: one related to project cost and one to construction schedule. The project cost was considered the most important; thus, it received a weighting of $70 \%$, and the construction schedule received a weighting of $30 \%$. For Criteria T2.2 and T2.3, there is only one metric for each criterion so they received a weighting of $100 \%$.

For Goal 3 related to secondary missions, there is only one criterion and is thus given a $100 \%$ weighting. There is one metric for this criterion so it also received a $100 \%$ weighting.

\section{A-1.6 Demonstration Reactor Metric Bins}

The following section identifies the three scoring bins used for the metrics defined for the demonstration reactor evaluation. (Only the metrics are listed below).

\begin{tabular}{|l|c|c|c|}
\hline \multicolumn{1}{|c|}{ Metric/Score } & $\mathbf{9}$ & $\mathbf{5}$ & $\mathbf{1}$ \\
\hline $\begin{array}{l}\text { Metric D1.1.1. } \\
\text { Does the } \\
\text { demonstration } \\
\text { system have safety } \\
\text { characteristics and } \\
\text { systems/component } \\
\text { s expected in the } \\
\text { commercial plant? }\end{array}$ & $\begin{array}{c}\text { Demo replicates the } \\
\text { passive and inherent } \\
\text { safety characteristics } \\
\text { and has prototypic } \\
\text { systems/components }\end{array}$ & $\begin{array}{c}\text { Demo has some of the } \\
\text { passive and inherent } \\
\text { safety characteristics } \\
\text { and the resultant safety } \\
\text { behavior of Demo can } \\
\text { be confidently scaled to } \\
\text { the commercial system }\end{array}$ & $\begin{array}{c}\text { Safety behavior of } \\
\text { Demo has important } \\
\text { non-scalable aspects }\end{array}$ \\
\hline $\begin{array}{l}\text { Metric D1.2.1 } \\
\text { Does the design } \\
\text { have adequate } \\
\text { instrumentation and } \\
\text { will it gather } \\
\text { appropriate data for } \\
\text { code validation } \\
\text { tests? }\end{array}$ & $\begin{array}{c}\text { High fidelity } \\
\text { performance and safety } \\
\text { data to validate } \\
\text { models }\end{array}$ & $\begin{array}{c}\text { Some instrumentation } \\
\text { and data to validate } \\
\text { performance and safety } \\
\text { models }\end{array}$ & $\begin{array}{c}\text { Limstrumentation and } \\
\text { data to validate } \\
\text { performance and } \\
\text { safety models }\end{array}$ \\
& & & \\
\hline
\end{tabular}




\begin{tabular}{|c|c|c|c|}
\hline Metric/Score & 9 & 5 & 1 \\
\hline $\begin{array}{l}\text { Metric D1.3.1. } \\
\text { Does the design } \\
\text { implement } \\
\text { technology } \\
\text { selections that are } \\
\text { prototypic or } \\
\text { scalable to } \\
\text { commercial unit? }\end{array}$ & Prototypic & Scalable & Neither \\
\hline $\begin{array}{l}\text { Metric D1.4.1 } \\
\text { Does the design } \\
\text { have maintenance } \\
\text { approaches that are } \\
\text { prototypic or } \\
\text { scalable to } \\
\text { commercial unit? }\end{array}$ & Prototypic & Scalable & Neither \\
\hline $\begin{array}{l}\text { Metric D1.5.1 } \\
\text { Does the design use } \\
\text { prototypic or } \\
\text { scalable } \\
\text { technologies in the } \\
\text { fabrication of } \\
\text { important systems } \\
\text { and components? }\end{array}$ & Prototypic & Scalable & Neither \\
\hline $\begin{array}{r}\text { Metric D2.1.1 } \\
\text { Project cost } \\
\end{array}$ & Prototypic & Scalable & Neither \\
\hline $\begin{array}{l}\text { Metric D2.1.2 } \\
\text { Project Schedule - } \\
\text { The time from today } \\
\text { to first operation }\end{array}$ & $<10$ years & $10-15$ years & $>15$ years \\
\hline $\begin{array}{l}\text { Metric D2.2.1 } \\
\text { Annual operating } \\
\text { costs } \\
\end{array}$ & $\begin{array}{c}<\$ 0 / \mathrm{MWt}-\mathrm{h}, \text { (revenue } \\
\text { exceeds cost) }\end{array}$ & $\$ 0-10 / M W t-h$ & $>\$ 10 / \mathrm{MWt}-\mathrm{h}$ \\
\hline $\begin{array}{l}\text { Metric D2.3.1. } \\
\text { Availability factor }\end{array}$ & $>90 \%$ & $70-90 \%$ & $<70 \%$ \\
\hline $\begin{array}{l}\text { Metric D3.1.1 } \\
\text { Ability to address } \\
\text { key licensing issues } \\
\text { for follow-on } \\
\text { commercial units }\end{array}$ & $\begin{array}{l}\text { Demonstration unit can } \\
\text { address most of key } \\
\text { licensing issues for } \\
\text { follow-on commercial } \\
\text { units }\end{array}$ & $\begin{array}{l}\text { Demonstration unit can } \\
\text { address some of key } \\
\text { licensing issues for } \\
\text { follow-on commercial } \\
\text { units }\end{array}$ & $\begin{array}{l}\text { Demonstration unit can } \\
\text { address limited } \\
\text { number of key } \\
\text { licensing issues for } \\
\text { follow-on commercial } \\
\text { units }\end{array}$ \\
\hline $\begin{array}{c}\text { Metric D3.1.2 } \\
\text { EPZ size }\end{array}$ & $\mathrm{EPZ}<400 \mathrm{~m}$ & $\begin{array}{l}\text { EPZ between } 400 \mathrm{~m} \\
\text { and } 16 \mathrm{~km}\end{array}$ & $\mathrm{EPZ}$ at $16 \mathrm{~km}$ \\
\hline $\begin{array}{l}\text { Metric D4.1.1 } \\
\text { Demonstrating } \\
\text { (prototypic or } \\
\text { scalable) integral } \\
\text { component } \\
\text { performance. }\end{array}$ & Prototypic & Scalable & Neither \\
\hline
\end{tabular}




\begin{tabular}{|c|c|c|c|}
\hline Metric/Score & 9 & 5 & 1 \\
\hline $\begin{array}{l}\text { Metric D4.2.1 } \\
\text { Number of } \\
\text { alternative core } \\
\text { configurations } \\
\end{array}$ & More than 2 & $1-2$ & None \\
\hline $\begin{array}{l}\text { Metric D4.2.2 } \\
\text { Number of } \\
\text { alternative fuel } \\
\text { types }\end{array}$ & More than 2 & $1-2$ & None \\
\hline $\begin{array}{c}\text { Metric D4.3.1 } \\
\text { R\&D time } \\
\end{array}$ & $0-5$ years & $5-10$ years & $>10$ years \\
\hline $\begin{array}{c}\text { Metric } \mathbf{D} 4.3 .2 \\
\text { R\&D cost }\end{array}$ & $<\$ 250 \mathrm{M}$ & $\$ 250-500 \mathrm{M}$ & $>\$ 500 \mathrm{M}$ \\
\hline $\begin{array}{l}\text { Metric D4.4.1 } \\
\text { Fast flux conditions } \\
\text { at test location }\end{array}$ & $\begin{array}{c}>5 \times 10^{15} \mathrm{n} / \mathrm{cm}^{2}-\mathrm{s} \text { fast } \\
(>0.1 \mathrm{MeV})\end{array}$ & $\begin{array}{c}5 \times 10^{14} \text { to } 5 \times 10^{1} \\
\mathrm{n} / \mathrm{cm}^{2} \text {-s fast }(>0.1 \mathrm{Mev})\end{array}$ & $\begin{array}{l}<5 \times 10^{14} \text { fast } \\
(>0.1 \mathrm{MeV})\end{array}$ \\
\hline $\begin{array}{l}\text { Metric D4.4.2 } \\
\text { Thermal Flux } \\
\text { conditions at test } \\
\text { location } \\
\end{array}$ & $>5 \times 10^{14} \mathrm{n} / \mathrm{cm}^{2}-\mathrm{s}$ thermal & $\begin{array}{c}1 \text { to } 5 \times 10^{14} \mathrm{n} / \mathrm{cm}^{2}-\mathrm{s} \\
\text { thermal }\end{array}$ & $<1 \times 10^{14}$ thermal \\
\hline $\begin{array}{l}\text { Metric D4.4.3 } \\
\text { Irradiation volumes } \\
\text { and length }\end{array}$ & $\begin{array}{l}\text { Volume }>10 \text { liters } \\
\text { Length }>2 \text { meter }\end{array}$ & $\begin{array}{l}5 \text { to } 10 \text { liters volume } \\
0.5 \text { to } 2 \text { meter length }\end{array}$ & $\begin{array}{c}\text { Volume }<5 \text { liters } \\
\text { Length }<0.5 \mathrm{~m}\end{array}$ \\
\hline $\begin{array}{l}\text { Metric D5.1.1 } \\
\text { Use of fuel natural } \\
\text { resources }\end{array}$ & $<20 \mathrm{MT}-\mathrm{U} / \mathrm{GWeyr}$ & 20-150 MT-U/GWeyr & >150 MT-U/GWeyr \\
\hline $\begin{array}{l}\text { Metric D5.2.1. } \\
\text { Is the fuel } \\
\text { fabrication } \\
\text { approach prototypic } \\
\text { or scalable to } \\
\text { commercial unit? }\end{array}$ & Prototypic & Scalable & Neither \\
\hline $\begin{array}{l}\text { Metric D5.3.1 } \\
\text { Is the anticipated } \\
\text { fuel performance } \\
\text { prototypic or } \\
\text { scalable to } \\
\text { commercial unit? }\end{array}$ & Prototypic & Scalable & Neither \\
\hline $\begin{array}{l}\text { Metric D5.4.1 } \\
\text { Is the spent fuel } \\
\text { handling prototypic } \\
\text { or scalable to } \\
\text { commercial unit? }\end{array}$ & Prototypic & Scalable & Neither \\
\hline
\end{tabular}




\begin{tabular}{|c|c|c|c|}
\hline Metric/Score & $\mathbf{9}$ & $\mathbf{5}$ & $\mathbf{1}$ \\
\hline $\begin{array}{c}\text { Metric D6.1.1 } \\
\text { Number of energy } \\
\text { conversion systems } \\
\text { or industrial } \\
\text { applications }\end{array}$ & More than 3 & $1-3$ & None \\
\hline $\begin{array}{l}\text { Metric D6.2.1 } \\
\text { Coolant outlet } \\
\text { temperature }\end{array}$ & $>700^{\circ} \mathrm{C}$ & $400-700^{\circ} \mathrm{C}$ & $<400^{\circ} \mathrm{C}$ \\
\hline
\end{tabular}

\section{A-1.7 Test Reactor Metric Bins}

The following section identifies the three scoring bins used for the metrics defined for the test reactor evaluation.

\begin{tabular}{|c|c|c|c|}
\hline Metric/Score & 9 & 5 & 1 \\
\hline $\begin{array}{l}\text { Metric T1.1.1 } \\
\text { Fast flux conditions }\end{array}$ & $\begin{array}{c}>5 \times 10^{15} \mathrm{n} / \mathrm{cm}^{2}-\mathrm{s} \text { fast } \\
(>0.1 \mathrm{MeV})\end{array}$ & $\begin{array}{c}5 \times 10^{14} \text { to } 5 \times 10^{15} \mathrm{n} / \mathrm{cm}^{2}- \\
\mathrm{s} \text { fast }(>0.1 \mathrm{Mev})\end{array}$ & $\begin{array}{c}<5 \times 10^{14} \text { fast }(>0.1 \\
\mathrm{MeV})\end{array}$ \\
\hline $\begin{array}{l}\text { Metric T1.1.2 } \\
\text { Thermal flux } \\
\text { conditions }(0.625 \\
\mathrm{eV}) \\
\end{array}$ & $\begin{array}{c}>5 \times 10^{14} \mathrm{n} / \mathrm{cm}^{2}-\mathrm{s} \\
\text { thermal }\end{array}$ & $\begin{array}{c}1 \text { to } 5 \times 10^{14} \mathrm{n} / \mathrm{cm}^{2}-\mathrm{s} \\
\text { thermal }\end{array}$ & $<1 \times 10^{14}$ thermal \\
\hline $\begin{array}{l}\text { Metric T1.1.3 } \\
\text { Irradiation volumes } \\
\text { and length for } \\
\text { largest test location }\end{array}$ & $\begin{array}{l}\text { Volume }>10 \text { liters } \\
\text { Length }>2 \text { meter }\end{array}$ & $\begin{array}{l}5 \text { to } 10 \text { liters volume } \\
0.5 \text { to } 2 \text { meter length }\end{array}$ & $\begin{array}{c}\text { Volume }<5 \text { liters } \\
\text { Length }<0.5 \mathrm{~m}\end{array}$ \\
\hline $\begin{array}{l}\text { Metric T1.1.4 } \\
\text { Maximum } \\
\text { sustainable time at } \\
\text { power, to provide a } \\
\text { time-at-power for a } \\
\text { single irradiation } \\
\text { (i.e., cycle length) }\end{array}$ & $>90$ days & 45 to 90 days & $<45$ days \\
\hline $\begin{array}{l}\text { Metric T1.1.5 } \\
\text { Provisions for } \\
\text { testing prototypic } \\
\text { and bounding } \\
\text { conditions } \\
\text { (Temperature, } \\
\text { Coolant, Chemistry) }\end{array}$ & $\begin{array}{l}\text { Prototypic and } \\
\text { bounding for different } \\
\text { reactor coolants }\end{array}$ & $\begin{array}{l}\text { Prototypic and } \\
\text { bounding for base test } \\
\text { reactor coolant }\end{array}$ & $\begin{array}{l}\text { Not prototypic or } \\
\text { bounding }\end{array}$ \\
\hline $\begin{array}{l}\text { Metric T1.2.1 } \\
\text { Number of test zones }\end{array}$ & $>25$ locations & 10 to 25 locations & $<10$ locations \\
\hline $\begin{array}{l}\text { Metric T1.2.2. } \\
\text { Number and type of } \\
\text { distinct irradiation } \\
\text { test loops each with } \\
\text { a different cooling } \\
\text { system } \\
\text { independent of the }\end{array}$ & 3 or more & 1 or 2 & None \\
\hline
\end{tabular}




\begin{tabular}{|c|c|c|c|}
\hline Metric/Score & $\mathbf{9}$ & $\mathbf{5}$ & $\mathbf{1}$ \\
\hline $\begin{array}{l}\text { primary reactor } \\
\text { coolant }\end{array}$ & At power (e.g., rabbit) & $\begin{array}{c}\text { Limited handling } \\
\text { capability }\end{array}$ & Only at shutdown \\
\hline $\begin{array}{l}\text { Metric T1.2.3. } \\
\text { Ability to } \\
\text { insert/retrieve } \\
\text { irradiation } \\
\text { specimen while } \\
\text { staying at power }\end{array}$ & $<\$ 2.5 \mathrm{~B}$ & $10-15$ years & $>15$ years \\
\hline $\begin{array}{l}\text { Metric T2.1.1 } \\
\text { Project cost }\end{array}$ & $<10$ years & & \\
\hline $\begin{array}{l}\text { Metric T2.1.2 } \\
\text { Project Schedule - } \\
\text { The time from today } \\
\text { to first operation }\end{array}$ & $<\$ 100 \mathrm{M} / \mathrm{yr}$ & $\$ 100-150 \mathrm{M} / \mathrm{yr}$ & $>\$ 150 \mathrm{M} / \mathrm{yr}$ \\
\hline $\begin{array}{l}\text { Metric T2.2.1 } \\
\text { Annual operating } \\
\text { costs }\end{array}$ & $>80 \%$ & $60-80 \%$ & $<60 \%$ \\
\hline $\begin{array}{l}\text { Metric T2.3.1 } \\
\text { Availability factor }\end{array}$ & Sale of energy products & Other secondary & None \\
\hline $\begin{array}{l}\text { Metric T3.1.1 } \\
\text { Number of } \\
\text { secondary missions }\end{array}$ & & missions & \\
\hline
\end{tabular}


Appendix B

\section{Technology Readiness Levels used in this Assessment}




\section{Appendix B \\ Technology Readiness Levels used in this \\ Assessment}

\section{B-1. Demonstration Reactor Goals, Criteria, and Metrics}

Department of Energy (DOE) Guide 413.3-4A was developed to assist individuals and teams involved in conducting technology readiness assessments and developing technology maturation plans for the DOE capital acquisition assets subject to DOE O 413.3B, "Program and Project Management for the Acquisition of Capital Assets."

The complete guide can be obtained from DOE and, as of the date of issue of this document, downloaded from the DOE website at https://www.directives.doe.gov/directives-documents/400-series/0413.3-EGuide-04a.

The following table was extracted from the guide.

\begin{tabular}{|c|c|c|c|}
\hline $\begin{array}{c}\text { Relative Level } \\
\text { of Technology } \\
\text { Development }\end{array}$ & TRL & $\begin{array}{c}\text { TRL } \\
\text { Definition }\end{array}$ & Description \\
\hline $\begin{array}{l}\text { System } \\
\text { Operations }\end{array}$ & TRL 9 & $\begin{array}{l}\text { Actual system } \\
\text { operated over the } \\
\text { full range of } \\
\text { expected mission } \\
\text { conditions. }\end{array}$ & $\begin{array}{l}\text { The technology is in its final form and operated under the } \\
\text { full range of operating mission conditions. Examples } \\
\text { include using the actual system with the full range of } \\
\text { wastes in hot operations. }\end{array}$ \\
\hline $\begin{array}{l}\text { System } \\
\text { Commissioning }\end{array}$ & TRL 8 & $\begin{array}{l}\text { Actual system } \\
\text { completed and } \\
\text { qualified through } \\
\text { test and } \\
\text { demonstration. }\end{array}$ & $\begin{array}{l}\text { The technology has been proven to work in its final form } \\
\text { and under expected conditions. In almost all cases, this } \\
\text { technology readiness level (TRL) represents the end of } \\
\text { true system development. Examples include } \\
\text { developmental testing and evaluation of the system with } \\
\text { actual waste in hot commissioning. Supporting information } \\
\text { includes operational procedures that are virtually } \\
\text { complete. An operational readiness review has been } \\
\text { successfully completed prior to the start of hot testing. }\end{array}$ \\
\hline
\end{tabular}




\begin{tabular}{|c|c|c|c|}
\hline $\begin{array}{l}\text { Relative Level } \\
\text { of Technology } \\
\text { Development }\end{array}$ & TRL & $\begin{array}{c}\text { TRL } \\
\text { Definition }\end{array}$ & Description \\
\hline $\begin{array}{l}\text { System } \\
\text { Commissioning } \\
\text { (cont'd) }\end{array}$ & TRL 7 & $\begin{array}{l}\text { Full-scale, similar } \\
\text { (prototypical) } \\
\text { system } \\
\text { demonstrated in } \\
\text { relevant } \\
\text { environment }\end{array}$ & $\begin{array}{l}\text { This represents a major step up from TRL } 6 \text {, requiring } \\
\text { demonstration of an actual system prototype in a relevant } \\
\text { environment. Examples include testing a full-scale } \\
\text { prototype in the field with a range of simulants in cold } \\
\text { commissioning. Supporting information includes results } \\
\text { from the full-scale testing and analysis of the differences } \\
\text { between the test environment, and analysis of what the } \\
\text { experimental results mean for the eventual operating } \\
\text { system/environment. Final design is virtually complete. }\end{array}$ \\
\hline $\begin{array}{l}\text { Technology } \\
\text { Demonstration }\end{array}$ & TRL 6 & $\begin{array}{l}\text { Engineering/ } \\
\text { pilot-scale, similar } \\
\text { (prototypical), } \\
\text { system validation } \\
\text { in relevant } \\
\text { environment }\end{array}$ & $\begin{array}{l}\text { Engineering-scale models or prototypes are tested in a } \\
\text { relevant environment. This represents a major step up in a } \\
\text { technology's demonstrated readiness. Examples include } \\
\text { testing an engineering scale prototypical system with a } \\
\text { range of simulants. Supporting information includes } \\
\text { results from the engineering scale testing and analysis of } \\
\text { the differences between the engineering scale, } \\
\text { prototypical system/environment, and analysis of what the } \\
\text { experimental results mean for the eventual operating } \\
\text { system/environment. TRL } 6 \text { begins true engineering } \\
\text { development of the technology as an operational system. } \\
\text { The major difference between TRL } 5 \text { and } 6 \text { is the step up } \\
\text { from laboratory scale to engineering scale and the } \\
\text { determination of scaling factors that will enable design of } \\
\text { the operating system. The prototype should be capable of } \\
\text { performing all the functions that will be required of the } \\
\text { operational system. The operating environment for the } \\
\text { testing should closely represent the actual operating } \\
\text { environment. }\end{array}$ \\
\hline $\begin{array}{l}\text { Technology } \\
\text { Development }\end{array}$ & TRL 5 & $\begin{array}{l}\text { Laboratory scale, } \\
\text { similar system } \\
\text { validation in } \\
\text { relevant } \\
\text { environment }\end{array}$ & $\begin{array}{l}\text { The basic technological components are integrated so } \\
\text { that the system configuration is similar to (matches) the } \\
\text { final application in almost all respects. Examples include } \\
\text { testing a high-fidelity, laboratory-scale system in a } \\
{\text { simulated environment with a range of simulants }{ }^{\mathrm{a}} \text { and }} \\
\text { actual waste. }^{\text {b }} \text { Supporting information includes results } \\
\text { from the laboratory scale testing, analysis of the } \\
\text { differences between the laboratory and eventual operating } \\
\text { system/environment, and analysis of what the }\end{array}$ \\
\hline
\end{tabular}




\begin{tabular}{|c|c|c|c|}
\hline $\begin{array}{l}\text { Relative Level } \\
\text { of Technology } \\
\text { Development }\end{array}$ & TRL & $\begin{array}{c}\text { TRL } \\
\text { Definition }\end{array}$ & Description \\
\hline \multirow[t]{2}{*}{$\begin{array}{l}\text { Technology } \\
\text { Development } \\
\text { (cont'd) }\end{array}$} & & & $\begin{array}{l}\text { experimental results mean for the eventual operating } \\
\text { system/environment. The major difference between TRL } 4 \\
\text { and } 5 \text { is the increase in the fidelity of the system and } \\
\text { environment to the actual application. The system tested } \\
\text { is almost prototypical. }\end{array}$ \\
\hline & TRL 4 & $\begin{array}{l}\text { Component and/or } \\
\text { system validation } \\
\text { in laboratory } \\
\text { environment }\end{array}$ & $\begin{array}{l}\text { The basic technological components are integrated to } \\
\text { establish that the pieces will work together. This is } \\
\text { relatively "low fidelity" compared with the eventual system. } \\
\text { Examples include integration of ad hoc hardware in a } \\
\text { laboratory and testing with a range of simulants and small } \\
\text { scale tests on actual waste. Supporting information } \\
\text { includes the results of the integrated experiments and } \\
\text { estimates of how the experimental components and } \\
\text { experimental test results differ from the expected system } \\
\text { performance goals. TRL } 4-6 \text { represent the bridge from } \\
\text { scientific research to engineering. TRL } 4 \text { is the first step in } \\
\text { determining whether the individual components will work } \\
\text { together as a system. The laboratory system will probably } \\
\text { be a mix of on-hand equipment and a few special purpose } \\
\text { components that may require special handling, calibration, } \\
\text { or alignment to get them to function. }\end{array}$ \\
\hline $\begin{array}{l}\text { Research to } \\
\text { Prove Feasibility }\end{array}$ & TRL 3 & $\begin{array}{l}\text { Analytical and } \\
\text { experimental } \\
\text { critical function } \\
\text { and/or } \\
\text { characteristic } \\
\text { proof of concept }\end{array}$ & $\begin{array}{l}\text { Active research and development is initiated. This } \\
\text { includes analytical studies and laboratory-scale studies to } \\
\text { physically validate the analytical predictions of separate } \\
\text { elements of the technology. Examples include } \\
\text { components that are not yet integrated or representative } \\
\text { tested with simulants. Supporting information includes } \\
\text { results of laboratory tests performed to measure } \\
\text { parameters of interest and comparison to analytical } \\
\text { predictions for critical subsystems. At TRL } 3 \text {, the work has } \\
\text { moved beyond the paper phase to experimental work that } \\
\text { verifies that the concept works as expected on simulants. } \\
\text { Components of the technology are validated, but there is } \\
\text { no attempt to integrate the components into a complete } \\
\text { system. Modeling and simulation may be used to } \\
\text { complement physical experiments. }\end{array}$ \\
\hline
\end{tabular}




\begin{tabular}{|c|c|c|c|}
\hline $\begin{array}{l}\text { Relative Level } \\
\text { of Technology } \\
\text { Development }\end{array}$ & TRL & $\begin{array}{c}\text { TRL } \\
\text { Definition }\end{array}$ & Description \\
\hline \multirow[t]{2}{*}{$\begin{array}{l}\text { Basic } \\
\text { Technology } \\
\text { Research }\end{array}$} & TRL 2 & $\begin{array}{l}\text { Technology } \\
\text { concept and/or } \\
\text { application } \\
\text { formulated }\end{array}$ & $\begin{array}{l}\text { Once basic principles are observed, practical applications } \\
\text { can be invented. Applications are speculative, and there } \\
\text { may be no proof or detailed analysis to support the } \\
\text { assumptions. Examples are still limited to analytic studies. } \\
\text { Supporting information includes publications or other } \\
\text { references that outline the application being considered } \\
\text { and that provide analysis to support the concept. The step } \\
\text { up from TRL } 1 \text { to TRL } 2 \text { moves the ideas from pure to } \\
\text { applied research. Most of the work is analytical or paper } \\
\text { studies with the emphasis on understanding the science } \\
\text { better. Experimental work is designed to corroborate the } \\
\text { basic scientific observations made during TRL } 1 \text { work. }\end{array}$ \\
\hline & TRL 1 & $\begin{array}{l}\text { Basic principles } \\
\text { observed and } \\
\text { reported }\end{array}$ & $\begin{array}{l}\text { This is the lowest level of technology readiness. Scientific } \\
\text { research begins to be translated into applied research and } \\
\text { development. Examples might include paper studies of a } \\
\text { technology's basic properties or experimental work that } \\
\text { consists mainly of observations of the physical world. } \\
\text { Supporting information includes published research or } \\
\text { other references that identify the principles that underlie } \\
\text { the technology. }\end{array}$ \\
\hline \multicolumn{4}{|c|}{$\begin{array}{l}\text { a. Simulants should match relevant chemical and physical properties. } \\
\text { b. Testing with as wide a range of actual waste as practicable and consistent with waste availability, safety, as low as } \\
\text { reasonably achievable, cost, and project risk is highly desirable }\end{array}$} \\
\hline
\end{tabular}

\section{B-2. Description and Assessment of Generation-IV Concepts}

The six Generation-IV (Gen-IV) reactor concepts were evaluated as they span the range of power reactors being considered for near- or medium-term deployment. However, each Gen-IV concept may include a number of specific designs or unique design features. For reactor concepts of low overall technical maturity, the choice of specific design is less important as the subsystems have not been developed sufficiently to be distinguishable.

The specific designs chosen are described briefly here along with a summary of the evaluations for the assigned TRL scores. The actual scores for each system and subsystem are listed in Section B-3. The extent of design detail and technology pedigree differs greatly among the concepts and this is reflected in the following descriptions. For those cases for which a power conversion system (PCS) was not specified, a Rankine (steam cycle) PCS was assumed. 


\section{B-2.1 Gas-Cooled Fast Reactor}

\section{Description}

The gas-cooled fast reactor (GFR) is neither the subject of study or technology development by DOE nor has any particular design been evaluated by the NRC as part of a licensing application. One private vendor, GA, has developed a conceptual GFR design, the EM².

EM$^{2}$ system is a high-temperature, helium-cooled, fast-spectrum reactor supporting a closed fuel cycle. It combines the advantages of fast-spectrum systems for long-term sustainability of uranium resources and waste minimization (through multiple fuel reprocessing steps and fission of long-lived actinides) with those of high-temperature systems (high-thermal cycle efficiency and industrial use of the generated heat, similar to very high temperature reactor [VHTR]).

The GFR was first proposed and studied in France in the 1990s. Some R\&D continues under the Generation IV International Forum (GIF) umbrella. The original GFR reference concept, the $600 \mathrm{MWt}$ ALLEGRO [Ref 1] was eventually replaced with a $2400 \mathrm{MWt}$ version as calculations indicated that the $600 \mathrm{MWt}$ reactor was unable meet the breakeven breeding requirement. The U.S.-designed $500 \mathrm{MWt}$ $E^{2}{ }^{2}$ was selected as the reference GFR for the purposes of this technical evaluation, but all GFRs share the major attributes of the $\mathrm{EM}^{2}$, including a fast spectrum for superior fuel resource utilization, chemically inert gas coolant, ceramic fuel, and in-vessel convective decay heat removal.

The $\mathrm{EM}^{2}$ would use uranium carbide (UC) fuel with $6.5 \%$ average enrichment and has a 30 -year refueling cycle. The design has one loop and utilizes two shutdown systems, control drums, and separate shutdown rods. It would use the PCS for normal decay heat removal from the reactor vessel with the passive direct auxiliary cooling system (DRACS). The fuel would be vented porous uranium carbide clad in silicon carbide. Conventional light water reactor (LWR) pressure vessel steel (SA508/533) would be used for the pressure vessel and the modular construction below grade. The reactor would use helium $\left(850^{\circ} \mathrm{C}\right.$ at the outlet) to drive a Brayton PCS rather than a steam cycle. While it could probably drive a steam turbine as well, for this evaluation the gas turbine PCS is assumed.

The GFR would avoid a number of the issues of the other fast reactors such as chemical compatibility (due to its inert gas coolant), high positive void coefficient (smaller than other concepts but still positive), and coolant phase change (by having single phase gas coolant). Therefore, the GFR allows high-temperature operation without the corrosion and coolant radiotoxicity problems associated with liquid metal reactors.

\section{Evaluation}

Except for residual heat removal, the heat transport, power conversion, and other non-nuclear systems of $\mathrm{EM}^{2}$ were considered to be similar to the High Temperature Gas-Cooled Reactor (HTGR). The TRLs for the GFR and VHTR (see Section 3.3) are identical except for the nuclear heat supply and safety systems. TRL scores were determined mainly from the information given in Gen-IV International Forum Annual Report 2014 [Ref 2]. No gas-cooled fast spectrum reactor has been built.

Gas is a poor heat transfer medium and, without the thermal inertia of the VHTR's graphite moderator, rapid heat-up of the core would be expected following loss of forced cooling. As a fast spectrum reactor, the power density is characteristically high such that the VHTR scenario of a benign "conduction cool-down" is not feasible and powerful decay heat removal systems must be considered. 
Also, the gas-coolant density is too low to achieve enough natural convection to cool the core, and the power requirements for the blower are important at low pressure. Lastly, additional consideration will need to be given to the effects of the fast neutron dose on the reactor pressure vessel in the absence of core moderation (the graphite moderator provides protection for VHTR systems).

The main challenge is the development of the carbide or other ceramic fuel form that can withstand the high temperatures and power densities of a gas-cooled core, particularly during an upset condition. The nitride and oxide fuels under consideration among GIF countries are at a similarly low development state. The pressure vessel and core internals will need to withstand a drop in forced cooling without the benefit of the thermal and radiation buffer afforded by the graphite in an HTGR. Therefore, the overall nuclear heat supply system was assigned a TRL of 2 .

The other approach to preventing severe core damage is through the use of a decay heat removal system that can extract core heat at a sufficient rate to keep fuel temperatures below acceptable limits. This almost surely would be an active safety system as opposed to the passive vessel cooling systems proposed for smaller SFRs and HTGRs. Such a system has not yet been designed for GFR duty. The overall safety system score was assigned a TRL of 2 .

Mainly because of the challenges of fuel qualification and decay heat removal during an upset condition, the GFR concept is not likely to be ready for preliminary design and licensing activities within the next 20 years.

\section{B-2.2 Lead-Cooled Fast Reactor}

\section{Description}

The lead-cooled fast reactor (LFR) is neither the subject of current study or technology development by DOE nor has any particular design been evaluated by the NRC as part of a licensing application. A small, transportable battery LFR has been developed at Lawrence Livermore National Laboratory-the Small, Sealed, Transportable, Autonomous Reactor. Russia has operated LFRs for submarine propulsion. One private vendor, Gen4 Energy, has developed a conceptual small modular LFR design. Westinghouse is now pursuing LFR technology and is proposing a 500-MWt demonstration reactor using qualified fuel and cladding that would operate at less demanding conditions while a more corrosion-resistant cladding and steam generator tube material is developed. This reactor is described in Section 4. All proposed LFRs share the important attributes of this particular design including a fast neutron spectrum, ceramic fuel, and lead or lead-bismuth coolant. The high boiling point of lead allows operation at near-atmospheric pressures and at higher temperatures while maintaining significant thermal margins. Unlike sodium, neither lead nor lead-bismuth react chemically with air or water.

\section{Evaluation}

The absence of an energetic reaction with water comparable to the sodium case is an attractive feature of the LFR, but corrosion of metallic components by lead, particularly at higher temperatures $\left(>500^{\circ} \mathrm{C}\right)$, is considered a significant technical challenge [3]. The current corrosion suppression strategy relies on carefully managing oxygen concentration in the lead, but the effectiveness of this approach in large pool-type LFRs is unproven. This drives the lower TRL $(\sim 3)$ for most of the subsystems with the nuclear heat supply and heat transport systems. Like the other metal-cooled systems, in-service inspection of reactor internals remains a challenge, the magnitude of which depends upon heretofore 
unspecified requirements by the regulator. It is assumed that any residual heat removal system and accident behavior would be similar to that of the SFR, but no such system has been tested in an LFR environment.

Lead has a high-melting point that could lead to localized freezing if the temperature is not actively maintained. The lead-bismuth eutectic melts at a lower temperature, but neutron capture by the bismuth results in radioactive polonium production, a significant radiological hazard.

Mainly because of the unresolved corrosion challenges [4, the LFR concept is considered less mature.

\section{B-2.3 Molten Salt Reactor}

\section{Description}

Molten Salt Reactors (MSRs) were first proposed and developed shortly after World War II when a 2.5-MWt proof-of-principle test reactor (Aircraft Reactor Experiment) was developed and operated for 100 hours at high temperature $\left(860^{\circ} \mathrm{C}\right)$ in 1954 . At Oak Ridge National Laboratory, the 8-MWt Molten Salt Reactor Experiment (MSRE) was operated from 1965 to 1969, with over 13,000 fuel power operation hours, including an 8,000-hour continuous period of operation. This experiment demonstrated the basic technology of MSR with dissolved and recycled fuel (both U-235 and U-233). The Fluoride High Temperature Reactor (FHR) is a molten salt cooled or fueled reactor with a fluoride salt.

A solid-fuel, salt-cooled FHR is currently the subject of a DOE Cooperative Research and Development Agreement with China (analysis and experimental work) as well as two integrated research programs (IRPs) with a number of leading U.S. universities [5]. This FHR is moderated by graphite and uses the coated particle fuel form of the HTGR. FLiBe (lithium/beryllium fluoride eutectic) is the primary salt candidate for most FHRs but others can be considered. The choice of fuel geometry may be either block (prismatic) or pebble. The high outlet temperature of the FHR supports efficient power conversion and an open-air gas turbine system, using off-the-shelf components, is part of the power plant design.

A major subset of the MSR is the liquid-fueled MSR, of which the MSRE noted above is an example. Fresh fuel, actinides, and fission products are dissolved in the salt and circulated through the primary heat transfer loop. Depending on the coolant and core structural materials, the liquid-fueled MSR may have a fast neutron spectrum. Online fuel processing supports continuous operation and limits fission product buildup such that high conversion or even breeding can be achieved, particularly in the fast spectrum versions. Liquid-fueled MSR designs have been proposed by a number of private U.S. and non-U.S. companies (e.g., Transatomic Power, Terrestrial Energy), but currently the U.S. government supports no research into the liquid-fueled MSR.

The high boiling point of molten salts enables operation at near atmospheric pressures, greatly diminishing the potential for a significant source term release. The high-heat capacity and thermal conductivity (compared to helium) allows high-power densities to be attained in the fuel. Increased core temperatures lead to a decrease in salt density that reduces moderation and, along with Doppler feedback in the fuel, yields strong negative temperature feedback. 


\section{Evaluation}

The solid-fuel FHR was chosen for this TRL evaluation with background data obtained from a previous technical review [7]. Because of the considerable interest among private companies, the readiness of the liquid-fueled MSR was also evaluated.

The current design path for the FHR uses the tristructural isotropic particle and graphite being qualified for the VHTR so the TRLs for the fuel element and reactor internals (graphite) match those of the VHTR [2]. Uncertainty in the long-term corrosion effects of $\mathrm{FLiBe}$ on core metallic components greatly limits the TRL of the reactivity control, instrumentation, and reactor enclosure (vessel). One of the strategies is to develop $\mathrm{C} / \mathrm{C}$ or $\mathrm{SiC} / \mathrm{SiC}$ composites for instrumentation sleeves and other barriers between the metals and the salt and to help withstand the higher temperatures. Qualification of metals in the MSR environment needs to be conducted. As with the other concepts, the reactor vendor will establish the level of instrumentation needed to support the safety case, which will then be used for licensing.

The open-air Brayton cycle PCS would use commercial gas turbine components, but these have yet to be coupled to a reactor.

Likewise, the heat transport system TRL is also constrained by the lack of data on long-term corrosion in FLiBe and other salts. Furthermore, lithium-bearing salts generate considerable amounts of tritium under irradiation that permeate structural materials and pose a radiological hazard. Both tritium and FLiBe have been studied under the fusion program, but the issues remain unresolved to date. Mitigation and control of corrosion in some metallic components were demonstrated in the MSRE along with salt purification, but qualification of all the necessary metals and components is a long-term effort for any salt that is chosen. Like lead, the salt temperature must be maintained $\left(>400^{\circ} \mathrm{C}\right)$ to prevent freezing.

Some of the passive safety characteristics of the MSR were demonstrated in the MSRE. This test should be considered laboratory scale or perhaps engineering scale although it was not connected to a PCS.

Mainly because of the unresolved corrosion and tritium challenges, the MSR (FHR) is considered less mature. A commercial design will not likely be deployable within next 20 years but a smaller engineering demonstration may be licensable in the nearer term and would provide a significant stepping stone toward a performance demonstration. A liquid-fueled MSR faces an additional challenge with regard to nuclear material safeguards.

\section{B-2.4 Sodium Fast Reactor}

\section{Description}

The SFR has been under development by the U.S. government almost since the inception of nuclear electricity production in the 1950s. Experimental and demonstration facilities were built and operated starting in the early 1960s with the Experimental Breeder Reactor II (EBR-II) in Idaho and the Fermi-1 power plant in Michigan, both of which generated electricity. The Fast Flux Test Facility is a 400-MWt SFR in Washington State that was used for materials irradiations. Both EBR-II and Fast Flux Test Facility were shut down in the 1990s. 
EBR-II used a metal fuel cladded in stainless steel that was resistant to radiation damage and has a high-thermal conductivity (the Fast Flux Test Facility used a mixed oxide fuel with a higher melting point, but metallic fuels were irradiated in Fast Flux Test Facility). Recycling of the fuel was achieved in an electro-metallurgical process developed at Argonne National Laboratory (ANL). Fission heat from EBR-II was transferred to a steam generator via an intermediated heat exchange system. The sodium loops were driven by electromagnetic pumps.

Passive safety was demonstrated in EBR-II in 1986 in a series of experiments in which the electricity supply to the plant was disconnected, thereby disabling the emergency shutdown system and the primary coolant pumps. The subsequent temperature increase led to expansion of the core and subcriticality via excess neutron leakage. Decay heat was removed through natural heat transfer mechanisms and the plant achieved a safe condition.

The basic technology of EBR-II was adopted by GE-Hitachi in its design of the Power Reactor Inherently Safe Module (PRISM) reactor. The 471-MWt PRISM/Mod-A design was submitted for a pre-application review by the NRC [8], during which a number of issues were identified as requiring further development and demonstration. Higher power designs were also developed (840 MWt PRISM/Mod-B and 1000 MWt-SPRISM). The PRISM version submitted to the DOE Technical Review Panel [7] would feature a higher efficiency superheated steam PCS. DOE-sponsored SFR development continues at ANL, focusing on the design of the next generation of SFR. The AFR-100 [9] is a $100 \mathrm{MWe}$ small-modular SFR adopting advanced new fuel design and driving a supercritical $\mathrm{CO}_{2}$ PCS for higher efficiency and lower risk of sodium-water interaction.

As with any new technology, the track record of SFR demonstration plants is mixed. In the U.S., EBR-II boasted a $69 \%$ load factor over about 30 years and is largely considered a great success. The Fermi-1 reactor operated from 1963 to 1966 when it suffered some core damage as the result of a blocked coolant channel. After successful repairs it operated until 1972. In Russia, Beloyarsk-3 (a Russian BN-600) achieved a 75\% load factor over 30 years of operation. The French Phénix reactor operated successfully for over 15 years before a series of unexpected transient events forced a shutdown and investigation. It started up again in 1994 and ran (at reduced power for a while) until 2009. The large prototype fast reactors (e.g., SuperPhénix in France and Monju in Japan) struggled with various (non-radiologically significant) engineering problems and never achieved full power (although restart of Monju remains a possibility).

\section{Evaluation}

SFRs have been successfully tested as materials irradiation facilities in the U.S. (EBR-II, and the Fast Flux Test Facility) and elsewhere. The only major outstanding issue to achieve a design of TRL 6 or higher is that of fuel qualification and licensing. Experimental or demonstration SFRs currently operate in Russia, India, and China. Japan, France, U.S., and the United Kingdom also operated such facilities at one time. Except for EBR- II and the Prototype Fast Breeder Reactor soon to be operating in India, these reactors use an oxide fuel form. 
A demonstration reactor built upon the EBR-II platform is relatively mature. The metallic fuel forms $\mathrm{U}-\mathrm{Zr}$ and U-Zr-Pu were extensively tested in that reactor, but the U-TRU-Zr fuel testing was not completed, which would limit its ability to realize its anticipated waste minimization goals. An important gap to fill prior to licensing is the characterization of the source term from metallic fuel under normal and accident conditions. Adequate fuel fabrication capability may exist at INL to support test reactor operation, but a production-level capability needs to be developed to support demo or commercial deployment.

The GE-Hitachi PRISM reactor design using, for the most part, technologies demonstrated in EBR-II. PRISM/Mod-A is a much larger core than EBR-II (471 MWt versus $62 \mathrm{MWt}$ ); thus, issues may emerge in scaling to this size, particularly with regard to the size of the vessel and support structures. In-service inspection, depending upon NRC requirements, may require new detection techniques suitable to the opaque coolant.

The Direct Reactor Auxiliary Cooling System utilized in EBR-Il was effective for a reactor of that size. A larger reactor may require a different technology, such as a Reactor Vessel Auxiliary Cooling System (RVACS), that would require qualification for NRC licensing. Experiments with a scaled RVACS cooling system are underway at ANL. The fuel handling system used in EBR-Il will require further development for use in PRISM as will the electromagnetic coolant pumps.

Electrometallurgical reprocessing of spent SFR fuel was demonstrated at ANL and has achieved a relatively high, though not yet commercial-scale, maturity.

The 100-MWe small-modular AFR-100 under development at ANL builds upon EBR-II technology (in particular, the sodium-bonded metallic fuel) but will also employ features that will require considerable technical development. The fission-gas vented fuel is being investigated and may have a significant impact upon worker dose in a demonstration reactor, perhaps less so in a test reactor. AFR-100 would use a DRACS decay heat rejection system. The other major advance is a supercritical $\mathrm{CO}_{2} \mathrm{PCS}$. An electrically heated system has been tested at a laboratory scale, but the coupling to the sodium loop via an intermediate heat exchanger would still require demonstration to support licensing, particularly given some observed reactions between sodium and $\mathrm{CO}_{2}$. For these reasons, the TRL is considered low.

Preliminary design and licensing activities for an SFR built upon the EBR-II platform may be initiated within 10 years if final fuel qualification and source term characterization can be conducted in conjunction with reactor demonstration. Continued R\&D of key AFR-100 technologies are needed before demonstration.

\section{B-2.5 Supercritical Water-cooled Reactor}

\section{Description}

In the Supercritical Water-cooled Reactor (SCWR), superheated coolant under very high pressure emerges from the core and is sent directly to a turbine without separation and drying before being returned to the core. Furthermore, in-vessel coolant pumps are not required; thus, the primary loop is simpler than older boiling water reactor (BWR) designs. The SCWR operates at higher temperatures than today's LWRs and can potentially achieve higher efficiencies (about 45\%). 
SCWR is not currently the subject of study by the U.S. DOE or vendor nor has any particular design been evaluated by the NRC. DOE participated to a limited extent in SCWR research through the GIF [2].This design [10] featured a thermal spectrum and direct-cycle PCS for simplicity. Water at a supercritical temperature (about $510^{\circ} \mathrm{C}$ ) and pressure $(25 \mathrm{MPa}$ ) served as both coolant and moderator. Variations on the SCWR concept include a heavy water-moderated version (Canada) and a fast spectrum version (Europe and Japan). All designs under investigation by GIF member countries are at the pre-conceptual stage.

The SCWR uses water as a coolant and can draw upon 50 years of operational experience and research infrastructure with conventional LWRs and fossil plants that use supercritical water-based power conversion. Therefore, the path to deployment may be relatively straightforward and can rely on existing R\&D infrastructure.

\section{Evaluation}

Although the SCWR relies on existing water reactor technology, especially for the fuel and geometry, there are technical challenges to overcome. The high pressure requires thick-walled pipes and components. The higher temperature leads to greater corrosion and degradation of structural materials than observed in LWR systems. Indeed, supercritical fluid systems are considered promising for leaching metals from metal ores with a minimal amount of waste. However, the same attributes also lead to extensive corrosion in certain alloys, particularly zircaloy; a problem that is compounded by radiolysis. SCWR technology can rely on the considerable data available on supercritical water behavior in fossil fuel plants but little of that data is applicable to water reactor fuel assemblies. Experiments with test loops are underway within GIF, but much more data is needed to support a licensing effort. The major area of research in SCWR systems is materials characterization and qualification.

The heat transfer and other thermal-hydraulic properties of water near its critical point are not well characterized; thus, extensive testing in tube bundles is necessary to provide data for safety analysis codes. Non-uniformities in local power and coolant mass flow rates give rise to hotspots exacerbated by the larger enthalpy rise in the core. Large density variations in water near the critical point could lead to significant local fluctuations in neutron flux and cladding temperature.

The need to qualify new cladding and structural material and to characterize and control neutronic and thermal fluid behavior in SCWR fuel assemblies prevents near-term deployment of this reactor concept as either a test or demonstration reactor. If adequately supported, the SCWR may be ready for preliminary design work in the 10 to 20 -year timeframe.

\section{B-2.6 Very High Temperature Reactor}

\section{Description}

The modular High Temperature Gas-cooled Reactor (HTGR) uses a helium cooled, graphitemoderated core. The fuel elements consist of thousands of tiny coated, tristructural isotropic (TRISO) particles of ceramic fuel dispersed in a graphitic-material compact. Compacts are stacked in graphite blocks (or embedded in spheres and stacked randomly in a pebble bed). This highly robust fuel form, along with a low-power density and large thermal inertia of the graphite, make the core resistant to damage from a complete loss of coolant. The high outlet temperature $\left(>700^{\circ} \mathrm{C}\right)$ of the inert helium is suitable for driving high-efficient power conversion or numerous process heat applications. 
A subset of the HTGR, the VHTR, heats the coolant outlet to temperatures in excess of $850^{\circ} \mathrm{C}$. Even though these temperatures have been achieved in engineering scale reactors, such as the German Arbeitsgemeinschaft Versuchsreaktor (AVR), the Japanese High Temperature Engineering Test Reactor (HTTR), and the Chinese HTR-10, only HTGRs with lower outlet temperatures $\left(675-800^{\circ} \mathrm{C}\right)$ are being proposed for commercial deployment at this time.

A 625-MWt SC-HTGR is proposed by AREVA and is described in Section 4. The reference design burns fuel once to high burnup (no recycle) to drive a Rankine PCS. The fuel and graphite are being qualified under the ART program. The SC-HTGR is designed to reject decay heat to the atmosphere via a passive reactor cavity cooling system.

HTGRs have been the subject of U.S. government and industry investment on and off since the 1960s. The Peach Bottom 1 and Fort St. Vrain demonstration HTGRs were designed and built by General Atomics. Peach Bottom 1 employed an earlier version of the coated fuel particle and had a much smaller power output. Although its size and power output were such that it could not reject decay heat passively, Fort St. Vrain used a TRISO fuel and demonstrated the basic physics and system technology likely to be deployed in the AREVA SC-HTGR.

As with the SFR, the track record of the early HTGRs is mixed. In Germany, the AVR (comparable in power output to EBR-II) operated for over 20 years with a $62 \%$ load factor, despite having suffered a major water ingress event and being shut down for over 1 year. Melt-wire tests revealed core temperatures considerably higher than expected that, while not posing an imminent threat to the core, did raise questions about the ability to model core conditions. The larger Thorium HochTemperatur Reactor (THTR) suffered from broken pebbles and hardware failure that, although manageable, were exacerbated by political and economic conditions and it was shut down after just a few years. In the U.S., Peach Bottom 1 achieved a capacity factor of roughly $70 \%$ over an 8-year operating lifetime. Fort St. Vrain, on the other hand, achieved only a $15 \%$ capacity factor, having suffered from a significant water incursion from water-cooled gas circulators. Of the currently operating HTGRs, the HTTR in Japan and HTR-10 in China are small engineering-scale demonstrators that operate intermittently according to their test plans. Except for extended shutdowns ordered after the Fukushima accident, both have operated without incident since startup around 2000.

\section{Evaluation}

The modular HTGR, with outlet temperatures limited to less than $800^{\circ} \mathrm{C}$, is suitable for near-term deployment as a demonstration reactor. The unique coated particle fuel embedded in a graphite matrix was found early on to provide a superior (melt-down proof) fuel form even as the coolant and core are driven to temperatures significantly higher than other reactor types. Demonstration plants put electricity on the grid (Peach Bottom - 1 and Fort St. Vrain) despite experiencing engineering difficulties not uncommon to new technologies. 
As with the PRISM reactor, the U.S. government collaborated with industry to develop a small, modular version of the HTGR in the 1980s. The GA Modular High Temperature Gas-Cooled Reactor (MHTGR) was subjected to pre-application safety review by the NRC. The SC-HTGR shares the major features of the MHTGR, including passive decay heat removal. The detailed technical status of the MHTGR and its pebble bed counterpart developed in Germany, the HTR-Modul, are described in reference [11]. The HTR-Modul design was submitted to the German regulator in the late 1980s, but none was ever built. A two-unit pebble-bed modular HTGR power plant based upon the German design is under construction in China.

Under certain beyond design basis event scenarios in modular HTGRs, metallic components exposed to core conditions may be subjected to excessive temperatures. If coolant temperatures are limited as mentioned above, SA508/533 (the steel alloy used in LWRs) is adequate for the pressure vessel. However, Metallic control rod drive tubes and seals may fail in the event of the most severe loss-of-forced-cooling events. While this event will not cause fuel failure or vessel depressurization, replacement of the drive guide tubes would be necessary. Qualification of new alloys or even the use of carbon or $\mathrm{SiC}$ composites for the guide tubes may eliminate metallic core component failure. The control elements in a smaller reactor ( $<100 \mathrm{MWt}$ ) are not anticipated to reach failure temperatures, but this has yet to be confirmed. Additionally, the upper-tier performance standard for the VHTR's functional containment that has been found reasonable by the NRC technical staff has not yet been confirmed with the Commission.

Under contract from the NGNP program, AREVA conducted a technology readiness evaluation of their original NGNP design (Antares). It has the same core as the SC-HTGR, but it would drive a Brayton cycle PCS. The TRLs listed for the SC-HTGR were influenced by, or taken from, the AREVA report [12].

If operation at higher temperatures $\left(>850^{\circ} \mathrm{C}\right)$ is desired (e.g., for a VHTR), new alloys or composites will need to be developed and qualified. The technology readiness of the VHTR is comparable to the SCWR in this regard.

Current HTGR technology supports preliminary design and licensing activity of either a test or demonstration reactor within the next 5 to 10 years provided that coolant outlet temperatures are limited to about $800^{\circ} \mathrm{C}$. In the near term, a demonstration reactor would drive a steam cycle PCS. Helium gas turbine components are at a relatively low technology readiness and so cannot be used in a demonstration reactor in the short term.

\section{B-3. Technical Maturity Levels of Systems and Subsystems}

TRLs obtained for each reference design are summarized in this section. For some systems and subsystems, values could be applied broadly as the technology is somewhat independent of the nuclear heat supply system that for the most part distinguishes the concepts.

The numerical scores for the different reactors are tabulated in the following table. The scale, using the readiness levels in Appendix $B$, ranges from 9 for technologies with operational experience down to 1 where the technologies basic principles have been observed and reported. Explanations of overall system results are then provided. 
The overall TRL for the reference concepts was obtained by taking the minimum value of the TRLs of the key subsystems shown in shaded cells in Table B-1.

Table B-1. Technology readiness levels for each system and subsystem for reactor deployment. *

\begin{tabular}{|c|c|c|c|c|c|c|c|c|}
\hline & GFR & LFR & SF & & VHTR & SCWR & & ISR \\
\hline & $\mathrm{EM}^{2}$ & Gen4 & AFR-100 & PRISM & SC-HTGR & & FHR & LF-MSR \\
\hline Nuclear Heat Supply & 2 & 3 & 3 & 5 & 5 & 3 & 3 & 3 \\
\hline $\begin{array}{l}\text { Fuel Element } \\
\text { (fuel, cladding, assembly) }\end{array}$ & 2 & 3 & 3 & 5 & 6 & 3 & 6 & 5 \\
\hline Reactor Internals & 3 & 3 & 3 & 6 & 6 & 3 & 6 & 5 \\
\hline Reactivity Control & 4 & 3 & 6 & 6 & 6 & 3 & 4 & 4 \\
\hline Reactor Enclosure & 4 & 3 & 3 & 5 & 5 & 3 & 3 & 3 \\
\hline $\begin{array}{l}\text { Operations/Inspection/ } \\
\text { Maintenance }\end{array}$ & 4 & 3 & 3 & 5 & 5 & 5 & 3 & 5 \\
\hline Core Instrumentation & 3 & 3 & 3 & 5,3 & 6,3 & 3 & 3 & 5,3 \\
\hline Heat Transport & 3 & 3 & 4 & 4 & 5,3 & 5 & 4 & 3 \\
\hline $\begin{array}{l}\text { Coolant Chemistry } \\
\text { Control/Purification }\end{array}$ & 6 & 3 & 6 & 6 & 6 & 5 & 4 & 3 \\
\hline $\begin{array}{l}\text { Primary Heat Transport } \\
\text { System } \\
\text { (hot duct) }\end{array}$ & 6 & 3 & 6 & 6 & 6 & 5 & 4 & 4 \\
\hline $\begin{array}{l}\text { Intermediate Heat Exchanger } \\
\text { (if applicable) }\end{array}$ & $\mathrm{NA} / 3$ & 3 & 3 & 6 & $\mathrm{NA} / 3$ & NA & 4 & 4 \\
\hline Pumps/Valves/Piping & 5 & 3 & 4 & 4 & 5 & 5 & 4 & 4 \\
\hline Auxiliary Cooling & 6 & 3 & NA & NA & 6 & 5 & 4 & 4 \\
\hline Residual Heat Removal & 3 & 4 & 5 & 5 & 5 & 5 & 4 & 4 \\
\hline Power Conversion & 3 & 7 & 4 & 7 & 6 & 7 & 6 & 6 \\
\hline Turbine & 3 & 7 & 4 & 7 & 7 & 7 & 7 & 7 \\
\hline $\begin{array}{l}\text { Compressor/Recuperator } \\
\text { (Brayton) }\end{array}$ & 3 & NA & 4 & NA & NA & NA & NA & NA \\
\hline $\begin{array}{l}\text { Reheater/Superheater/ } \\
\text { Condenser (Rankine) }\end{array}$ & NA & 7 & 4 & 7 & 7 & 7 & 7 & 7 \\
\hline Steam Generator & 3 & 7 & 4 & 7 & 7 & 7 & 7 & 7 \\
\hline Pumps/Valves/Piping & 3 & 7 & 4 & 7 & 6 & 7 & 6 & 7 \\
\hline Process Heat Plant (e.g., $\mathrm{H}_{2}$ ) & $\mathrm{NA} / 3$ & NA & NA & NA & $\mathrm{NA} / 3$ & NA & $\mathrm{NA} / 3$ & NA \\
\hline Balance of Plant & 6 & 6 & 4 & 4 & 6 & 7 & 4 & 4 \\
\hline $\begin{array}{l}\text { Fuel Handling and Interim } \\
\text { Storage }\end{array}$ & 6 & 6 & 4 & 4 & 6 & 7 & 6 & 4 \\
\hline Waste Heat Rejection & 7 & 6 & 6 & 6 & 7 & 7 & 6 & 6 \\
\hline Instrumentation and Control & 7 & 6 & 6 & 6 & 6 & 7 & 4 & 6 \\
\hline $\begin{array}{l}\text { Radioactive Waste } \\
\text { Management }\end{array}$ & 6 & 6 & 6 & 6 & 6 & 7 & 6 & 6 \\
\hline Safety & 2 & 3 & 6 & 6 & 6 & 3 & 3 & 3 \\
\hline $\begin{array}{l}\text { Inherent (passive) Safety } \\
\text { Features }\end{array}$ & 3 & 3 & 3 & 6 & 6 & 3 & 4 & 5 \\
\hline Active Safety System & 2 & 3 & 3 & 6 & 6 & 3 & 3 & 3 \\
\hline Licensing & 1 & 3 & 3 & 3 & 3 & 1 & 2 & 2 \\
\hline
\end{tabular}


Table B-1. (continued).

\begin{tabular}{|c|c|c|c|c|c|c|c|c|}
\hline & \multirow{2}{*}{$\begin{array}{l}\text { GFR } \\
\mathrm{EM}^{2}\end{array}$} & \multirow{2}{*}{$\begin{array}{l}\text { LFR } \\
\text { Gen4 }\end{array}$} & \multicolumn{2}{|c|}{ SFR } & \multirow{2}{*}{$\begin{array}{c}\text { VHTR } \\
\text { SC-HTGR }\end{array}$} & \multirow[t]{2}{*}{ SCWR } & \multicolumn{2}{|c|}{ MSR } \\
\hline & & & AFR-100 & PRISM & & & FHR & LF-MSR \\
\hline $\begin{array}{l}\text { Safety Design Criteria and } \\
\text { Regulations }\end{array}$ & 3 & 3 & 3 & 3 & 3 & 3 & 3 & 3 \\
\hline Licensing Experience & 1 & 1 & 3 & 3 & 3 & 1 & 2 & 2 \\
\hline Safety and Analysis Tools & 3 & 3 & 5 & 5 & 4 & 3 & 3 & 3 \\
\hline Fuel Cycle & 6 & 6 & 6 & 6 & NA & NA & NA & 5 \\
\hline $\begin{array}{l}\text { Recycled Fuel Fabrication } \\
\text { Technology }\end{array}$ & 3 & 3 & 6 & 6 & & & & 5 \\
\hline $\begin{array}{l}\text { Used Fuel Separation } \\
\text { Technology }\end{array}$ & 3 & 3 & 6 & 6 & & & & 5 \\
\hline Safeguards & 3 & 3 & 3 & 3 & 3 & 7 & 3 & 3 \\
\hline $\begin{array}{l}\text { Proliferation Resistance - } \\
\text { Intrinsic Design Features } \\
\text { (e.g., SNM accountability) }\end{array}$ & 3 & 3 & 3 & 3 & 3 & 7 & 3 & 3 \\
\hline $\begin{array}{l}\text { Plant Protection - Intrinsic } \\
\text { Design Features }\end{array}$ & 3 & 3 & 3 & 3 & 3 & 7 & 3 & 3 \\
\hline
\end{tabular}

\section{B-4. References}

1. DOE, A Technology Roadmap for Generation IV Nuclear Energy Systems, Issued by the U.S. DOE Nuclear Energy Research Advisory Committee and the Generation IV International Forum, 2002.

2. Technology Readiness Assessment Guide, DOE G 413.3-4A, U.S. Department of Energy, September 2011.OECD Nuclear Energy Agency, Generation IV International Forum Annual Report 2014, 2015.

3. IAEA, Liquid Metal Coolants for Fast Reactors Cooled by Sodium Lead, and Lead-Bismuth Eutectic, International Atomic Energy Agency Nuclear Energy Series No. NP-T-1.6, 2012.

4. Tarantino, M., et al., "Lead-Cooled Fast Reactor (LFR) Development Gaps," Proceedings of the 2012 Technical Meeting to Identify Innovative Fast Neutron Systems Development Gaps, International Atomic Energy Agency, Vienna, Austria, February 2012.

5. Holcomb, D. E., et al., Small, Modular Advanced High-Temperature Reactor-Carbonate Thermochemical Cycle, ORNL/M-2014/88, Oak Ridge National Laboratory, March 2014.

6. MacPherson, H. G., "Development of Materials and Systems for Molten Salt-Reactor Concept," Reactor Technology, Vol. 15, No. 2, 1972, pp. 136-155.

7. DOE, Advanced Reactor Concepts Technical Review Panel Report-Evaluation and Recommendations for Future R\&D on Eight Advanced Reactor Concepts, Department of Energy, November 2012.

8. NRC, Preapplication Safety Evaluation Report for the Power Reactor Innovative Small Module (PRISM) Liquid-Metal Reactor, NUREG-1368, Nuclear Regulatory Commission, 1994.

9. Grandy, C. et al., Advanced Fast Reactor - 100 (AFR-100) Report for the Technical Review Panel, ANL-ARC-288, Argonne National Laboratory, June 2014. 
10. Buongiorno, J. et al, Progress Report for the FY-03 Generation IV R\&D Activities for the Development of the SCWR in the U.S., INEEL/EXT-03-01210, September 2003.

11. Gougar, H., Baseline Concept Description of a Small Modular High Temperature Reactor, INL/EXT-14-31541 Rev. 1, Idaho National Laboratory, May 2014.

12. AREVA, NGNP Technology Readiness Levels for Conventional Steam Cycle Configuration, TDR-3001463-000, March 2009. 
Appendix C

\section{Demonstration and Test Reactor Detailed Assessment Results}




\section{Appendix C \\ Demonstration and Test Reactor Detailed Assessment Results}

In this appendix, the detailed raw and weighted scores are presented for the demonstration and test reactors. The results from the sensitivity studies performed for the demonstration reactor are also included.

\section{C-1. Demonstration Reactor Detailed Results C-1.1 Raw Scores}

An expanded data set for the four demonstration reactor raw scores and variances are presented in Table C-1. The mean scores vary significantly between the 25 metrics, depending on each design's attributes and current development status.

Table C-1. Mean raw scores and variances per metric for all four DRs.

\begin{tabular}{|c|c|c|c|c|c|c|c|c|}
\hline \multirow{2}{*}{ Metric } & \multicolumn{6}{|c|}{ Mean Values } & \multicolumn{4}{|c|}{ 10 } \\
\cline { 2 - 9 } & HTGR & SFR & LFR & FHR & HTGR & SFR & LFR & FHR \\
\hline D1.1.1 & 9.0 & 9.0 & 5.4 & 4.3 & 0.0 & 0.0 & 2.2 & 2.4 \\
\hline D1.2.1 & 9.0 & 9.0 & 9.0 & 9.0 & 0.0 & 0.0 & 0.0 & 0.0 \\
\hline D1.3.1 & 9.0 & 9.0 & 5.0 & 5.4 & 0.0 & 0.0 & 0.0 & 1.2 \\
\hline D1.4.1 & 9.0 & 9.0 & 7.2 & 5.0 & 0.0 & 0.0 & 2.8 & 0.0 \\
\hline D1.5.1 & 9.0 & 9.0 & 7.2 & 4.6 & 0.0 & 0.0 & 2.1 & 1.2 \\
\hline D2.1.1 & 7.9 & 7.9 & 6.1 & 9.0 & 1.9 & 1.9 & 1.9 & 0.0 \\
\hline D2.1.2 & 5.0 & 4.6 & 3.5 & 5.7 & 1.8 & 2.2 & 2.7 & 2.4 \\
\hline D2.2.1 & 7.9 & 7.2 & 6.1 & 1.0 & 1.9 & 2.1 & 1.9 & 0.0 \\
\hline D2.3.1 & 8.6 & 8.6 & 6.8 & 6.1 & 1.2 & 1.2 & 2.1 & 3.1 \\
\hline D3.1.1 & 8.6 & 9.0 & 7.2 & 6.8 & 1.2 & 0.0 & 2.1 & 2.1 \\
\hline D3.1.2 & 8.3 & 7.5 & 7.2 & 7.9 & 1.6 & 2.0 & 2.1 & 1.9 \\
\hline D4.1.1 & 9.0 & 9.0 & 6.1 & 5.4 & 0.0 & 0.0 & 2.6 & 1.2 \\
\hline D4.2.1 & 9.0 & 9.0 & 9.0 & 9.0 & 0.0 & 0.0 & 0.0 & 0.0 \\
\hline D4.2.2 & 9.0 & 9.0 & 9.0 & 9.0 & 0.0 & 0.0 & 0.0 & 0.0 \\
\hline D4.3.1 & 5.0 & 7.2 & 4.3 & 4.3 & 0.0 & 2.1 & 1.6 & 1.6 \\
\hline D4.3.2 & 5.4 & 6.8 & 4.3 & 5.4 & 1.2 & 2.1 & 1.6 & 2.2 \\
\hline D4.4.1 & 1.0 & 5.0 & 5.0 & 1.0 & 0.0 & 0.0 & 0.0 & 0.0 \\
\hline D4.4.2 & 5.0 & 2.1 & 1.0 & 5.0 & 0.0 & 1.9 & 0.0 & 0.0 \\
\hline D4.4.3 & 9.0 & 6.8 & 6.1 & 9.0 & 0.0 & 2.1 & 1.9 & 0.0 \\
\hline D5.1.1 & 1.4 & 9.0 & 9.0 & 1.4 & 1.2 & 0.0 & 0.0 & 1.2 \\
\hline D5.2.1 & 8.6 & 8.6 & 6.1 & 5.0 & 1.2 & 1.2 & 3.1 & 1.8 \\
\hline D5.3.1 & 8.6 & 9.0 & 5.4 & 6.8 & 1.2 & 0.0 & 3.3 & 2.1 \\
\hline D5.4.1 & 8.6 & 9.0 & 8.3 & 5.4 & 1.2 & 0.0 & 1.6 & 2.8 \\
\hline D6.1.1 & 9.0 & 5.0 & 5.0 & 9.0 & 0.0 & 0.0 & 0.0 & 0.0 \\
\hline D6.2.1 & 9.0 & 5.0 & 5.0 & 9.0 & 0.0 & 0.0 & 0.0 & 0.0 \\
\hline & & & & & & & & \\
\hline
\end{tabular}


The detailed raw score breakdown for each design is provided in Table C-2 (SC-HTGR), Table C-3 (PRISM SFR), Table C-4 (DLFR) and Table C-5 (FHR). The results are also summed for a total score and converted to a percent of total possible score in the tables.

Table C-2. SC-HTGR raw scores.

\begin{tabular}{|c|c|c|c|c|c|c|c|c|c|c|c|c|c|}
\hline Metric & A & B & C & D & E & F & G & H & I & J & K & Mean & 1 \\
\hline D1.1.1 & 9 & 9 & 9 & 9 & 9 & 9 & 9 & 9 & 9 & 9 & 9 & 9.0 & 0.0 \\
\hline D1.2.1 & 9 & 9 & 9 & 9 & 9 & 9 & 9 & 9 & 9 & 9 & 9 & 9.0 & 0.0 \\
\hline D1.3.1 & 9 & 9 & 9 & 9 & 9 & 9 & 9 & 9 & 9 & 9 & 9 & 9.0 & 0.0 \\
\hline D1.4.1 & 9 & 9 & 9 & 9 & 9 & 9 & 9 & 9 & 9 & 9 & 9 & 9.0 & 0.0 \\
\hline D1.5.1 & 9 & 9 & 9 & 9 & 9 & 9 & 9 & 9 & 9 & 9 & 9 & 9.0 & 0.0 \\
\hline D2.1.1 & 9 & 9 & 5 & 9 & 9 & 9 & 9 & 5 & 9 & 5 & 9 & 7.9 & 1.9 \\
\hline D2.1.2 & 1 & 5 & 5 & 9 & 5 & 5 & 5 & 5 & 5 & 5 & 5 & 5.0 & 1.8 \\
\hline D2.2.1 & 9 & 9 & 5 & 9 & 5 & 9 & 9 & 5 & 9 & 9 & 9 & 7.9 & 1.9 \\
\hline D2.3.1 & 9 & 9 & 5 & 9 & 9 & 9 & 9 & 9 & 9 & 9 & 9 & 8.6 & 1.2 \\
\hline D3.1.1 & 9 & 9 & 5 & 9 & 9 & 9 & 9 & 9 & 9 & 9 & 9 & 8.6 & 1.2 \\
\hline D3.1.2 & 9 & 9 & 5 & 9 & 9 & 9 & 9 & 9 & 5 & 9 & 9 & 8.3 & 1.6 \\
\hline D4.1.1 & 9 & 9 & 9 & 9 & 9 & 9 & 9 & 9 & 9 & 9 & 9 & 9.0 & 0.0 \\
\hline D4.2.1 & 9 & 9 & 9 & 9 & 9 & 9 & 9 & 9 & 9 & 9 & 9 & 9.0 & 0.0 \\
\hline D4.2.2 & 9 & 9 & 9 & 9 & 9 & 9 & 9 & 9 & 9 & 9 & 9 & 9.0 & 0.0 \\
\hline D4.3.1 & 5 & 5 & 5 & 5 & 5 & 5 & 5 & 5 & 5 & 5 & 5 & 5.0 & 0.0 \\
\hline D4.3.2 & 5 & 9 & 5 & 5 & 5 & 5 & 5 & 5 & 5 & 5 & 5 & 5.4 & 1.2 \\
\hline D4.4.1 & 1 & 1 & 1 & 1 & 1 & 1 & 1 & 1 & 1 & 1 & 1 & 1.0 & 0.0 \\
\hline D4.4.2 & 5 & 5 & 5 & 5 & 5 & 5 & 5 & 5 & 5 & 5 & 5 & 5.0 & 0.0 \\
\hline D4.4.3 & 9 & 9 & 9 & 9 & 9 & 9 & 9 & 9 & 9 & 9 & 9 & 9.0 & 0.0 \\
\hline D5.1.1 & 1 & 5 & 1 & 1 & 1 & 1 & 1 & 1 & 1 & 1 & 1 & 1.4 & 1.2 \\
\hline D5.2.1 & 9 & 9 & 5 & 9 & 9 & 9 & 9 & 9 & 9 & 9 & 9 & 8.6 & 1.2 \\
\hline D5.3.1 & 9 & 9 & 5 & 9 & 9 & 9 & 9 & 9 & 9 & 9 & 9 & 8.6 & 1.2 \\
\hline D5.4.1 & 9 & 9 & 5 & 9 & 9 & 9 & 9 & 9 & 9 & 9 & 9 & 8.6 & 1.2 \\
\hline D6.1.1 & 9 & 9 & 9 & 9 & 9 & 9 & 9 & 9 & 9 & 9 & 9 & 9.0 & 0.0 \\
\hline D6.2.1 & 9 & 9 & 9 & 9 & 9 & 9 & 9 & 9 & 9 & 9 & 9 & 9.0 & 0.0 \\
\hline Total & 189 & 201 & 161 & 197 & 189 & 193 & 193 & 185 & 189 & 189 & 193 & 189 & 10.3 \\
\hline \% & $\mathbf{8 4 . 0}$ & $\mathbf{8 9 . 3}$ & $\mathbf{7 1 . 6}$ & $\mathbf{8 7 . 6}$ & $\mathbf{8 4 . 0}$ & $\mathbf{8 5 . 8}$ & $\mathbf{8 5 . 8}$ & $\mathbf{8 2 . 2}$ & $\mathbf{8 4 . 0}$ & $\mathbf{8 4 . 0}$ & $\mathbf{8 5 . 8}$ & $\mathbf{8 4 . 0}$ & $\mathbf{4 . 6}$ \\
\hline
\end{tabular}


Table C-3. PRISM SFR raw scores.

\begin{tabular}{|c|c|c|c|c|c|c|c|c|c|c|c|c|c|}
\hline Metric & A & B & C & D & E & F & G & H & I & J & K & Mean & 1 \\
\hline D1.1.1 & 9 & 9 & 9 & 9 & 9 & 9 & 9 & 9 & 9 & 9 & 9 & 9.0 & 0.0 \\
\hline D1.2.1 & 9 & 9 & 9 & 9 & 9 & 9 & 9 & 9 & 9 & 9 & 9 & 9.0 & 0.0 \\
\hline D1.3.1 & 9 & 9 & 9 & 9 & 9 & 9 & 9 & 9 & 9 & 9 & 9 & 9.0 & 0.0 \\
\hline D1.4.1 & 9 & 9 & 9 & 9 & 9 & 9 & 9 & 9 & 9 & 9 & 9 & 9.0 & 0.0 \\
\hline D1.5.1 & 9 & 9 & 9 & 9 & 9 & 9 & 9 & 9 & 9 & 9 & 9 & 9.0 & 0.0 \\
\hline D2.1.1 & 9 & 9 & 5 & 9 & 9 & 9 & 5 & 9 & 9 & 5 & 9 & 7.9 & 1.9 \\
\hline D2.1.2 & 5 & 5 & 5 & 9 & 5 & 1 & 5 & 5 & 1 & 5 & 5 & 4.6 & 2.2 \\
\hline D2.2.1 & 9 & 5 & 5 & 9 & 9 & 9 & 9 & 5 & 5 & 5 & 9 & 7.2 & 2.1 \\
\hline D2.3.1 & 9 & 9 & 5 & 9 & 9 & 9 & 9 & 9 & 9 & 9 & 9 & 8.6 & 1.2 \\
\hline D3.1.1 & 9 & 9 & 9 & 9 & 9 & 9 & 9 & 9 & 9 & 9 & 9 & 9.0 & 0.0 \\
\hline D3.1.2 & 9 & 5 & 5 & 9 & 9 & 5 & 9 & 9 & 5 & 9 & 9 & 7.5 & 2.0 \\
\hline D4.1.1 & 9 & 9 & 9 & 9 & 9 & 9 & 9 & 9 & 9 & 9 & 9 & 9.0 & 0.0 \\
\hline D4.2.1 & 9 & 9 & 9 & 9 & 9 & 9 & 9 & 9 & 9 & 9 & 9 & 9.0 & 0.0 \\
\hline D4.2.2 & 9 & 9 & 9 & 9 & 9 & 9 & 9 & 9 & 9 & 9 & 9 & 9.0 & 0.0 \\
\hline D4.3.1 & 5 & 5 & 9 & 5 & 9 & 9 & 5 & 9 & 5 & 9 & 9 & 7.2 & 2.1 \\
\hline D4.3.2 & 5 & 5 & 9 & 5 & 9 & 9 & 5 & 9 & 5 & 5 & 9 & 6.8 & 2.1 \\
\hline D4.4.1 & 5 & 5 & 5 & 5 & 5 & 5 & 5 & 5 & 5 & 5 & 5 & 5.0 & 0.0 \\
\hline D4.4.2 & 5 & 1 & 1 & 5 & 5 & 1 & 1 & 1 & 1 & 1 & 1 & 2.1 & 1.9 \\
\hline D4.4.3 & 9 & 5 & 5 & 9 & 9 & 5 & 5 & 5 & 5 & 9 & 9 & 6.8 & 2.1 \\
\hline D5.1.1 & 9 & 9 & 9 & 9 & 9 & 9 & 9 & 9 & 9 & 9 & 9 & 9.0 & 0.0 \\
\hline D5.2.1 & 9 & 9 & 9 & 9 & 9 & 9 & 5 & 9 & 9 & 9 & 9 & 8.6 & 1.2 \\
\hline D5.3.1 & 9 & 9 & 9 & 9 & 9 & 9 & 9 & 9 & 9 & 9 & 9 & 9.0 & 0.0 \\
\hline D5.4.1 & 9 & 9 & 9 & 9 & 9 & 9 & 9 & 9 & 9 & 9 & 9 & 9.0 & 0.0 \\
\hline D6.1.1 & 5 & 5 & 5 & 5 & 5 & 5 & 5 & 5 & 5 & 5 & 5 & 5.0 & 0.0 \\
\hline D6.2.1 & 5 & 5 & 5 & 5 & 5 & 5 & 5 & 5 & 5 & 5 & 5 & 5.0 & 0.0 \\
\hline Total & 197 & 181 & 181 & 201 & 205 & 189 & 181 & 193 & 177 & 189 & 201 & 190 & 9.7 \\
\hline \% & $\mathbf{8 7 . 6}$ & $\mathbf{8 0 . 4}$ & $\mathbf{8 0 . 4}$ & $\mathbf{8 9 . 3}$ & $\mathbf{9 1 . 1}$ & $\mathbf{8 4 . 0}$ & $\mathbf{8 0 . 4}$ & $\mathbf{8 5 . 8}$ & $\mathbf{7 8 . 7}$ & $\mathbf{8 4 . 0}$ & $\mathbf{8 9 . 3}$ & $\mathbf{8 4 . 6}$ & $\mathbf{4 . 3}$ \\
\hline
\end{tabular}


Table C-4. DLFR raw scores.

\begin{tabular}{|c|c|c|c|c|c|c|c|c|c|c|c|c|c|}
\hline Metric & A & B & C & D & E & F & G & H & I & J & K & Mean & 1 \\
\hline D1.1.1 & 5 & 1 & 5 & 9 & 5 & 5 & 5 & 5 & 5 & 5 & 9 & 5.4 & 2.2 \\
\hline D1.2.1 & 9 & 9 & 9 & 9 & 9 & 9 & 9 & 9 & 9 & 9 & 9 & 9.0 & 0.0 \\
\hline D1.3.1 & 5 & 5 & 5 & 5 & 5 & 5 & 5 & 5 & 5 & 5 & 5 & 5.0 & 0.0 \\
\hline D1.4.1 & 9 & 1 & 5 & 9 & 5 & 5 & 9 & 9 & 9 & 9 & 9 & 7.2 & 2.8 \\
\hline D1.5.1 & 9 & 5 & 5 & 9 & 5 & 9 & 5 & 5 & 9 & 9 & 9 & 7.2 & 2.1 \\
\hline D2.1.1 & 9 & 5 & 5 & 9 & 5 & 5 & 5 & 5 & 5 & 5 & 9 & 6.1 & 1.9 \\
\hline D2.1.2 & 1 & 1 & 1 & 9 & 1 & 1 & 5 & 5 & 5 & 5 & 5 & 3.5 & 2.7 \\
\hline D2.2.1 & 9 & 5 & 5 & 9 & 5 & 5 & 5 & 5 & 5 & 5 & 9 & 6.1 & 1.9 \\
\hline D2.3.1 & 5 & 5 & 5 & 9 & 9 & 5 & 9 & 5 & 9 & 5 & 9 & 6.8 & 2.1 \\
\hline D3.1.1 & 9 & 5 & 5 & 9 & 5 & 5 & 9 & 5 & 9 & 9 & 9 & 7.2 & 2.1 \\
\hline D3.1.2 & 9 & 5 & 5 & 9 & 9 & 5 & 9 & 9 & 5 & 5 & 9 & 7.2 & 2.1 \\
\hline D4.1.1 & 9 & 1 & 5 & 9 & 5 & 5 & 5 & 5 & 5 & 9 & 9 & 6.1 & 2.6 \\
\hline D4.2.1 & 9 & 9 & 9 & 9 & 9 & 9 & 9 & 9 & 9 & 9 & 9 & 9.0 & 0.0 \\
\hline D4.2.2 & 9 & 9 & 9 & 9 & 9 & 9 & 9 & 9 & 9 & 9 & 9 & 9.0 & 0.0 \\
\hline D4.3.1 & 5 & 5 & 5 & 5 & 1 & 5 & 1 & 5 & 5 & 5 & 5 & 4.3 & 1.6 \\
\hline D4.3.2 & 5 & 1 & 5 & 5 & 5 & 5 & 5 & 1 & 5 & 5 & 5 & 4.3 & 1.6 \\
\hline D4.4.1 & 5 & 5 & 5 & 5 & 5 & 5 & 5 & 5 & 5 & 5 & 5 & 5.0 & 0.0 \\
\hline D4.4.2 & 1 & 1 & 1 & 1 & 1 & 1 & 1 & 1 & 1 & 1 & 1 & 1.0 & 0.0 \\
\hline D4.4.3 & 9 & 5 & 5 & 5 & 9 & 5 & 5 & 5 & 5 & 5 & 9 & 6.1 & 1.9 \\
\hline D5.1.1 & 9 & 9 & 9 & 9 & 9 & 9 & 9 & 9 & 9 & 9 & 9 & 9.0 & 0.0 \\
\hline D5.2.1 & 9 & 1 & 5 & 9 & 5 & 5 & 1 & 5 & 9 & 9 & 9 & 6.1 & 3.1 \\
\hline D5.3.1 & 9 & 1 & 5 & 9 & 1 & 5 & 1 & 5 & 9 & 9 & 5 & 5.4 & 3.3 \\
\hline D5.4.1 & 9 & 5 & 5 & 9 & 9 & 9 & 9 & 9 & 9 & 9 & 9 & 8.3 & 1.6 \\
\hline D6.1.1 & 5 & 5 & 5 & 5 & 5 & 5 & 5 & 5 & 5 & 5 & 5 & 5.0 & 0.0 \\
\hline D6.2.1 & 5 & 5 & 5 & 5 & 5 & 5 & 5 & 5 & 5 & 5 & 5 & 5.0 & 0.0 \\
\hline Total & 177 & 109 & 133 & 189 & 141 & 141 & 145 & 145 & 165 & 165 & 185 & 154 & 24.3 \\
\hline \% & 78.7 & 48.4 & 59.1 & 84.0 & 62.7 & 62.7 & 64.4 & 64.4 & 73.3 & 73.3 & 82.2 & 68.5 & 10.8 \\
\hline
\end{tabular}


Table C-5. FHR raw scores.

\begin{tabular}{|c|c|c|c|c|c|c|c|c|c|c|c|c|c|}
\hline Metric & A & B & C & D & $E$ & $\mathbf{F}$ & G & H & I & $\mathbf{J}$ & K & Mean & $1 \sigma$ \\
\hline D1.1.1 & 5 & 1 & 5 & 9 & 1 & 5 & 5 & 5 & 5 & 1 & 5 & 4.3 & 2.4 \\
\hline D1.2.1 & 9 & 9 & 9 & 9 & 9 & 9 & 9 & 9 & 9 & 9 & 9 & 9.0 & 0.0 \\
\hline D1.3.1 & 5 & 5 & 5 & 5 & 5 & 5 & 9 & 5 & 5 & 5 & 5 & 5.4 & 1.2 \\
\hline D1.4.1 & 5 & 5 & 5 & 5 & 5 & 5 & 5 & 5 & 5 & 5 & 5 & 5.0 & 0.0 \\
\hline D1.5.1 & 5 & 5 & 5 & 5 & 1 & 5 & 5 & 5 & 5 & 5 & 5 & 4.6 & 1.2 \\
\hline D2.1.1 & 9 & 9 & 9 & 9 & 9 & 9 & 9 & 9 & 9 & 9 & 9 & 9.0 & 0.0 \\
\hline D2.1.2 & 1 & 5 & 5 & 9 & 9 & 5 & 9 & 5 & 5 & 5 & 5 & 5.7 & 2.4 \\
\hline D2.2.1 & 1 & 1 & 1 & 1 & 1 & 1 & 1 & 1 & 1 & 1 & 1 & 1.0 & 0.0 \\
\hline D2.3.1 & 5 & 1 & 5 & 9 & 1 & 9 & 9 & 9 & 9 & 5 & 5 & 6.1 & 3.1 \\
\hline D3.1.1 & 9 & 5 & 5 & 9 & 5 & 9 & 9 & 5 & 9 & 5 & 5 & 6.8 & 2.1 \\
\hline D3.1.2 & 9 & 5 & 5 & 9 & 9 & 9 & 9 & 9 & 9 & 9 & 5 & 7.9 & 1.9 \\
\hline D4.1.1 & 5 & 5 & 5 & 5 & 5 & 5 & 9 & 5 & 5 & 5 & 5 & 5.4 & 1.2 \\
\hline D4.2.1 & 9 & 9 & 9 & 9 & 9 & 9 & 9 & 9 & 9 & 9 & 9 & 9.0 & 0.0 \\
\hline D4.2.2 & 9 & 9 & 9 & 9 & 9 & 9 & 9 & 9 & 9 & 9 & 9 & 9.0 & 0.0 \\
\hline D4.3.1 & 1 & 5 & 5 & 5 & 5 & 1 & 5 & 5 & 5 & 5 & 5 & 4.3 & 1.6 \\
\hline D4.3.2 & 5 & 1 & 5 & 5 & 9 & 5 & 5 & 9 & 5 & 5 & 5 & 5.4 & 2.2 \\
\hline D4.4.1 & 1 & 1 & 1 & 1 & 1 & 1 & 1 & 1 & 1 & 1 & 1 & 1.0 & 0.0 \\
\hline D4.4.2 & 5 & 5 & 5 & 5 & 5 & 5 & 5 & 5 & 5 & 5 & 5 & 5.0 & 0.0 \\
\hline D4.4.3 & 9 & 9 & 9 & 9 & 9 & 9 & 9 & 9 & 9 & 9 & 9 & 9.0 & 0.0 \\
\hline D5.1.1 & 1 & 5 & 1 & 1 & 1 & 1 & 1 & 1 & 1 & 1 & 1 & 1.4 & 1.2 \\
\hline D5.2.1 & 5 & 5 & 5 & 9 & 5 & 1 & 5 & 5 & 5 & 5 & 5 & 5.0 & 1.8 \\
\hline D5.3.1 & 9 & 9 & 5 & 9 & 5 & 5 & 9 & 5 & 9 & 5 & 5 & 6.8 & 2.1 \\
\hline D5.4.1 & 1 & 5 & 5 & 5 & 1 & 5 & 9 & 9 & 9 & 5 & 5 & 5.4 & 2.8 \\
\hline D6.1.1 & 9 & 9 & 9 & 9 & 9 & 9 & 9 & 9 & 9 & 9 & 9 & 9.0 & 0.0 \\
\hline D6.2.1 & 9 & 9 & 9 & 9 & 9 & 9 & 9 & 9 & 9 & 9 & 9 & 9.0 & 0.0 \\
\hline $\begin{array}{l}\text { Total } \\
\text { (225) }\end{array}$ & 141 & 137 & 141 & 169 & 137 & 145 & 173 & 157 & 161 & 141 & 141 & 149 & 13.2 \\
\hline$\%$ & 62.7 & 60.9 & 62.7 & 75.1 & 60.9 & 64.4 & 76.9 & 69.8 & 71.6 & 62.7 & 62.7 & 66.4 & 5.9 \\
\hline
\end{tabular}

\section{C-1.1.1 Weighted Scores against Strategic Objectives 1-3}

The effective contributions of the demonstration reactor metrics and their relative importance ranking for each strategic objective are indicated in Table C-6. The difference in weighting functions between the three objectives result in different weights for each metric and different importance rankings. For example, the metrics D5.1.1 through D5.4.1 collectively determine 25\% of the total score for Objective 2, compared to zero and almost zero contributions for Objectives 1 and 3 . The top five metrics for each strategic objective are summarized in Table C-7. 
Table C-6. Demonstration reactor effective metric contributions.

\begin{tabular}{|c|c|c|c|c|c|c|c|c|c|c|c|c|c|}
\hline \multicolumn{4}{|c|}{ Goal } & \multirow{2}{*}{\multicolumn{2}{|c|}{ Criteria }} & \multirow{2}{*}{\multicolumn{2}{|c|}{ Metrics }} & \multicolumn{3}{|c|}{ Effective weight } & \multicolumn{3}{|c|}{ Rank } \\
\hline & 1 & 2 & 3 & & & & & 1 & 2 & 3 & 1 & 2 & 3 \\
\hline \multirow{5}{*}{ D1 } & \multirow{5}{*}{0.25} & \multirow{5}{*}{0.20} & \multirow{5}{*}{0.35} & D1.1 & 0.35 & D1.1.1 & 1.00 & 0.09 & 0.07 & 0.12 & 4 & 3 & 1 \\
\hline & & & & D1.2 & 0.15 & D1.2.1 & 1.00 & 0.04 & 0.03 & 0.05 & 12 & 14 & 7 \\
\hline & & & & D1.3 & 0.20 & D1.3.1 & 1.00 & 0.05 & 0.04 & 0.07 & 9 & 11 & 3 \\
\hline & & & & D1.4 & 0.15 & D1.4.1 & 1.00 & 0.04 & 0.03 & 0.05 & 12 & 14 & 7 \\
\hline & & & & D1.5 & 0.15 & D1.5.1 & 1.00 & 0.04 & 0.03 & 0.05 & 12 & 14 & 7 \\
\hline \multirow{4}{*}{ D2 } & \multirow{4}{*}{0.20} & \multirow{4}{*}{0.20} & \multirow{4}{*}{0.20} & \multirow{2}{*}{ D2.1 } & \multirow{2}{*}{0.55} & D2.1.1 & 0.50 & 0.06 & 0.06 & 0.06 & 6 & 5 & 5 \\
\hline & & & & & & D2.1.2 & 0.50 & 0.06 & 0.06 & 0.06 & 6 & 5 & 5 \\
\hline & & & & D2.2 & 0.20 & D2.2.1 & 1.00 & 0.04 & 0.04 & 0.04 & 11 & 11 & 12 \\
\hline & & & & D2.3 & 0.25 & D2.3.1 & 1.00 & 0.05 & 0.05 & 0.05 & 9 & 8 & 11 \\
\hline \multirow{2}{*}{ D3 } & \multirow{2}{*}{0.15} & \multirow{2}{*}{0.15} & \multirow{2}{*}{0.15} & \multirow{2}{*}{ D3.1 } & \multirow{2}{*}{1.00} & D3.1.1 & 0.65 & 0.10 & 0.10 & 0.10 & 3 & 2 & 2 \\
\hline & & & & & & D3.1.2 & 0.35 & 0.05 & 0.05 & 0.05 & 8 & 7 & 7 \\
\hline \multirow{8}{*}{ D4 } & \multirow{8}{*}{0.20} & \multirow{8}{*}{0.20} & \multirow{8}{*}{0.20} & D4.1 & 0.35 & D4.1.1 & 1.00 & 0.07 & 0.07 & 0.07 & 5 & 3 & 3 \\
\hline & & & & \multirow{2}{*}{ D4.2 } & \multirow{2}{*}{0.30} & D4.2.1 & 0.50 & 0.03 & 0.03 & 0.03 & 15 & 14 & 13 \\
\hline & & & & & & D4.2.2 & 0.50 & 0.03 & 0.03 & 0.03 & 15 & 14 & 13 \\
\hline & & & & \multirow{2}{*}{ D4.3 } & \multirow{2}{*}{0.20} & D4.3.1 & 0.50 & 0.02 & 0.02 & 0.02 & 17 & 19 & 18 \\
\hline & & & & & & D4.3.2 & 0.50 & 0.02 & 0.02 & 0.02 & 17 & 19 & 18 \\
\hline & & & & & & D4.4.1 & 0.40 & 0.01 & 0.01 & 0.01 & 19 & 21 & 20 \\
\hline & & & & D4.4 & 0.15 & D4.4.2 & 0.25 & 0.01 & 0.01 & 0.01 & 21 & 23 & 24 \\
\hline & & & & & & D4.4.3 & 0.35 & 0.01 & 0.01 & 0.01 & 20 & 22 & 21 \\
\hline & & & & D5.1 & 0.45 & D5.1.1 & 1.00 & 0.00 & 0.11 & 0.02 & 22 & 1 & 17 \\
\hline & & & & D5.2 & 0.20 & D5.2.1 & 1.00 & 0.00 & 0.05 & 0.01 & 22 & 8 & 22 \\
\hline D5 & 0.00 & 0.25 & 0.05 & D5.3 & 0.20 & D5.3.1 & 1.00 & 0.00 & 0.05 & 0.01 & 22 & 8 & 22 \\
\hline & & & & D5.4 & 0.15 & D5.4.1 & 1.00 & 0.00 & 0.04 & 0.01 & 22 & 13 & 24 \\
\hline & & & & D6.1 & 0.50 & D6.1.1 & 1.00 & 0.10 & 0.00 & 0.03 & 1 & 24 & 15 \\
\hline D6 & 0.20 & 0.00 & 0.05 & D6.2 & 0.50 & D6.2.1 & 1.00 & 0.10 & 0.00 & 0.03 & 1 & 24 & 15 \\
\hline
\end{tabular}

Table C-7. Demonstration reactor top 5 metrics for Objectives 1-3.

\begin{tabular}{|c|l|c|c|c|}
\hline \multirow{2}{*}{ Metric } & \multicolumn{1}{|c|}{ Description } & \multicolumn{3}{|c|}{ Effective weight (\%) } \\
\cline { 3 - 5 } & & $\mathbf{1}$ & $\mathbf{2}$ & $\mathbf{3}$ \\
\hline D1.1.1 & $\begin{array}{l}\text { Capability to demonstrate safety behavior of commercial } \\
\text { system }\end{array}$ & 9 & 7 & 12 \\
\hline D1.3.1 & $\begin{array}{l}\text { Technology selections that are prototypic/scalable to } \\
\text { commercial unit }\end{array}$ & - & - & 7 \\
\hline D2.1.1 & Project cost & - & 6 & 6 \\
\hline D3.1.1 & Ability to address key licensing issues for commercial units & 10 & 10 & 10 \\
\hline D4.1.1 & $\begin{array}{l}\text { Demonstration of components expected in commercial } \\
\text { units }\end{array}$ & 7 & 7 & 7 \\
\hline D5.1.1 & Use of fuel natural resources & - & 11 & - \\
\hline D6.1.1 & $\begin{array}{l}\text { Number of energy conversion systems or industrial } \\
\text { applications }\end{array}$ & 10 & - & - \\
\hline D6.2.1 & Coolant outlet temperature & 10 & - & - \\
\hline
\end{tabular}

The mean weighted value and standard deviation of the individual assessment teams scores for each metric is provided in Table C-8 (Strategic Objective 1), Table C-9 (Strategic Objective 2), and Table C-10 (Strategic Objective 3). The tables also contain the overall summed score across all metrics for each point design and the standard deviations. 
Table C-8. Mean weighted scores per metric for all four DRs: Objective 1.

\begin{tabular}{|c|c|c|c|c|c|c|c|c|}
\hline \multirow{2}{*}{ Metric } & \multicolumn{4}{|c|}{ Mean Values } & \multicolumn{4}{|c|}{$1 \sigma$} \\
\hline & HTGR & SFR & LFR & FHR & HTGR & SFR & LFR & FHR \\
\hline D1.1.1 & 8.8 & 8.8 & 5.2 & 4.2 & 0.0 & 0.0 & 2.1 & 2.3 \\
\hline D1.2.1 & 3.8 & 3.8 & 3.8 & 3.8 & 0.0 & 0.0 & 0.0 & 0.0 \\
\hline D1.3.1 & 5.0 & 5.0 & 2.8 & 3.0 & 0.0 & 0.0 & 0.0 & 0.7 \\
\hline D1.4.1 & 3.8 & 3.8 & 3.0 & 2.1 & 0.0 & 0.0 & 1.1 & 0.0 \\
\hline D1.5.1 & 3.8 & 3.8 & 3.0 & 1.9 & 0.0 & 0.0 & 0.9 & 0.5 \\
\hline D2.1.1 & 4.8 & 4.8 & 3.7 & 5.5 & 1.1 & 1.1 & 1.1 & 0.0 \\
\hline D2.1.2 & 3.1 & 2.8 & 2.2 & 3.5 & 1.1 & 1.3 & 1.6 & 1.5 \\
\hline D2.2.1 & 3.5 & 3.2 & 2.7 & 0.4 & 0.8 & 0.9 & 0.8 & 0.0 \\
\hline D2.3.1 & 4.8 & 4.8 & 3.8 & 3.4 & 0.7 & 0.7 & 1.2 & 1.7 \\
\hline D3.1.1 & 9.4 & 9.8 & 7.8 & 7.4 & 1.3 & 0.0 & 2.3 & 2.3 \\
\hline D3.1.2 & 4.8 & 4.4 & 4.2 & 4.6 & 0.9 & 1.2 & 1.2 & 1.1 \\
\hline D4.1.1 & 7.0 & 7.0 & 4.7 & 4.2 & 0.0 & 0.0 & 2.0 & 0.9 \\
\hline D4.2.1 & 3.0 & 3.0 & 3.0 & 3.0 & 0.0 & 0.0 & 0.0 & 0.0 \\
\hline D4.2.2 & 3.0 & 3.0 & 3.0 & 3.0 & 0.0 & 0.0 & 0.0 & 0.0 \\
\hline D4.3.1 & 1.1 & 1.6 & 0.9 & 0.9 & 0.0 & 0.5 & 0.4 & 0.4 \\
\hline D4.3.2 & 1.2 & 1.5 & 0.9 & 1.2 & 0.3 & 0.5 & 0.4 & 0.5 \\
\hline D4.4.1 & 0.1 & 0.7 & 0.7 & 0.1 & 0.0 & 0.0 & 0.0 & 0.0 \\
\hline D4.4.2 & 0.4 & 0.2 & 0.1 & 0.4 & 0.0 & 0.2 & 0.0 & 0.0 \\
\hline D4.4.3 & 1.1 & 0.8 & 0.7 & 1.1 & 0.0 & 0.2 & 0.2 & 0.0 \\
\hline D5.1.1 & 0.0 & 0.0 & 0.0 & 0.0 & 0.0 & 0.0 & 0.0 & 0.0 \\
\hline D5.2.1 & 0.0 & 0.0 & 0.0 & 0.0 & 0.0 & 0.0 & 0.0 & 0.0 \\
\hline D5.3.1 & 0.0 & 0.0 & 0.0 & 0.0 & 0.0 & 0.0 & 0.0 & 0.0 \\
\hline D5.4.1 & 0.0 & 0.0 & 0.0 & 0.0 & 0.0 & 0.0 & 0.0 & 0.0 \\
\hline D6.1.1 & 10.0 & 5.6 & 5.6 & 10.0 & 0.0 & 0.0 & 0.0 & 0.0 \\
\hline D6.2.1 & 10.0 & 5.6 & 5.6 & 10.0 & 0.0 & 0.0 & 0.0 & 0.0 \\
\hline Total (\%) & 92.3 & 83.7 & 67.3 & 73.6 & 4.1 & 3.6 & 11.4 & 7.4 \\
\hline
\end{tabular}


Table C-9. Mean weighted scores per metric for all four DRs: Objective 2.

\begin{tabular}{|c|c|c|c|c|c|c|c|c|}
\hline \multirow{2}{*}{ Metric } & \multicolumn{7}{|c|}{ Mean Values } & \multicolumn{3}{|c|}{ 10 } \\
\cline { 2 - 9 } & HTGR & SFR & LFR & FHR & HTGR & SFR & LFR & FHR \\
\hline D1.1.1 & 7.0 & 7.0 & 4.2 & 3.3 & 0.0 & 0.0 & 1.7 & 1.9 \\
\hline D1.2.1 & 3.0 & 3.0 & 3.0 & 3.0 & 0.0 & 0.0 & 0.0 & 0.0 \\
\hline D1.3.1 & 4.0 & 4.0 & 2.2 & 2.4 & 0.0 & 0.0 & 0.0 & 0.5 \\
\hline D1.4.1 & 3.0 & 3.0 & 2.4 & 1.7 & 0.0 & 0.0 & 0.9 & 0.0 \\
\hline D1.5.1 & 3.0 & 3.0 & 2.4 & 1.5 & 0.0 & 0.0 & 0.7 & 0.4 \\
\hline D2.1.1 & 4.8 & 4.8 & 3.7 & 5.5 & 1.1 & 1.1 & 1.1 & 0.0 \\
\hline D2.1.2 & 3.1 & 2.8 & 2.2 & 3.5 & 1.1 & 1.3 & 1.6 & 1.5 \\
\hline D2.2.1 & 3.5 & 3.2 & 2.7 & 0.4 & 0.8 & 0.9 & 0.8 & 0.0 \\
\hline D2.3.1 & 4.8 & 4.8 & 3.8 & 3.4 & 0.7 & 0.7 & 1.2 & 1.7 \\
\hline D3.1.1 & 9.4 & 9.8 & 7.8 & 7.4 & 1.3 & 0.0 & 2.3 & 2.3 \\
\hline D3.1.2 & 4.8 & 4.4 & 4.2 & 4.6 & 0.9 & 1.2 & 1.2 & 1.1 \\
\hline D4.1.1 & 7.0 & 7.0 & 4.7 & 4.2 & 0.0 & 0.0 & 2.0 & 0.9 \\
\hline D4.2.1 & 3.0 & 3.0 & 3.0 & 3.0 & 0.0 & 0.0 & 0.0 & 0.0 \\
\hline D4.2.2 & 3.0 & 3.0 & 3.0 & 3.0 & 0.0 & 0.0 & 0.0 & 0.0 \\
\hline D4.3.1 & 1.1 & 1.6 & 0.9 & 0.9 & 0.0 & 0.5 & 0.4 & 0.4 \\
\hline D4.3.2 & 1.2 & 1.5 & 0.9 & 1.2 & 0.3 & 0.5 & 0.4 & 0.5 \\
\hline D4.4.1 & 0.1 & 0.7 & 0.7 & 0.1 & 0.0 & 0.0 & 0.0 & 0.0 \\
\hline D4.4.2 & 0.4 & 0.2 & 0.1 & 0.4 & 0.0 & 0.2 & 0.0 & 0.0 \\
\hline D4.4.3 & 1.1 & 0.8 & 0.7 & 1.1 & 0.0 & 0.2 & 0.2 & 0.0 \\
\hline D5.1.1 & 1.7 & 11.3 & 11.3 & 1.7 & 1.5 & 0.0 & 0.0 & 1.5 \\
\hline D5.2.1 & 4.8 & 4.8 & 3.4 & 2.8 & 0.7 & 0.7 & 1.7 & 1.0 \\
\hline D5.3.1 & 4.8 & 5.0 & 3.0 & 3.8 & 0.7 & 0.0 & 1.8 & 1.2 \\
\hline D5.4.1 & 3.6 & 3.8 & 3.4 & 2.2 & 0.5 & 0.0 & 0.7 & 1.2 \\
\hline D6.1.1 & 0.0 & 0.0 & 0.0 & 0.0 & 0.0 & 0.0 & 0.0 & 0.0 \\
\hline D6.2.1 & 0.0 & 0.0 & 0.0 & 0.0 & 0.0 & 0.0 & 0.0 & 0.0 \\
\hline Total (\%) & $\mathbf{8 2 . 2}$ & $\mathbf{9 2 . 4}$ & $\mathbf{7 3 . 7}$ & $\mathbf{6 1 . 2}$ & $\mathbf{6 . 3}$ & $\mathbf{3 . 7}$ & $\mathbf{1 3 . 7}$ & $\mathbf{8 . 0}$ \\
\hline & & & & & & & & \\
\hline
\end{tabular}


Table C-10. Mean weighted scores per metric for all four DRs: Objective 3.

\begin{tabular}{|c|c|c|c|c|}
\hline \multirow{2}{*}{ Metric } & \multicolumn{2}{|c|}{ Mean Values } & \multicolumn{2}{|c|}{10} \\
\hline & LFR & FHR & LFR & FHR \\
\hline D1.1.1 & 7.3 & 5.8 & 2.9 & 3.3 \\
\hline D1.2.1 & 5.3 & 5.3 & 0.0 & 0.0 \\
\hline D1.3.1 & 3.9 & 4.2 & 0.0 & 0.9 \\
\hline D1.4.1 & 4.2 & 2.9 & 1.6 & 0.0 \\
\hline D1.5.1 & 4.2 & 2.7 & 1.2 & 0.7 \\
\hline D2.1.1 & 3.7 & 5.5 & 1.1 & 0.0 \\
\hline D2.1.2 & 2.2 & 3.5 & 1.6 & 1.5 \\
\hline D2.2.1 & 2.7 & 0.4 & 0.8 & 0.0 \\
\hline D2.3.1 & 3.8 & 3.4 & 1.2 & 1.7 \\
\hline D3.1.1 & 7.8 & 7.4 & 2.3 & 2.3 \\
\hline D3.1.2 & 4.2 & 4.6 & 1.2 & 1.1 \\
\hline D4.1.1 & 4.7 & 4.2 & 2.0 & 0.9 \\
\hline D4.2.1 & 3.0 & 3.0 & 0.0 & 0.0 \\
\hline D4.2.2 & 3.0 & 3.0 & 0.0 & 0.0 \\
\hline D4.3.1 & 0.9 & 0.9 & 0.4 & 0.4 \\
\hline D4.3.2 & 0.9 & 1.2 & 0.4 & 0.5 \\
\hline D4.4.1 & 0.7 & 0.1 & 0.0 & 0.0 \\
\hline D4.4.2 & 0.1 & 0.4 & 0.0 & 0.0 \\
\hline D4.4.3 & 0.7 & 1.1 & 0.2 & 0.0 \\
\hline D5.1.1 & 2.3 & 0.3 & 0.0 & 0.3 \\
\hline D5.2.1 & 0.7 & 0.6 & 0.3 & 0.2 \\
\hline D5.3.1 & 0.6 & 0.8 & 0.4 & 0.2 \\
\hline D5.4.1 & 0.7 & 0.4 & 0.1 & 0.2 \\
\hline D6.1.1 & 1.4 & 2.5 & 0.0 & 0.0 \\
\hline D6.2.1 & 1.4 & 2.5 & 0.0 & 0.0 \\
\hline Total (\%) & 70.3 & 66.7 & 13.3 & 8.5 \\
\hline
\end{tabular}

\section{C-1.1.2 Weighting Factor Sensitivity Studies}

In this section the more information is supplied on the sensitivity Studies 1 and 3.

\section{C-1.1.3 Sensitivity Study 1: Goals D1-D6 sequentially set to $100 \%$}

In the first sensitivity study, the weights of the six goals defined in Section 2 are sequentially set to $100 \%$, while keeping all other goal weights at zero. The effective weights applied for Goals 1-6 are presented in Table C-11 to Table C-16. Note that since the goals for the three objectives are all set equal to 1.0 , the effective weights are the same for all three objectives. 
Table C-11. Weights for Goal D1 set to $100 \%$.

\begin{tabular}{|c|c|c|c|c|c|c|c|c|c|c|}
\hline \multicolumn{4}{|c|}{ Goal } & \multirow{2}{*}{\multicolumn{2}{|c|}{ Criteria }} & \multirow{2}{*}{\multicolumn{2}{|c|}{ Metrics }} & \multicolumn{3}{|c|}{ Effective Weight } \\
\hline & 1 & 2 & 3 & & & & & 1 & 2 & 3 \\
\hline \multirow{5}{*}{ D1 } & \multirow{5}{*}{1.00} & \multirow{5}{*}{1.00} & \multirow{5}{*}{1.00} & D1.1 & 0.35 & D1.1.1 & 1.00 & 0.35 & 0.35 & 0.35 \\
\hline & & & & D1.2 & 0.15 & D1.2.1 & 1.00 & 0.15 & 0.15 & 0.15 \\
\hline & & & & D1.3 & 0.20 & D1.3.1 & 1.00 & 0.20 & 0.20 & 0.20 \\
\hline & & & & D1.4 & 0.15 & D1.4.1 & 1.00 & 0.15 & 0.15 & 0.15 \\
\hline & & & & D1.5 & 0.15 & D1.5.1 & 1.00 & 0.15 & 0.15 & 0.15 \\
\hline
\end{tabular}

Table C-12. Weights for Goal D2 set to $100 \%$.

\begin{tabular}{|c|c|c|c|c|c|c|c|c|c|c|}
\hline \multicolumn{4}{|c|}{ Goal } & \multirow{2}{*}{\multicolumn{2}{|c|}{ Criteria }} & \multirow{2}{*}{\multicolumn{2}{|c|}{ Metrics }} & \multicolumn{3}{|c|}{ Effective Weight } \\
\hline & 1 & 2 & 3 & & & & & 1 & 2 & 3 \\
\hline \multirow{4}{*}{ D2 } & \multirow{4}{*}{1.00} & \multirow{4}{*}{1.00} & \multirow{4}{*}{1.00} & \multirow{2}{*}{ D2.1 } & \multirow{2}{*}{0.55} & D2.1.1 & 0.50 & 0.28 & 0.28 & 0.28 \\
\hline & & & & & & D2.1.2 & 0.50 & 0.28 & 0.28 & 0.28 \\
\hline & & & & D2.2 & 0.20 & D2.2.1 & 1.00 & 0.20 & 0.20 & 0.20 \\
\hline & & & & D2.3 & 0.25 & D2.3.1 & 1.00 & 0.25 & 0.25 & 0.25 \\
\hline
\end{tabular}

Table C-13. Weights for Goal D3 set to $100 \%$.

\begin{tabular}{|c|c|c|c|c|c|c|c|c|c|c|}
\hline \multicolumn{4}{|c|}{ Goal } & \multirow{2}{*}{\multicolumn{2}{|c|}{ Criteria }} & \multirow{2}{*}{\multicolumn{2}{|c|}{ Metrics }} & \multicolumn{3}{|c|}{ Effective Weight } \\
\hline & 1 & 2 & 3 & & & & & 1 & 2 & 3 \\
\hline \multirow{2}{*}{ D3 } & \multirow{2}{*}{1.00} & \multirow{2}{*}{1.00} & \multirow{2}{*}{1.00} & \multirow{2}{*}{ D3.1 } & \multirow{2}{*}{1.00} & D3.1.1 & 0.65 & 0.65 & 0.65 & 0.65 \\
\hline & & & & & & D3.1.2 & 0.35 & 0.35 & 0.35 & 0.35 \\
\hline
\end{tabular}

Table C-14. Weights for Goal D4 set to 100\%.

\begin{tabular}{|c|c|c|c|c|c|c|c|c|c|c|}
\hline \multicolumn{4}{|c|}{ Goal } & \multirow{2}{*}{\multicolumn{2}{|c|}{ Criteria }} & \multirow{2}{*}{\multicolumn{2}{|c|}{ Metrics }} & \multicolumn{3}{|c|}{ Effective Weight } \\
\hline & 1 & 2 & 3 & & & & & 1 & 2 & 3 \\
\hline \multirow{8}{*}{ D4 } & \multirow{8}{*}{1.00} & \multirow{8}{*}{1.00} & \multirow{8}{*}{1.00} & D4.1 & 0.35 & D4.1.1 & 1.00 & 0.35 & 0.35 & 0.35 \\
\hline & & & & \multirow{2}{*}{ D4.2 } & \multirow{2}{*}{0.30} & D4.2.1 & 0.50 & 0.15 & 0.15 & 0.15 \\
\hline & & & & & & D4.2.2 & 0.50 & 0.15 & 0.15 & 0.15 \\
\hline & & & & \multirow{2}{*}{ D4.3 } & \multirow{2}{*}{0.20} & D4.3.1 & 0.50 & 0.10 & 0.10 & 0.10 \\
\hline & & & & & & D4.3.2 & 0.50 & 0.10 & 0.10 & 0.10 \\
\hline & & & & \multirow{3}{*}{ D4.4 } & \multirow{3}{*}{0.15} & D4.4.1 & 0.40 & 0.06 & 0.06 & 0.06 \\
\hline & & & & & & D4.4.2 & 0.25 & 0.04 & 0.04 & 0.04 \\
\hline & & & & & & D4.4.3 & 0.35 & 0.05 & 0.05 & 0.05 \\
\hline
\end{tabular}


Table C-15. Weights for Goal D5 set to $100 \%$.

\begin{tabular}{|c|c|c|c|c|c|c|c|c|c|c|}
\hline \multicolumn{4}{|c|}{ Goal } & \multirow{2}{*}{\multicolumn{2}{|c|}{ Criteria }} & \multirow{2}{*}{\multicolumn{2}{|c|}{ Metrics }} & \multicolumn{3}{|c|}{ Effective Weight } \\
\hline & 1 & 2 & 3 & & & & & 1 & 2 & 3 \\
\hline \multirow{4}{*}{ D5 } & \multirow{4}{*}{1.00} & \multirow{4}{*}{1.00} & \multirow{4}{*}{1.00} & D5.1 & 0.45 & D5.1.1 & 1.00 & 0.45 & 0.45 & 0.45 \\
\hline & & & & D5.2 & 0.20 & D5.2.1 & 1.00 & 0.20 & 0.20 & 0.20 \\
\hline & & & & D5.3 & 0.20 & D5.3.1 & 1.00 & 0.20 & 0.20 & 0.20 \\
\hline & & & & D5.4 & 0.15 & D5.4.1 & 1.00 & 0.15 & 0.15 & 0.15 \\
\hline
\end{tabular}

Table C-16. Weights for Goal D6 set to $100 \%$.

\begin{tabular}{|c|c|c|c|c|c|c|c|c|c|c|}
\hline \multicolumn{4}{|c|}{ Goal } & \multirow{2}{*}{\multicolumn{2}{|c|}{ Criteria }} & \multirow{2}{*}{\multicolumn{2}{|c|}{ Metrics }} & \multicolumn{3}{|r|}{ Effective weight } \\
\hline & 1 & 2 & 3 & & & & & 1 & 2 & 3 \\
\hline \multirow{2}{*}{ D6 } & \multirow{2}{*}{1.00} & \multirow{2}{*}{1.00} & \multirow{2}{*}{1.00} & D6.1 & 0.50 & D6.1.1 & 1.00 & 0.50 & 0.50 & 0.50 \\
\hline & & & & D6.2 & 0.50 & D6.2.1 & 1.00 & 0.50 & 0.50 & 0.50 \\
\hline
\end{tabular}

\section{C-1.1.4 Sensitivity Study 3: Reduce the set of 25 metrics to only 5}

In the final sensitivity study, only the top five metrics for each objective were preserved and re-normalized to $100 \%$. The weights for all other metrics were set to zero. The resultant effective weights are shown in Table C-17.

Table C-17. Updated weighting factors for the top five metrics.

\begin{tabular}{|c|l|c|c|c|}
\hline \multirow{2}{*}{ Metric } & \multicolumn{1}{|c|}{ Description } & \multicolumn{2}{|c|}{ Effective Weight (\%) } \\
\cline { 3 - 5 } D1.1.1 & $\begin{array}{l}\text { Capability to demonstrate safety behaviour of } \\
\text { commercial system }\end{array}$ & 19 & $\mathbf{2}$ & $\mathbf{3}$ \\
\hline D1.3.1 & $\begin{array}{l}\text { Technology selections that are } \\
\text { prototypic/scalable to commercial unit }\end{array}$ & - & - & 29 \\
\hline D2.1.1 & Project cost & - & 17 & 17 \\
\hline D3.1.1 & $\begin{array}{l}\text { Ability to address key licensing issues for } \\
\text { commercial units }\end{array}$ & 23 & 24 & 23 \\
\hline D4.1.1 & $\begin{array}{l}\text { Demonstration of components expected in } \\
\text { commercial units }\end{array}$ & 15 & 17 & 17 \\
\hline D5.1.1 & Use of fuel natural resources & - & 27 & - \\
\hline D6.1.1 & $\begin{array}{l}\text { Number of energy conversion systems or } \\
\text { industrial applications }\end{array}$ & 22 & - & - \\
\hline D6.2.1 & Coolant outlet temperature & 22 & - & - \\
\hline
\end{tabular}

\section{C-1.2 Test Reactor Detailed Results}

The summarized raw score and standard deviation breakdowns are provided for each test reactor metric in Table C-18 for both test reactors (HTGR-TR) and (SFR-TR). The detailed scores of the assessment team members for the two designs are provided in Table C-19 and Table C-20. The results are also summed for a total score and converted to a percent of total possible score in the tables. 
Table C-18. Mean and standard deviation raw scores per metric for the two test reactors.

\begin{tabular}{|c|c|c|c|c|}
\hline \multirow{2}{*}{ Metric } & \multicolumn{2}{|c|}{ Mean Values } & \multicolumn{2}{c|}{ 正 } \\
\cline { 2 - 5 } & HTGR & SFR-TR & HTGR & SFR-TR \\
\hline T1.1.1 & 1.0 & 9.0 & 0.0 & 0.0 \\
\hline T1.1.2 & 5.0 & 9.0 & 0.0 & 0.0 \\
\hline T1.1.3 & 9.0 & 6.8 & 0.0 & 2.1 \\
\hline T1.1.4 & 9.0 & 9.0 & 0.0 & 0.0 \\
\hline T1.1.5 & 6.5 & 9.0 & 3.2 & 0.0 \\
\hline T1.2.1 & 9.0 & 9.0 & 0.0 & 0.0 \\
\hline T1.2.2 & 6.1 & 9.0 & 3.6 & 0.0 \\
\hline T1.2.3 & 9.0 & 9.0 & 0.0 & 0.0 \\
\hline T2.1.1 & 4.6 & 5.0 & 1.2 & 0.0 \\
\hline T2.1.2 & 4.6 & 4.6 & 1.2 & 1.2 \\
\hline T2.2.1 & 5.0 & 5.0 & 0.0 & 0.0 \\
\hline T2.3.1 & 5.0 & 7.9 & 0.0 & 1.9 \\
\hline T3.1.1 & 9.0 & 9.0 & 0.0 & 0.0 \\
\hline Total (\%) & $\mathbf{7 1}$ & $\mathbf{8 7}$ & $\mathbf{5 . 8}$ & $\mathbf{2 . 8}$ \\
\hline
\end{tabular}

Table C-19. HTGR-TR raw scores.

\begin{tabular}{|c|c|c|c|c|c|c|c|c|c|c|c|c|c|}
\hline Metric & A & B & C & D & E & F & G & H & I & J & K & Mean & 10 \\
\hline T1.1.1 & 1 & 1 & 1 & 1 & 1 & 1 & 1 & 1 & 1 & 1 & 1 & $\mathbf{1 . 0}$ & 0.0 \\
\hline T1.1.2 & 5 & 5 & 5 & 5 & 5 & 5 & 5 & 5 & 5 & 5 & 5 & $\mathbf{5 . 0}$ & 0.0 \\
\hline T1.1.3 & 9 & 9 & 9 & 9 & 9 & 9 & 9 & 9 & 9 & 9 & 9 & $\mathbf{9 . 0}$ & 0.0 \\
\hline T1.1.4 & 9 & 9 & 9 & 9 & 9 & 9 & 9 & 9 & 9 & 9 & 9 & $\mathbf{9 . 0}$ & 0.0 \\
\hline T1.1.5 & 5 & 9 & 5 & 9 & 5 & 9 & 1 & 9 & 9 & 9 & 1 & $\mathbf{6 . 5}$ & 3.2 \\
\hline T1.2.1 & 9 & 9 & 9 & 9 & 9 & 9 & 9 & 9 & 9 & 9 & 9 & $\mathbf{9 . 0}$ & 0.0 \\
\hline T1.2.2 & 1 & 9 & 5 & 9 & 9 & 9 & 1 & 5 & 9 & 9 & 1 & $\mathbf{6 . 1}$ & 3.6 \\
\hline T1.2.3 & 9 & 9 & 9 & 9 & 9 & 9 & 9 & 9 & 9 & 9 & 9 & $\mathbf{9 . 0}$ & 0.0 \\
\hline T2.1.1 & 5 & 5 & 1 & 5 & 5 & 5 & 5 & 5 & 5 & 5 & 5 & $\mathbf{4 . 6}$ & 1.2 \\
\hline T2.1.2 & 5 & 5 & 5 & 5 & 1 & 5 & 5 & 5 & 5 & 5 & 5 & $\mathbf{4 . 6}$ & 1.2 \\
\hline T2.2.1 & 5 & 5 & 5 & 5 & 5 & 5 & 5 & 5 & 5 & 5 & 5 & $\mathbf{5 . 0}$ & 0.0 \\
\hline T2.3.1 & 5 & 5 & 5 & 5 & 5 & 5 & 5 & 5 & 5 & 5 & 5 & $\mathbf{5 . 0}$ & 0.0 \\
\hline T3.1.1 & 9 & 9 & 9 & 9 & 9 & 9 & 9 & 9 & 9 & 9 & 9 & $\mathbf{9 . 0}$ & 0.0 \\
\hline Total & 77 & 89 & 77 & 89 & 81 & 89 & 73 & 85 & 89 & 89 & 73 & 82.8 & 6.8 \\
\hline \% & $\mathbf{6 5 . 8}$ & $\mathbf{7 6 . 1}$ & $\mathbf{6 5 . 8}$ & $\mathbf{7 6 . 1}$ & $\mathbf{6 9 . 2}$ & $\mathbf{7 6 . 1}$ & $\mathbf{6 2 . 4}$ & $\mathbf{7 2 . 6}$ & $\mathbf{7 6 . 1}$ & $\mathbf{7 6 . 1}$ & $\mathbf{6 2 . 4}$ & $\mathbf{7 0 . 8}$ & $\mathbf{5 . 8}$ \\
\hline
\end{tabular}


Table C-20. SFR-TR raw scores.

\begin{tabular}{|c|c|c|c|c|c|c|c|c|c|c|c|c|c|}
\hline Metric & A & B & C & D & E & F & G & H & I & J & K & Mean & 1 \\
\hline T1.1.1 & 9 & 9 & 9 & 9 & 9 & 9 & 9 & 9 & 9 & 9 & 9 & 9.0 & 0.0 \\
\hline T1.1.2 & 9 & 9 & 9 & 9 & 9 & 9 & 9 & 9 & 9 & 9 & 9 & 9.0 & 0.0 \\
\hline T1.1.3 & 9 & 5 & 5 & 9 & 9 & 9 & 5 & 5 & 9 & 5 & 5 & 6.8 & 2.1 \\
\hline T1.1.4 & 9 & 9 & 9 & 9 & 9 & 9 & 9 & 9 & 9 & 9 & 9 & 9.0 & 0.0 \\
\hline T1.1.5 & 9 & 9 & 9 & 9 & 9 & 9 & 9 & 9 & 9 & 9 & 9 & 9.0 & 0.0 \\
\hline T1.2.1 & 9 & 9 & 9 & 9 & 9 & 9 & 9 & 9 & 9 & 9 & 9 & 9.0 & 0.0 \\
\hline T1.2.2 & 9 & 9 & 9 & 9 & 9 & 9 & 9 & 9 & 9 & 9 & 9 & 9.0 & 0.0 \\
\hline T1.2.3 & 9 & 9 & 9 & 9 & 9 & 9 & 9 & 9 & 9 & 9 & 9 & 9.0 & 0.0 \\
\hline T2.1.1 & 5 & 5 & 5 & 5 & 5 & 5 & 5 & 5 & 5 & 5 & 5 & 5.0 & 0.0 \\
\hline T2.1.2 & 5 & 5 & 5 & 5 & 1 & 5 & 5 & 5 & 5 & 5 & 5 & 4.6 & 1.2 \\
\hline T2.2.1 & 5 & 5 & 5 & 5 & 5 & 5 & 5 & 5 & 5 & 5 & 5 & 5.0 & 0.0 \\
\hline T2.3.1 & 9 & 5 & 5 & 9 & 9 & 9 & 9 & 5 & 9 & 9 & 9 & 7.9 & 1.9 \\
\hline T3.1.1 & 9 & 9 & 9 & 9 & 9 & 9 & 9 & 9 & 9 & 9 & 9 & 9.0 & 0.0 \\
\hline Total & 105 & 97 & 97 & 105 & 101 & 105 & 101 & 97 & 105 & 101 & 101 & 101.4 & 3.3 \\
\hline \% & $\mathbf{8 9 . 7}$ & $\mathbf{8 2 . 9}$ & $\mathbf{8 2 . 9}$ & $\mathbf{8 9 . 7}$ & $\mathbf{8 6 . 3}$ & $\mathbf{8 9 . 7}$ & $\mathbf{8 6 . 3}$ & $\mathbf{8 2 . 9}$ & $\mathbf{8 9 . 7}$ & $\mathbf{8 6 . 3}$ & $\mathbf{8 6 . 3}$ & $\mathbf{8 6 . 6}$ & $\mathbf{2 . 8}$ \\
\hline
\end{tabular}

\section{C-1.2.1 Weighted Scores against Strategic Objective 4}

The effective contributions of the test reactor metrics and their relative importance ranking are indicated in Table C-21.

Table C-21. Test reactor effective metric contributions.

\begin{tabular}{|c|l|c|c|}
\hline Metrics & \multicolumn{1}{|c|}{ Description } & Effective weight & Rank \\
\hline T1.1.1 & Fast Flux conditions & $16 \%$ & 1 \\
\hline T1.1.2 & Thermal Flux conditions & $9 \%$ & 5 \\
\hline T1.1.3 & Irradiation volumes and length & $11 \%$ & 2 \\
\hline T1.1.4 & Maximum sustainable time at power & $5 \%$ & 11 \\
\hline T1.1.5 & Provisions for testing prototypic and bounding conditions & $5 \%$ & 11 \\
\hline T1.2.1 & Number of test zones & $10 \%$ & 3 \\
\hline T1.2.2 & Number and type of distinct and independent irradiation test loops & $10 \%$ & 3 \\
\hline T1.2.3 & Ability to insert/retrieve irradiation specimen while staying at power & $5 \%$ & 10 \\
\hline T2.1.1 & Project cost & $6 \%$ & 8 \\
\hline T2.1.2 & Project Schedule & $3 \%$ & 13 \\
\hline T2.2.1 & Annual operating costs & $8 \%$ & 7 \\
\hline T2.3.1 & Availability factor & $9 \%$ & 6 \\
\hline T3.1.1 & Number of secondary missions & $5 \%$ & 9 \\
\hline
\end{tabular}

The mean weighted value and standard deviation of the individual assessment teams scores for each metric are provided in Table C-22 (HTGR-TR) and Table C-23 (SFR TR). The tables also contain the overall summed score across all metrics for each point design and the standard deviations. 
Table C-22. Detailed weighted scores per metric for the HTGR-TR.

\begin{tabular}{|c|c|c|c|c|c|c|c|c|c|c|c|c|c|}
\hline Metric & A & B & C & D & E & F & G & H & I & J & K & Mean & 1 \\
\hline T1.1.1 & 1.8 & 1.8 & 1.8 & 1.8 & 1.8 & 1.8 & 1.8 & 1.8 & 1.8 & 1.8 & 1.8 & 1.8 & 0.0 \\
\hline T1.1.2 & 5.1 & 5.1 & 5.1 & 5.1 & 5.1 & 5.1 & 5.1 & 5.1 & 5.1 & 5.1 & 5.1 & 5.1 & 0.0 \\
\hline T1.1.3 & 11.4 & 11.4 & 11.4 & 11.4 & 11.4 & 11.4 & 11.4 & 11.4 & 11.4 & 11.4 & 11.4 & 11.4 & 0.0 \\
\hline T1.1.4 & 4.6 & 4.6 & 4.6 & 4.6 & 4.6 & 4.6 & 4.6 & 4.6 & 4.6 & 4.6 & 4.6 & 4.6 & 0.0 \\
\hline T1.1.5 & 2.5 & 4.6 & 2.5 & 4.6 & 2.5 & 4.6 & 0.5 & 4.6 & 4.6 & 4.6 & 0.5 & 3.3 & 1.6 \\
\hline T1.2.1 & 9.8 & 9.8 & 9.8 & 9.8 & 9.8 & 9.8 & 9.8 & 9.8 & 9.8 & 9.8 & 9.8 & 9.8 & 0.0 \\
\hline T1.2.2 & 1.1 & 9.8 & 5.4 & 9.8 & 9.8 & 9.8 & 1.1 & 5.4 & 9.8 & 9.8 & 1.1 & 6.6 & 3.9 \\
\hline T1.2.3 & 4.9 & 4.9 & 4.9 & 4.9 & 4.9 & 4.9 & 4.9 & 4.9 & 4.9 & 4.9 & 4.9 & 4.9 & 0.0 \\
\hline T2.1.1 & 3.4 & 3.4 & 0.7 & 3.4 & 3.4 & 3.4 & 3.4 & 3.4 & 3.4 & 3.4 & 3.4 & 3.2 & 0.8 \\
\hline T2.1.2 & 1.5 & 1.5 & 1.5 & 1.5 & 0.3 & 1.5 & 1.5 & 1.5 & 1.5 & 1.5 & 1.5 & 1.4 & 0.4 \\
\hline T2.2.1 & 4.2 & 4.2 & 4.2 & 4.2 & 4.2 & 4.2 & 4.2 & 4.2 & 4.2 & 4.2 & 4.2 & 4.2 & 0.0 \\
\hline T2.3.1 & 4.9 & 4.9 & 4.9 & 4.9 & 4.9 & 4.9 & 4.9 & 4.9 & 4.9 & 4.9 & 4.9 & 4.9 & 0.0 \\
\hline T3.1.1 & 5.0 & 5.0 & 5.0 & 5.0 & 5.0 & 5.0 & 5.0 & 5.0 & 5.0 & 5.0 & 5.0 & 5.0 & 0.0 \\
\hline Total & $\mathbf{6 0 . 0}$ & $\mathbf{7 0 . 7}$ & $\mathbf{6 1 . 6}$ & $\mathbf{7 0 . 7}$ & $\mathbf{6 7 . 5}$ & $\mathbf{7 0 . 7}$ & $\mathbf{5 7 . 9}$ & $\mathbf{6 6 . 3}$ & $\mathbf{7 0 . 7}$ & $\mathbf{7 0 . 7}$ & $\mathbf{5 7 . 9}$ & $\mathbf{6 5 . 9}$ & $\mathbf{5 . 5}$ \\
\hline
\end{tabular}

Table C-23. Detailed weighted scores per metric for SFR-TR.

\begin{tabular}{|c|c|c|c|c|c|c|c|c|c|c|c|c|c|}
\hline Metric & A & B & C & D & $E$ & $F$ & G & $\mathbf{H}$ & I & $\mathbf{J}$ & K & Mean & $1 \sigma$ \\
\hline T1.1.1 & 15.9 & 15.9 & 15.9 & 15.9 & 15.9 & 15.9 & 15.9 & 15.9 & 15.9 & 15.9 & 15.9 & 15.9 & 0.0 \\
\hline T1.1.2 & 9.1 & 9.1 & 9.1 & 9.1 & 9.1 & 9.1 & 9.1 & 9.1 & 9.1 & 9.1 & 9.1 & 9.1 & 0.0 \\
\hline T1.1.3 & 11.4 & 6.3 & 6.3 & 11.4 & 11.4 & 11.4 & 6.3 & 6.3 & 11.4 & 6.3 & 6.3 & 8.6 & 2.6 \\
\hline T1.1.4 & 4.6 & 4.6 & 4.6 & 4.6 & 4.6 & 4.6 & 4.6 & 4.6 & 4.6 & 4.6 & 4.6 & 4.6 & 0.0 \\
\hline T1.1.5 & 4.6 & 4.6 & 4.6 & 4.6 & 4.6 & 4.6 & 4.6 & 4.6 & 4.6 & 4.6 & 4.6 & 4.6 & 0.0 \\
\hline T1.2.1 & 9.8 & 9.8 & 9.8 & 9.8 & 9.8 & 9.8 & 9.8 & 9.8 & 9.8 & 9.8 & 9.8 & 9.8 & 0.0 \\
\hline T1.2.2 & 9.8 & 9.8 & 9.8 & 9.8 & 9.8 & 9.8 & 9.8 & 9.8 & 9.8 & 9.8 & 9.8 & 9.8 & 0.0 \\
\hline T1.2.3 & 4.9 & 4.9 & 4.9 & 4.9 & 4.9 & 4.9 & 4.9 & 4.9 & 4.9 & 4.9 & 4.9 & 4.9 & 0.0 \\
\hline T2.1.1 & 3.4 & 3.4 & 3.4 & 3.4 & 3.4 & 3.4 & 3.4 & 3.4 & 3.4 & 3.4 & 3.4 & 3.4 & 0.0 \\
\hline T2.1.2 & 1.5 & 1.5 & 1.5 & 1.5 & 0.3 & 1.5 & 1.5 & 1.5 & 1.5 & 1.5 & 1.5 & 1.4 & 0.4 \\
\hline T2.2.1 & 4.2 & 4.2 & 4.2 & 4.2 & 4.2 & 4.2 & 4.2 & 4.2 & 4.2 & 4.2 & 4.2 & 4.2 & 0.0 \\
\hline T2.3.1 & 8.8 & 4.9 & 4.9 & 8.8 & 8.8 & 8.8 & 8.8 & 4.9 & 8.8 & 8.8 & 8.8 & 7.7 & 1.8 \\
\hline T3.1.1 & 5.0 & 5.0 & 5.0 & 5.0 & 5.0 & 5.0 & 5.0 & 5.0 & 5.0 & 5.0 & 5.0 & 5.0 & 0.0 \\
\hline Total & 92.8 & 83.8 & 83.8 & 92.8 & 91.6 & 92.8 & 87.7 & 83.8 & 92.8 & 87.7 & 87.7 & 88.9 & 3.9 \\
\hline
\end{tabular}


Appendix D

\section{Gap Analysis of Test Reactor Capabilities for Advanced Reactor Testing}




\section{Appendix D \\ Gap Analysis of Test Reactor Capabilities for Advanced Reactor Testing}

D-1. Gap Analysis

Nuclear reactor systems are envisioned to operate over a wide range of dose and temperature depending on the reactor design. For fuels and materials testing, the key metric is the radiation-induced displacement damage in terms of displacements-per-atom (dpa). The level of damage is a function of the material being tested, the damage cross section, the neutron energy spectrum and the time of irradiation. Figure D-1 shows the displacement dose/temperature operating windows for LWRs shown as Generation II-III, the different Gen-IV concepts, and fusion. LWRs operate at low temperature $\left(300^{\circ} \mathrm{C}\right)$ and low dose $(<5-50 \mathrm{dpa}$ ) [1]. VHTRs (and thermal-spectrum fluoride salt cooled high temperature systems not shown in the figure) also operate at low doses $(<5-30 \mathrm{dpa})$ but high temperatures $\left(600-1000^{\circ} \mathrm{C}\right)$. Fast neutron systems (such as the SFR, LFR, GFR, and fast-spectrum MSR) operate at much higher dose $(50-200 \mathrm{dpa})$ and a range of temperatures $\left(400-1000^{\circ} \mathrm{C}\right)$ depending on the design concept. (Shown in the figure is the Traveling Wave Reactor, which has expected damage levels of $500 \mathrm{dpa}$.) These operating windows establish the basic testing needs for these systems. Although the state of development varies between the Gen-IV concepts, these advanced systems would benefit from a test reactor capability for irradiation testing and post-irradiation examination in hot cells to develop and qualify fuels and materials.

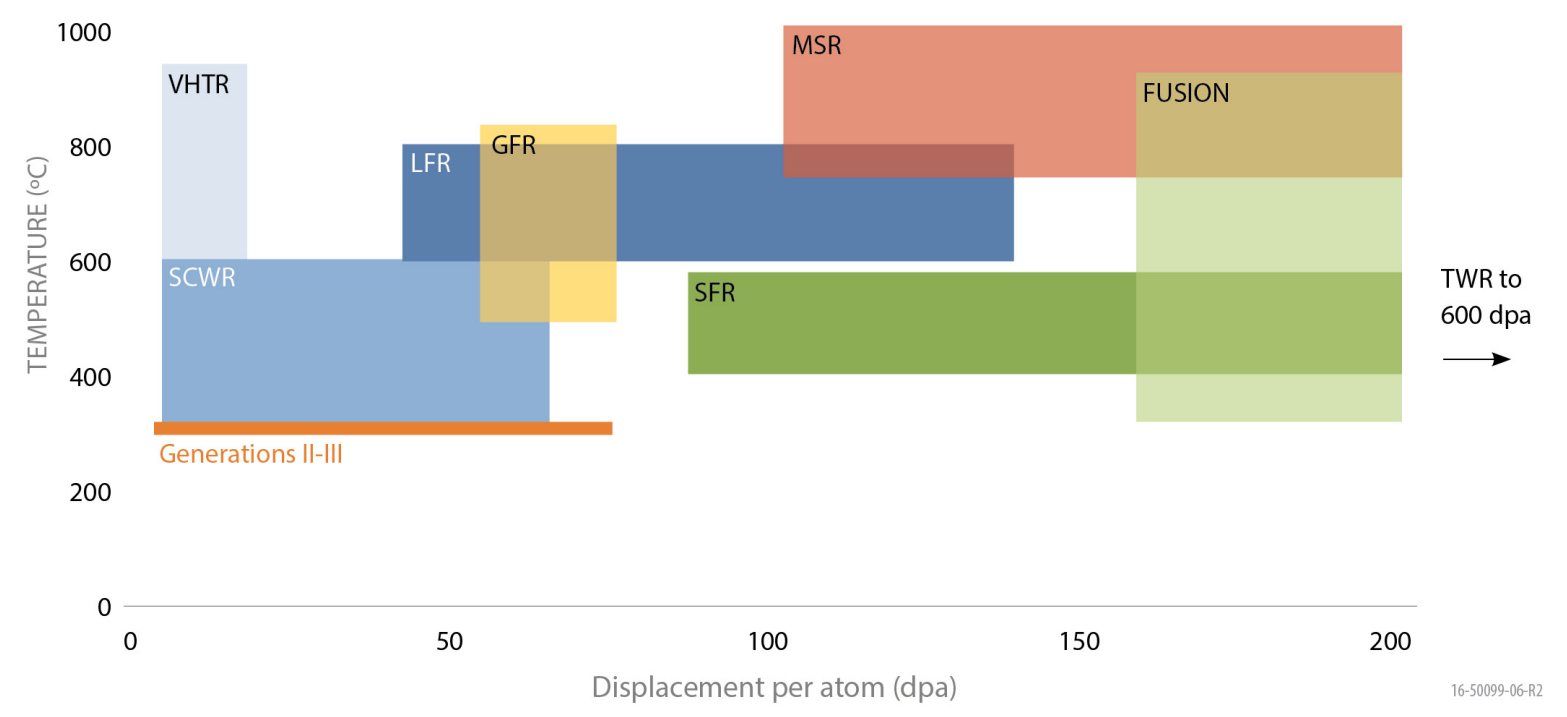

Figure D-1. Temperature/displacement damage (dose) windows for fission and fusion concepts. 
Table D-1 lists all of the major reactor irradiation facilities in operation around the world along with a description of the maximum fluxes and power level. For simplicity, a fast flux of $1 \mathrm{E} 15 \mathrm{n} / \mathrm{cm}^{2}-\mathrm{s}$ is the equivalent of $10 \mathrm{dpa} / \mathrm{year}$ in iron if the test reactor operates with high availability. The availability of test reactors varies widely between 160 and 310 days per year because of a combination of required fuel change outs and budget constraints that limit how much damage a sample can obtain. For example, today High-Flux Isotope Reactor (HFIR) runs 6 cycles or 24 weeks (169 days) per year. HFR-Petten, when it is operating, runs for 11 cycles and 44 weeks (308 days) per year. The HBWR at Halden operates 35 cycles for 28 weeks (196 days) during a year. ATR operates between 180 and 220 days at about $110 \mathrm{MW}$.

Note that peak fluxes in the table and corresponding damage rates may occur in very small volumes that limit the ability for a large number of samples to experience the peak damage rate during irradiation. Also note that flux levels for the flux traps in thermal reactor irradiation facilities can be misleading. Often the peak thermal and fast fluxes occur in the same region, in which case the absorption reactions (fission and capture) are dominated by thermal neutrons, but material damage is dominated by fast neutrons. This can be non-prototypic for reactor environments. For example, in such environments with thermal and fast neutrons, fast reactor fuel would have burnup and activation from thermal neutrons, with damage from fast-resulting in wrong burnup/damage ratio or too much activation in structural steels. Thus, simplistic comparisons between test reactor systems can be misleading.

The volumes available for testing vary widely in these reactors. For example, of the 34 ATR in-core test locations, nine are large flux traps that range from 7.5 to $12.5 \mathrm{~cm}$ in diameter. The reflector contains 36 test positions. HFIR has 37 in-core irradiation channels and 42 channels in the reflector. HFR-Petten has 19 in-core channels and 12 in the reflector. A few of these locations in both facilities are also large irradiation locations (5 to $10 \mathrm{~cm}$ in diameter). In thermal irradiation facilities, many of the locations of peak fast flux are in much smaller channels, typically 1.25 to $2.5 \mathrm{~cm}$ in diameter. The fast flux in these test reactors follows a typical cosine over their axial length. For ATR, a 1.2-meter high core, the peak-to-average ratio is 1.44 , so the average damage along the axial length is only $70 \%$ of the peak value.

In general, large volumes are advantageous for fuels testing because they can incorporate test specimens that can be more prototypic of actual fuel geometry. However, usually the larger test volumes suffer from a decrease in flux compared to the locations of peak fluxes that tend to be much smaller. This is of less concern when irradiating materials specimens; specimen size can be quite small and still obtain useful performance information. Fuel testing is usually done in real time or near real time conditions, whereas material testing is often conducted under very accelerated conditions. These divergent approaches lead to fuels irradiation positions usually being different than materials testing positions in the materials test reactor. Thus, depending on the needs of the customer, flux levels, test volumes, and fast-to-thermal ratios differ. A test reactor that offers a wide variety of conditions is most useful to meet the broadest range of needs. 
Table D-1. Listing of reactor irradiation facilities around the world. ${ }^{a}$

\begin{tabular}{|c|c|c|c|c|}
\hline \multicolumn{5}{|c|}{ Maximum Flux } \\
\hline \multicolumn{5}{|c|}{ U.S. Thermal Test Reactors } \\
\hline ATR & $\begin{array}{l}\text { Thermal } \\
\text { Neutron } \\
\text { MTR }\end{array}$ & $\begin{array}{c}\text { USA } \\
\text { Idaho Falls }\end{array}$ & $\begin{array}{l}8.5 \times 10^{14} \text { Thermal } \\
\text { (steady state }[\mathrm{SS}] \text { ) } \\
1.8 \times 10^{14} \text { Fast }(\mathrm{SS}) \\
2.5 \times 10^{5} \mathrm{~kW} \text { Steady } \\
\text { Thermal Power } \\
1 \times 10^{15} \text { Flux (In-Core) }\end{array}$ & $\begin{array}{l}\text { Five pressurized loops. Thirty-four in-core } \\
\text { irradiation channels. Thirty-six reflector } \\
\text { irradiation channels. Light water cooled. } \\
\text { Large volume and high flux. }\end{array}$ \\
\hline HFIR & $\begin{array}{l}\text { Thermal } \\
\text { Neutron } \\
\text { MTR }\end{array}$ & $\begin{array}{c}\text { USA } \\
\text { Oak Ridge }\end{array}$ & $\begin{array}{l}2.5 \times 10^{15} \text { Thermal (SS) } \\
1.0 \times 10^{15} \text { Fast (SS) } \\
8.5 \times 10^{4} \mathrm{~kW} \text { Steady } \\
\text { Thermal Power } \\
2.5 \times 10^{15} \text { Flux (In-Core) } \\
1.5 \times 10^{15} \text { Flux } \\
\text { (Reflector) }\end{array}$ & $\begin{array}{l}\text { Light water cooled. Thirty-seven in-core } \\
\text { irradiation channels. Forty-two reflector } \\
\text { irradiation channels. Use: Neutron } \\
\text { scattering research, materials neutron } \\
\text { damage testing, isotope production, } \\
\text { neutron activation analysis. Small volume } \\
\text { high flux. }\end{array}$ \\
\hline MITR & $\begin{array}{l}\text { Thermal } \\
\text { Neutron } \\
\text { MTR }\end{array}$ & $\begin{array}{c}\text { USA } \\
\text { Cambridge }\end{array}$ & $\begin{array}{l}7.0 \times 10^{13} \text { Thermal (SS) } \\
1.7 \times 10^{14} \text { Fast }(\mathrm{SS}) \\
6 \times 10^{3} \mathrm{~kW} \text { Steady } \\
\text { Thermal Power } \\
1.7 \times 10^{14} \text { Flux (In-Core) }\end{array}$ & $\begin{array}{l}\text { Three pressurized water loops. Light Water } \\
\text { cooled. Three in-core irradiation channels. } \\
\text { Six reflector irradiation channels. Use: } \\
\text { Teaching, neutron scattering, chemical } \\
\text { assay, neutron activation analysis, dose } \\
\text { reduction, coolant chemistry, irradiation } \\
\text { effects, high-temperature materials testing. }\end{array}$ \\
\hline MURR & $\begin{array}{l}\text { Thermal } \\
\text { Neutron } \\
\text { MTR }\end{array}$ & $\begin{array}{c}\text { USA } \\
\text { Columbia }\end{array}$ & $\begin{array}{l}6.0 \times 10^{14} \text { Thermal }(\mathrm{SS}) \\
1.0 \times 10^{14} \text { Fast }(\mathrm{SS}) \\
1.0 \times 10^{4} \mathrm{~kW} \text { Steady } \\
\text { Thermal Power } \\
6.2 \times 10^{14} \text { Flux (In-Core) }\end{array}$ & $\begin{array}{l}\text { Light water cooled. Three in core irradiation } \\
\text { channels. Sixteen reflector irradiation } \\
\text { channels. Use: Crystallography, Small } \\
\text { angle neutron scattering (SANS), } \\
\text { interferometry, surface layers, neutron } \\
\text { activation analysis (NAA), isotope } \\
\text { production, silicon doping. Small volume } \\
\text { high flux. }\end{array}$ \\
\hline NSBR & $\begin{array}{l}\text { Thermal } \\
\text { Neutron } \\
\text { MTR }\end{array}$ & $\begin{array}{c}\text { USA } \\
\text { Gaithersburg }\end{array}$ & $\begin{array}{l}4.0 \times 10^{14} \text { Thermal Flux } \\
\text { (SS) } \\
2.0 \times 10^{14} \text { Fast flux (SS) } \\
2.0 \times 10^{4} \mathrm{~kW} \text { Steady } \\
\text { Thermal Power } \\
4.0 \times 10^{14} \text { In-Core Flux }\end{array}$ & $\begin{array}{l}\text { Heavy water cooled. Uses: Scattering, } \\
\text { diffraction, SANS, reflectometry, } \\
\text { nondestructive examination (NDE), } \\
\text { dosimetry, radiography, gamma ray trace } \\
\text { analysis, long-term irradiations. }\end{array}$ \\
\hline
\end{tabular}


Table D-1. (continued).

\begin{tabular}{|c|c|c|c|c|}
\hline Name & Type & Location & $\begin{array}{c}\text { Maximum Flux } \\
\left(\mathrm{n} / \mathrm{cm}^{2}-\mathrm{s}\right) \text { and Power }\end{array}$ & Comment \\
\hline \multicolumn{5}{|c|}{ International Thermal Test Reactors } \\
\hline $\mathrm{HFR}^{\mathrm{b}}$ & $\begin{array}{l}\text { Thermal } \\
\text { Neutron } \\
\text { MTR }\end{array}$ & $\begin{array}{l}\text { Netherlands } \\
\text { Petten }\end{array}$ & $\begin{array}{l}2.7 \times 10^{14} \text { Thermal (SS) } \\
5.1 \times 10^{14} \text { Fast (SS) } \\
4.5 \times 10^{4} \text { kW Steady } \\
\text { Thermal Power } \\
5.6 \times 10^{14} \text { Flux (In-Core) }\end{array}$ & $\begin{array}{l}\text { Two core loops. Light water cooled. } \\
\text { Nineteen in-core irradiation channels. } \\
\text { Twelve reflector irradiation channels. Use: } \\
\text { Solid state physics, neutron radiography, } \\
\text { BNCT, NAAHY, NAA Modest volumes and } \\
\text { high flux. }\end{array}$ \\
\hline SAFARI & $\begin{array}{l}\text { Thermal } \\
\text { Neutron } \\
\text { MTR }\end{array}$ & $\begin{array}{l}\text { South Africa } \\
\text { Tshwane }\end{array}$ & $\begin{array}{l}2.4 \times 10^{14} \text { Thermal (SS) } \\
2.8 \times 10^{14} \text { Fast (SS) } \\
2.0 \times 10^{4} \mathrm{~kW} \text { Steady } \\
\text { Thermal Power } \\
4.0 \times 10^{14} \text { Flux (In-Core) }\end{array}$ & $\begin{array}{l}\text { Light water cooled. Twelve in-core } \\
\text { irradiation channels. Two reflector } \\
\text { irradiation channels. Use: Isotope } \\
\text { production, neutron beam research, } \\
\text { radiography, diffraction. Small volume high } \\
\text { flux. }\end{array}$ \\
\hline $\mathrm{BR} 2^{\mathrm{b}}$ & $\begin{array}{l}\text { Thermal } \\
\text { Neutron } \\
\text { MTR }\end{array}$ & $\begin{array}{l}\text { Belgium } \\
\text { Mol }\end{array}$ & $\begin{array}{l}1.0 \times 10^{15} \text { Thermal (SS) } \\
7.0 \times 10^{14} \text { Fast (SS) } \\
1.0 \times 10^{5} \mathrm{~kW} \text { Steady } \\
\text { Thermal Power } \\
7.0 \times 10^{14} \text { Flux (In-Core) }\end{array}$ & $\begin{array}{l}\text { Has water loops. Has done HTGR and } \\
\text { SFR fuels testing. Limited lifetime. Light } \\
\text { water cooled. Be, water as moderator } \\
\text { material. Variable number of control rods. } \\
\text { Forty in-core irradiation channels. Fifty } \\
\text { reflector irradiation channels. Use: neutron } \\
\text { radiography, fuel and material testing, } \\
\text { isotope production. }\end{array}$ \\
\hline HBWR & $\begin{array}{l}\text { Boiling } \\
\text { HWR }\end{array}$ & $\begin{array}{l}\text { Norway } \\
\text { Halden }\end{array}$ & $\begin{array}{l}1.5 \times 10^{14} \text { Thermal (SS) } \\
8.0 \times 10^{13} \text { Fast (SS) } \\
2.0 \times 10^{4} \mathrm{~kW} \text { Steady } \\
\text { Thermal Power } \\
1.5 \times 10^{14} \text { Flux (In-Core) }\end{array}$ & $\begin{array}{l}\text { History of LWR testing. Ten Loops. Heavy } \\
\text { water cooled. Forty in-core irradiation } \\
\text { channels. Five reflector irradiation } \\
\text { channels. Use: Fuel and core material } \\
\text { performance studies, fuel and core material } \\
\text { studies: BWR, pressure water reactor } \\
\text { (PWR) conditions. }\end{array}$ \\
\hline HANARO & $\begin{array}{l}\text { Thermal } \\
\text { Neutron } \\
\text { MTR }\end{array}$ & $\begin{array}{l}\text { South Korea } \\
\text { Deokjin-dong }\end{array}$ & $\begin{array}{l}4.5 \times 10^{14} \text { Thermal (SS) } \\
2.0 \times 10^{14} \text { Fast (SS) } \\
3.0 \times 10^{4} \mathrm{~kW} \text { Steady } \\
\text { Thermal Power } \\
4.5 \times 10^{14} \text { Flux (In-Core) } \\
1.6 \times 10^{14} \text { Flux } \\
\text { (Reflector) }\end{array}$ & $\begin{array}{l}\text { Light water cooled. Seven in-core } \\
\text { irradiation channels. Twenty-five reflector } \\
\text { irradiation channels. Use: Beam } \\
\text { experiments, isotope production, NAA, } \\
\text { material testing, NTD, fuel testing, 3-PIN } \\
\text { PWR and CANDU fuel irradiation. One } \\
\text { pressurized loop in reactor core. Modest } \\
\text { volume and high flux. Fuel test loop. }\end{array}$ \\
\hline
\end{tabular}


Table D-1. (continued).

\begin{tabular}{|c|c|c|c|c|}
\hline Name & Type & Location & $\begin{array}{l}\text { Maximum Flux } \\
\left(\mathrm{n} / \mathrm{cm}^{2}-\mathrm{s}\right) \text { and Power }\end{array}$ & Comment \\
\hline IVV-2M c & Pool Type & $\begin{array}{l}\text { Russia } \\
\text { Zarechny }\end{array}$ & $\begin{array}{l}5.0 \times 10^{14} \text { Thermal (SS) } \\
2.0 \times 10^{14} \text { Fast (SS) } \\
1.5 \times 10^{4} \mathrm{~kW} \text { Steady } \\
\text { Thermal Power } \\
5.0 \times 10^{14} \text { Flux (In-Core) }\end{array}$ & $\begin{array}{l}\text { Light water cooled. Be, water as moderator } \\
\text { material. Five loops in core. Thirteen in- } \\
\text { core irradiation channels. Thirty-six } \\
\text { reflector irradiation channels. Use: Fuel } \\
\text { and structure materials test. Has one loop } \\
\text { with reduced flux. }\end{array}$ \\
\hline MIR.M1 c & $\begin{array}{l}\text { Thermal } \\
\text { MTR }\end{array}$ & $\begin{array}{l}\text { Russia } \\
\text { Dimitrovgrad }\end{array}$ & $\begin{array}{l}5.0 \times 10^{14} \text { Thermal (SS) } \\
1.0 \times 10^{14} \text { Fast (SS) } \\
1.0 \times 10^{5} \mathrm{~kW} \text { Steady } \\
\text { Thermal Power } \\
5.0 \times 10^{14} \text { Flux (In-Core) }\end{array}$ & $\begin{array}{l}\text { Light water cooled. Be, water moderator } \\
\text { material. Eleven in-core irradiation } \\
\text { channels. Seven loops. Use: fuel and } \\
\text { material tests, reactor material test, isotope } \\
\text { production. Water loops; gas loop; ramp, } \\
\text { LOCA and RIA testing. }\end{array}$ \\
\hline$S M-3^{c}$ & $\begin{array}{l}\text { Thermal } \\
\text { MTR }\end{array}$ & $\begin{array}{l}\text { Russia } \\
\text { Dimitrovgrad }\end{array}$ & $\begin{array}{l}5.0 \times 10^{15} \text { Thermal (SS) } \\
2.0 \times 10^{15} \text { Fast (SS) } \\
1.0 \times 10^{5} \mathrm{~kW} \text { Steady } \\
\text { Thermal Power } \\
1.9 \times 10^{15} \text { Flux (In-Core) } \\
1.35 \times 10^{15} \text { Flux } \\
\text { (Reflector) }\end{array}$ & $\begin{array}{l}\text { Classified as a pressure vessel reactor. } \\
\text { Light water cooled. Six in-core irradiation } \\
\text { channels. Thirty reflector irradiation } \\
\text { channels. Use: Irradiation, testing } \\
\text { materials, transuranic isotopes, testing } \\
\text { reactor materials, isotope production, both } \\
\text { high and low temperature. Irradiation } \\
\text { positions, flux trap, and water loops. }\end{array}$ \\
\hline OPAL & $\begin{array}{l}\text { Thermal } \\
\text { Neutron } \\
\text { MTR }\end{array}$ & $\begin{array}{l}\text { Australia } \\
\text { Lucas Heights }\end{array}$ & $\begin{array}{l}2.0 \times 10^{14} \text { Thermal (SS) } \\
2.1 \times 10^{14} \text { Fast (SS) } \\
2.0 \times 10^{4} \mathrm{~kW} \text { Steady } \\
\text { Thermal Power } \\
2.0 \times 10^{14} \text { Flux (In-Core) }\end{array}$ & $\begin{array}{l}\text { Light water cooled. No in-core irradiation } \\
\text { channels. No core loops. Seventy-eight } \\
\text { reflector irradiation channels. Use: Neutron } \\
\text { beam science, condensed matter studies, } \\
\text { RI production, NTD of Si, NAA, Limited } \\
\text { volume; beams, isotopes and Si irradiation. }\end{array}$ \\
\hline JMTR & $\begin{array}{l}\text { Thermal } \\
\text { MTR }\end{array}$ & $\begin{array}{l}\text { Japan } \\
\text { Narita-cho }\end{array}$ & $\begin{array}{l}4.0 \times 10^{14} \text { Thermal (SS) } \\
4.0 \times 10^{14} \text { Fast (SS) } \\
5.0 \times 10^{4} \mathrm{~kW} \text { Steady } \\
\text { Thermal Power } \\
4.0 \times 10^{14} \text { Flux (In-Core) }\end{array}$ & $\begin{array}{l}\text { Temporarily shut down for refurbishing. } \\
\text { Light water cooled. Twenty in-core } \\
\text { irradiation channels. Forty reflector } \\
\text { irradiation channels. Two core loops. Use: } \\
\text { One hydraulic rabbit device and one } \\
\text { shroud facility. }\end{array}$ \\
\hline JHR & $\begin{array}{l}\text { Thermal } \\
\text { Neutron } \\
\text { MTR }\end{array}$ & $\begin{array}{l}\text { France } \\
\text { Cadarache }\end{array}$ & $\begin{array}{l}5.5 \times 10^{14} \text { Thermal (SS) } \\
1 \times 10^{15} \text { Fast }(\mathrm{SS}) \\
1 \times 10^{5} \mathrm{~kW} \text { Steady } \\
\text { Thermal Power }\end{array}$ & $\begin{array}{l}\text { Light water cooled. The 1st criticality is } \\
\text { expected in 2016. Partners: Europe and } \\
\text { OECD-NEA. Available } 2019 \text { (?). Under } \\
\text { construction. Large volume and high flux. } \\
\text { Unique capsules for LWR testing. }\end{array}$ \\
\hline
\end{tabular}


Table D-1. (continued).

\begin{tabular}{|c|c|c|c|c|}
\hline \multicolumn{5}{|c|}{ Maximum Flux } \\
\hline \multicolumn{5}{|c|}{ International Fast Reactor Systems } \\
\hline BOR $60^{\circ}$ & $\begin{array}{l}\text { Na Fast } \\
\text { Reactor }\end{array}$ & $\begin{array}{l}\text { Russia } \\
\text { Dimitrovgrad }\end{array}$ & $\begin{array}{l}2.0 \times 10^{14} \text { Thermal (SS) } \\
3.7 \times 10^{15} \text { Fast (SS) } \\
6.0 \times 10^{4} \mathrm{~kW} \text { Steady } \\
\text { Thermal Power } \\
3.7 \times 10^{15} \text { Flux (In-Core) }\end{array}$ & $\begin{array}{l}\text { Fast breeder reactor. Liquid Na cooled. } \\
\text { Fifteen in-core irradiation channels. Ten } \\
\text { reflector irradiation channels. Use: Reactor } \\
\text { material tests, isotope production. }\end{array}$ \\
\hline FBTR & Fast Reactor & $\begin{array}{l}\text { India } \\
\text { Kalpakkam }\end{array}$ & $\begin{array}{l}3.3 \times 10^{15} \text { Fast Flux (SS) } \\
4.0 \times 10^{4} \mathrm{~kW} \text { Thermal } \\
\text { Power Steady } \\
3.3 \times 10^{15} \text { In-Core Flux }\end{array}$ & $\begin{array}{l}\text { 'Fast Breeder' type reactor. Sodium cooled. } \\
\text { One in-core irradiation channel. Use: } \\
\text { Isotope production, training, materials and } \\
\text { fuel testing. }\end{array}$ \\
\hline JOYO & $\begin{array}{l}\text { Sodium Fast } \\
\text { Test Reactor }\end{array}$ & $\begin{array}{l}\text { Japan } \\
\text { Oarai }\end{array}$ & $\begin{array}{l}4.0 \times 10^{15} \text { (Fast Flux) } \\
(\mathrm{SS}) \\
1.4 \times 10^{5} \mathrm{~kW} \text { Steady } \\
\text { Thermal Power } \\
5.7 \times 10^{15} \text { Flux (In-Core) }\end{array}$ & $\begin{array}{l}\text { Temporarily Shutdown. Liquid sodium } \\
\text { cooled. Twenty-one in-core irradiation } \\
\text { channels. Uses: FBR fuel and material } \\
\text { irradiation, teaching, training }\end{array}$ \\
\hline $\mathrm{MBIR}^{\mathrm{c}}$ & Fast Reactor & $\begin{array}{l}\text { Russia } \\
\text { Dimitrovgrad }\end{array}$ & $\begin{array}{l}5.5 \times 10^{15} \text { Fast (SS) } \\
1.5 \times 10^{5} \mathrm{~kW} \text { Steady } \\
\text { Thermal Power }\end{array}$ & $\begin{array}{l}\text { Fast Power reactor. Planned to be } \\
\text { constructed. Liquid Na cooled. Three in- } \\
\text { core irradiation channels. Three core loops. } \\
\text { Available in } 2020 \text {; loops potentially }\end{array}$ \\
\hline MYRRHA & $\begin{array}{l}\text { Accelerator- } \\
\text { based } \mathrm{Pb} \\
\text { Cooled } \\
\text { Subcritical } \\
\text { System }\end{array}$ & $\begin{array}{l}\text { Belgium } \\
\text { Mol }\end{array}$ & $\begin{array}{l}1 \times 10^{15} \text { Fast (SS) } \\
8.5 \times 10^{4} \mathrm{~kW} \text { Steady } \\
\text { Thermal Power }\end{array}$ & $\begin{array}{l}\text { Fast test system. Planned to be } \\
\text { constructed. To be a multipurpose hybrid } \\
\text { research reactor for high tech applications, } \\
\text { ADS system with spallation. Coolant } \\
\text { material to be tested. Available } 2026 \text {. }\end{array}$ \\
\hline $\begin{array}{l}\text { a. Green is } \\
\text { b. Nearing } \\
\text { Internati } \\
\text { c. Reactor }\end{array}$ & $\begin{array}{l}\text { of life, but repl } \\
\text { Atomic Energy } \\
\text { nyms available }\end{array}$ & $\begin{array}{l}\text { ems, yellow is } \\
\text { ent facilities are } \\
\text { ncy (IAEA) date } \\
\text { in Russian (no }\end{array}$ & $\begin{array}{l}\text { nporarily shut down, and re } \\
\text { Inder discussion (e.g., Palla } \\
\text { ase http://nucleus.iaea.org/ } \\
\text { ncluded in Acronyms listing }\end{array}$ & $\begin{array}{l}\text { under construction. } \\
\text { replace HFR Petten). Data on all reactors from } \\
\text { B/RR/ReactorSearch.aspx. }\end{array}$ \\
\hline
\end{tabular}

The development cycle for qualifying a new fuel form can be long, usually 15 to 25 years depending on the technical design aspects of the fuel form, its degree of departure from fuel forms already in use, and its intended service conditions. For non-LWR fuels, although the designs are significantly different, they progress through a similar set of development steps to achieve an adequate level of technology readiness [2]:

1. Fuel candidate selection: identification of fuel form that will meet the reactor mission.

2. Concept definition and feasibility: establishment of a fuel specification, physical property characterization, fuel fabrication process development, and early irradiation and safety testing.

3. Fuel design improvement and evaluation: scaling up fabrication process, optimizing the design, developing a fuel performance model, and finalizing the fuel specification. 
4. Fuel demonstration and qualification: fabricating fuel at industrial scale that meets the specification and conducting a qualification irradiation and safety testing (e.g., proof test) to demonstrate acceptable behavior to support the design validation and safety analysis. Validate predictive fuel performance models.

The long duration of the fuel development effort is usually associated with Steps 2 and 3 above because those activities are aimed at providing very high confidence that the fuel demonstration and qualification (Step 4) activities will be successful. These steps are not related to the size of available irradiation volumes but the technical steps necessary to increase the overall technology readiness of the fuel concept. It is also important to note that the schedule for Steps 2 and 3 also accounts for the potential need to re-trace steps when technical issues arise in either fabrication or testing. Thus, the actual final Step 4, while costing a lot because of the scale involved, is not the most schedule-intensive.

For evolutionary changes in an existing fuel form (e.g., LWR fuel rod), the development time is less and can usually proceed much more quickly to a proof test in the form of a lead test assembly in an operating LWR. A lead test assembly is usually required per the NRC Standard Review Plan [3] because:

1. No irradiation in a test reactor can completely replicate the conditions in an operating LWR

2. Precedent that has been set with prior LWR fuel testing

3. Both fuel vendors and NRC are very conservative when deciding what kinds of design changes require lead test assembly confirmation because of the ramifications and liabilities involved.

Thus, while large volumes may offer some technical testing benefits depending on the specific aspect of LWR fuel design that is being changed, regulatory requirements, precedence, and technical risk considerations will not obviate the need for lead test assembly testing in an operating LWR.

Inspection of the list in Table D-1 indicates that water-cooled test reactors have been the workhorse of nuclear fuels and materials testing for thermal reactor systems over the past 50 years. These materials test reactors (MTRs) produce high-damage rates (relative to LWRs) on the order of 1 to $10 \mathrm{dpa} / \mathrm{yr}$; thus, the testing to qualify new materials or identify material changes can be accomplished fairly quickly and in a schedule-efficient manner. However, because water-cooled test reactors are never a perfect match in terms of irradiation environment (neutron spectrum, temperature, chemistry) and the size of irradiation locations are limited, additional testing of materials and fuels is usually performed under actual operating reactor conditions (e.g., in lead test assemblies to provide final confirmation that a material and/or fuel system will perform as intended).

Preconceptual designs of a number of water-cooled test reactors have been developed over the past few decades including the Advanced Neutron Source [3], the Broad Application Test Reactor [4] and more recently LEU adaptations of such a family of designs concepts in Pope et al.'s 2013 report [5]. In addition, the Jules Horowitz Reactor (JHR) is the best example of an advanced materials test reactor, currently under construction at CEA Cadarache. Details of the project can be found on CEA's website [6]. These serve as good resources for what such a new water-cooled test reactor could look like and what flux and fast neutron damage levels could be achieved in these systems.

The gas-cooled reactor community has used water-cooled test reactors (e.g., ATR, HFIR, HFR-Petten, Belgian Reactor 2 [BR2]) to test their fuels and materials over the past 50 years. With the shutdown and decommissioning of the early gas-cooled reactors like Arbeitsgemeinschaft 
Versuchsreaktor (AVR) and Peach Bottom, the water-cooled test reactors are the main option for the HTGR community. The design of a gas test loop was explored for the ATR to support gas-cooled fast reactor R\&D, but the project did not go beyond the conceptual design phase [7].

The more sophisticated water-cooled test reactors have pressurized water loops that can simulate PWR and BWR pressure, temperature, and water chemistry conditions separate from the conditions in the actual test reactor to enable the study of corrosion mitigation approaches for use in LWRs. Such loops exist at ATR, the Massachusetts Institute of Technology reactor, and Halden. Because of reactivity effects, the loops in ATR cannot allow boiling; however, in the Massachusetts Institute of Technology reactor and the Halden reactor, boiling is allowed, which provides testing under prototypic BWR conditions.

The ability to have a separate loop in the facility offers the potential for other concepts to test their coolants for corrosion control. For example, fluoride salt-cooled high-temperature reactors could use a loop in any of the existing water-cooled test reactors to test redox/corrosion control and tritium permeation mitigation strategies in the presence of the neutron flux that will be required prior to building a large-scale system. In the past, a sodium loop, the Sodium Loop Safety Facility, was installed in the Engineering Test Reactor (ETR) at Idaho National Laboratory to perform testing on the performance of fast reactor fuels including fuel behavior under sodium boiling conditions [8]. However, because of the reactive nature of sodium, loops with these coolants are not anticipated to be used today in a water-cooled test reactor. MBIR, a fast test reactor in Russia, is planning for three such loops in their design.

For advanced fast neutron reactor systems, neutron damage rates are significantly higher because the neutrons are not thermalized and the magnitude of the fast neutron flux is much higher than for thermal systems. Thus, using a water-cooled test reactor is not feasible to attain peak dose in a reasonable amount of time. For example, in the Terra Power and $\mathrm{EM}^{2}$ fast reactor concepts, the cladding would experience 200 to $500 \mathrm{dpa}$ in their lifetime. Cladding materials testing in a water-cooled test reactor even at $10 \mathrm{dpa} / \mathrm{yr}$ would take 20 to 50 years. (Similar arguments can be made for fusion reactor systems with important caveats and differences in the fast fission and fusion neutron spectrums.)

Investigation of Table D-1 indicates that there are significant capabilities to irradiate LWR components in water-cooled test reactors. The major test reactors include the ATR, HFIR, HFR-Petten, Halden, BR2 and the soon to be commissioned JHR. These facilities provide large irradiation volumes, test rigs and test trains designs, trained personnel, good instrumentation capabilities, and operating hot cells-all of the infrastructure necessary to run modern thermal nuclear fuels and materials testing programs. Thus, it can be concluded that this set of test reactors along with the capability for lead test assemblies in LWRs is sufficient both in its depth and breadth for the current LWR industry; therefore, this judgment does not warrant the design and construction of an irradiation test reactor specifically for the irradiation of lead test assemblies for LWRs.

Today, fast reactor fuel testing includes "rodlets" of fast reactor fuel pins tested in a water-cooled test reactor with a heavy cadmium shroud to slow the rate of fission in the fuel relative to the rate of fast neutron damage on the cladding. While a clever way to perform such testing in a thermal MTR, the irradiated rodlets contain "old" fuel that has reached its burnup goal and "young" cladding because it has not attained the relevant level of displacement damage. This occurs, because even with strong absorbers such as cadmium, it is not possible to eliminate all thermal and epithermal neutrons, which will dominate 
the fuel burnup rather than fast neutrons as would occur in the actual fast spectrum system, nor does it boost the fast neutron flux to levels prototypic of a fast reactor. While some have argued [9] that with modern modeling and simulation tools, one could extrapolate these results, it is non-prototypic and will most likely not be acceptable as an adequate demonstration in the regulatory arena. Thus, for these fast neutron reactor systems, there is a need for a high fast flux test reactor that can produce damage rates of 30 to $50 \mathrm{dpa} /$ year to test and qualify fast reactor fuels and materials in a timely and near prototypic manner. A beneficial feature of a fast flux test capability is the flexibility to generate high flux thermal spectrum test zones through the use of local moderators. The inverse option (i.e., designing thermal spectrum test reactor with flexibility to allow localized fast spectrum tests) is much more difficult to achieve in practice, if even possible.

By any metric of comparison, there is much less fast neutron than thermal neutron capability to qualify fuels and materials for advanced reactor systems. The domestic thermal material test reactors have severely limited fast neutron capability (most are high flux for a small volume), and fast neutron facilities with the appropriate infrastructure exist today only in Russia and India (see Table D-1). e However, concerns over political issues, transportation to and from the United States, and equivalencies of quality assurance programs make those facilities difficult to rely upon. Furthermore, there are needs for test loops with Gen-IV non-water coolants that can access fast neutrons to study for example corrosion control in lead systems and advanced fast reactor fuels under unique coolant conditions that do not perturb the driver core of the test reactor.

Therefore, based on the above considerations, a water-cooled reactor cannot meet the needs to support research and development of advanced reactor designs because it is not possible to achieve sufficiently high fast neutron flux without thermal neutron contamination that is needed for the development of any fast spectrum system and to accelerate materials irradiations for both thermal and fast reactors. Further, while there is ongoing research needs to support LWR development, current and near-term international material test reactors and lead test assemblies in actual operating reactors can provide the necessary irradiation services and a future test reactor based on non-water coolants can support those irradiation needs.

Independent of the design, to meet the diverse set of testing requirements from the U.S. nuclear industry, a new MTR will be a billion-dollar-level endeavor. Beyond construction costs, successful test reactors require an operating budget that allows for cost efficient testing to meet its customers' needs and a maintenance budget to ensure the MTR's availability. This entails having both resources and trained personnel that can execute the testing mission. MTRs in Europe (e.g., Halden and in some cases HFR Petten) use standardized test rigs with an array of advanced instrumentation for their irradiations that offer economic solutions for customers. (Development of specialized test rigs can take time and money that make development difficult from both a schedule and cost perspective.) They also have sufficient base funding to maintain a trained staff that know how to execute the experiments (which is different than the skill set used to operate the reactor). The new JHR is planning a similar operations funding strategy. The lack of such an approach in U.S. reactors, such as ATR, has driven the U.S. nuclear industry, and in some cases DOE, to fulfill their nuclear testing needs overseas, largely in Halden.

e. The Chinese test reactor (CEFR) although operational today has not been included because of the lack of local supporting infrastructure that prevents a robust fuels and materials testing program to be executed in that reactor. 
The U.S. DOE should adopt the European operations funding approach for its existing MTRs and any new U.S. MTR if the U.S. is to remain globally competitive globally and attract domestic and international customers to the U.S. for their testing needs.

\section{D-2. References}

1. Zinkle, S. J., and G. Was, "Materials Challenges in Nuclear Energy," Acta Materialia, Vol. 61, 2013, pp. 735-758.

2. Crawford, D. C., D. L. Porter, S. L. Hayes, M. K. Meyer, D. A. Petti, and K. Pasamehmetoglu, "An Approach to Fuel Development and Qualification," Journal of Nuclear Materials, Vol. 371, 2007, pp. 232-242.

3. NRC, Standard Review Plan for the Review of Safety Analysis Reports for Nuclear Power Plants: LWR Edition, NUREG-0800, United States Nuclear Regulatory Commission, Rev. 3, March = 2007.

4. Hayter, J., and C. D. West, "Status of the Advanced Neutron Source Project," Neutron News, Vol. 3 No. 1, 1992.

5. Ryskamp, J. M., (ed.), Safety Requirements, Facility User Needs, and Reactor Concepts for a New Broad Application Test Reactor, Idaho National Laboratory Report, NRRT-N-91-036, October 1991.

6. Pope, M. A., H. D. Gougar, and J. M. Ryskamp, Evaluation of Concepts for Multiple Application Thermal Reactor for Irradiation Experiments (MATRIX), INL/EXT-13-30045, September 2013.

7. CEA, The Jules Horowitz Reactor (JHR), http://www-cadarache.cea.fr/rjh/, September 2013.

8. Wemple, "C. A., Design Of A Gas Test Loop Facility For The Advanced Test Reactor," Joint Meeting of the National Organization of Test Research and Training Reactors and the International Group on Research Reactors (TRTR/IGORR 10), INL/CON-05-00526, September 2005.

9. Braid, T. H., et al., "Operation of the Cover Gas System in SLSF Tests," ANS topical meeting on fast, thermal and fusion reactor experiments; Salt Lake City, Utah (USA); April 12-15, 1982;

CONF-820406-35. 


\section{Appendix E}

\section{NRC Power and Non-Power Reactor License Application Review Processes}




\section{Appendix E NRC Power and Non-Power Reactor License Application Review Processes}

\section{E-1. Two-Step Licensing Approach (10 CFR PART 50)}

New nuclear power plants (NPPs) can be licensed by structuring the license application in alignment with one of two existing structures. The first approach is the two-step process described in $10 \mathrm{CFR}$ Part 50, which requires both a construction permit and a separate operating license. This is the licensing process that was used by the existing fleet of NPPs in the United States.

\section{E-2. Construction Permit}

For the two-step approach, after Nuclear Regulatory Commission (NRC) conducts a review and is satisfied with the safety of the preliminary NPP design and the suitability of the prospective site, NRC issues a construction permit that allows an applicant (e.g., utility) to begin building an NPP. Sometime during construction, the utility submits an application for an operating license, which NRC issues only if all safety and environmental requirements are met.

The application for a construction permit must contain the following three types of information:

- Preliminary safety analyses

- An environmental review

- Financial and anti-trust statements.

If NRC determines that the construction permit application includes the required information, the agency publishes a notice of receipt in the Federal Register. NRC then reviews the application and documents its findings on site safety characteristics and emergency planning in a safety evaluation report. To encourage public participation in the licensing process, NRC schedules public meetings near the proposed site to familiarize the public with the safety and environmental aspects of the application, the planned location and type of plant, NRC's licensing process, and the opportunities for public participation in the proceeding. In addition, NRC holds frequent public meetings with the applicant throughout the licensing process to discuss the NPP's design and construction.

NRC also conducts an environmental review, in accordance with National Environmental Policy Act (NEPA), to evaluate the potential environmental impacts and benefits of the proposed NPP. This includes impacts on air; water; animal life; vegetation; natural resources; and property of historic, archaeological, or architectural significance. Other items evaluated include economic, social, and cultural impacts. After completing this review, NRC issues a draft environmental impact statement for comment by the public, including appropriate federal, state, and local agencies. The agency then issues and makes public a final environmental impact statement, which addresses all the comments the agency received. NRC may authorize an applicant to do some work at a site before a construction permit is issued. This "limited work authorization" can only be granted after the Atomic Safety and Licensing Board (ASLB) has made all of the environmental findings required for a construction permit and determined that the proposed site is a suitable location for an NPP of the general size and type proposed. 


\section{E-3. Operating License}

Final design information and plans for operation are developed during construction of the NPP. The applicant then submits an application to NRC for an operating license. The application contains a final safety analysis report and an updated environmental report. The safety analysis report describes the NPP's final design, safety evaluation, operational limits, anticipated response of the NPP to postulated accidents, and plans for coping with emergencies. NRC reviews the applicant's emergency plans in consultation with the Federal Emergency Management Agency to determine whether the plans are adequate and whether there is reasonable assurance that they can be implemented. A Federal Register notice is published to provide an opportunity for any person whose interests might be affected by the proceeding to petition NRC for a hearing. If a public hearing is held, it is conducted by the ASLB using the same decision process described for the construction permit hearing.

\section{E-4. One-Step Licensing Approach (10 CFR Part 52)}

The second approach is the one-step licensing process described in 10 CFR Part 52, which incorporates the following:

- Design certifications

- Combined Licenses (COLs)

- Early Site Permits (ESPs) - optional

- Limited work authorizations (LWAs) - optional.

A flow diagram of the one-step licensing approach is shown in Figure E-1. Note that the technical requirements are consistent, regardless of which regulatory approach is used. Therefore, the difference between the two approaches is a matter of process.

This one-step approach divides the various types of information required for NPP licensing into separate applications, providing flexibility in packaging and scheduling of the submittals. It also provides finality on the acceptability of the individual submittal topics after the NRC staff has finished their application reviews and the related public hearings are complete. The one-step NPP licensing process was designed to reduce both licensing risk and attendant financial risk compared to the two-step process described in 10 CFR Part 50. Risk is reduced because NRC has to approve the final design, site, verification criteria, and operational and procedural aspects of the application before any significant construction begins; therefore, the term "one-step". This licensing was developed to make efficient use of NRC and applicant resources, while minimizing licensing risk. This licensing approach also should reduce financial risk to the industry stakeholders funding the project. 


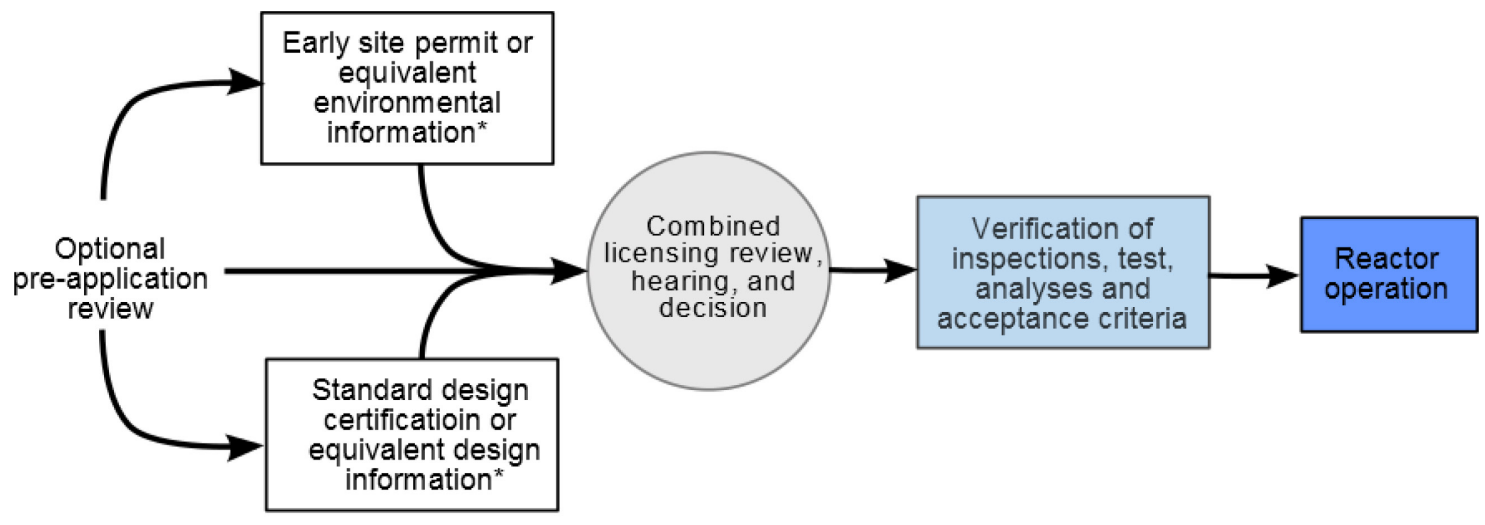

*a combined license application can reference an early site permit, a standard design certification, both, or neither. If an application does not reference an early site permit and/or a standard design certification, the applicant must provide an equivalent level of information in the combined license application

Figure E-1. One-step licensing approach.

\section{E-5. Design Certification}

NRC can certify a reactor design for 15 years through the rulemaking process, independent of a specific site. The flow chart showing the process steps is given in Figure E-2. An application for a standard design certification must contain information and proposed tests, inspections, analyses, and acceptance criteria (ITAAC) for the standard design. If the design is acceptable, the NRC staff can certify it through a rulemaking. Under this process, NRC publishes a public notice of the proposed rule in the Federal Register, seeking public comments. NRC reviews the comments and makes any changes to the final rule, which is then published in the Federal Register and becomes an appendix to 10 CFR Part 52 of the regulations.

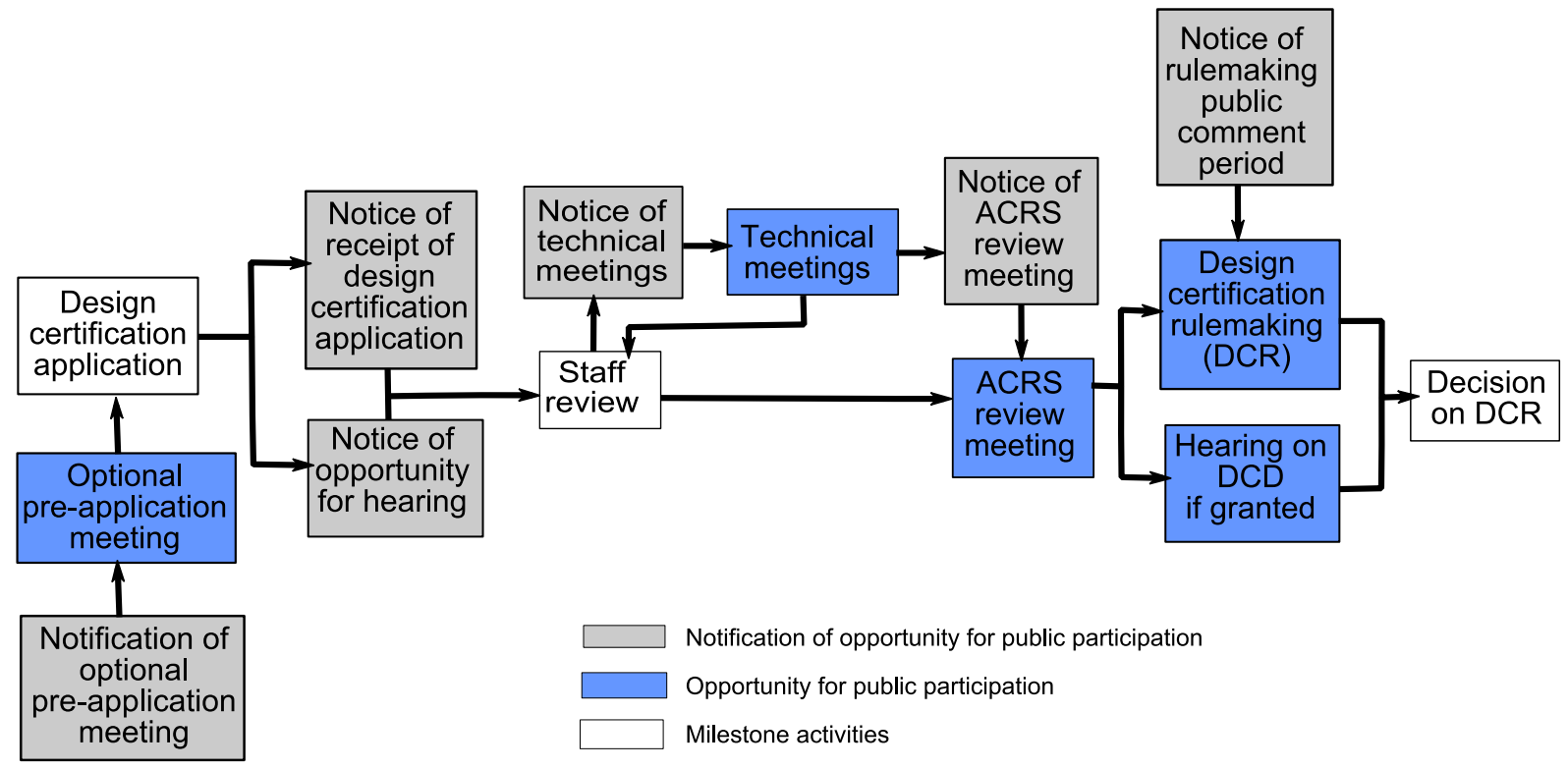

Figure E-2. Design certification process. 


\section{E-6. Combined Operational License (COL)}

A COL authorizes construction and conditional operation of an NPP. The application for a COL must contain essentially the same information required in an application for an operating license issued under 10 CFR Part 50, including financial and antitrust information and an assessment of the need for power. The application also must describe the ITAAC that are necessary to ensure the NPP has been properly constructed and will operate safely. An application for a COL may reference a standard design certification, an ESP, both, or neither.

- If the application does not reference a standard design certification, the applicant must provide complete design information, including the information that they otherwise would have submitted for a standard design certification.

- If the application references an ESP, the applicant must demonstrate that the design of the NPP is compatible with the ESP.

- The application also must include information on those issues that were not required with the ESP application (such as the need for power from the proposed NPP).

- If the application does not reference an ESP, the applicant must provide the site information that would be included in an ESP and also must include a complete emergency plan.

After issuing a COL, NRC verifies that the licensee has completed the required ITAAC satisfactorily. NRC publishes notices of the successful completion of the inspections, tests, and analyses. Then, at least 180 days before the scheduled date for initial loading of nuclear fuel into the reactor, NRC publishes a notice providing an opportunity for members of the public to participate in a hearing conducted by the ASLB. A flow chart showing the steps in the COL application process is provided in Figure E-3.

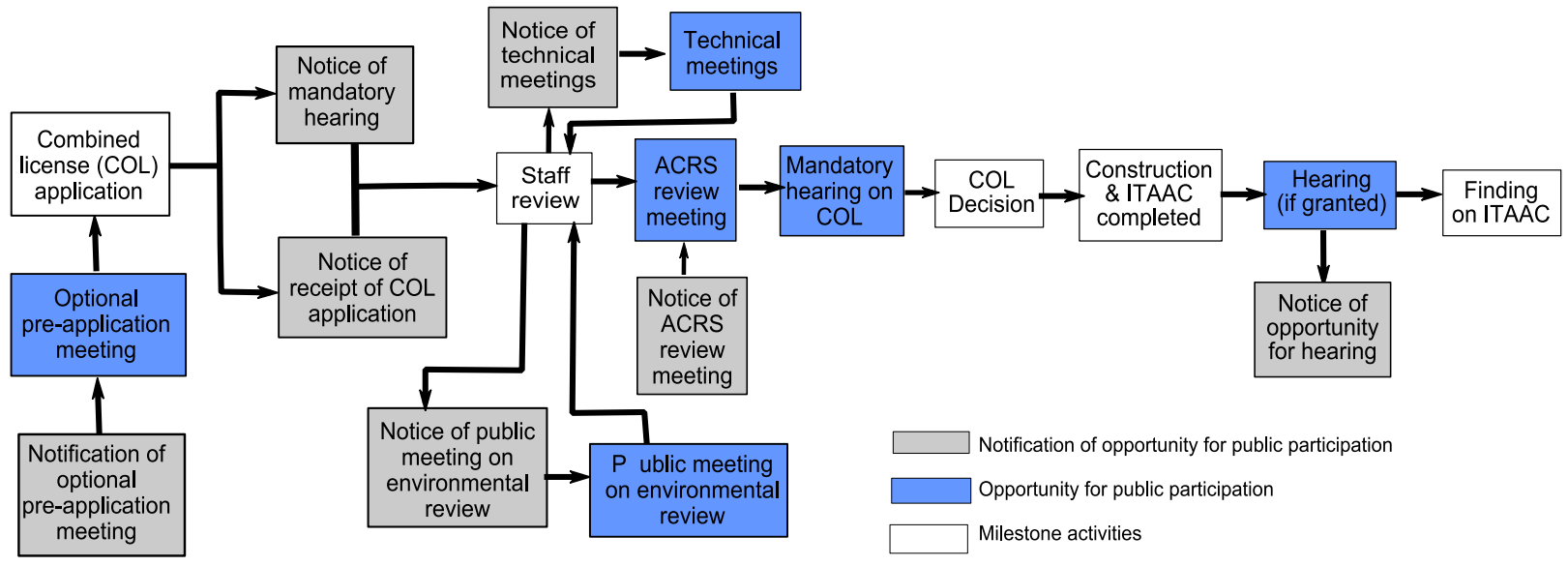

Figure E-3. Combined license application process.

\section{E-7. 10 CFR Part 52 Options}

In addition to design certifications and COLs, 10 CFR Part 52 allows an applicant to use the ESP licensing process for approval of one or more sites separate from an application for a COL. These permits are good for 10 to 20 years and can be renewed for an additional 10 to 20 years. They address site safety issues, environmental protection issues, and plans for coping with emergencies, independent of the review of a specific NPP design. Pursuit of an ESP is optional, but it can provide a vehicle for resolving 
site-related issues early in the licensing process. Pursuing a limited work authorization is also optional because it can provide authorization to start limited construction up to approximately 10 to 12 months before NRC issues the construction authorization for the complete NPP (i.e., the COL).

\section{E-8. NRC Non-Power License Application Review Process}

The NRC's license application review process for research and test reactors is built around a more limited version of the 10 CFR Part 50 ("two-step") licensing process described in Appendix E-1, and consists of series applications for a construction permit followed by an operating license (see Figure E-4). Although no NRC regulations apply specifically to the submittal of a Safety Analysis Report for non-power reactors, the Safety Analysis Report format has historically been used in direct support of this process and is expected to provide the most efficient and effective method for facilitating the NRC's review of the demonstration reactors discussed in this report.

The application for a construction permit must contain the following three types of information:

- Preliminary safety analyses

- An environmental review

- Financial and anti-trust statements.

NRC also conducts an environmental review, in accordance with NEPA, to evaluate the potential environmental impacts and benefits of the proposed test reactor facility.

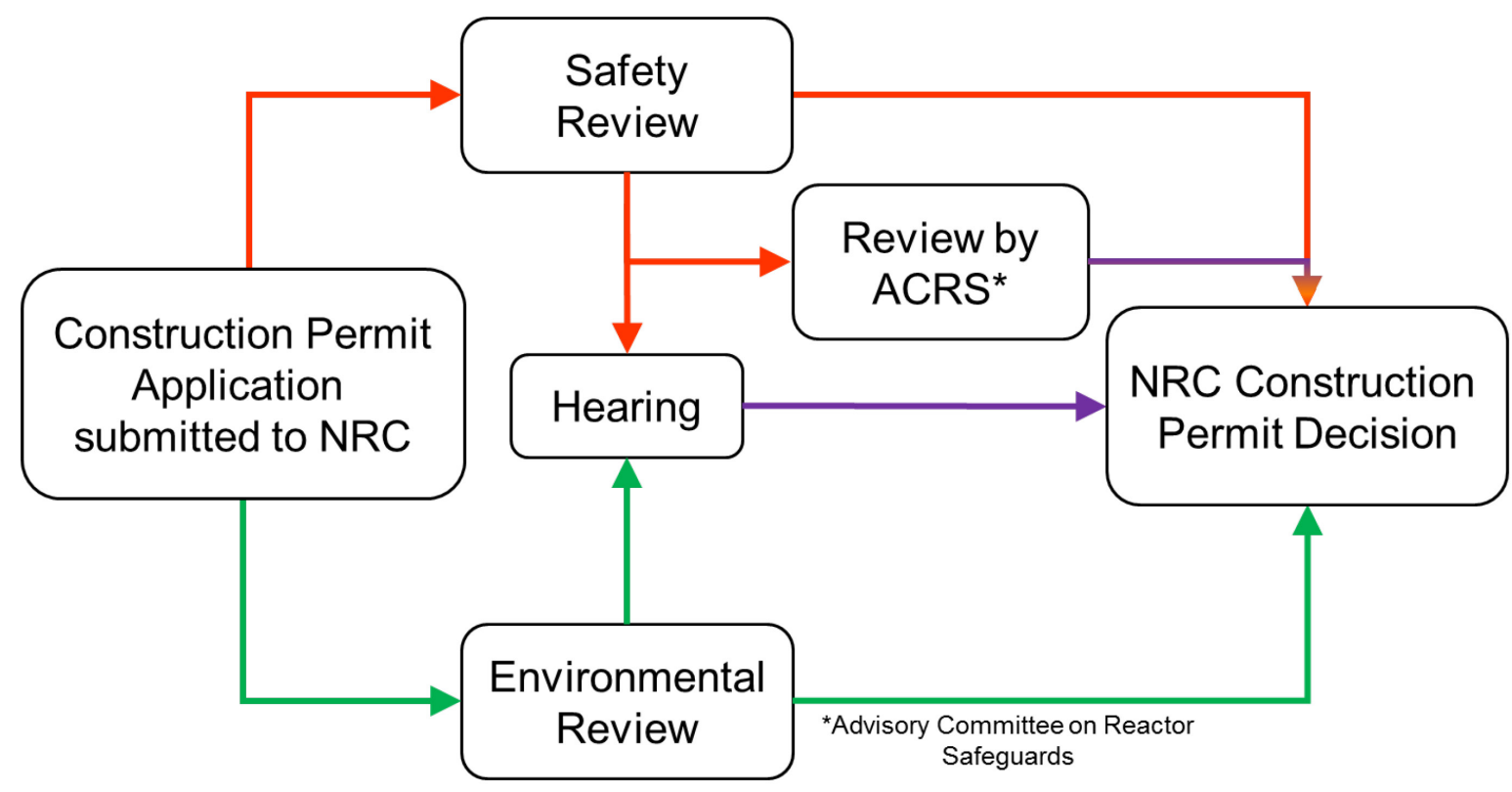

Figure E-4. Test reactor construction permit review.

Final design information and plans for operation are developed during construction of the facility. The applicant then submits an application to NRC for an operating license. The application contains a final safety analysis report, an updated environmental report, and a description of the plans for operation, including technical specifications. The review process is depicted in Figure E- 5 and is similar to that applied to the construction permit application, but may exclude certain steps (hearing, etc.) depending on petitions received. 


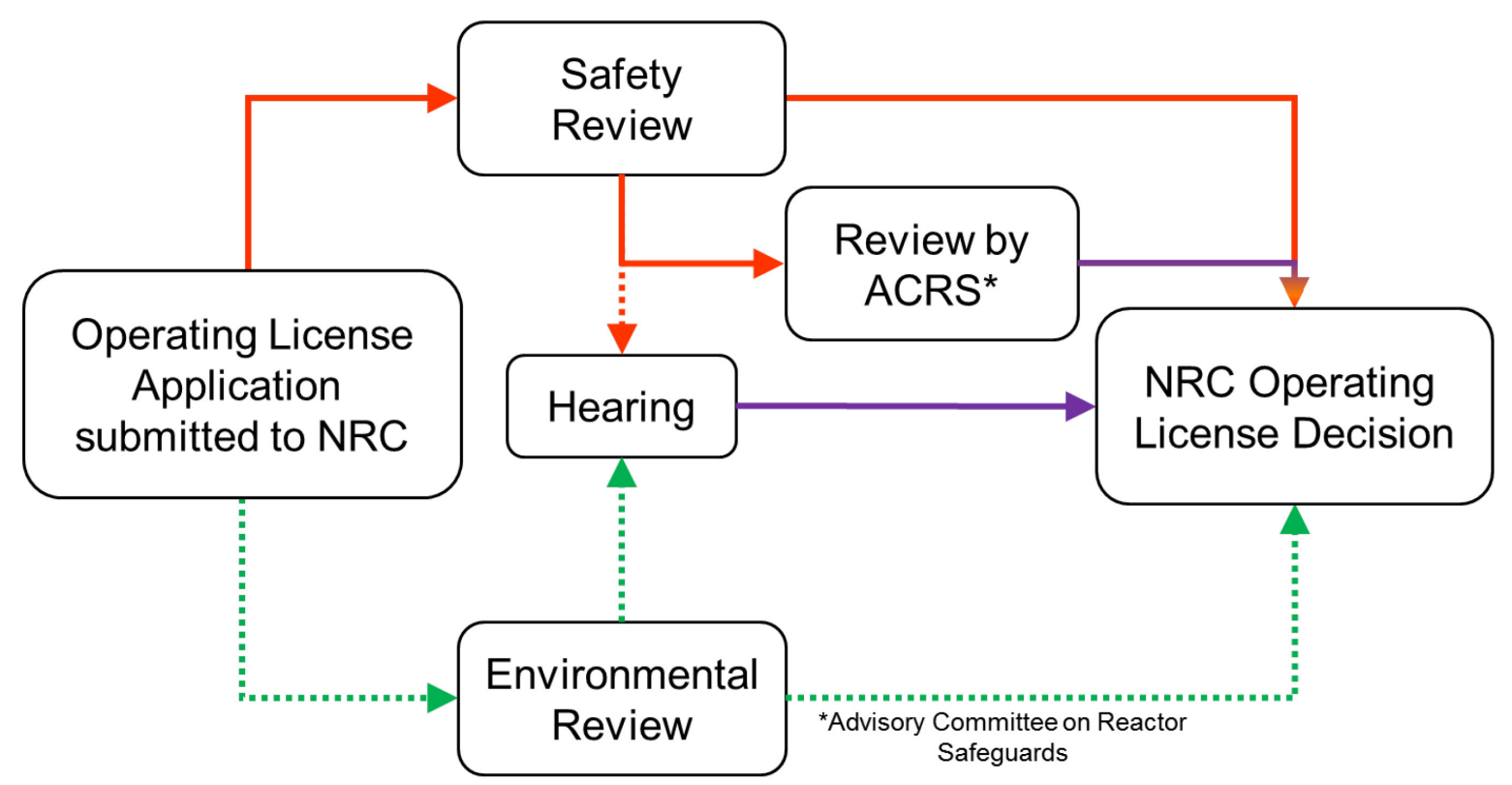

Figure E-5. Test reactor operating license review. 


\section{Appendix F}

\section{Key Siting Requirements and Considerations}




\section{Appendix $F$ Key Siting Requirements and Considerations}

Determining a suitable location for a nuclear facility built and operated under Nuclear Regulatory Commission (NRC) regulatory authority requires early and careful consideration of site features relative to licensing requirements. Applicants must understand how site-specific attributes combine in relation to reactor safety design elements and how plant construction and operation activities will influence the area. To help applicants address these requirements, guidance (relative to a typical Generation II LWR design) can be found in NUREG-0800 (See Ref. [1].

Application for a construction permit (CP), or early site permit (ESP), or combined license (COL) will trigger site investigation and consequence analysis for elements ranging from physical and biological attributes of the site to factors dealing with regional demographics and socioeconomics. The licensing process also mandates consideration of alternative sites with adequate detail to support submission of an environmental report (ER) by the applicant; this report will be the basis for an environmental impact statement (EIS), which satisfies requirements of the National Environmental Policy Act (NEPA).

NRC review of an ER generally takes about two years and is followed by public hearing(s) and an EIS decision where NRC acts as the lead federal agency. How DOE NEPA requirements (including issues regarding DOE "programmatic" EIS needs) might interface with and be satisfied by the NRC NEPA process remains to be clarified through inter-agency consultations and agreement. It is reasonable to assume the ESP portion of a license application (starting with initial site characterization work and continuing through NRC approval) would take around 5 years.

With the exception of severe seismic hazards, most site risks can be mitigated through appropriate nuclear facility designs and/or planning to meet minimum NRC site acceptance criteria. However, locations like those prone to periodic surface flooding or located near densely populated areas may prove more problematic than alternative sites and require complex and costly mitigations. Most applicants look for sites free of major hazards to plant operation and thereby avoid need for mitigations.

The following subsections discuss key considerations the site selection and risk/consequence characterization process. It should be remembered, however, that siting a nuclear plant will always remain a strong function of the unique operational and safety envelope of a specific design as well as the needs of the owner, operator, and energy customer.

\section{F-1. Site Geology, Seismology, and Soil Geotechnical Properties}

Besides analyzing the potential for surface deformation attributable to active geologic processes at a site, seismic evaluations are required concerning potential earthquake-induced vibratory shaking based on analyses of regional and local faults, tectonic stress conditions, historic and instrumental seismicity, and site geologic/stratigraphic conditions (e.g., shear wave velocity profile). Levels of seismic ground shaking are estimated for a specific probability (hazard) level defined by regulatory criteria given in the Code of Federal Regulations (CFR). 10 CFR Part 100, Section 100.23, "Geologic and Seismic Siting Criteria," define these criteria based on important geologic, geotechnical, geophysical, and seismic characteristics. A safe shutdown earthquake is used when evaluating ground shaking from potential earthquake sources; a nuclear plant must be able to retain function under a safe shutdown earthquake 
level of ground shaking as determined for the site [2]. Seismic evaluations can be performed according to the NRC Regulatory Guideline (RG) 1.208, "A Performance-Based Approach to Define the Site-Specific Earthquake Ground Motion" [3].

\section{F-2. Hydrology and Water Use}

Safety-related SSCs must be designed to withstand the worst predicted flood caused by combinations of hypothetical events. A license will be established based on bounding, hypothetical, worst-case flood scenarios and address probable maximum flood events, coincident wind-generated waves, probable maximum storm, probable maximum tsunamis/surge/seiche, seismic failures of upstream and downstream dams, ice jams, and so forth. Acceptable flood protection measures are described in RG 1.102, "Flood Protection for Nuclear Power Plants." RG 1.59, "Design Basis Floods for Nuclear Power Plants," describes probable maximum flood estimation methods for nuclear plants located on streams, along lakeshores, coastlines, and estuaries [4].

Nuclear plants require water sufficient to meet design requirements for cooling during normal operations and shutdown, to act as an ultimate sink for excess reactor core heat, and for fire protection. Nuclear facility water use must be compatible with water use plans already operating in the area. In the absence of area water use plans, NRC will evaluate the effect of plant water usage on area water users and consider the ability of all area users to obtain adequate supplies and still meet applicable water quality standards [5].

\section{F-3. Nearby Hazardous Activities Affecting Plant Safety}

Identification of hazardous activities proximal to the site triggers NRC review of all factors pertaining to the hazard. Often, this focuses on transportation facilities and routes such as airports, airways, roadways, railways, pipelines, and navigable waters but could also include transient industrial and military operations. Nearby material storage (e.g., anhydrous ammonia, chlorine gas, propane tanks) could also offer significant risks due to accidental release effects.

10 CFR 100.20(b) requires the nature and proximity of man-related hazards be evaluated to determine if the nuclear plant design can reasonably accommodate those hazards [6]. Normally, this means assessing potential hazards within 5 and 10 miles $(8$ and $16 \mathrm{~km})$ of the site to establish the degree of risk posed to plant safety and security. The basis for the evaluation is discussed in NUREG-0800, Section 2.2.1-2.2.2, "Identification of Potential Hazards in Site Vicinity" [1].

\section{F-4. Dispersion of Radiological Releases During Accident Conditions}

High quality meteorological data representative of a candidate site must be collected and carefully evaluated with respect to short-term atmospheric dispersion characteristics relative to postulated nuclear plant accident conditions. Because short-term exposures are the primary concern during accidents, the licensing review will focus on estimates of worst-case, short-term, atmospheric dispersion. 
Atmospheric diffusion efficiency is primarily a function of site wind speed, wind direction, and changes in air temperature with respect to height, which in turn affect atmospheric stability. The best way to calculate atmospheric dispersion is to use at least 1 year of actual onsite meteorological data; representative values gathered at locations other than the specific site can be initially used, but eventually values must be confirmed through onsite data collection. Analysis must account for site-specific characteristics like topography that could affect dispersion estimates.

Representative site atmospheric dispersion values are used to calculate post-accident doses at the site exclusion area boundary $(E A B)$ and within the facility local planning zone. This demonstration is used to meet the siting criteria established in 10 CFR Part 100, "Reactor Site Criteria" [6]. A site is acceptable if the $E A B$ doses for the proposed reactor technology radiological source term meet the limits of $\S 50.34(a)(1)[7]$.

\section{F-5. Dose Limits}

There are a number of NRC criteria that explicitly constrain the risk and/or allowable consequences of radiological releases from nuclear power facilities. These criteria include requirements to evaluate the adequacy of the proposed design of the plant against specific limits.

The dose limits for non-power Class 104(c) licensed test reactors are summarized below in Table F-1.

Table F-1. Test reactors: occupational, public, and accident dose requirements.

\begin{tabular}{|l|l|}
\hline \multicolumn{2}{|c|}{ Test Reactors-Occupational, Public, and Accident Dose Requirements } \\
\hline Occupational Dose Annual Limit & a. Total Effective Dose Equivalent (TEDE) $\leq 5$ rems, or \\
10 CFR 20.1201 [8] & b. Organ Dose $\leq 50$ rem \\
\hline Public Dose Limits & a. Annual TEDE $\leq 100$ mrem \\
10 CFR 20.1301 [9] & b. Hourly External Dose $\leq 2$ mrem \\
\hline Accident Dose Limits - Worker & a. Whole Body $\leq 25$ rem, or \\
10 CFR 100.11 [1] & b. Thyroid Dose $\leq 300$ rem \\
\hline
\end{tabular}

The dose limits for power Class 103 power reactors are summarized below in Table F-2.

Table F-2. Power reactors: top-level regulatory requirements associated with dose.

\begin{tabular}{|c|c|c|}
\hline \multicolumn{3}{|c|}{ Power Reactors-Top Level Regulatory Requirements } \\
\hline \multirow{4}{*}{$\begin{array}{l}\text { Normal } \\
\text { Operations and } \\
\text { Anticipated } \\
\text { Operational } \\
\text { Occurrences }\end{array}$} & $\begin{array}{l}\text { Dose Limits from Exposure to } \\
\text { Plant Effluents: } \\
10 \text { CFR 50, Appendix B [1] }\end{array}$ & $\begin{array}{l}\text { a. Whole Body Dose } \leq 5 \mathrm{mrem} / \mathrm{yr} \\
\text { b. Thyroid Dose } \leq 15 \mathrm{mrem} / \mathrm{yr} \text {. }\end{array}$ \\
\hline & $\begin{array}{l}\text { Occupational Dose Annual } \\
\text { Limit - } 10 \text { CFR } 20.1201 \text { [8] }\end{array}$ & $\begin{array}{l}\text { a. Total effective dose equivalent (TEDE) } \leq 5 \mathrm{rem} \\
\text { b. Organ Dose } \leq 50 \mathrm{rem}\end{array}$ \\
\hline & $\begin{array}{l}\text { Public Dose Limits: } \\
10 \text { CFR } 20.1301 \text { [9] }\end{array}$ & $\begin{array}{l}\text { a. Annual TEDE } \leq 100 \text { mrem } \\
\text { b. Hourly External Dose } \leq 2 \mathrm{mrem}\end{array}$ \\
\hline & $\begin{array}{l}\text { Public Dose Limits: } \\
40 \text { CFR } 190 \text { Subpart B [10] } \\
\text { Environmental (EPA) Std. [11] }\end{array}$ & $\begin{array}{l}\text { a. Whole Body } \leq 25 \text { mrem } \\
\text { b. Thyroid Dose } \leq 75 \text { mrem } \\
\text { c. Organ Dose } \leq 25 \mathrm{mrem}\end{array}$ \\
\hline
\end{tabular}


Table F-2. (continued).

\begin{tabular}{|c|c|c|}
\hline \multicolumn{3}{|c|}{ Power Reactors-Top Level Regulatory Requirements } \\
\hline \multirow{2}{*}{$\begin{array}{l}\text { Design Basis } \\
\text { Accidents } \\
\text { (DBA) }\end{array}$} & $\begin{array}{l}\text { Offsite Dose Limits: } \\
10 \text { CFR 50.34/52.47 [7] }\end{array}$ & $\begin{array}{l}\text { a. TEDE } \leq 25 \text { rem for } 2 \text { hours at the EAB } \\
\text { b. TEDE } \leq 25 \text { rem for } 30 \text { days at the low population } \\
\text { zone boundary }\end{array}$ \\
\hline & $\begin{array}{l}\text { EPA Protective Action } \\
\text { Guidelines (PAGs) for Public } \\
\text { Sheltering \& Evacuation } \\
(1992)[11]\end{array}$ & $\begin{array}{l}\text { a. TEDE } \leq 1 \text { rem at the EPZ boundary } \\
\text { b. Dose } \leq 5 \text { rem at the EPZ boundary }\end{array}$ \\
\hline $\begin{array}{l}\text { Beyond Design } \\
\text { Basis Events }\end{array}$ & $\begin{array}{l}\text { NRC Safety Goal Policy } \\
\text { Statement (1986) [12] }\end{array}$ & $\begin{array}{l}\text { a. Risk to public of prompt fatalities should not } \\
\text { exceed } 0.1 \% \text { of the sum of prompt fatality risks } \\
\text { resulting from other accidents to which the } \\
\text { public is generally exposed } \\
\text { b. Risk to public of cancer fatalities should not } \\
\text { exceed } 0.1 \% \text { of the sum of cancer fatality risks } \\
\text { from all other causes }\end{array}$ \\
\hline
\end{tabular}

\section{F-6. Emergency Planning}

A nuclear facility emergency can involve release of radioactive materials to the environment at levels that impact the health and safety of surrounding public. Onsite and offsite emergency plans are required to ensure adequate protective measures are implemented to protect onsite workers and the public. Federal oversight of emergency planning is shared by NRC and the Federal Emergency Management Agency through a memorandum of understanding. However, with respect to issuing a plant license, decisional authority in emergency planning/preparedness resides with NRC.

Regulations on nuclear facility emergency planning are specified in 10 CFR 50.47 and Appendix E to Part 50 for operating licenses and ESP applications with a "full and integrated emergency plan" and COL (10 CFR 52.17 for ESPs and 10 CFR 52.79 for COLs) [7,13]. Emergency planning considers three major areas: (1) risks and challenges in meeting regulatory requirements and guidance, (2) impediments to emergency plan development, and (3) overall public acceptance of a nuclear facility at the proposed site. Offsite emergency planning regulations focus on 16 planning standards that are to be met to assure adequate measures will be taken in the event of radiological emergency.

Four of these standards are identified as "Risk Significant Planning Standards," which must always be satisfied (i.e., timely and accurate classification of nuclear plant events, timely and accurate notification of offsite governmental authorities, timely and accurate development of public protective action recommendations for offsite authorities, and assessment of offsite consequences). Three of the planning standards are controlled by the applicant and/or reactor technology while the fourth (dealing with notification of offsite governmental authorities) is mostly influenced by supporting entities.

In 2014, INL examined the potential cost benefits realized if a nuclear plant EPZ were reduced in size as a function of enhanced safety design [14]. Cost data from 20 operating commercial nuclear power plants were collected and analyzed to ascertain life-cycle costs when EPZ boundary distance was reduced from the current 10-mile requirement to 5 miles, 2 miles, and co-location at a site boundary. 
Analysis was also performed concerning reduction in the nominal 50-mile ingestion pathway EPZ now required by NRC regulation. The study found start-up of a 10-mile offsite emergency planning program incurred a mean cost of $\$ 10$ million and a mean annual operating and maintenance cost of $\$ 2.25$ million. While reduction in EPZ size from 10 miles to 5 miles and again to 2 miles did provide some incremental cost reductions, reducing EPZ size to the site boundary was seen as most effective by reducing all offsite emergency planning costs by over $90 \%$. Cost savings associated with ingestion pathway EPZ reductions were found to be negligible.

\section{F-7. Additional Siting Considerations F-7.1 Extreme Weather}

Nuclear plant safety parameters are not to be exceeded during plausible extreme weather conditions. Limiting extreme weather conditions regarding this concern are established using information on local probable maximum precipitation, maximum probable wind speed and severe wind events, tornadoes and waterspouts, thunderstorms, lightning and hail, freezing rain and ice storms, dust storms, 100-year return snowpack, weight of 48-hour probable maximum winter precipitation, maximum dry bulb temperature and ambient temperature, and their combination. NUREG-0800 Section 2.3.1 and 2.3.2, "Regional Climatology," and "Local Meteorology," respectively, provide meteorological parameter acceptance criteria [1]. Onsite data collection systems are discussed in RG 1.23, "Meteorological Monitoring Programs for Nuclear Power Plants," and generally require at least 1 year (preferably 2 or more years) of data collection to be useful [15].

\section{F-7.2 Area Population Impacts}

An application must assess area population density and population center impacts. NRC will review this information according to Section 2.1.3, "Population Distribution," of NUREG-0800 [1]. With respect to LWR technology, reviewers will consider the nearest boundary of a population center containing 25,000 or more residents to determine if that boundary is at least one and one-third times the distance from the reactor to the outer boundary of the plant low population zone. This particular requirement must be considered carefully during siting as the issue is difficult to mitigate and underlying analysis presumptions may not properly reflect a non-LWR technology risk profile.

\section{F-7.3 Societal Effects}

Public acceptance is a major siting consideration for NRC staff. Environmental justice issues are also examined on the basis of identifying disproportionate impacts to low income and minority populations as defined by Nuclear Regulatory Research Office Instruction No. LIC-203, "Procedural Guidance for Preparing Environmental Assessments Considering Environmental Issues," Appendix D [16]. The proximity of a site and associated transmission and transportation corridors to low income and minority populations may indicate the presence of an environmental justice concern which is often difficult to mitigate and complicates licensing evaluations. If significant societal impacts or impacts to local infrastructure are found, NRC will look for coordination between the applicant and impacted parties for resolution. 


\section{F-7.4 Ecological Impacts}

Biotic impact evaluations cover many factors that affect local faunal or floral communities. Applicable federal regulations include 10 CFR 51.10, which requires NRC compliance with NEPA and the Endangered Species Act [17]. Temporal and spatial impacts, both temporary and permanent, will be evaluated as will losses of upland or wetland habitat and adverse impacts to protected species and/or associated habitat. An application requiring cooling water and water intake/outflow structures must consider how faunal communities will be altered due to entrainment and impingement, temperature shock, changes in flow regime, removal or alteration of habitat, or changes in behavior related to heated effluents, which affect migration or spawning.

\section{F-7.5 Land Use for Transmission Corridors and Transportation Routes}

A land use analysis must be conducted on associated transmission corridors, transportation routes, and potential land use mitigations. This includes the public's aesthetic experience with sensitive areas or view sheds, conflicts with existing or planned public land use objectives (e.g., local recreational use, mineral resource extraction, national parks, or Indian tribal lands and reservations), and disruption of land dedicated to unique agricultural markets and prime farmland. NRC RG 4.7, "General Site Suitability for Nuclear Power Stations," states that any conflict between governing land use plans and a proposed nuclear plant should be reviewed and resolved through consultation [18].

\section{F-7.6 Historic/Archeological/Cultural Resources}

A historic property is any prehistoric or historic district, site, building, structure, or object included in, or eligible for inclusion in, the National Register of Historic Places as maintained by the Secretary of the Interior (36 CFR 63) [19]. This includes artifacts, records, and remains related to and located within such properties and includes properties of traditional religious and cultural importance to Native Americans that meet the National Register Criteria listed in 36 CFR 60.4 [20].

Historic properties typically include prehistoric archaeological sites, historic archaeological sites, aboveground historic sites manifested by a standing structure (usually more than 50 -years old), and traditional cultural properties. Methods related to discovery and analysis of historic properties are well developed and done in conjunction with policies and guidelines that accompany the major federal decisions required by NEPA.

\section{F-7.7 Land Availability to Support Safe Operations}

Site selection must consider land area availability and a plant buffer zone. It must also consider switchyards, transmission facilities, and costs of acquiring land. Applicable federal regulations include 10 CFR 100.21 and 10 CFR100.3, which require every nuclear plant site to have an exclusion area (EA) [1]. EA is defined as the area surrounding the reactor where the licensee has authority to determine all activities and exclude or remove personnel and property from the area. Specific requirements relative to the EA are given in 10 CFR 50.34(a)(1)(ii)(D) [7].

The EA size is based on nuclear plant radiological release criteria analyzed as a function of atmospheric dispersion. Applicants must ensure adequate land area at the site so that an EA can be established that satisfies 10 CFR 100 requirements [2]. While the EA may be traversed by a highway, 
railroad, or waterway, these routes must not interfere with plant operations or effective emergency control. Activities unrelated to reactor operation may be permitted in an EA provided no significant hazards result.

The site must also assure sufficient area to permit adequate security standoff distances. This area will normally prohibit public access and provide sufficient space for vital structures or equipment to satisfy security measures stated in 10 CFR 73.55 (e.g., protected area barriers, detection equipment, isolation zones, and vehicle barriers) [20]. Additional design features or other requirements may be necessary if required standoff distances cannot be satisfied through site layout and boundaries.

\section{F-8. Plant Constructability}

Site construction feasibility depends heavily on two issues: (1) the ability to deliver construction equipment and major facility components to the location, and (2) the ability to deliver plant outputs to a customer (i.e., electricity to the transmission line grid, process heat and/or steam, etc.). NRC will also consider factors such as availability of a skilled and qualified work force, issues associated with the plant footprint, construction laydown areas, and construction material availability (especially concrete that may be used in great quantities).

Large reactor components are typically delivered either by rail or barge. If distances are great, land acquisition and state approvals may create difficulties in new rail spur installation. Recent proposals in small modular reactor concepts envision over-the-road truck delivery for all components. However, absent such a design option, the ability to access an in-service rail line is likely a nominal siting requirement.

A nuclear facility connected to the electrical grid may face obstacles in establishing reliable connections in remote regions due to distance from load centers, land procurement, and Federal Energy Regulatory Commission (FERC) approval for new transmission lines. The FERC transmission reliability mission intertwines with NRC's mission for public safety at nuclear power generation stations. One confirmed risk to bulk power system reliability is the sudden shutdown of a large nuclear plant supplying power to the grid. Conversely, the loss of offsite power caused by grid failure is a major concern to safe operation in most nuclear plant designs.

Because of tight specifications concerning offsite power, certain nuclear safety activities may require plant operators to know the status of and contingencies that affect reliability of offsite power. Plant risks and grid instability are interrelated in that tripping a nuclear power plant can cause grid instability and grid instability can result in tripping a plant. When evaluating how the grid affects a nuclear power plant, most studies focus on loss-of-offsite-power (LOOP) events where all offsite power lines into the plant are temporarily de-energized. A LOOP event typically results in an automatic scram of a nuclear plant and actuation of safety systems; a process that presents a measurable risk to nuclear safety. Reducing the number of LOOP events in-turn reduces challenge to nuclear plant safety systems and lessens overall plant risk. Electrical trips also are a nuclear safety concern because transients are a large contributor to core melt risk; increasing the number of nuclear power plant trips increases the risk of core melt at LWRs and may contribute similar risks to some advanced reactor designs. 
FERC has issued standards for offsite power coordination that cover the nuclear power plant and the transmission system so that involved entities are made aware of, plan for, and operate in accordance with the needs of the nuclear plant and customers. Interface agreements must be developed between the nuclear power plant and transmission operators to ensure post-trip voltages are adequate to maintain NRC licensing requirements.

\section{F-9. References}

1. NUREG-0800, "Standard Review Plan for the Review of Safety Analysis Reports for Nuclear Power Plants: LWR Edition,” United States Nuclear Regulatory Commission, July 17, 2014.

2. 10 CFR 100, "Reactor Site Criteria," United States Nuclear Regulatory Commission, March 23, 2015.

3. NRC RG 1.208, "A Performance-Based Approach to Define the Site-Specific Earthquake Ground Motion," October 2006.

4. NRC RG 1.102, "Flood Protection for Nuclear Power Plants," United States Nuclear Regulatory Commission, September 2014.

5. NRC RG 1.59, "Design Basis Floods for Nuclear Power Plants," United States Nuclear Regulatory Commission, August 1977.

6. 10 CFR 100.20(b), "Evaluation Factors for Stationary Power Reactor Site Applications on or After January 10, 1997," United States Nuclear Regulatory Commission, December 11, 1996.

7. 10 CFR 50, "Domestic Licensing of Production and Utilization," United States Nuclear Regulatory Commission, March 23, 2016.

8. 10 CFR 20.1201, "Occupational Dose Limits," United States Nuclear Regulatory Commission, May 21, 1991.

9. 10 CFR 20.1301, "Radiation Dose Limits for Individual Members of the Public," United States Nuclear Regulatory Commission, May 21, 1991.

10. 40 CFR 190, "Environmental Radiation Protection Requirements for Normal Operations of Activities in the Uranium Fuel Cycle," United States Nuclear Regulatory Commission, November 1976.

11. EPA, "Protective Action Guidelines (PAGs) for Public Sheltering \& Evacuation," Environmental Protection Agency, 1992.

12. NRC, "Safety Goal Policy Statement," United States Nuclear Regulatory Commission, 1986.

13. 10 CFR 52, "Licenses, Certifications, and Approvals for Nuclear Power Plants," United States Nuclear Regulatory Commission, August 28, 2007.

14. Moe, W., Opportunities in SMR Emergency Planning, INL/EXT-14-33137, December 17, 2014.

15. NRC RG 1.23, "Meteorological Monitoring Programs for Nuclear Power Plants," United States Nuclear Regulatory Commission, October 2006.

16. LIC-203, "Procedural Guidance for Preparing Environmental Assessments Considering Environmental Issues," United States Nuclear Regulatory Commission, June 24, 2013.

17. 10 CFR 51.10, Purpose and Scope of Subpart; Application of Regulations of Council on Environmental Quality," United States Nuclear Regulatory Commission, December 2, 2015. 
18. NRC RG 4.7, "General Site Suitability for Nuclear Power Stations," United States Nuclear Regulatory Commission, December 30, 2011.

19. 36 CFR 63, "Parks, Forests, and Public Property," National Park Service, March 22, 2016.

20. 36 CFR 60.4, "National Register of Historic Places, Criteria for Evaluation," National Park Service, July $1,2012$.

21. 10 CFR 73.55, "Requirements for Physical Protection of Licensed Activities in Nuclear Power Reactors against Radiological Sabotage," United States Nuclear Regulatory Commission, December 2, 2015. 